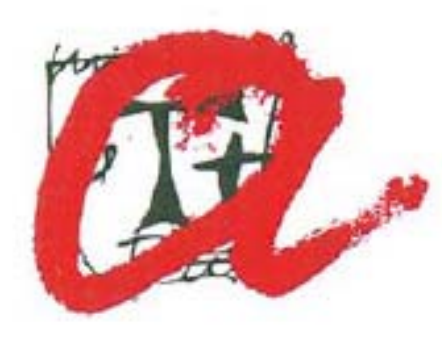

UNIVERSITAT ROVIRA I VIRGILI

Departament d'Enginyeria Química

\title{
AUTOHYDROLYSIS OF AGRICULTURAL BY-PRODUCTS FOR THE PRODUCTION OF XYLO-OLIGOSACCHARIDES
}

\author{
Dissertation presented by \\ DEBORA ALCIDA NABARLATZ \\ in partial fulfillment of the requirements for the degree of \\ Doctor by the Universitat Rovira i Virgili \\ European PhD \\ Supervised by Dr. Daniel Montané i Calaf \\ Tarragona, $2^{\text {th }}$ of September 2006
}


El sotasignant

\section{FA CONSTAR}

que el present treball, que porta per títol

\section{AUTOHYDROLYSIS OF AGRICULTURAL BY-PRODUCTS FOR THE PRODUCTION OF XYLO-OLIGOSACCHARIDES}

i que presenta Debora Alcida Nabarlatz per optar al grau de Doctor per la Universitat Rovira i Virgili, ha estat realitzat en aquesta Universitat sota la meva direcció, i que tots els resultats presentats i l'anàlisi corresponent són fruït de la investigació realitzada per l'esmentat candidat.

i per a què se'n prengui coneixement i als efectes que correspongui, signa aquest certificat,

Dr. Daniel Montané i Calaf

Professor Titular

Departament d'Enginyeria Química

Universitat Rovira i Virgili 
DUTOHYDROLYSIS OF AGRI
Debora Alcida Nabarlat

ISBN: 978-84-690-7617-0 / DL: T.1385-2007 


\section{MEMBERS OF THE ASSESSMENT COMMISSION}

Dr. Mercedes Ballesteros Perdices

CIEMAT - Centro de Investigaciones Energéticas, Medioambientales y

Tecnológicas, Spain.

Dr. Joan Salvadó

Universitat Rovira i Virgili, Spain.

Dr. Anna Ebringerová

Institute of Chemistry, Slovak Academy of Sciences, Slovakia.

Dr. Cristina Palet Ballús

Universitat Autónoma de Barcelona, Spain.

Dr. Montserrat Ferrando Cogollos

Universitat Rovira i Virgili, Spain.

Dr. Paloma Manzanares Secades

CIEMAT - Centro de Investigaciones Energéticas, Medioambientales y Tecnológicas, Spain.

Dr. Jan Hirsh

Institute of Chemistry, Slovak Academy of Sciences, Slovakia.

\section{External reviewers}

Dr. Alain Celzard

Université Henri Poincaré, France.

Dr. Francesco Zimbardi

ENEA, Italian Agency for New Technology, Energy and Environment, Italy. 
DUTOHYDROLYSIS OF AGRI
Debora Alcida Nabarlat

ISBN: 978-84-690-7617-0/ DL: T.1385-2007 
En memoria de mi abuelo, don Miguel Tartaglio (Cholo).

Tarragona, 6 de Mayo de 2006

Balcarce, Abril de 1986

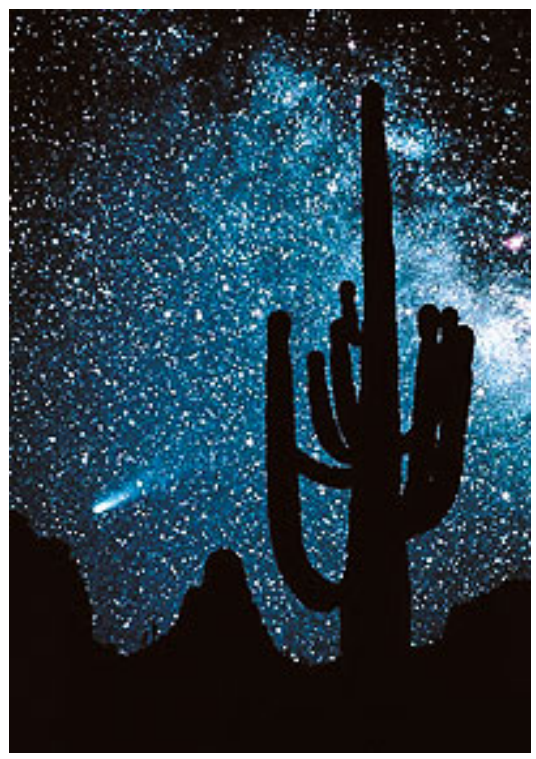

Era una noche de otoño, fresquita como siempre cuando se empieza a acercar el invierno.... Yo contaba por ahí unos 8 años, y aunque no lo recuerdo muy bien, supongo que sería una noche de viernes, o un sábado, cuando podía quedarme en su casa sin problemas para ir a la escuela. Recuerdo que dormía con ellos en su habitación (mis abuelos no me dejaban dormir sola), en mi cama con sábanas blancas de algodón, colchón de lana, y una colcha amarillita con flores rosadas. Mi abuelo me despertó suavemente, y me dijo "Levantáte, nena". Yo medio adormilada, y sin entender nada (eran las 3 de la mañana en punto) me levanté, y lo seguí. Me puse una campera encima del pijama, él también se abrigó, y juntos salimos al patio. Era una noche estrellada como nunca. Empezó a buscarlo por ahí, y decía, "Puta, ya veo que no lo vamos a poder ver", rezongaba. Pero al cabo de unos minutos lo encontró, y me lo señaló. Nunca había visto un cometa, y me sorprendió verle la colita, apenas perceptible, pero que demostraba que no era como los demás. Que era diferente. Que era especial, y mi abuelo quería que yo lo viera junto con él. Nunca olvidaré ese momento, y aún hoy, 20 años después, recuerdo esa noche como si fuera esta noche. El silencio en el campo, el cielo lleno de estrellas, y el Halley brillando apenas para nosotros. Quizá ahí haya comenzado todo, la verdad es que no lo sé. Hoy intento recordar una escena típica entre nosotros, y esa es una de las mejores. También recuerdo todas las veces que me decía, "Nena, estudiá, eso es lo único que nadie podrá quitarte", y que con esa cantilena me hinchó más de 20 años. Hoy te recuerdo, y te necesito, y este pequeño relato es un homenaje para vos. Sé que estarás orgulloso ahí donde estés, y aunque ya hace 3 años que te fuiste quiero que sepas que me seguís guiando como esa noche cuando era chica... Cuando te levantaste a las 3 de la madrugada para mostrarle a tu nieta preferida la llegada del cometa Halley... 
AUTOHYDROLYSIS OF AGRICULTURAL BY-PRODUCTS FOR THE PRODUCTION OF XYLO-OLIGOSACCHARIDES.

Debora Alcida Nabarlatz

ISBN: 978-84-690-7617-0 / DL: T.1385-2007 


\section{AGRADECIMIENTOS}

Antes que nada, quiero que sepan que esta etapa ha sido maravillosa para mí. Como la mariposa, que siendo gusano se atreve a desplegar las alas, y mira al mundo maravillada aunque sea solo por unas horas, así he sentido mi transformación durante estos últimos cuatro años. En ese tiempo mucha gente ha pasado por mi vida, pocos significaron mucho, muchos significaron poco, pero todos me rozaron y han dejado su marca (alguna más que indeleble) en mí. A todos ustedes, gracias!!!!! Lo que leerán a continuación ha sido (sólo) una parte de mi vida aquí.

Primero quiero agradecer tanto a los miembros del tribunal, como a los que evaluarán el manuscrito para emitir el informe. Me siento orgullosa de que alguien se lea esto! Esto que me ha brindado tantas penas y alegrías, tanta curiosidad y aburrimiento, y que no representa nada, pero nada, de las horas de laboratorio, de los experimentos mal hechos, mal acabados, bien hechos, bien acabados. Sólo es una selección (apta para la lectura) y un ensayo de muchos aciertos y algunos errores, que espero corregir y mejorar en mi siguiente vida. Por su paciencia, gracias!

A mi director de tesis, el Dr. Daniel Montané. Sé que no le gusta que le agradezca nada, pero tiene que reconocer que gracias a usted aprendí ; todo! lo necesario para poder empezar y ahora continuar en este camino. Ha sido el mejor jefe que hubiera podido tener. Gracias!

A la Generalitat de Catalunya, gracias por el apoyo económico recibido durante estos cuatro años. También a la Universitat Rovira $i$ Virgili, y especialmente al Departament d'Enginyeria Química, porque ha sido mi hogar y sus pasillos estarán siempre en mi memoria. Especialmente quiero agradecer al Dr. Ioanis Katakis y al Dr. Azael Fabregat, porque fueron quienes me dieron la oportunidad de venir a Tarragona y me acompañaron en el aterrizaje. Muchas gracias también a la Dra. Flor Siperstein, Dra. Vanessa Fierro y Dra. Ana Lea Cukierman por la magnífica posibilidad que me han brindado de formar parte del proyecto Lignocarb. También quiero agradecer a todos aquellos que han colaborado en el desarrollo de esta tesis, aportando equipos, experiencia, consejos, etc... 
Special thanks to Dr. Anna Ebringerová. Thanks for your inconditional help, advices, your happiness, and all the good time that we had in Bratislava. I want to thanks also to all the people from the Institute of Chemistry, specially to Dr. Anna Malovíková, Dr. Alzsbeta (Betka) Kardosová and Nadezda (Natka) Sporanková for their patience, love and special care during my stay. Thanks Natka for make me feel as part of your family. Thanks to all the other people that collaborated with my work there, Dr. Zdenka Hromadková, Eva, Slávka, and many others. I want to thanks also to my colleagues and lunchmates, specially Rucho, Katy and Sylvia, which taught me the istone, paper, scissor!... I want to thanks to my friends from the residence, Jadwiga, Julia, Katrine, and specially to Jana, which was my best friend for the trips around the forest, and to walk, walk and walk. Thanks for the tiramisu party!!!!

Gracias también a quienes me formaron y me prepararon para poder completar esta etapa con éxito. Entre ellos quiero agradecer especialmente a la Dra. Patricia Haure, quien me brindó la posibilidad y el apoyo necesarios para venir a Tarragona. También a quienes me formaron y su imagen quedó grabada para siempre, entre ellos la Dra. Rosa Fenoglio, Dra. Claudia Bidabehere, Dra. Norma Marcovich, Dra. Mirta Aranguren, y muchos otros...

A mis compañeros y amigos del grupo Biopolímeros Vegetales. No sólo a los de ahora, sino a todos los que han estado y pasado por allí durante todos estos años. Especialmente a Pepa (que sería de nosotros sin ti, amiga mía), a Ana (compartimos un año fantástico), Carles, Modest, Jordi, Luizildo, Jor, Freddy, Baltazar, Nour-eddine, Xiao, Dayiong, Ïu, Vannessa, José Antonio, Dawitt, Gautier, Camilo, Guillermo, Lulú, etc., etc., etc. También a los jefes, Xavier, Ricard, Joan, Vanesa y Francesc, con quienes hemos compartido no sólo el trabajo sino también más de una calçotada y paella.

También quiero nombrar a mis amigos, quienes han sido un poco "mi familia" durante estos últimos cuatro años. A toda la trouppe venezolana, especialmente a María Eugenia y Pedro, y Carmelo, y también a Alicia por los momentos compartidos. A Gus, compañero de domingos ya lejanos. A papá Henry y mamá Jor por cuidar de mí, y a los compis de café, charlas, alegrías y penas, Carles y Luizildo (siempre nos tocan las mismas cosas, no Luiz?). 
A Fredyto, eterno navegante, mi diaria alegría, amor inconmensurable, paciencia infinita. Que tu puerto sea mi puerto, allí donde la vida nos lleve... y que el destino nos una para siempre...

A mis amigas y amigos que quedaron lejos y aún así permanecieron fieles a la amistad. La lista es enorme, lo saben, pero hay gente más que especial. Fundamentalmente tuve la suerte de contar con Vero y mi adorada sobrina Agustina, con Andrea, con Leo, y mi prima Silvana y su hija (mi ahijada) Martina, luz de mi corazón. A Carlitos y Vicky por los asados, charlas y momentos compartidos. También a Lucrecia, Mariana, Laura, Silvana y Solange, compañeras de carrera, y años de universidad, y ahora amigas desparramadas por el mundo. A Paola, con quien compartí tres meses de locas aventuras. A ellas, mujeres valerosas y con un corazón de oro, gracias por estar ahí siempre!!!

Dentro de mis amigas, Jorgelina merece un párrafo aparte. ¿Qué hubiera sido de mí sin ti, eh?. Has sido madre, hermana, amiga, juez y parte en cada uno de los acontecimientos en los últimos diez años. Gracias a vos vine acá, permanecí acá y sobreviví acá. No lo olvidaré nunca. Gracias Jor!

A mi madre. Porque ha sido y sigue siendo mi ejemplo de lucha, amor, paciencia, optimismo y buena voluntad. Porque siempre respetaste mis decisiones y me apoyaste, muchas veces sabiendo que me equivocaba, y aún así después me ayudaste a levantarme cuando estaba en el suelo. A Osvaldo, gracias por ser mi padre y acompañarme como tal estos últimos 12 años. A mis hermanas Virginia (quien pronto me hará tía), y María por su amor, cariño, alegría, y por estar conmigo siempre (saben que las adoro). A mis abuelos Olga y Cholo, por criarme, apoyarme y alentarme en mi búsqueda, especialmente a mi abuelo Cholo por todo su amor. Al resto de mi familia, (la grande y la chica), mis tíos y mis primos, mis tíos y tías abuelos, y a todo aquel que siempre le pregunta a mi mamá, ¿Cómo está la Débora?.

A todos los que de una manera u otra no sólo han colaborado con este trabajo, sino conmigo, a todos aquellos que me han apoyado y ayudado, aguantando lloradas, extrañitis, melancolías y nostalgias. A todos ustedes, y todos ellos, ;Gracias! Esta será una etapa que no olvidaré jamás. 
AUTOHYDROLYSIS OF AGRICULTURAL BY-PRODUCTS FOR THE PRODUCTION OF XYLO-OLIGOSACCHARIDES.

Debora Alcida Nabarlatz

ISBN: $978-84-690-7617-0 /$ DL: T.1385-2007 


\section{INDEX}

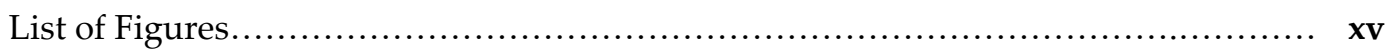

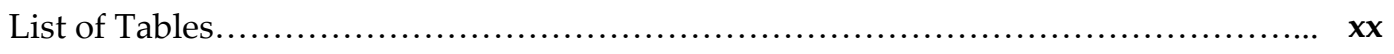

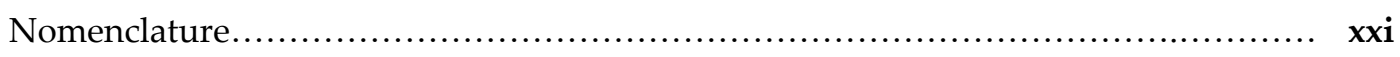

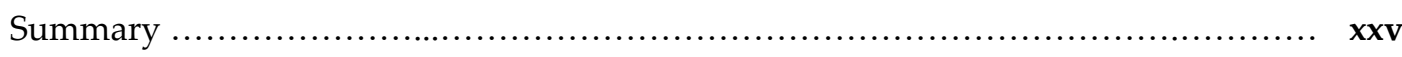

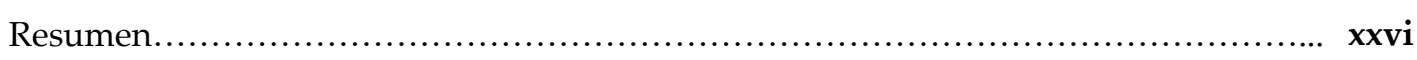

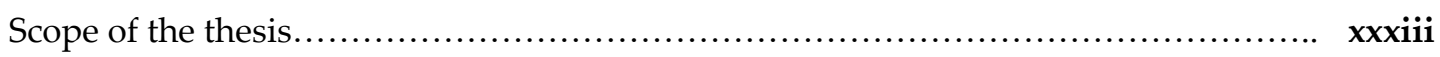

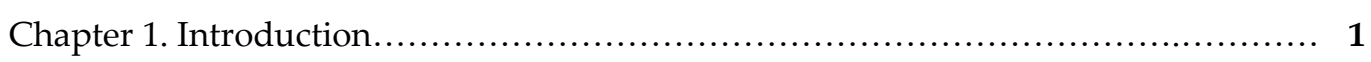

1.1. The oligosaccharides and their main applications.......................... 1

1.1.1. Applications of oligosaccharides as food additives..................... 1

1.1.2. Applications of oligosaccharides in the pharmaceutical field............... 5

1.2. The chemical structure of xylo-oligosaccharides............................... 7

1.2.1. Xylan characteristics.......................................................... 8

1.3. Hemicelluloses as component of wood.................................. 11

1.3.1. Chemical composition of wood .................................... 11

1.3.2. Anatomical structure of wood............................................ 16

1.4. Processes for the industrial production of hemicelluloses...................... 19

1.4.1. Hydrothermal treatments............................................ 22

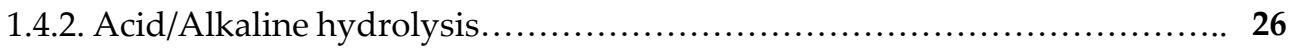

1.4.2.1. Mechanism of acid hydrolysis of hemicelluloses..................... 27

1.4.2.2. Mechanism of alkaline hydrolysis of hemicelluloses.................. 29

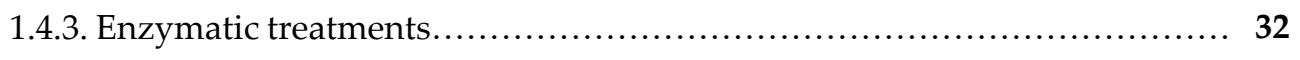

1.4.3.1. Mechanism of enzymatic hydrolysis.................................. 35

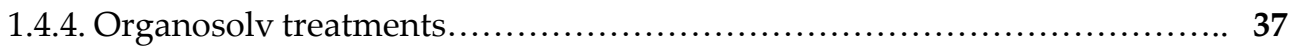

1.5. Recovery and purification of oligosaccharides............................. 38

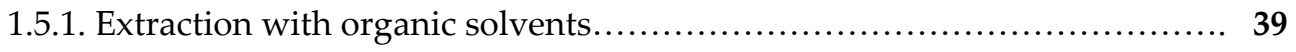

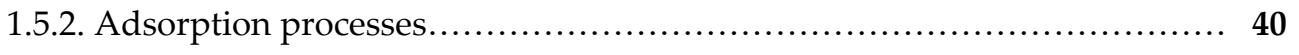

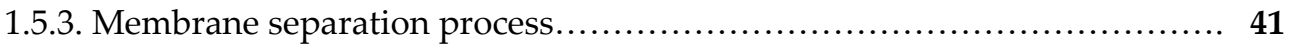

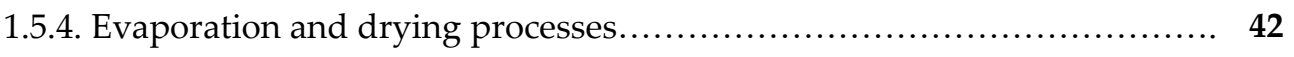

1.5.5. Ionic exchange resins.................................................... 42

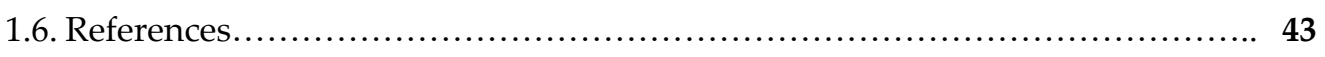

Chapter 2. Materials and Methods............................................... 55 
2.1. Autohydrolysis reaction.................................................. 55

2.1.1. Autohydrolysis reaction at small scale................................. 55

2.1.2. Autohydrolysis reaction in the $10 \mathrm{~L}$ reactor.............................. 57

2.1.3. Analysis of the samples.................................................... 59

2.1.3.1. Analysis of the raw materials..................................... 59

2.1.3.2. Analysis of the solid residue obtained after the reaction.............. 60

2.1.3.3. Analysis of the autohydrolysis liquor.............................61

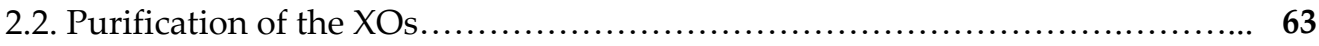

2.2.1. Ultrafiltration using polymeric membranes............................. 63

2.2.1.1. Retention of impurities and separation of different molecular

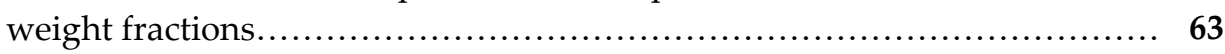

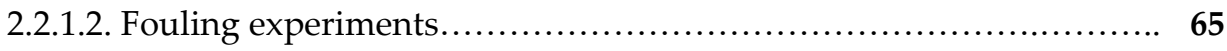

2.2.2. Adsorption on activated carbon........................................... 66

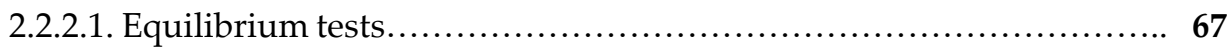

2.2.2.2. Adsorption on activated carbon in a column....................... 67

2.2.2.3. Characterization of the activated carbon.............................. 68

2.2.3. Precipitation with a non solvent....................................... 69

2.2.4. Enzymatic membrane reactors......................................... 70

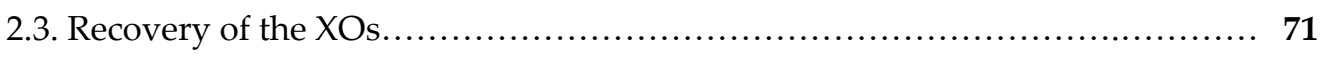

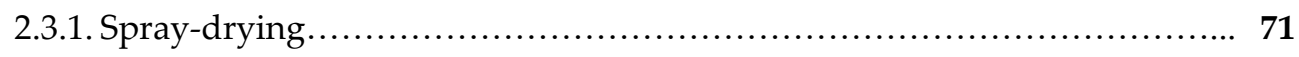

2.3.2. Lyophilization........................................................ 72

2.4. Preparative procedures.................................................. 73

2.4.1. Dialysis process used for purification of SXOs............................ 73

2.4.2. Purification with Amberlite XAD - 2 resin................................... 74

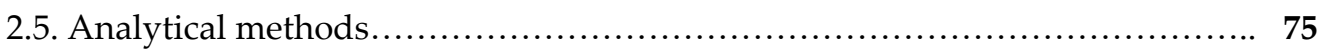

2.5.1. Ash content determination (ASTM D-1102-84) ........................... 75

2.5.2. Moisture content determination.......................................... 76

2.5.3. Removal of the organic extractives (ASTM D-1107-84 modified)............ 76

2.5.4. Determination of the Klason lignin (ASTM D 1106-84)...................... 76

2.5.5. Analysis of the XOs recovered............................................. 77

2.5.6. Posthydrolysis reaction for the quantification of total monomers........... 77

2.5.6.1. Posthydrolysis of samples from autohydrolysis liquor.............. 77

2.5.6.2. Posthydrolysis of SXOs and DXOs................................. 77

2.5.7. Total hydrolysis for the production of alditols and quantification by

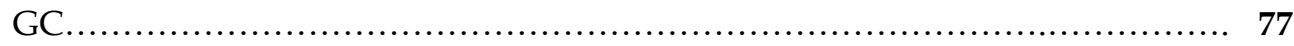


2.5.8. Determination of the acid - soluble lignin

2.5.9. Determination of uronic acid

2.5.9.1. Determination by colorimetry.

2.5.9.2. Determination by potentiometry

2.5.10. Determination of ferulic acid.

2.5.11. Procedure for the solvent extraction - Determination of phenolic acid..... 81

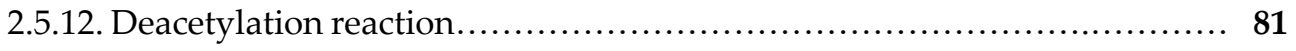

2.5.13. Methods for qualitative identification................................. 82

2.5.13.1. Descending Paper Chromatography ............................ 82

2.5.13.2. TLC (Thin Layer Chromatography).............................. 82

2.5.14. Antioxidant activity of xylo-oligosaccharides............................ 82

2.5.15. Mitogenic and comitogenic activity testing............................. 83

2.5.16. Instrumental methods......................................................... 84

2.5.16.1. High Pressure Liquid Chromatography Analysis..................... 84

2.5.16.2. Gel Permeation Chromatography ................................. 87

2.5.16.3. Nuclear Magnetic Resonance (NMR) analysis....................... 88

2.5.16.4. FT-IR and MALDI-TOF Mass Spectrometry ........................ 92

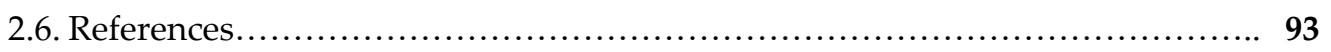

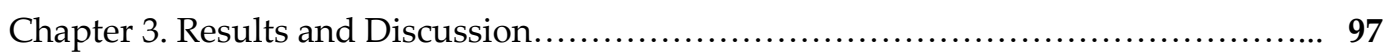

3.1. Autohydrolysis of corncobs and almond shells.............................. 99

3.1.1. Raw material composition.................................................. 99

3.1.2. Composition of the solid residue after autohydrolysis................... 100

3.1.3. Autohydrolysis of corncobs............................................ 104

3.1.3.1. Product distribution and reaction pathway....................... 104

3.1.3.2. Kinetics of xylan depolymerization............................... 110

3.1.4. Autohydrolysis of almond shells................................... 117

3.1.4.1. Product distribution and reaction pathway...................... 117

3.1.4.2. Kinetics of xylo-oligosaccharides formation......................... 122

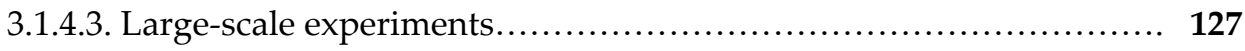

3.2. Autohydrolysis of different agricultural by-products...................... 132

3.2.1. Autohydrolysis-induced compositional changes.......................... 132

3.2.1.1. Composition of the raw materials............................... 132

3.2.1.2. Cellulose component........................................... 133

3.2.1.3. Lignin component............................................. 134 
3.2.1.4. Xylan component.

3.2.2. Molar mass distribution of the xylo-oligosaccharides

3.2.3. Structural features of the xylo-oligosaccharides

3.2.4. Characterization of xylo-oligosaccharides from almond shells

3.3. Purification treatments.

3.3.1 Precipitation with a non solvent.

3.3.2. Removal of lignin impurities by adsorption onto activated carbons.

3.3.2.1. Adsorption equilibrium tests.

3.3.2.2. Column tests

3.3.3. Ultrafiltration of xylo-oligosaccharides from almond shells

3.3.3.1. Composition of the crude xylo-oligosaccharides from almond shells

3.3.3.2 Ultrafiltration of the xylo-oligosaccharides solution.

3.3.4. Enzymatic membrane reactors.

3.4. Preliminary results about possible applications of xylo-oligosaccharides. 190

3.4.1. Antioxidant activity of the xylo-oligosaccharides. 190

3.4.2. Immunomodulatory activity of almond shells xylo-oligosaccharides. 191

3.5. References 193

Chapter 4. Conclusions and Future Work. 201

4.1. Conclusions. 201

4.2. Recommendations. 204

4.3. Future work. 206 


\section{LIST OF FIGURES}

Figure 1.1. Main applications of oligosaccharides.

Figure 1.2. Formulas of the sugar components of polyoses.

Figure 1.3. a) Partial chemical structure of O-acetyl-4-O-methylglucuronoxylan from hardwood (MGX). b) Partial chemical structure of arabino-4-O-methylglucuronoxylan (AGX) from softwood. c) Partial chemical structure of arabino-xylooligosaccharide (AX) from wheat bran hemicellulose. d) Partial chemical structure of arabinoxylan (AX) from grasses....

Figure 1.4. a) General scheme showing the chemical composition of wood. b) Approximate distribution of the macromolecular substances in wood.

Figure 1.5. Formula of cellulose. a) Central part of the molecular chain. b) Reducing and non reducing end group of the molecule of cellulose.

Figure 1.6. Building units of lignin: $p$-coumaryl alcohol (I), coniferyl alcohol (II), sinapyl alcohol (III)

Figure 1.7. Structural scheme of lignin

Figure 1.8. Schematic illustration of connections between softwood polyoses and lignin...

Figure 1.9. Most frequently suggested types of lignin-polysaccharide linkages....

Figure 1.10. Models of a softwood and a hardwood block, showing the main cutting planes for anatomical studies, and anatomical structures visible without optical aids

Figure 1.11. Representation of the cell wall structure of softwood tracheids and hardwood libriform fibres

Figure 1.12. Comparison between the cell wall of tracheids, fibres and vessels with that of parenchyma cells.

Figure 1.13. Main processes used in the fractionation of biomass.

Figure 1.14. Mechanism of acid hydrolysis of glycosidic linkages....

Figure 1.15. Half-chair conformation of the tautomeric carbonium-oxonium ion pair.

Figure 1.16. Formation of furfural, hydroxymethylfurfural, levulinic acid and formic acid from monosaccharides in acidic medium....

Figure 1.17. Endwise degradation of polysaccharides. a) reactions involved in peeling, b) main stopping reactions

Figure 1.18. Hydrolysis of glycosidic bonds in alkaline medium

Figure 1.19. A hypothetical plant heteroxylan fragment and the sites of attack by xylanolytic enzymes.

Figure 1.20. Activity mechanism of the different enzymes on arabinoglucuronoxylan, arabinoxylan, and glucuronoxylan. 
Figure 1.21. Main methods used for the purification of oligosaccharides

Figure 2.1. Small reactors. 55

Figure 2.2. Typical temperature profile for the experiments in the $10 \mathrm{~L}$ reactor. 56

Figure 2.3. Scheme of the $10 \mathrm{~L}$ reactor system. 59

Figure 2.4. Equipment used for the membrane separation process 64

Figure 2.5. Module used for the separation using polymeric membranes 65

Figure 2.6. Spray drying equipment. 72

Figure 2.7. Lyophilization equipment. 73

Figure 2.8. Dialysis process used for purification of xylo-oligosaccharides 74

Figure 2.9. Equipment used for HPLC/GPC. 84

Figure 2.10. a) Chromatogram obtained with the RID detector for a sample of autohydrolysis liquor of almond shells after posthydrolysis treatment. b) Chromatogram obtained for the analysis of the different standards used....

Figure 2.11. a) Calibration curve for the standards of glucose, xylose, arabinose and acetic acid obtained with the RID detector. b) Calibration curve for the standards HMF and furfural obtained with the RID detector.

Figure 2.12. Typical Molar Mass Distribution (MMD), obtained for a mixture of XOs from almond shells after spray-drying process......

Figure 2.13. Calibration curve for GPC analysis. 88

Figure 2.14. Different spectra for DXOs from almond shells.

Figure 3.1. Composition of the solid residue after the reaction from corncobs and almond shells, for different temperatures as function of the reaction time.

Figure 3.2. Variation in the composition of the xylan remaining in the solid residue after the reaction, for different temperatures as function of the reaction time: anhydroxylose, anhydroarabinose and acetyl (as wt.\% of xylan).

Figure 3.3. $\mathrm{pH}$ of the resultant liquid after the reaction, as function of temperature and reaction time.

Figure 3.4. Distribution of the cellulose products in the liquid after the reaction (as \% of the original cellulose), as function of temperature and reaction time: gluco-oligosaccharides, glucose and HMF.....

Figure 3.5. Yield and compositions of the xylan remaining in the hydrolyzed corncobs.

Figure 3.6. Yield and compositions of the xylo-oligosaccharides from corncobs.

Figure 3.7. Yields of xylose, arabinose, acetic acid and furfural during corncobs autohydrolysis.

Figure 3.8. Molar mass distributions of the soluble products for the experiments performed at $190^{\circ} \mathrm{C}$ and $150^{\circ} \mathrm{C}$ and short reaction times.......

Figure 3.9. Reaction pathway for xylan autohydrolysis from corncobs. 
Figure 3.10. Amount and composition of the unreacted xylan remaining in the hydrolyzed almond shells.

Figure 3.11. Yield and composition of the xylo-oligosaccharides

Figure 3.12. Change in the molar mass distribution of the xylo-oligosaccharides during autohydrolysis at $150^{\circ} \mathrm{C}, 169^{\circ} \mathrm{C}$ and $190^{\circ} \mathrm{C}$.

Figure 3.13. Yields of xylose, acetic acid, arabinose and furfural, and the amount of degraded xylan.

Figure 3.14. Reaction pathway for the autohydrolysis of xylan from almond shells.

Figure 3.15. Autohydrolysis of almond shells in the $10 \mathrm{~L}$ stirred reactor at $179^{\circ} \mathrm{C}$. Comparison between the experimental yields and compositions and the values calculated with the kinetic model for xylan, xylo-oligosaccharides, and monomer products.

Figure 3.16. Yields and compositions for the autohydrolysis of almond shells at $179^{\circ} \mathrm{C}$ and $29 \mathrm{~min}$ and the recovery of the crude xylo-oligosaccharides by spray drying........

Figure 3.17. Molar mass distribution of the crude xylo-oligosaccharides in the autohydrolysis liquor and after recovery by spray drying, determined by GPC.

Figure 3.18. Distribution of cellulose among reaction products: hydrolysis residue (cellulose) and liquid products (gluco-oligosaccharides, glucose and HMF), expressed as \% of original cellulose in the different raw materials.

Figure 3.19. Distribution of lignin among reaction products: hydrolysis residue (Klason Lignin), and liquid products (acid - resistant and acid - soluble lignin), expressed as \% of original Klason lignin + organic extractives in the different raw materials.

Figure 3.20. Hemicellulose in the raw material and its distribution between the hydrolysis residue and the non-dried liquid products (XOs, monosaccharides, acetic acid and furfural), expressed as $\%$ of original hemicellulose in the different raw materials

Figure 3.21. Molar mass distribution of the xylo-oligosaccharides in the non-dried liquid product (XOs), obtained after spray drying (SXOs) and obtained after dialysis (DXOs), for the six raw materials studied.

Figure 3.22. ${ }^{13} \mathrm{C}$ NMR spectra (in $\mathrm{D}_{2} \mathrm{O}$ ) of DXOs from various plant sources.

Figure 3.23. ${ }^{1} \mathrm{H}$ NMR spectra of $\mathrm{XO}$ f from barley straw and corncobs.

Figure 3.24. The 2D HSQC spectrum of DXOs from olive stones, illustrating MeGA residues and various $\mathrm{Xyl} p$ residues.

Figure 3.25. FT-IR spectra of the crude almond shell SXOs and its purification products

Figure 3.26. ${ }^{13} \mathrm{C}$ NMR spectra (in $\mathrm{D}_{2} \mathrm{O}$ ) of (A) dialyzed almond shell xylo-oligosaccharides (DXOs) and (B) the deacetylated sample (DeXOs)

Figure 3.27. Partial ${ }^{1} \mathrm{H} /{ }^{13} \mathrm{C}$ HSQC NMR spectrum (in $\mathrm{D}_{2} \mathrm{O}$ ) of almond shell DXOs.

Figure 3.28. MALDI -TOF mass spectrum in $\mathrm{D}_{2} \mathrm{O}$ (sodium-adducts) of the deacetylated sample (DeXO).

Figure 3.29. MALDI -TOF mass spectrum (sodium-adducts) of almond shell xylooligosaccharides DXOs. 
Figure 3.30. Alcoholic precipitation.

Figure 3.31. Comparison of the molar mass distribution of the soluble products presents in the hydrolysis liquor and that of the xylo-oligosaccharides recovered by ethanol precipitation.

Figure 3.32. GPC chromatograms (time in log-scale) for the xylo-oligosaccharides remaining in solution in the equilibrium adsorption experiments at $30^{\circ} \mathrm{C}$ and different loads of the AC- 1 activated carbon.

Figure 3.33. Relation between the reduction in the concentrations of lignin-derived phenolics and carbohydrates at equilibrium for various loads of activated carbon at $30^{\circ} \mathrm{C} \ldots$

Figure 3.34. Pore volume distributions for the three activated carbons used in this study.....

Figure 3.35. Freundlich isotherms for the adsorption of lignin-derived phenolics (open symbols) and xylo-oligosaccharides (solid symbols) on the three activated carbons at $30^{\circ} \mathrm{C}$..

Figure 3.36. Variation in the constants of the Freundlich isotherms of lignin-derived compounds $\left(\mathrm{K}_{\mathrm{LP}}\right)$ and xylo-oligosaccharides $(\mathrm{K} \times \mathrm{O})$ with the surface properties of the activated carbons.

Figure 3.37. Adsorption of the crude xylo-oligosaccharides from reaction batch 2 on an AC1 activated carbon column: breakthrough curves for carbohydrates and lignin-derived products......

Figure 3.38. Adsorption of the crude xylo-oligosaccharides from reaction batch 2 on an AC1 activated carbon column: GPC chromatograms (time in log-scale) for the xylooligosaccharides remaining in solution.

Figure 3.39. GPC elugrams of the lignin-related products and the xylo-oligosaccharides in the feed and permeate of the GE $-1 \mathrm{kDa}$ membrane at the different pressures tested.

Figure 3.40. Influence of pressure on the fluxes of water and xylo-oligosaccharides solution for the thin-film ultrafiltration membranes.

Figure 3.41. Influence of pressure on the fluxes of xylo-oligosaccharides and lignin-related products.

Figure 3.42. Relationship between the dimensionless selectivity towards permeation of the lignin-related products and the flux of permeate.

Figure 3.43. Ultrafiltration of xylo-oligosaccharides: observed rejection curves for the four polymeric membranes (dextran-equivalent molar masses).

Figure 3.44. Relationship between the nominal MWCO of the membranes, and their apparent MWCO established from the molar mass distribution of the permeated xylooligosaccharides.

Figure 3.45. Membrane fouling: relationship between the water permeabilities of new and used membranes......

Figure 3.46. GPC elugrams of the lignin-related products and the xylo-oligosaccharides in the feed and permeate of the GE - $1 \mathrm{kDa}$ membrane as function of time for the fouling experiments.

Figure 3.47. Influence of time in the fluxes of lignin-derived products and xylooligosaccharides, for the fouling experiments in the GE - $1 \mathrm{kDa}$ membrane. 
Figure 3.48. a) Comparison between the monomers content (glucose, xylose and arabinose) and acetic acid, between the feed and permeate collected during $5 \mathrm{~h}$ of experiment. $\mathrm{b}$ ) Comparison between the oligosaccharides content (glucose, xylose and arabinose) and acetic acid, between the feed and permeate collected during $5 \mathrm{~h}$ of experiment. c)

Comparison of the uronic acid, furfural and HMF between the feed and permeate collected during $5 \mathrm{~h}$ of experiment.

Figure 3.49. (a) GPC signal of the dextran $(40 \mathrm{kDa})$ solution, the enzyme dextranase, and the samples of the mixture taken at different reaction times. b) GPC signal showing the activity of the enzyme-carbon complex, at different $\mathrm{pH}$ and different ratios carbon/enzyme. 18

Figure 3.50. GPC signal of the experiments for the EMR. Up: Feed (solution of dextran, MW: $40 \mathrm{kDa}$ ). Down: Permeate collected at different reaction times. 


\section{LIST OF TABLES}

Table 2.1. Reaction times at constant temperature for the experiments at small scale....

Table 2.2. Assignments for the $13 \mathrm{C}$ signals (up) and $1 \mathrm{H}$ signal (down) for each different carbon in the molecule.

Table 3.1. Average chemical composition and confidence interval $(\alpha=0.025)$ of the batch of corncobs and almond shells used for this study.

Table 3.2. Best-fit values for the activation energies and the frequency factors of rate constants $\mathrm{k} 1$ to $\mathrm{k} 8$ (min-1).

Table 3.3. Best-fit values for the amounts and compositions of the two types of xylan in native corncobs

Table 3.4. Best-fit values for the activation energy and the frequency factor of the rate constants $\mathrm{k} 1$ to $\mathrm{k} 9$. (min-1).

Table 3.5. Best-fit values for the amount and composition of the three types of xylan in native almond shells.

Table 3.6. Composition of the different raw materials (wt.\%), related to dry material, with confidence interval $(\alpha=0.025)$.

Table 3.7. Composition of the spray - dried liquid product (SXOs)

Table 3.8. Relative amounts of monosaccharides and acetyl groups, and distribution of acetyl groups among xylose residues in the DXOs from different raw materials....

Table 3.9. Chemical characteristics of the crude (SXO) and dialyzed XO (DXO) obtained from almond shells.

Table 3.10. HSQC NMR cross-peaks of various structural elements of almond shell DXO...

Table 3.11. Surface characteristics of the commercial activated carbons (NORIT) used in this study

Table 3.12. Freundlich isotherms: results for the adsorption of the carbohydrate fraction and the lignin-derived products on commercial activated carbons...

Table 3.13. Adsorption on an AC-1 activated carbon column: composition of the lyophilized samples of the product fractions collected during the experiment and retentions calculated for xylo-oligosaccharides and lignin-related products (Xylooligosaccharide solution from reaction batch 2)

Table 3.14. Autohydrolysis of almond shells at $179^{\circ} \mathrm{C}$ and 29 min: yields and composition of the products (based on $100 \mathrm{~kg}$ of dry almond shells).....

Table 3.15. Water permeability for the clean membranes...

Table 3.16. Antioxidant activity for XOs from the different raw materials.

Table 3.17. Mitogenic and comitogenic activities of partially O-acetylated xylooligosaccharides from almond shells (AS-DXO) and corncobs (CC-DXO) in comparison to the corncob xylan (CCX) used as positive control. 


\section{NOMENCLATURE}

${ }^{13} \mathrm{C}$ : One dimensional carbon spectra.

${ }^{1} \mathrm{H}$ : One dimensional proton spectra.

AA: Antioxidant activity.

AGX: arabinoglucuronoxylan.

AS: almond shells.

AS-DXO: dialyzed xylo-oligosaccharides from almond shells.

AX: arabinoxylan.

B: Concentration of lignin obtained by spectrophotometry (g/l).

BS: barley straw.

$\mathrm{C}_{0, j}$ : concentration of solute in the feed $(\mathrm{g} / \mathrm{L})$

CC: corncobs.

CC-DXO: dialyzed xylo-oligosaccharides from corncobs.

CCX: immunogenic water-soluble arabinoglucuronoxylan from corncobs.

$C_{e, j}$ equilibrium concentration of species $j$ in the solution $(\mathrm{g} / \mathrm{L})$.

CHX: complex heteroxylan.

$C_{j}$ : concentration of the species $j$ expressed as a mass percent of the initial xylan that has been converted into the species $j$.

$\mathrm{C}_{\mathrm{LP}}$ and $\mathrm{CXO}_{\mathrm{X}}$ t total concentrations of lignin-related products and XOs in the permeate.

CLP-feed and CXO-feed: total concentrations of lignin-related products and XOs in the feed.

COMP: Mass of component i (g) in dry basis obtained by HPLC analysis in the case of glucose, xylose, arabinose, acetic acid, furfural and HMF; and obtained by weight in the case of Klason lignin.

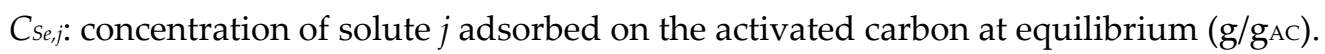

Cxo,M: concentration of a xylo-oligosaccharide of mass $\mathrm{M}$ in the permeate.

Cxo-feed,M: concentration of a xylo-oligosaccharide of mass $\mathrm{M}$ in the feed.

$\mathrm{Cx}_{\mathrm{y}}[0]$ : total amount of xylan.

$C_{x y i}[0]$ : amount of the type of xylan i present in the native raw material.

DeXO: Deacetylated xylo-oligosaccharides.

DFT: Density Functional Theory model.

DP: Degree of polymerization.

DS: Mass of original dry solid (g).

DSAc: degree of acetylation.

DSR: Mass of dry solid remaining after hydrolysis (g). 
DXOs: dialyzed xylo-oligosaccharides.

Eai: Activation energy of the rate constants $(\mathrm{kJ} / \mathrm{mol})$.

EAS: water-soluble phenolic fraction.

EMR: Enzymatic Membrane Reactor.

$f$ : sugar unit in furanose form.

FOS: fructo-oligosaccharides.

Fuc: Fucose.

Gal: Galactose.

GAX: glucuronoarabinoxylan.

Glc: Glucose.

GOS: gluco-oligosaccharides.

Hex: hexose unit.

HMF: hydroxymethylfurfural.

HSQC: Heteronuclear Single Quantum Correlation spectra.

$k_{i}$ : specific reaction rates $\left(\mathrm{min}^{-1}\right)$.

$K_{j:}$ unit-capacity parameter, for xylo-oligosaccharide adsorption $\left(K_{x}\right)$ and for lignin-derived phenolics $\left(K_{L P}\right)$.

LO: \% of soluble lignin associated based on xylo-oligosaccharides precipitated.

LP: liquid product.

$m$ : mass of activated carbon ( $\left.\mathrm{g}_{\mathrm{AC}}\right)$.

M: Molar mass (g/mol).

Man: Mannose.

MeS: water-insoluble phenolic fraction.

MGA or MeGA: 4 -O- methyl-D-glucuronic acid.

MGX: methylglucuronoxylan.

ML: middle lamella.

MMD: Molar mass distribution.

MON_OCi: \% of monomers presents in the autohydrolysis liquor (glucose and HMF), based on original cellulose.

MON_OMi: \% of monomers presents in the autohydrolysis liquor (glucose, xylose, arabinose) and furfural, acetic acid, and HMF, based on $100 \mathrm{~g}$ of original dry material.

MON_OX: \% of monomers presents in the autohydrolysis liquor (xylose, arabinose and acetic acid), based on original xylan.

MW: molecular weight.

MWCO: molecular weight cut off.

nj: site-energy parameter. 
NMR: Nuclear Magnetic Resonance.

NSP: non-starch polysaccharides.

OLIG_COMP: Composition of oligosaccharides in \% (xylose, arabinose and acetic acid).

OLIG_OMi: \% of component i (xylose, arabinose or acetic acid) that form part of xylooligosaccharides, based on $100 \mathrm{~g}$ of original dry material.

OLIG_OX $\mathrm{i}$ \% of component i (xylose, arabinose or acetic acid) that form part of xylooligosaccharides, based on original xylan.

OLIG_TOT: Total amount of xylo-oligosaccharides based on original xylan.

OS: olive stones.

P: primary wall.

$p$ : sugar unit in pyranose form.

PO: Mass of oligosaccharides precipitated (g).

PREC_OM: Yield of precipitated oligosaccharides based on $100 \mathrm{~g}$ of original dry material.

PREC_OX: Yield of precipitated oligosaccharides based on original xylan.

PuXOs: purified XOs.

PZC: point of zero charge.

$r d_{j}$ : reductions in the concentrations of lignin-derived products and carbohydrates.

RH: rice husks.

Rha: Rhamnose.

RI: Refraction Index signal, for permeate and retentate.

Robs,M: retention for a xylo-oligomer with a molar mass of M.

RS: resistant starch.

S: Mass of dried solid used for Klason lignin analysis (g).

S1: secondary wall one.

S2: secondary wall two.

SB: \% of solubilized solid.

SLP/CH: Selectivity of the membrane.

SOL_OCi: \% of component $\mathrm{i}$ in the hydrolyzed solid, based on $\%$ of component $\mathrm{i}$ in raw material (for lignin, cellulose and xylan).

SOL_OMi: \% of component $\mathrm{i}$ in the hydrolyzed solid, based on $100 \mathrm{~g}$ of original dry material (for lignin, cellulose and xylan).

SOL_RAW $\mathrm{i}$ \% of component $\mathrm{i}$ in raw material for lignin and cellulose. In the case of xylan, it is calculated as a sum of the corresponding percentages of xylose, arabinose and acetic acid in raw material.

SXOs: spray - dried xylo-oligosaccharides.

T: temperature $\left({ }^{\circ} \mathrm{C}\right)$. 
T: tertiary wall.

$\mathrm{t}$ : time (min).

V: Volume of solution (L).

W: wart.

WS: wheat straw.

X2: 2-O-acetylated xylose unit.

X23: 2,3-di-O-acetylated xylose unit.

X3: 3-O-acetylated xylose unit.

XG: MeGA 2-O-linked to a xylose unit.

XG3: MeGA 2-O-linked and 3-O-acetylated xylose unit.

Xint: non-substituted internal xylose unit.

$\mathrm{X}_{\mathrm{n}}$ : neutral xylo-oligosaccharides.

$\mathrm{X}_{\mathrm{n}} \mathrm{Acm}$ : neutral xylo-oligosaccharides with one to two acetyl groups.

$\mathrm{X}_{\mathrm{n}} \mathrm{MeGA}$ : acidic xylo-oligosaccharides branched with one uronic acid.

$X_{n} M e G A A c$ acidic oligomers containing one acetyl group with one uronic acid.

XOS: xylo-oligosaccharides.

Xt: non-reducing terminal xylose unit.

$x$ XO-Ace: mass fractions of acetyl in the average composition of the oligomers.

$x$ xo-Ara: mass fractions of anhydroarabinose in the average composition of the oligomers.

$x$ xo-xyl: mass fractions of anhydroxylose in the average composition of the oligomers.

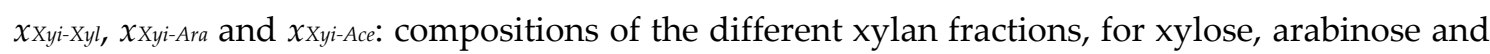
acetyl groups.

$x_{X y-X y l}[0], x_{X y-A r a l}[0]$ and $x_{X y-A c e}[0]$ : composition of the original xylan, for xylose, arabinose and acetyl groups.

XYL_OMi: \% of component i (xylose, arabinose or acetic acid) in the hydrolyzed solid, based on $100 \mathrm{~g}$ of original dry material.

XYL_OX: \% of component i (xylose, arabinose or acetic acid) in the hydrolyzed solid, based on original xylan.

XYL_RE: Total xylan remaining in the hydrolyzed solid based on original xylan.

XYL_RE_COMP: \% of component i (xylose, arabinose or acetic acid) in xylan remaining in the hydrolyzed solid.

X $\alpha$ : Reducing end $\alpha$ of a xylose unit.

$X \beta$ : Reducing end $\beta$ of a xylose unit. 


\section{SUMMARY}

Lignocellulosic biomass is a fully renewable resource that can be used as raw material for the production of a wide variety of compounds, such as biomass-derived fuels, power, chemicals or materials. In the present research, agricultural residues typical from the Mediterranean region of Spain, were used for the production of xylooligosaccharides with potential applications in the food and pharmaceutical field.

Autohydrolysis reaction was tested at several temperatures and reaction times to produce these xylo-oligosaccharides. It was found that the increase in the temperature and longer reaction times increased the depolymerization of xylan and the formation of low molar mass products. Cellulose and lignin remained quantitatively in the solid, which suggests that the solid residue could be used to recover them in a subsequent step. The maximal yield of xylo-oligosaccharides was around $63 \mathrm{wt} \%$ for almond shells at $190^{\circ} \mathrm{C}$ and $19 \mathrm{~min}$ of reaction. The molar mass distribution of the products was very broad (between 100 to $10^{6} \mathrm{~g} / \mathrm{mol}$ ), being strongly dependent on the reaction conditions and the raw material used.

All the xylo-oligosaccharides obtained by autohydrolysis reaction showed structural features of a partially $\mathrm{O}$-acetylated 4-O-methylglucuronoxylan with different degrees of substitution depending on the raw material where they came from.

Several purification methods were tested for the removal of impurities and/or separation in different molecular weight fractions. The precipitation using a non solvent allowed to recover between $85 \%$ and $95 \%$ of the theoretical xylooligosaccharides for corncobs and almond shells, respectively, obtained at $169^{\circ} \mathrm{C}$ and $25 \mathrm{~min}$ of reaction. The yield of product precipitated tended to be much lower at higher reactions times, since the low molar mass oligomers and monomers were soluble in the ethanol-water mixture.

The ultrafiltration using polymeric membranes seems the most promising method for the removal of low molar mass impurities, and also for the separation in 
different molecular weight fractions. The results obtained demonstrated that the $1 \mathrm{kDa}$ membrane was the more selective for the removal of lignin-derived impurities. It was also observed that the increase in the pressure of operation decrease the selectivity, and for this reason the membranes should be operated at low pressure to maximize it, although this will imply a larger area for the same flow rate of permeate.

The adsorption of impurities on activated carbons was tested, and it was higher for lignin-related products than for xylo-oligosaccharides. The retention for ligninderived products was limited because part of them seemed to be linked to the xylooligosaccharides.

Preliminary results obtained with the experiments using enzymatic membrane reactors showed that is possible to depolymerize dextrans and separate dextran oligomers in only one step, which suggest that the same treatment could be applied for the production of low molar mass xylo-oligosaccharides useful for food applications.

The antioxidant activity was measured for the different xylo-oligosaccharides obtained, and it was higher for xylo-oligosaccharides from corncobs and olive stones. It was found that all of them have a strong antioxidant activity compared with natural products, making them potential candidates for their use as food additives.

Preliminary results about the immunomodulatory activity of xylooligosaccharides from almond shells demonstrated that they showed dose-dependent direct mitogenic as well as comitogenic activities, similarly as the immunogenic watersoluble arabinoglucuronoxylan from corncobs used as positive control. The activities in the whole doses range were about $30 \%$ lower in comparison to the control. Further studies have to be done in the possible applications of these xylo-oligosaccharides, determining the corresponding combination of reaction/separation process to obtain the required product. 


\section{RESUMEN}

La biomasa lignocelulósica es un recurso completamente renovable, que está cobrando cada vez mayor importancia debido a que puede ser utilizado para la producción de una amplia variedad de compuestos. Entre ellos, los más importantes son los combustibles derivados de biomasa (biocombustibles), y otros productos químicos y materiales (biopolímeros) que pueden reemplazar a los derivados de petróleo. Para la realización de esta tesis, se han utilizado diversos residuos procedentes de cultivos agrícolas (típicos de la región del Mediterráneo en España), con el objetivo de producir xilo-oligosacáridos con potencial aplicación en la industria alimentaria y farmacéutica. Los materiales elegidos son la cáscara de almendra, hueso de oliva, marlos de maíz, cáscara de arroz, y la paja de trigo y de cebada.

Los oligosacáridos son polímeros de bajo peso molecular formado por azúcares de 5 carbonos (pentosas), en este caso basados en xilosa. Para su separación del resto de los componentes de la madera, se propuso una etapa de reacción basada en la autohidrólisis (reacción directa de la biomasa con agua). Esta etapa de reacción se ha estudiado variando la temperatura, el tiempo de reacción, y el material original empleado, evaluando el efecto de dichos parámetros en las características de los xilooligosacáridos obtenidos. Se ha observado que el incremento en la temperatura de reacción junto con tiempos de reacción más largos, aumentan el grado de depolimerización del xilano y la formación de productos de bajo peso molecular. La celulosa y la lignina permanecen en el sólido, lo que sugiere que dicho residuo sólido puede ser recuperado y utilizado en una etapa subsiguiente para la producción de otros componentes (tales como la fermentación de la celulosa para la producción de glucosa y/o etanol, y la producción de compuestos químicos derivados de la lignina). El máximo rendimiento de xilo-oligosacáridos es alrededor del 63\% (peso/peso) para la cáscara de almendra a $190^{\circ} \mathrm{C}$ y 19 min de reacción. La distribución de masa molar de los productos presentes en el licor recuperado luego de la reacción (xilo-oligosacáridos, monómeros y productos de bajo peso molecular) es muy amplia (entre 100 a 106 g/mol), 
siendo ésta fuertemente dependiente de las condiciones de reacción, y del material original utilizado.

La estructura química de los xilo-oligosacáridos obtenidos mediante la reacción de autohidrólisis es la misma para todos los residuos agrícolas estudiados, siendo en todos los casos del tipo 4-O-metil-glucuronoxilano parcialmente acetilado, con diferentes grados de sustitución dependiendo de la especie de origen. Los grupos acetilo se ubican en la molécula de xilosa principalmente en la posición 3 (entre el 60 y el $67 \%$ mol), mientras que la cantidad presente en la posición 2 y en las posiciones 2 - 3 es similar (19-30\% mol, y $8-25 \%$ mol, respectivamente). Los grupos sustituyentes de ácido 4-O-metil-glucurónico (MeGA) se presentan en una relación MeGA / Xyl que varía entre $2.5: 100(\mathrm{~mol}: \mathrm{mol})$ para marlos de maíz, hasta $9.1: 100(\mathrm{~mol}: \mathrm{mol})$ para el hueso de oliva.

La reacción de autohidrólisis genera, además de los oligómeros de interés, otros derivados tales como monómeros, furfural e hydroxymethylfurfural (HMF), ácidos fenólicos, urónicos y ferúlicos y otros productos de degradación. Debido a esto, se evaluaron diversos métodos de purificación con el objetivo de remover el material de bajo peso molecular, y/o separar en fracciones de diferente peso molecular. Para ello se estudiaron tres métodos de separación, la precipitación con un no solvente, la separación por ultrafiltración con membranas poliméricas, y la adsorción en carbones activados.

La precipitación con un no solvente (etanol) permite recuperar entre el 85\% y el 95\% (para marlos de maíz y cáscara de almendra, respectivamente) de la cantidad teórica presente en la solución, obtenida a $169^{\circ} \mathrm{C}$ y $25 \mathrm{~min}$ de reacción. El rendimiento del producto precipitado disminuye considerablemente a tiempos de reacción mayores, debido a que los oligómeros de bajo peso molecular junto con los monómeros permanecen solubles en la mezcla etanol-agua.

La ultrafiltración con membranas poliméricas parece ser el método más prometedor para la eliminación de impurezas de bajo peso molecular, así como para la 
separación de los oligómeros en fracciones de distinto peso molecular. Los resultados demuestran que la membrana con molecular weight cut off (MWCO) igual a $1 \mathrm{kDa}$ es la más selectiva para la eliminación de las impurezas derivadas de lignina. También se observa que el aumento en la presión de operación disminuye dicha selectividad, lo que obliga a trabajar a bajas presiones para maximizarla. Esta característica, sin embargo, hace que el área de las membranas a utilizar sea mayor para mantener la misma velocidad de flujo del permeato.

La adsorción de impurezas en carbones activados comerciales también fue evaluada. Se pudo observar que la adsorción es mayor para los productos derivados de lignina y las impurezas de bajo peso molecular que para los xilo-oligosacáridos. La retención para los compuestos derivados de la lignina se ve limitada porque parte de ellos parecen estar enlazados a los xilo-oligosacáridos. La selectividad entre ambos tipos de compuestos se ve mejorada cuando los carbones son altamente microporosos, y tienen bajo volumen de mesoporos, junto con un diámetro de mesoporos pequeño. Los experimentos en columna demuestran que durante las primeras 2 h de operación, el carbón es capaz de retener un promedio del $64 \%$ de los compuestos derivados de lignina y el 21\% de los xilo-oligosacáridos.

Con el objetivo de integrar la reacción y la purificación en un solo paso, se está evaluando la posibilidad de construir un reactor enzimático de membrana. Los resultados preliminares obtenidos hasta ahora demuestran que es posible depolimerizar dextranos y separar los oligómeros de dextrano obtenidos en sólo un paso. Con este propósito, la enzima dextranasa fue inmobilizada en carbón activado, el cual fue posteriormente incorporado a una membrana polimérica. La separación fue realizada con una membrana polimérica comercial con MWCO de $1 \mathrm{kD}$, físicamente enlazada a la membrana enzimática. Estos resultados sugieren que el mismo tratamiento podría ser aplicado para la producción de xilo-oligosacáridos de bajo peso molecular, los cuales tienen potencial aplicación como aditivo alimentario. 
Se han realizado algunos estudios preliminares para evaluar las posibles aplicaciones de los xilo-oligosacáridos obtenidos. Con este propósito, se evaluó la actividad antioxidante de los distintos xilo-oligosacáridos procedentes de diferentes residuos agrícolas, encontrando que aquellos obtenidos a partir de huesos de oliva o marlos de maíz tenían la mayor actividad antioxidante. Esta actividad es muy alta si se la compara con la actividad antioxidante de frutos naturales, lo que hace a estos xilooligosacáridos candidatos potenciales para su uso como aditivos alimentarios. En un estudio diferente, se evaluó la actividad inmuno-modulatoria de los xilo-oligosacáridos procedentes de la cáscara de almendra. Se encontró que estos xilo-oligosacáridos poseen actividad, tanto mitogénica como comitogénica, cuando se los compara con el arabinoglucuronoxilano obtenido de marlos de maíz, el cual tiene actividad inmunogénica y fue usado como control. La actividad inmunogénica fue un 30\% menor comparada con la del control.

En el futuro, otros estudios deberían llevarse a cabo sobre las posibles aplicaciones de estos xilo-oligosacáridos, determinando la combinación correspondiente de los pasos de reacción y purificación de acuerdo al producto requerido. 
AUTOHYDROLYSIS OF AGRICULTURAL BY-PRODUCTS FOR THE PRODUCTION OF XYLO-OLIGOSACCHARIDES.

Debora Alcida Nabarlatz

ISBN: 978-84-690-7617-0 / DL: T.1385-2007 


\section{SCOPE OF THE THESIS}

The scope of the thesis is to evaluate several lignocellulosic materials coming from agriculture residues common in Mediterranean regions for the production of hemicelluloses (xylo-oligosaccharides). These oligosaccharides have potential applications in the food industry and in the pharmaceutical field, being of interest their high-scale production by using ambient - friendly processes in all the stages of production and purification.

\section{Objectives of the thesis}

The general objective is to obtain xylo-oligosaccharides from biomass, testing at the same time the method of production and possible purification methods, and characterizing the product obtained. For this purpose, was proposed a hydrolytic reaction stage followed by several purification processes, evaluating their effects in the xylo-oligosaccharides obtained.

The main objective of the research was divided into particular objectives according to the different steps of the process:

$\checkmark$ Perform an exhaustive and systematic study of the autohydrolysis reaction at small scale (25 $\mathrm{mL}$ in volume), to optimize the production of xylooligosaccharides from corncobs and almond shells by autohydrolysis at temperatures between $150^{\circ} \mathrm{C}$ and $190^{\circ} \mathrm{C}$. The objective was to obtain experimental details about the maximal yield of xylo-oligosaccharides, their chemical composition, and their molar mass distribution correlated as function of reaction temperature and time, to propose a model based on the kinetic of the autohydrolysis reaction that can be used for the reactor design.

$\checkmark$ Produce larger batches of $\mathrm{XO}$ (that can be used in the subsequent purification steps) by using a $10 \mathrm{~L}$ reactor to validate the experimental data and the kinetic model proposed, and to optimize the recovery of the oligosaccharides by spraydrying. In this stage six raw materials were tested: almond shells, corncobs, olive stones, rice shells, and wheat and barley straw. 
$\square$ Evaluate the purification and/or recovery of the xylo-oligosaccharides by precipitation, adding a non solvent (like ethanol), to determine the yield, molar mass distribution and composition of the final xylo-oligosaccharides obtained.

$\checkmark$ Evaluate the application of commercial polymeric membranes (in ultrafiltration regime) to separate xylo-oligosaccharides into different molecular weight fractions or remove low molecular weight material. In this step four polymeric membranes with different molecular weight cut off were tested.

$\checkmark$ Evaluate the use of activated carbons for the selective adsorption of impurities, phenolic compounds and lignin, derived from the hydrolytic reaction stage. The differences in the composition and molar mass distribution of the product obtained after adsorption in the activated carbons were studied.

$\checkmark$ Elucidate the chemical structure of the xylo-oligosaccharides obtained, to establish the differences between them when they are obtained from different raw materials.

$\checkmark$ Establish possible sequences for the different steps of the process, based in the results of the different purification methods tested and in the possible applications of the xylo-oligosaccharides. 
AUTOHYDROLYSIS OF AGRICULTURAL BY-PRODUCTS FOR THE PRODUCTION OF XYLO-OLIGOSACCHARIDES.

Debora Alcida Nabarlatz

ISBN: 978-84-690-7617-0 / DL: T.1385-2007

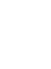




\subsection{THE OLIGOSACCHARIDES AND THEIR MAIN APPLICATIONS}

Considering the scope of the thesis, first of all is necessary to determine the possible applications of the oligosaccharides and their typical characteristics. Oligosaccharides are substances obtained from natural resources, which are gaining importance as additives in the food industry, and that are also being studied for several pharmaceutical applications. Figure 1.1 shows the main uses of oligosaccharides.

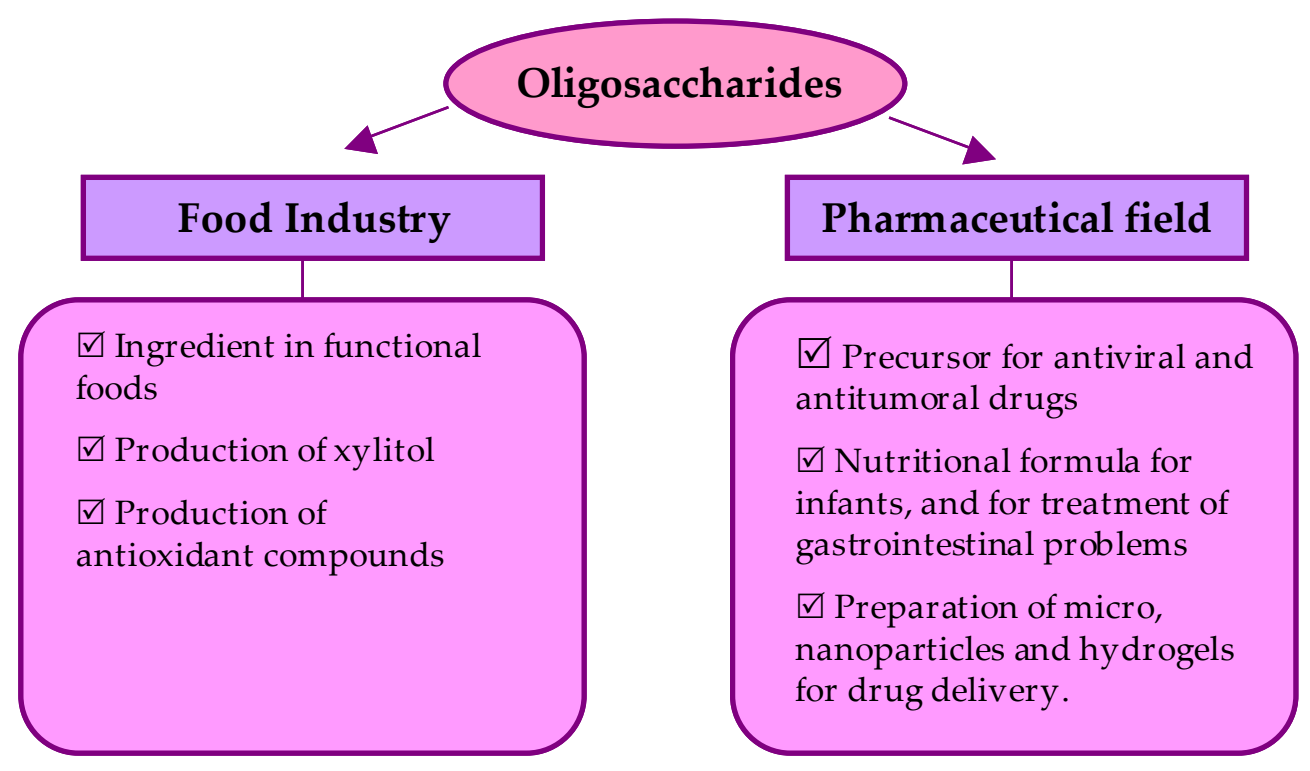

Figure 1.1. Main applications of oligosaccharides.

\subsubsection{Applications of oligosaccharides as food additives}

From the $80^{\prime}$ s, the popularity of several oligosaccharides as food ingredients has grown rapidly, particularly in Japan and Europe, mainly because of the possible health effects associated to the consumption of these compounds [1]. In the early 90's, the Japanese government legislated for "foods for specified health use" (FOSHU), which incorporate oligosaccharides as the functional ingredient in foods. Currently "functional foods" are defined as those that in addition to act as nutrients that may positively affect specific biological functions, improving the general state of health and/or reducing the risk of suffering different diseases [2]. 
The dietary fibre has the characteristics required for its consideration as an important ingredient in the formulation of functional foods, because of its beneficial effects such as increasing the volume of faecal bulk, decreasing the time of intestinal transit, cholesterol and glycaemia levels, trapping substances that can be dangerous for the human organism, stimulating the growth of the intestinal flora, etc. Biologically, the concept of fibre was associated to several meanings along the years, being the most accepted that dietary fibre is composed by the parts of the plant cells or analogous carbohydrates that are resistant to digestion and absorption in the human small intestine, with complete or partial fermentation in the large intestine. Dietary fibre is naturally present in cereals, vegetable, fruit, and nuts, and its amount and composition differs from food to food. There are three main components of dietary fibre: the nonstarch polysaccharides (NSP), the resistant starch (RS) and the oligosaccharides [3]. The NSP are cell wall polysaccharides that differ from starch in the lack of $\alpha$-glycosidic bonds, and the RS is starch or its hydrolysis products that escape digestion and passes to the large intestine. Finally, the oligosaccharides considered here are mostly sugarlike compounds comprising between two and ten carbohydrate units, which are soluble in $80 \%$ ethanol and largely resist digestion by pancreatic and brush board enzymes.

About the beneficial effects on health, in the case of NSP, the mechanisms of action are not clear. They act as a substrate for fermentation, stimulating the microbial growth and normalizing the bowel habit, and helping to prevent the diverticular disease and the colo-rectal cancer. Also, they have physical effects in the small bowel, helping in the glycaemic responses (diabetes) and in the lipid absorption, which has implications in the coronary heart disease. They have effects on the appetite possibly because to the delaying of the gastric emptying and the production of short chain fatty acids that provides energy. The resistant starch (RS) affects mainly the bowel habit, and act again as substrate for fermentation, mainly for the production of short chain fatty acids (especially butyrate), and contributes to the control of glycaemic response. But the oligosaccharides have been the newest and most exciting development, because whilst they are already fermentable substances, their effects on bowel habit are negligible and their contribution to the human health relies on their remarkable effects on the large intestinal flora. For this reason they are called "prebiotics". To be considered a prebiotic, the ingredient has to be resistant to host digestion, absorption and adsorption processes, it has to be fermented by the microflora colonizing the 
gastrointestinal system, and it has to selectively stimulate the growth and/or the activity of one or a limited number of bacteria within the gastrointestinal system [4]. Several oligosaccharides have been tested using various in vitro methods, animal models and human clinical trials, being the best documented ones the fructooligosaccharides (FOS), lactulose, galacto-oligosaccharides and inulin. They are produced at large scale and added to various products in the food industry. Also, there are studies (but in minor proportion) about soybean-oligosaccharides, lactosucrose, isomalto-oligosaccharides, gluco-oligosaccharides and xylo-oligosaccharides, having evidences in all of them of promoting the growth of microflora. Particularly, long-chain xylo-oligosaccharides have intestinal improving and hypolipemic activities [5]. Glucuronic acid-containing xylo-oligosaccharides show plant growth regulating activity [6] and antimicrobial activity against some bacteria [7]. It was demonstrated, for example, that the in vitro growth of Bifidobacterium spp was enhanced by xylooligomers [8], which were as effective as raffinose and better than fructooligosaccharides.

There are several beneficial effects on health due to the prebiotic intake. The first one is the protection against the development of colon cancer mainly by the production of protective metabolites (such as butyrate, which stimulates apoptosis in colonic cancer cell lines) and by stimulating the growth of bacteria (like lactic acid bacteria) that are believed to have inhibitory effects on several bacteria that produce carcinogenic enzymes [9-16]. The food-grade oligosaccharides promote the proliferation of Bifidobacterium spp for which the reported beneficial effects on human health includes [8]: (i) suppressing activity of entero putrefactive bacteria, preventing the formation of products such as toxic amines, (ii) repression of the proliferation of pathogenic bacteria because of the production of short-chain organic acids (such as lactic acid or acetic acid) leading to decreased $\mathrm{pH}$ in the gastrointestinal tract, and (iii) promotion of the digestion and absorption of nutrients. These properties result in the ability to prevent gastrointestinal infections, to reduce the duration of diarrhea episodes and to maintain the faecal water content within normal levels with delayed gastric emptying. Also, the inhibitory properties of lactic acid bacteria and bifidobacteria protect from other pathogens that i.e. cause gastroenteritis, and stimulate the immunoresponse of the human organism. Another characteristic is the possibility of increasing mineral absorption (particularly calcium), and the modulation of blood lipids such as cholesterol and triglycerides [17, 18]. 
In general, food-grade oligosaccharides are not pure products, but are mixtures containing oligosaccharides of different degrees of polymerization (between 2 and 10 sugar moieties) [8]. Depending on the type, oligosaccharides are water-soluble and mildly sweet, typically $0.3-0.6$ times of that of sucrose, and they have low caloric value, which makes them suitable for low-calorie food preparations. They are used in food production for the enhancement of other food flavors; to alter the freezing temperature of foods, or to prevent the excessive drying and maintain a low water activity in food, which is convenient in controlling microbial contamination. The main reason for their use is that they have suitable organoleptic properties, they are stable to moderate temperature and $\mathrm{pH}$, and because of this it is easy to store and add them into processed foods. The potential food applications for prebiotics as food ingredients to improve the gastrointestinal health of the consumer are as additive in beverages and fermented milks, health drinks, bakery products, sauces, infant formulae, cereals, biscuits, confectionery, dairy products, etc. Worldwide, until 1996 there were 12 classes of food-grade oligosaccharides in commercial production (oligosaccharides based on galactose, fructose, palatinose, maltose, isomaltose, gentiose, soybean, and xylose; and lactulose, lactosucrose, glucosyl-sucrose and cyclodextrins) [1]. In the case of xylooligosaccharides, they represent only a small proportion of the total oligosaccharides market, but the demand is increasing every year. The production of xylooligosaccharides reported by the company Suntory increased from $70 \mathrm{t}$ in 1994 to more than $300 \mathrm{t}$ in 1996. In 2000, about 60 companies used xylo-oligosaccharides in about 100 products (i.e. Yoghurina produced by Suntory Ltd., Marushige Genkisu produced by Marushige Ueda Co., etc.) [8]. These oligosaccharides are used predominantly in both prebiotic and synbiotic drinks. Synbiotic includes both a prebiotic and a live microbial food ingredient (probiotic) that is beneficial to health. An example of them is "Bikkle", produced by Suntory Ltd. since 1993, which is a synbiotic drink containing bifidobacteria, xylo-oligosaccharides, whey minerals and oolong tea extract.

Another application but also with implications in the food industry, is the production of antioxidant compounds and low calorie sweeteners as xylitol. There are typical examples, such as the production of detoxified fermentation media (xylose solutions for the fermentative production of xylitol), removing the polyphenols with antioxidant activity from hemicellulosic wood hydrolysates [19-23]. 


\subsubsection{Applications of oligosaccharides in the pharmaceutical field}

Oligosaccharides from several origins are being investigated to find applications in the pharmaceutical field, mainly as precursors for antitumoral and antiviral drugs. Heparin has been used for many years as anticoagulant, and for this reason sulfated oligoxylans were developed as anticoagulant heparin-mimetics several decades ago. A mixture of sulfated oligoxylans (in this case sulfated 1-4- $\beta$-D-oligoxylans produced by chemical sulfation of beechwood) mimics most other biological actions of natural heparins in vitro, including inhibition of the human immunodeficiency virus. The mechanism is not clear, but the results suggest that certain oligosaccharides in the sulfated xylan preparation have structures that may specifically act to inhibit the reactions between the virus envelope and the target cell membrane [24]. Sulfated xylogalactans from the red seaweed Nothogenia fastigiata [25] and a xylomannan derived from algal [26] demonstrated antiviral activity against herpes simplex virus types 1 and 2. A polysaccharide mixture (formed by glucose, xylose, mannose and glucuronic acid) obtained from marine algae has antiviral activity, and when it is bounded to a protein, both (the original polysaccharide and this complex) act as a biological response modifier, exerting a great influence on the immune system. They have an inhibiting activity against adsorption of HIV on human-derived lymphocytes and also, inhibit the activity of reverse transcriptase, which is an enzyme essential for the proliferation of HIV [27].

Several polysaccharides have been studied because of their antitumoral activity. It was demonstrated in vitro that a fraction of xylose, xylo-oligosaccharides and water soluble lignin has cytotoxic effects (may be due to apoptosis) and they reduced the viability of leukemia cell lines derived from acute lymphoblastic leukemia [28].

Different applications were also found based in the indigestible properties of the oligosaccharides. As was mentioned before, the proliferation of Bifidobacterium bifidum that is beneficial for human health was promoted by a mixture of xylo-oligosaccharides containing mainly xylobiose [29]. Based on this principle, a nutritional product was developed for persons having ulcerative colitis. This product combines an oil blend (which contains eicosapentaenoic acid and/or docosahexaenoic acid) and a source of indigestible carbohydrate which is metabolized to short chain fatty acids by the microorganisms present in the human colon [30,31]. Indigestible oligosaccharides (in this case fructo-oligosaccharides) were used to prevent gastrointestinal infections and 
also they reduce the duration of diarrhea episodes in humans [32]. Also, indigestible oligosaccharides constitute the main component of an oral rehydration solution, which inhibits the infection caused by the primary etiology of antibiotic-associated diarrhea (Clostridium difficile) and normalize the microflora [33].

Fructo-oligosaccharides were used also to reduce the incidence of otitis media in infants and young children, and they can be incorporated in any nutritional product such as infant formula [34].

Other applications are being developed for controlled drug delivery systems because of the possibility of obtaining micro- and nanoparticles directly from xylan [35], which remain unaltered in the digestive tract and can be used to deliver drugs into the body at controlled rates. Other polysaccharides were tested (such as pectin and inulin) to target drugs to the colon. They have promising characteristics because of they are specifically degraded by the colonic microflora and can be used as polymer drugs conjugates, coatings and matrix agents [36]. Ethers and esters prepared from xylan and xylo-oligosaccharides have been synthesized and used as thermoplastic compounds for biodegradable plastics, water soluble films, coatings, capsules and tablets [37]. In this context, biocompatible hydrogel seems to have promising characteristics for its use in drug delivery, implants, etc. [38]. Xylan of relatively high molar mass obtained from several sources (aspenwood and birchwood) was converted to hydrogel by reaction with chitosan $[39,40]$, and it was also used for the preparation of nanoparticles for drug release on oral administration [41]. In a completely different procedure, hemicelluloses from spruce were chemically modified and reacted with poly(2-hydroxyethyl methacrylate) (PHEMA) for the preparation of hydrogels [42].

As can be observed, oligosaccharides have potential applications in two important fields such as the food industry and the pharmaceutical one. Though hemicelluloses in general accounts up to $30 \%$ of the biomass of annual and perennial plants and have emerged as a immense renewable source of biopolymers, it has not yet been exploited at industrial scale [43]. Historically, the research on hemicelluloses was focused on the use of plant biomass and its conversion into sugars, chemicals, fuel, etc., but because of the structural varieties and diversity, the hemicelluloses are also attractive as biopolymers. For this reason is important to develop new ways of production of oligosaccharides, improving not only the reaction stage but also the purification processes that allow to recover pure fractions of oligosaccharides. 
Within the huge world of hemicelluloses, the attention will be focused on xylans because it corresponds to the hemicellulose of interest in this research. A brief description of the chemical composition for the different xylan types, and their relation with the other components in wood will be described below. Also, a general overview on the different ways of reaction of the hemicelluloses, and the different processes commonly used for the production of oligosaccharides will be described.

\subsection{THE CHEMICAL STRUCTURE OF XYLO- OLIGOSACCHARIDES}

Polyoses or hemicelluloses are branched heteropolymers whose monomer composition and degree of branching widely vary among different wood species. The sugar units (anhydro-sugars) making up the polyoses can be subdivided into groups such as pentoses (like xylose and arabinose), hexoses (like glucose, mannose and galactose), hexuronic acids, and deoxy-hexoses (Figure 1.2).

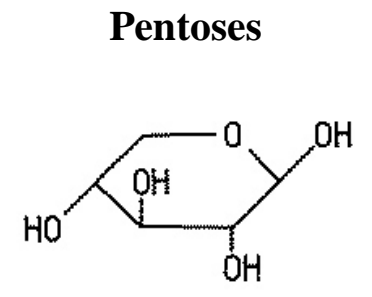

$\beta$-D- Xylose

\section{Hexoses}<smiles>OCC1OC(O)C(O)C(O)C1O</smiles>

$\beta$-D- Glucose
Hexuronic acids<smiles>O=C(O)C1OC(O)C(O)C2OC1C2O</smiles>

$\beta$-D- Glucuronic acid<smiles>CC1C(O)C(O)C(O)C1O</smiles>

$\alpha$-L- Rhamnose

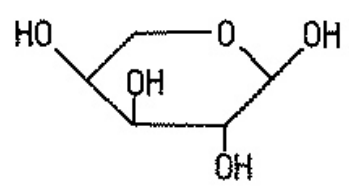

$\alpha-L-$ Arabinopyranose<smiles></smiles>

$\alpha-L-$ Arabinofuranose

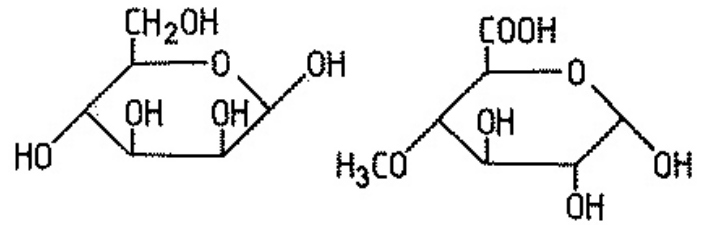

$\beta$-D- Mannose

$\alpha$-D- 4-O-Methylglucuronic acid

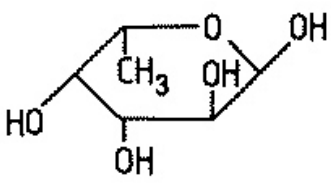

$\alpha-L-F u c o s e$

Figure 1.2. Formulas of the sugar components of polyoses [44]. 
The hemicelluloses can be classified into four general classes of structurally different cell-wall polysaccharide types: i.e. xylans, mannans, $\beta$-glucans with mixed linkages, and xyloglucans. They have structural variations differing in side-chain types, distribution, localization and/or types and distribution of the glycosidic linkages in the macromolecular backbone. The main chain of a polyose can consist of only one unit (homopolymer), e. g. xylans, or of two or more units (heteropolymer), e.g. glucomannans [44]. The main chains are much shorter than in the case of cellulose, having side groups and being branched in some cases.

Softwoods and hardwoods differ not only in the percentages of total polyoses but also in the percentages of individual polyoses and its composition. The dominating hemicellulose in hardwood is an $O$-acetyl-(4-O-methylglucurono)-xylan, accompanied by a small proportion of glucomannan. The major softwood hemicellulose is an $O$ acetyl-galactoglucomannan, followed by small proportions of arabino-(4-Omethylglucurono)xylan. In general, softwoods xylans differ from hardwood xylans by the lack of acetyl groups and by the presence of arabinofuranose units linked by $\alpha-(1 \rightarrow$ 3)-glycosidic bonds to the xylan backbone. Thus, the softwood xylans are arabino-4-Omethylglucuronoxylans. In addition to these hemicelluloses, the heartwood of larchwood contains arabinogalactan, and the reaction tissues of coniferous and deciduous trees contain polysaccharides based on galactose residues [45]. The hemicelluloses characteristics (specifically for xylan) are described deeply in the next section.

\subsubsection{Xylan characteristics}

Xylan-type polysaccharides are the main hemicellulose components of secondary cell walls constituting about $20-30 \%$ of the biomass of dicotyl plants (hardwoods and herbaceous plants). In some tissues of monocotyl plants (grasses and cereals), xylans occurs up to $50 \%$. Xylans are heteropolymers formed by a chain of xylose units linked through $\beta$ - $(1 \rightarrow 4)$-glycosidic linkages, which are branched by short carbohydrate chains (such as D-glucuronic acid or its 4-O-methylether, L-arabinose and/or various oligosaccharides, composed of D-xylose, L-arabinose, D- or L- galactose and Dglucose). Xylan-type polysaccharides can be divided into homoxylans and heteroxylans, which include glucuronoxylans, (arabino)glucuronoxylans, (glucurono)arabinoxylans, arabinoxylans and complex heteroxylans. 
Xylan, as true homopolymers, occurs in seaweeds of the Palmariales and Nemaliales, and their backbone consists of xylopyranose $(\mathrm{Xyl} p)$ residues linked by $\beta$ $(1 \rightarrow 3)$, or mixed $\beta-(1 \rightarrow 3,1 \rightarrow 4)$-glycosidic linkages.

Most of the glucuronoxylans have single 4-O-methyl- $\alpha$-D-glucopyranosyl uronic acid residues (MeGA) attached always at position 2 of the main chain Xylp units. This type of xylan is usually named as 4-O-methyl-D-glucurono-D-xylan (MGX). The glucuronic acid side chain may be present in both the 4-O-methylated and nonmethylated forms. MGX represents the main hemicellulose component of hardwoods, showing Xyl : MeGA ratios from $4: 1$ to $16: 1$ with an average ratio of about $10: 1$. In the native state, the xylan is supposed to be $O$-acetylated. The content of MGX isolated from hardwoods of temperate zones varies in the range of $3-13 \%$. The acetyl groups are splitted during the alkaline extraction, resulting in partial or complete water insolubility of the xylans, but the acetyl groups are partially preserved by treating with hot water or steam. The $\mathrm{O}$-acetyl groups substitute the $\mathrm{OH}$ in the $\mathrm{C} 2$ and $\mathrm{C} 3$ carbons of the xylose rings (Figure $1.3-\mathrm{a}$ ).

Both (arabino)glucuronoxylans (AGX) and (glucurono)arabinoxylans (GAX) have single MeGA and $\alpha$-L-arabinofuranose residues attached at position 2 and 3, respectively, to the $\beta$-(1 $\rightarrow 4)$-D-xylopyranose backbone, which might also be slightly acetylated. The AGX type occurs in coniferous species, but not as the predominant hemicellulose, and is the dominant hemicellulose in the cell walls of lignified supporting tissues of grasses and cereals. Generally, AGX has the backbone more heavily substituted by MeGA than that of hardwood MGX, with 5-6 Xylp residues per uronic acid group. An example of the AGX structure can be observed in Figure $1.3-b$. In contrast to AGX, the GAX consist of an arabinoxylan backbone, which contain about ten times fewer uronic acid side chains than $\alpha$-L-arabinofuranose ones, and have some xylose residues doubly substituted with these sugars. GAX are located in the nonendospermic tissues of cereal grains such as in wheat, corn and rice bran. The degree of substitution and its pattern depends strongly on the source from they are extracted.

Arabinoxylan (AX) has been detected in a variety of cereals, such as wheat, rye, barley, oat, rice, corn, sorghum, etc., as well as in other plants. They represent the major hemicellulose component of cell walls of the starchy endosperm (flour) and outer layers (bran) of the cereal grain (Figure 1.3 - c and d). 
a)

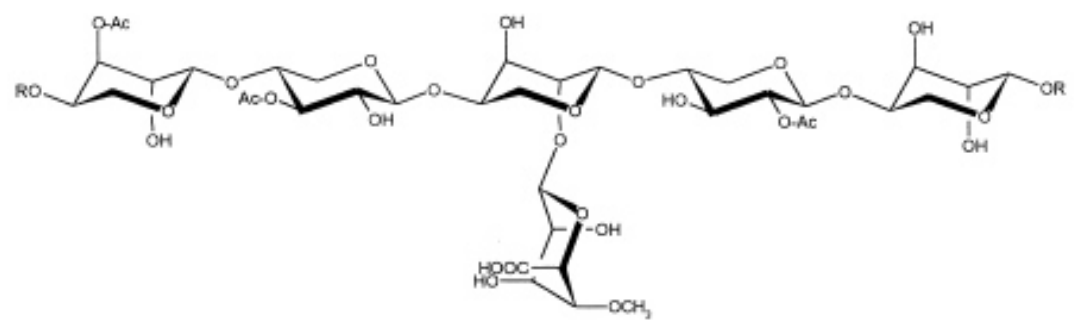

b)

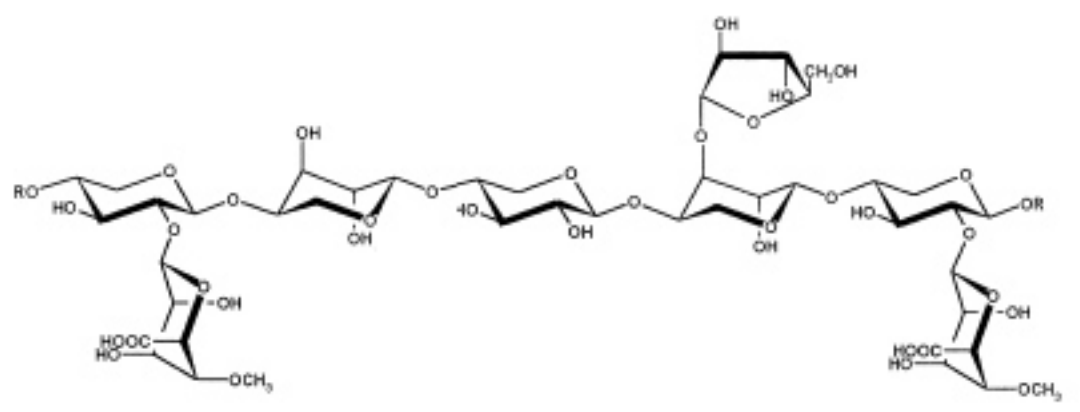

c)

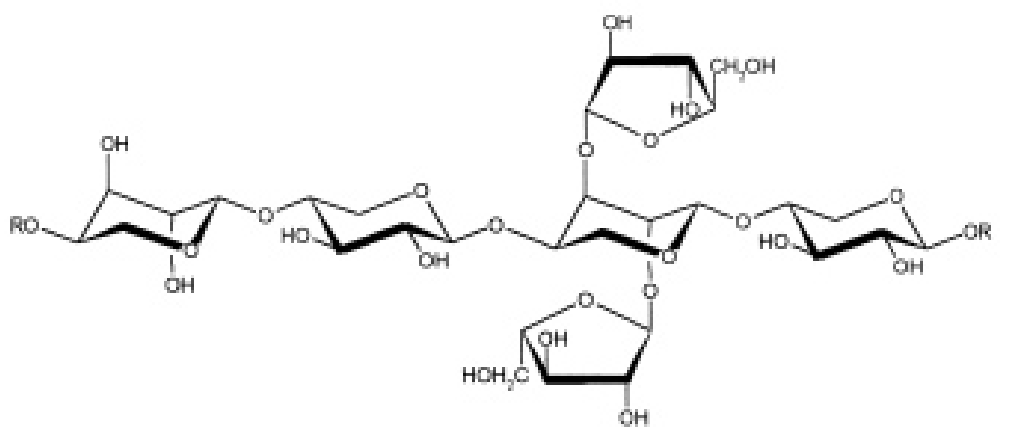

d)

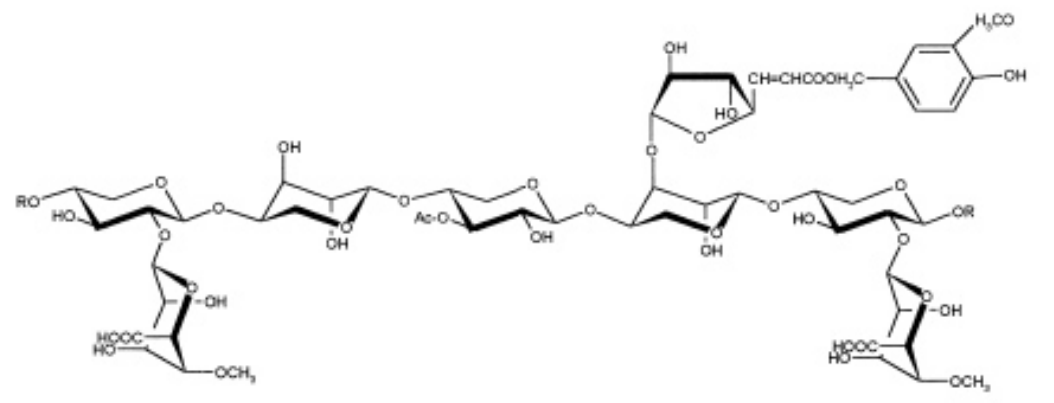

Figure 1.3. [8] a) Partial chemical structure of O-acetyl-4-O-methylglucuronoxylan from hardwood (MGX). b) Partial chemical structure of arabino-4-O-methylglucuronoxylan (AGX) from softwood. c) Partial chemical structure of arabino-xylooligosaccharide (AX) from wheat bran hemicellulose. d) Partial chemical structure of arabinoxylan (AX) from grasses. 
Arabinoxylans occur as neutral as well as slightly acidic polymers, because they have a linear backbone that is, in part, substituted by $\alpha$-L-arabinofuranose residues positioned either on $\mathrm{O}-2$ or $\mathrm{O}-3$ (monosubstituted), or on both positions (disubstituted) of the xylopyranose units. Phenolic acids such as ferulic acid and p-coumaric acid have been found to be esterified to $O-5$ of some arabinofuranose residues.

The complex heteroxylans (CHX) that are present in cereals, seeds, gum exudates and mucilages have a $\beta$-(1 $\rightarrow 4)$-D-xylopyranose backbone decorated with various mono- and oligoglycosyl side chains.

In the wood cell walls, the hemicelluloses are intimately related with the other main components, cellulose and lignin. For this reason, they will be described in the next section, together with a brief description of the structure of wood that will be useful to understand the behavior of the hemicelluloses and the other components during their chemical reactions.

\subsection{HEMICELLULOSES AS COMPONENT OF WOOD}

\subsubsection{Chemical composition of wood}

About the chemical composition of wood, it is necessary to distinguish between the main macromolecular cell wall components cellulose, hemicelluloses and lignin, which are present in all woods, and the minor low-molecular weight components (extractives and mineral substances), which depends strongly in kind and amount on the species of wood. The proportions and chemical composition of lignin and polyoses differ in softwoods and hardwoods, while cellulose is a uniform component of all woods. Figure 1.4 details the chemical wood components [44].

Cellulose is the most important macromolecular substance because of its abundance and historical use, and constitutes the basic building blocks for the cell wall of vegetal species, making up approximately one half of both softwoods and hardwoods. The hemicelluloses coexist with cellulose in the cell wall, and they are intimately related among themselves and with lignin in the cell wall. Lignin acts as an adhesive, holding the microfibrils, that are formed by cellulose chains covered by hemicellulose [46]. The percentage of cellulose in plant material varies depending on 
its origin. It is high in seed hairs and bast fibres (i.e. cotton have between $95-99 \%$ ), while mosses, horse-tail, and bacteria contain less cellulose (between $20-30 \%$ of cellulose). Cellulose is the basis of many technical products (paper, films, fibres, additives, etc.), and is therefore predominantly isolated from wood by pulping processes on a large scale.
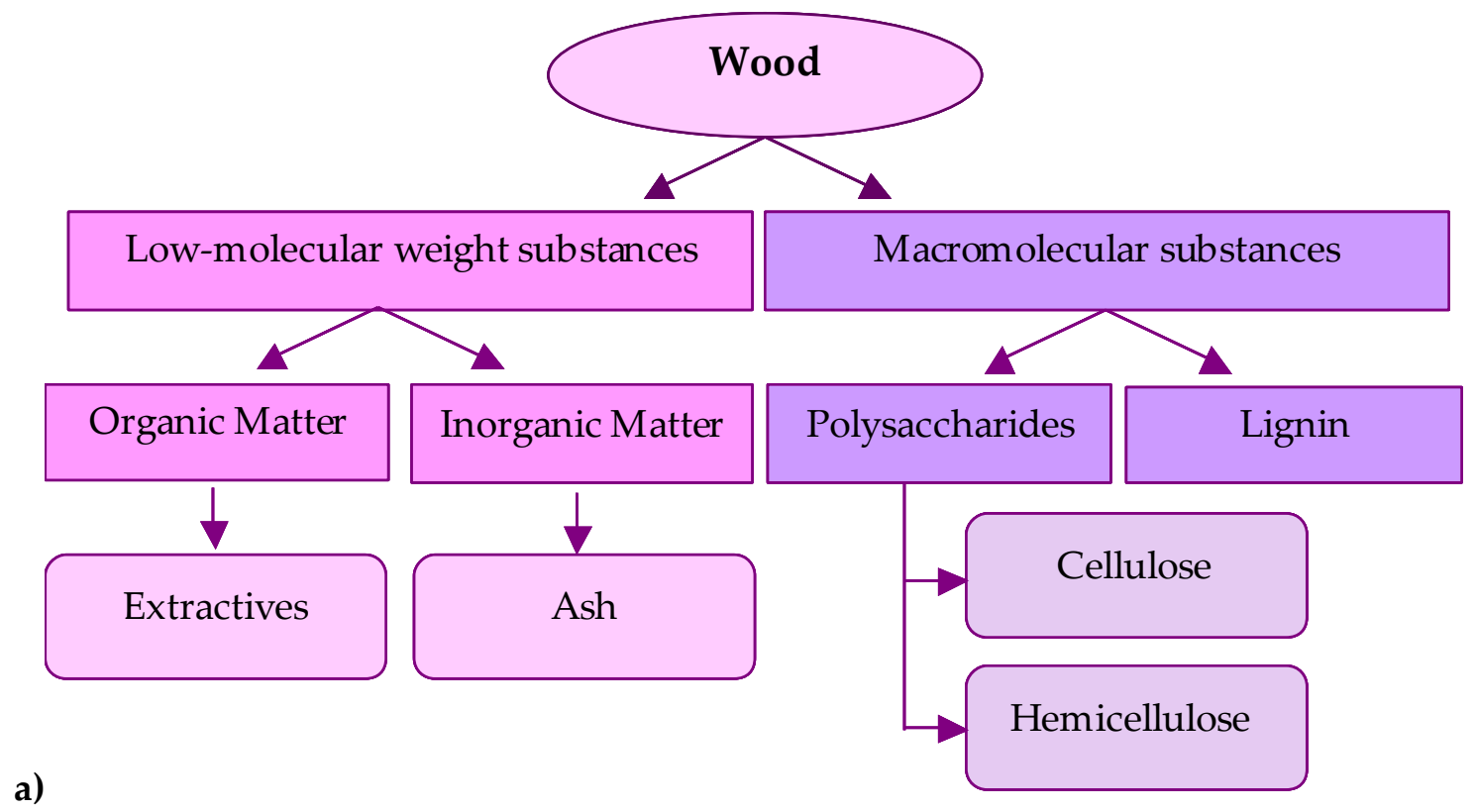

Macromolecular substances

b)

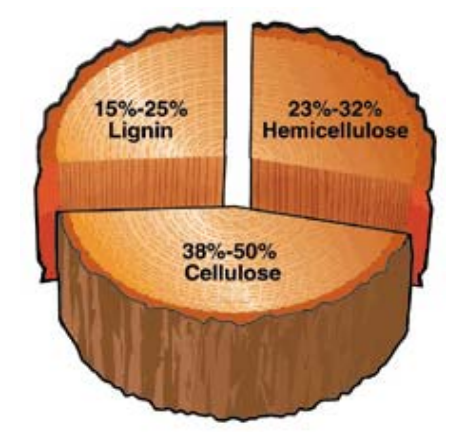

Figure 1.4. a) General scheme showing the chemical composition of wood. b) Approximate distribution of the macromolecular substances in wood.

Chemically, cellulose consists on anhydroglucopyranose units, which are joined to constitute a molecular chain, so it can be described as a linear-polymer glucan with an uniform chain structure. The units are bound by $\beta$-(1 $\rightarrow 4)$-glycosidic linkages (Figure 1.5 - a) [44]. 
Two adjacent glucose units are linked by elimination of one molecule of water between their hydroxylic groups at carbon 1 (C1) and carbon $4(\mathrm{C} 4)$. The $\beta$-position of the $\mathrm{OH}$-group at $\mathrm{C} 1$ needs a turning of the following glucose unit around the $\mathrm{C} 1-\mathrm{C} 4$ axis of the pyranose ring. The repeating unit of the cellulose chain is a cellobiose unit. Though there are $\mathrm{OH}$-groups at both ends of the cellulose chain, these OH-groups show a different behavior. The $\mathrm{C} 1-\mathrm{OH}$ is an aldehyde hydrate group deriving from the ring formation by an intramolecular hemiacetal linkage. That is why the OH-group at the $\mathrm{C} 1$-end has reducing properties, while the $\mathrm{OH}$-group at the C4-end of the cellulose chain is an alcoholic hydroxyl group and therefore non-reducing (Figure $1.5-b$ ). The cellulose chain is elongated, and the glucose units are arranged in one plane, due to the $\beta$-position of the $\mathrm{OH}$-group at $\mathrm{C} 1$, the conformation of the molecule in chair form and the equatorial arrangement of the hydroxylic groups.

a)

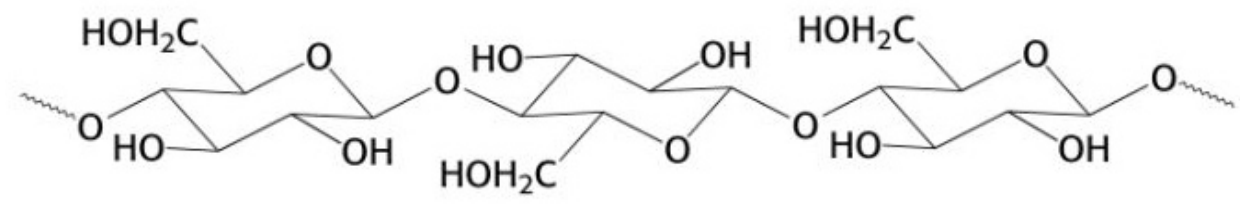

b)

\section{Non reducing end}

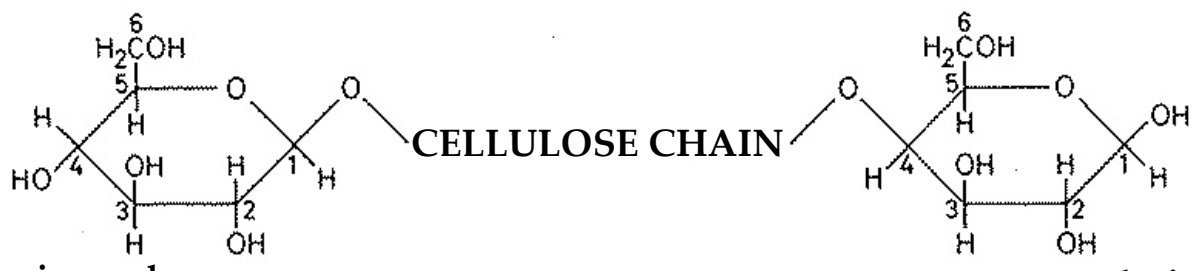

Reducing end

Figure 1.5. Formula of cellulose. a) Central part of the molecular chain. b) Reducing and non reducing end group of the molecule of cellulose.

Lignin is the third macromolecular wood component, and its function is to increase the mechanical strength properties. The amounts of lignin present in the different plants are quite variable, while in wood species the content ranges between 20 $-40 \%$, aquatic and herbaceous angiosperms as well as many monocotyledons are less lignified. The molecules of lignin are built up quite differently from those of the polysaccharides, because they consist on an aromatic system composed of phenylpropane units. The lignin macromolecule cannot be described by a simple 
combination of one or few monomeric units, or by one or few types of linkages as in the case of cellulose or hemicellulose. Numerous studies with radioactive carbon $\left({ }^{14} \mathrm{C}\right)$ have confirmed that the $p$-hydroxy-cinnamyl alcohol, $p$-coumaryl alcohol, coniferyl alcohol and sinapyl alcohol are the primary precursors and building units of all types of lignin (Figure 1.6).<smiles>OCC=Cc1ccc(O)cc1</smiles>

I<smiles>COc1cc(C=CCO)ccc1O</smiles>

II<smiles>COc1cc(C=CCO)cc(OC)c1O</smiles>

III

Figure 1.6. Building units of lignin: p-coumaryl alcohol (I), coniferyl alcohol (II), sinapyl alcohol (III) [44].

The lignin structure is still matter of models, and a proposed structure can be observed in Figure 1.7.

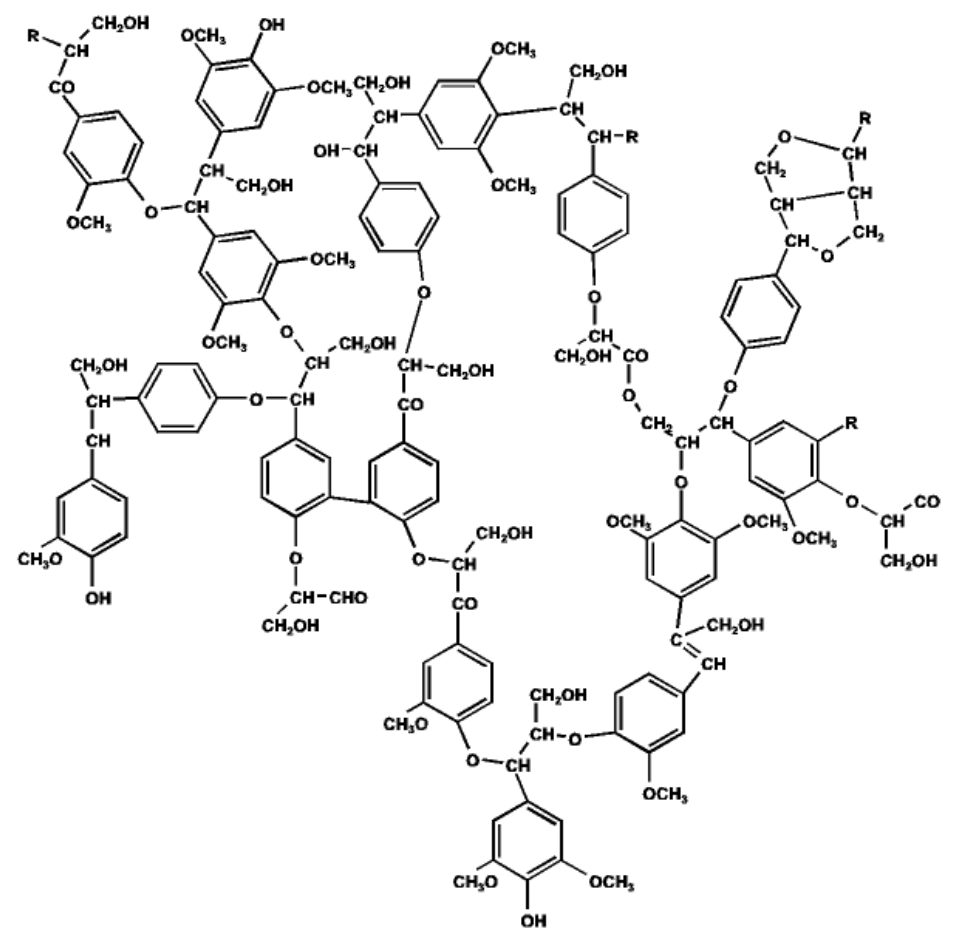

Figure 1.7. Structural scheme of lignin. 
Lignin seems to be not simply deposited between the cell wall polysaccharides, but linked and associated with a part of them. The phenomenon of the intimate association between the polysaccharide and lignin as part of the cell wall is described by the terms lignin-polysaccharide complex. This term describes the fact that in very different fractions isolated from wood, containing variable lignin and polysaccharide portions, the components cannot be totally separated by selective chemical treatments or special separation and purification techniques. As connecting links to lignin the polyoses side-groups arabinose, galactose and 4-O-methylglucuronic acid are most frequently suggested, because of their sterically favoured positions (see Figure 1.8).

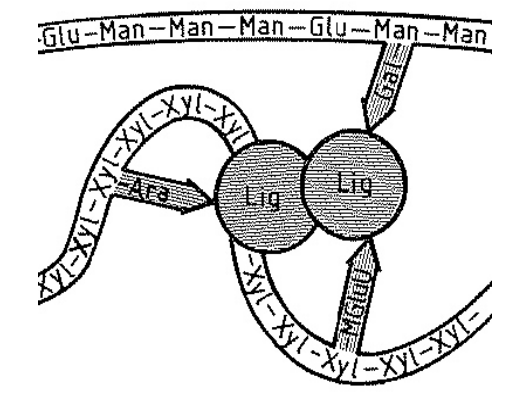

Figure 1.8. Schematic illustration of connections between softwood polyoses and lignin [44].

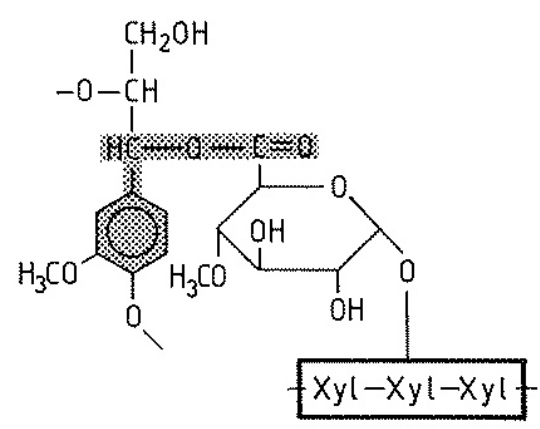

Benzyl ester linkage

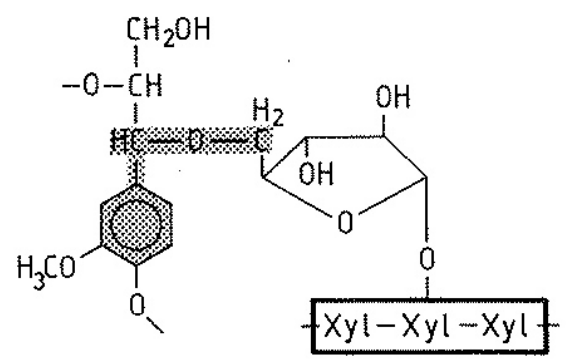

Benzyl ether linkage<smiles>COC(O)CO</smiles>

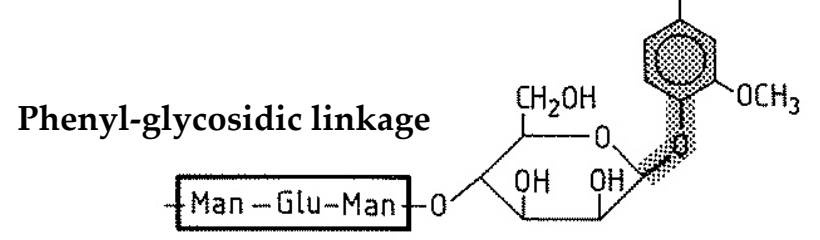

Figure 1.9. Most frequently suggested types of lignin-polysaccharide linkages [44]. 
The probable types of covalent linkages between lignin and polyoses are ether linkages (alkali stable), ester linkages (alkali labile) as well as glycosidic bonds (see Figure 1.9).

Besides the cell wall components, there are numerous compounds of low molecular weight that are called extractive material of wood. They can be divided into organic and inorganic matter, in which the organic matter is called extractive, and the inorganic matter is obtained as ash. The main components of ash are calcium, magnesium and potassium. Among the extractives there are the aromatic (phenolic) compounds (i.e. tanning compounds, stilbenes, lignans and flavonoids, etc.), terpenes, aliphatic acids, alcohols, etc.

\subsubsection{Anatomical structure of wood}

As was mentioned before, the distribution of the main components in wood depends strongly on its nature, but also on its anatomical structure. For this reason, it is necessary to know some details about the physical structure of the wood. Wood shows differences not only between softwoods and hardwoods, as well as between various species, but also differences within one sample, depending on the function of this tissue in the complete structure (such as sapwood and heartwood, growth rings, earlywood and latewood, etc.) [44]. As consequence, the different tissues are constructed to meet the natural necessities of the tree, and consists therefore of strengthening, conducting and storing cells. The arrangement of the cells can be recognized in the cross - sections in the three main planes used for the anatomical characterization of wood: the cross or transverse section, the tangential section and the radial section (Figure 1.10).

Softwood shows a relatively simple structure as it consists of $90-95 \%$ tracheids, which are arranged in radial files and are oriented in the direction of the stem axes. In evolving from earlywood to latewood the cell diameters become smaller while the cell walls become thicker. This abrupt change is visible to the eye as an annual or growth ring. The thick-walled latewood tracheids provide strength, while the spaceous earlywood tracheids predominantly conduct water and mineral within the tree. The storage and the transport of nutrients takes place within the parenchyma cells, and the 
secreting elements are the epithelial cells, which surround the resin canals. These canals are the vertical and radial cavities within the tissue of most softwoods.

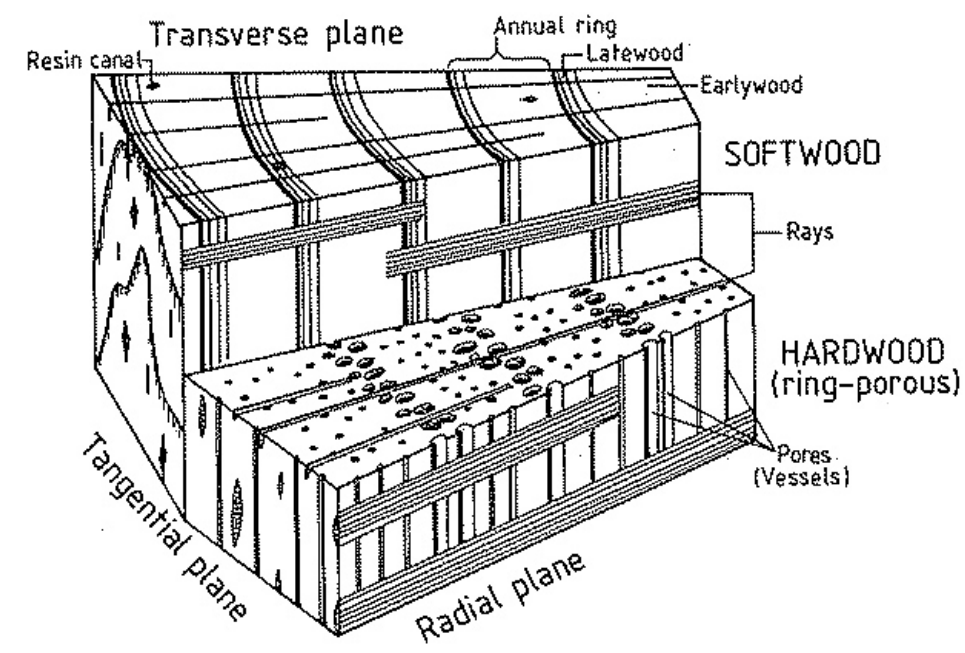

Figure 1.10. Models of a softwood and a hardwood block, showing the main cutting planes for anatomical studies and anatomical structures visible without optical aids.

Hardwoods have a basic tissue for strength containing libriform fibres and fibres tracheids. Within this strengthening tissue are distributed conducting vessels, which are long pipes ranging from few centimeters up to some meters in length. Diffuseporous and ring-porous hardwoods can be distinguished by the arrangement and the diameter of the vessels. The dimensions of the hardwood fibres, which form the basic tissue, are smaller than those of the softwood tracheids, mainly because they have thicker cell walls and smaller lumina, and the differences in wall thickness and lumen diameters between earlywood and latewood are not as extreme as in softwoods. The parenchyma cells are short compact cells with stubby ends, being the number of parenchyma cells in hardwoods higher than in softwoods.

In the wood cell walls, different layers can be recognized and their concentric arrangement is caused by the differences in the chemical composition and different orientations of the structural elements. The components of the cell walls are divided into structural (i.e. cellulose) and substructural, i.e. hemicelluloses and lignin. Figure 1.11 shows a model of the construction of wood cell walls. 


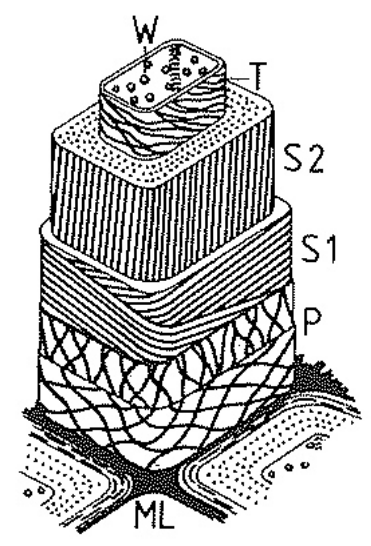

Figure 1.11. Representation of the cell wall structure of softwood tracheids and hardwood libriform fibres [44]. $\mathrm{ML}=$ Middle lamella, $\mathrm{P}$ = primary wall, $\mathrm{S} 1$ = secondary wall one, $\mathrm{S} 2$ = secondary wall two, $\mathrm{T}=$ tertiary wall, $\mathrm{W}=$ wart layer.

Between the individual cells, there is a thin layer called the middle lamella, which glues the cells together to form the tissue. Though single fibrils may cross it, the mentioned layer is, in principle, free of cellulose. In the primary wall $(\mathrm{P})$, the cellulose fibrils are arranged in thin crossing layers with an oblique orientation. The subsequent wall layer is the secondary wall one (S1) with a gentle helical slope of the fibrils. The thickest wall layer is the secondary wall (S2), in which the fibrils run at a steep angle. A third secondary wall layer (secondary wall three or S3) is present in parenchyma cells, whereas fibres of monocotyledons, e.g. bamboo, may have four or more secondary wall layers. The last fibrillar layer at the luminal border should be named tertiary wall (T), because is different from the S3 of the parenchyma cells (Figure 1.12) because of the fibrils, which are arranged under a gentle slope but not in a very strict parallel order. This layer has a higher concentration of non-structural substances, which gives a smooth appearance. In certain cases, the luminal surface is covered with warts, which develop at about the time cell wall lignification nears completion, and consists largely of lignin-like material with some amounts of carbohydrates and pectic substances.

The system of sloping fibrils in combination with the non-structural solidifying substances gives the wood cells a sturdy, but not inflexible construction which resists a wide range of forces acting on it. Because of the steep running fibrils the S2 is provided with tensile resistance, whereas the S1 with its gentle fibrillar slope is responsible for compression resistance, both along the cell axes. 


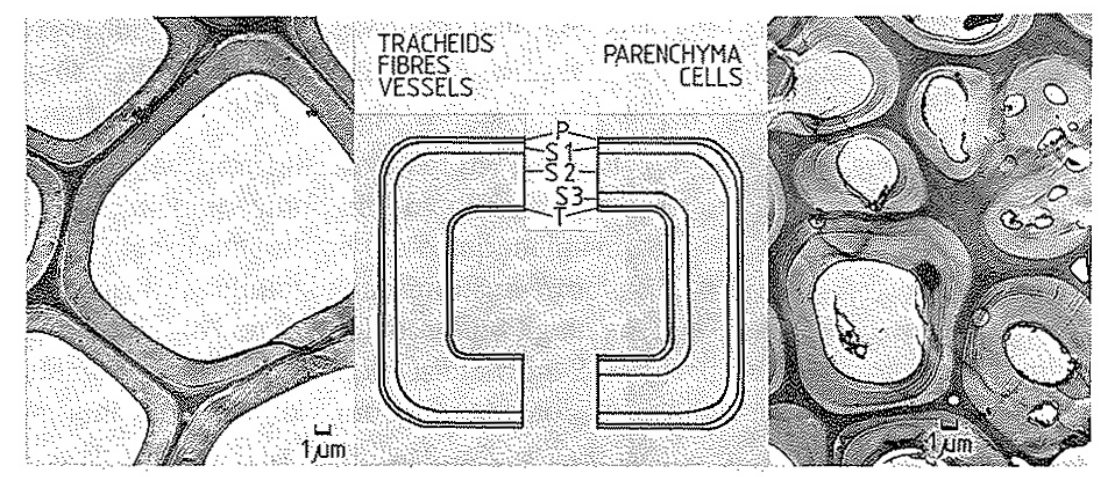

Figure 1.12. Comparison between the cell wall of tracheids, fibres and vessels with that of parenchyma cells [44]. Left: tracheids of umbrella tree (Sciadopitys verticillata). Right: ray parenchyma cells of beech (Fagus sylvatica).(TEM micrographs).

In all types of cells, the S2 accounts for the main portion of the cell wall. Extremely high percentages are reached by the latewood tracheids of softwoods and by the libriform fibres of hardwoods, where the S2 may take up more than $90 \%$ of the cell wall. The change in cell wall thickness from earlywood to latewood is determined by the S2, while the S1 and the tertiary wall contribute only minimally to this change.

After all the characteristics of the hemicelluloses are determined, such as their chemistry and the relations with the other components in wood, the next step is to explore the different ways of reaction of wood, specially detailed for the hemicelluloses. Depending on the way of reaction and the product required, different processes have been proposed for the fractionation of lignocellulosic biomass, alone or in combination between them depending on the susceptibility of the feedstock. For this reason, in the next sections several examples of processes will be detailed together with the reactions involved, specifically for the production of oligosaccharides and/or the fractionation of biomass.

\subsection{PROCESSES FOR THE INDUSTRIAL PRODUCTION OF HEMICELLULOSES}

Figure 1.13 presents the main methods used for the fractionation of biomass, being the most popular for the production of oligosaccharides the hydrolysis with 
addition of acid or alkali or without any of them (autohydrolysis), and the enzymatic hydrolysis.

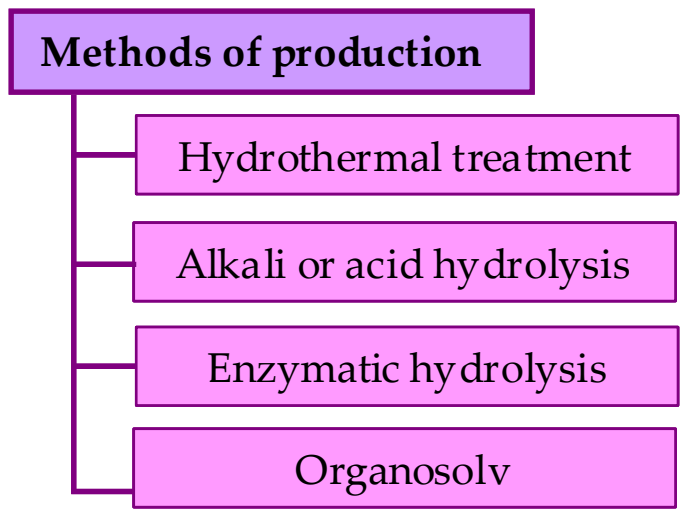

Figure 1.13. Main processes used in the fractionation of biomass.

Specifically for xylo-oligosaccharides production from lignocellulosic material, three different approaches have been used [8]:

$\checkmark$ Enzyme treatments of native lignocellulosic material containing xylan;

$\square$ Chemical fractionation of lignocellulosic material to isolate or solubilize xylan, with further enzymatic hydrolysis to xylo-oligosaccharides;

$\checkmark$ Hydrolytic degradation of xylan to xylo-oligosaccharides by steam, water or dilute solutions of mineral acids or alkali.

The direct production of xylo-oligosaccharides from xylan-containing lignocellulosic materials must be carried out from a susceptible feedstock. The production of xylo-oligosaccharides by combined chemical-enzymatic methods consists basically in two steps.

In the first one, the xylan can be obtained by treatment of the lignocellulosic materials with alkali (i.e. solutions of $\mathrm{NaOH}, \mathrm{KOH}$, etc.), being this treatment favored by the $\mathrm{pH}$ stability of this polymer. In some cases, the raw material has been pretreated with oxidizing agents, salts or alcohols to remove lignin or pectic substances. Once the xylan has been isolated or degraded to a soluble form, further molecular weight reduction can be accomplished by hydrolysis with xylanases. These enzymes can be 
directly added to the reaction media, immobilized, or produced in situ by microorganisms.

Alternatively, xylo-oligosaccharides can be produced from lignocellulosic materials in a single step by reaction with steam or water through hydroniumcatalyzed degradation of xylan, according to the procedure known as autohydrolysis, hydrothermolysis or water prehydrolysis. In the first stages of the reaction, the catalytic species are obtained from water autoionization, but side reactions (for example, cleavage of acetyl groups to give acetic acid) contribute to the generation of hydronium ions in further reaction stages. The hydrolytic degradation of hemicelluloses is facilitated when an acid is added externally (acid hydrolysis), but in this case, the oligosaccharides behave as reaction intermediates and the main reaction products are monosaccharides. Besides the degradation of xylan, several side-processes occur in such kinds of treatment, including extractive removal, solubilization of acid soluble lignin, and neutralization of ash, which contributes to the presence of undesired compounds in the final product. In this case, the purification of xylooligosaccharides becomes important.

Until 1996, there were 12 classes of food-grade oligosaccharides in commercial production [1], and with the exception of soybean oligosaccharides (which are produced by direct extraction), and lactulose (which is produced using an alkalicatalyzed reaction), the other food-grade oligosaccharides were manufactured using enzymatic processes. In the case of xylo-oligosaccharides, (for example for the production of "Bikkle", produced by Suntory Ltd., which is a synbiotic drink containing mainly bifidobacteria and xylo-oligosaccharides), the raw material for xylooligosaccharides synthesis is xylan extracted mainly from corncobs, and hydrolyzed to xylo-oligosaccharides by the activity of the enzyme endo-1,4- $\beta$-xylanase. To produce higher-purity oligosaccharides, the monomers and high molecular mass carbohydrates were removed using ultrafiltration and reverse osmosis process.

A non conventional method for the extraction of xylan from corncobs and cornhulls was used by combining ultrasonic irradiation in a neutral or alkaline aqueous medium, finding that the ultrasound-assisted extraction procedures are more efficient than the classical procedures. Using a short application of ultrasound, similar yields of the xylan extracted were achieved at lower extraction temperature and shorter reaction time, and the biological activity of xylans extracted with ultrasound 
was considerably higher than that of classical extracted ones [47-50] . Another example is the extraction of hemicelluloses from flax shive using hydrothermal microwave treatment followed by several purification steps [51]. When the microwave treatment was compared with steam treatment for the extraction of hemicelluloses from spruce, the highest yield of oligosaccharides was obtained using the microwave treatment [52].

In the next sections, the main treatments will be detailed giving more examples of application and explaining more deeply the reactions involved in each of them.

\subsubsection{Hydrothermal treatments}

Several technologies based on hydrothermal treatments have been used for the fractionation of biomass, and all of them have their antecedents in the thermomechanical processes developed by the pulp and paper of fibreboard industries [53]. The most effective process seems to be the steam and aqueous treatments, which separate the feedstock into two fractions: an aqueous extract composed mainly of hemicellulose derivatives along with some water-soluble lignin, and a pulp composed of cellulose and an easily extractable lignin.

The hydrothermal treatments of lignocellulosic biomass at moderate conditions, like autohydrolysis or steam explosion, are effective and simple processes for producing hemicellulose-derived oligosaccharides with reasonable yield and purity. Water treatment seems to be the simplest one [54] because no chemicals are necessary, being the whole process environmentally friendly. In this kind of treatment, hemicelluloses can be recovered at good yields with low byproduct generation. Its moderate conditions allows to control better the hydrolysis and there are no problems related to corrosion of the equipment because of the acids action. The stages of sludge handling and acid recycling are avoided, resulting in a simplified process structure. There are several examples of the utilization of autohydrolysis for the production of xylo-oligosaccharides. Several xylan rich by-products, wheat bran, brewery's spent grain, corncobs and Eucalyptus wood [55], and also rice husks and barley husks [56] were subjected to a mild hydrothermal treatment for the degradation of xylan. During the hydrothermal treatment, arabinose was rather easily removed from the xylanbackbone (in the case of wheat bran, brewery's spent grain and corncobs), the acetyl groups were partly released becoming available for the depolymerization of xylan, and 
also a part of the uronic acids were released (mainly for Eucalyptus). A wide variety of xylo-oligosaccharides with different structure were obtained depending on the original raw material used [57-59]. In the case of corncobs, autohydrolysis at non isothermal conditions allows to remove up to $94 \%$ of the xylan, while the cellulose was retained in the solid and partial delignification was achieved (up to 26\%) [58]. For the brewery's spent grain, the maximal xylo-oligosaccharides yield (61\% of the feedstock xylan) was obtained at $190^{\circ} \mathrm{C}$ after $5 \mathrm{~min}$ of reaction, while between $63-77 \%$ of the initial xylan was solubilized [59]. In a different procedure for the production of xylooligosaccharides, the corncobs were soaked in sulfuric acid, followed by a steaming process and enzymatic reaction. The yield of xylo-oligosaccharides after the enzymatic hydrolysis was close to $68 \%$ with a purity of over $70 \%$ based on total sugars in the hydrolysate [60]. Steaming treatment was also used for the production of xylooligosaccharides from bamboo grass [61], as pretreatment of aspenwood [62] and almond shells [63] for the recovery of cellulose, and for the production of ethanol from aspenwood [64].

Steam-aqueous pretreatments commonly exist at a commercial scale [46] and the technology based on the direct contact between lignocellulosic materials and saturated steam shows a higher grade of maturity than the aqueous-phase systems and, in fact, it has been used for decades at the industrial level by the paper industry. There are two particular designs that were tested at commercial levels, being the first one a batch process, called the Masonite Gun. This process is based on a batch digester, which is a vertical cylinder filled with wood chips and sealed. Saturated steam is then introduced at pressures up to 64 bars $\left(280^{\circ} \mathrm{C}\right)$. Typical conditions for this process are temperatures from $180^{\circ} \mathrm{C}$ to $260^{\circ} \mathrm{C}$ and steaming times from 2 to $15 \mathrm{~min}$, depending on the biomass being treated. The second one is based in the same principle, called the Stake reactor, which is a commercially available continuous unit for the steam pretreatment of lignocellulosic biomass. It is a modification of the Masonite process allowing a continuous operation. The Stake II technology was applied for a steam pretreatment of Populus tremuloides in a pilot plant scale, with the objective of recover the hemicelluloses and lignin and prepare the cellulose for subsequent enzymatic treatment. They could recover $65 \%$ of the potential hemicelluloses and $80 \%$ of total lignin [65]. The same experiment was applied to sugar cane bagasse, separating $62 \%$ of the potential hemicelluloses and $72 \%$ of lignin in this case [66]. There are also other processes for hydrothermal treatment, like the Rapid Steam Hydrolysis/Continuous 
Extraction (RASH), which drains continuously the reaction products; the Iotech or Siropulper processes, which treats the solid residue with organic solvents to remove lignin; the wet oxidation process, etc., [54].

Both the aqueous processes and the direct steam systems still present some limitations at their present stage of development, detailed as follows:

$\square$ High energy requirements

$\checkmark$ High pressure reactors, which implies mechanical problems mainly in the pumping equipment capable of dealing with high-consistency slurries.

$\square$ Corrosion in the high temperature reactors constructed in 316-L stainless steel may become a problem at long term, especially when acid catalysts are employed. Thus will require the use of higher alloys increasing the construction costs.

$\checkmark$ During the treatment, if acidic or basic catalysts are used, they are partially neutralized by the lignocellulosic components, and also after its collection it is highly diluted. The viability of recovering and reusing the catalyst is still under study.

In the steam-aqueous treatment of lignocellulosics, with or without explosive decompression, basically a hydrolytic process takes place catalyzed by the acids naturally formed from wood upon heating in aqueous media (autohydrolysis), or other acidic species added to the system (mineral acids, acetic acid, or $\mathrm{SO}_{2}$ ). The following phenomena are involved in the autohydrolytic process:

$\checkmark$ Upon heating by contact with the saturated steam, water is condensed into the porous structure of the cold lignocellulosic material. In this situation, wood liberates organic acids, mainly acetic acid and uronic acids, by saponification of the acetyl and uronic acids in the hemicellulose.

$\square$ The liberated acids catalyze the hydrolysis of the glycosidic bonds in the hemicellulose chains, resulting in a fast depolymerization that forms intermediate and low molecular weight oligomers that are soluble in the aqueous media, thus being partially dissolved. These oligomers maintain most of the side chains. Oligomer products are partial depolymerized in the aqueous 
phase to render monomeric sugars. Monosaccharides are not stable at the process temperatures in acidic media. They experience dehydration reactions to form furfural (pentoses) and hydroxymethylfurfural (hexoses), and other degradation products. The rate of these degradation processes is lower than that of oligosaccharides depolymerization and monomer formation.

$\checkmark$ Simultaneously, lignin is also depolymerized by acid hydrolysis through the breaking of the $\alpha$ and $\beta$ aryl-ether linkages in the polymer network. Lignin in the S2 layer in the cellular wall and in the middle lamella is the most affected by the process, mainly because of the intimate association between lignin and hemicellulose in these two layers. A small fraction of the depolymerized lignin is soluble in the aqueous media, and the other fraction migrates to the middle lamella and the lumen, where they aggregate in spherical particles.

$\square$ Depolymerized lignin slowly reacts with furfural and the other products formed by degradation of the hemicellulose, generating condensation products that are indistinct from lignin in the conventional Klason lignin analysis. The rate of formation of these condensation products, commonly referred as pseudolignin, appears to be much lower than those of oligosaccharides formation and degradation. So, the amount of pseudolignin formed does not become important until a large portion of the hemicellulose has been degraded.

$\nabla$ Cellulose is also modified during the hydrolytic treatment. Glycosidic bonds are randomly hydrolyzed resulting in a loss of degree of polymerization. However, this process appears to have a lower rate than the depolymerization of hemicellulose chains.

The addition of small amounts of supplementary acid increases the rate of the hydrolytic reactions, thus allowing the use of lower temperature and residence time to obtain a certain degree of conversion. The yield of depolymerized hemicellulose is also improved, but because the degradation reactions are also catalyzed by the acid, the process conditions have to be carefully selected to avoid excessive degradation and yield loss. The details of the mechanism of the hydrolysis reaction catalyzed by acids for the hemicelluloses is detailed in the next section. 


\subsubsection{Acid/Alkaline hydrolysis}

Diluted acid solutions were used for the fractionation of lignocellulosic materials, such as corn stover or corncobs $[67,68]$. The advantages that these processes present are based on the high hemicellulose sugar yield, high lignin removal, high cellulose digestibility, less chemical costs and limited fermentation inhibitors. This process was applied to the production of furfural by diluted acid hydrolysis of olive stones, obtaining yields up to 50 to $65 \%$ of the potential [69]. Also, a combination of a pretreatment step based on autohydrolysis or acid hydrolysis, followed by an alkaline extraction was applied to almond shells for the fractionation of the main components of biomass [70]. Depending on the reaction conditions, the recovery of hemicelluloses reach $66 \%$ of the potential. Up to $64 \%$ of the lignin was recovered and only $9 \%$ of the initial cellulose was degraded. If the reaction conditions are more severe, there is an increment of the recovery of lignin but the depolymerization of cellulose in these conditions becomes important. The same treatment with steam explosion and alkali delignification was applied to wheat straw, yielding $55 \%$ of the potential hemicelluloses, $70 \%$ of the potential lignin and $70 \%$ of the potential cellulose at the optimal conditions [71-73]. Several alkali solutions (like $\mathrm{NaOH}, \mathrm{KOH}, \mathrm{Ca}(\mathrm{OH})_{2}$ and $\left.\mathrm{Ba}(\mathrm{OH})_{2}\right)$ were tested, varying the alkali concentration, time of reaction and temperature to determine the optimum conditions for the extraction of hemicelluloses from Vetiver grass. It was found that the maximum yield was $35 \%$ for $4 \mathrm{M} \mathrm{NaOH}$ at ambient temperature for $8 \mathrm{~h}$ [74]. An alkali pretreatment with sodium hydroxide was proposed also for the separation of lignocellulosic materials from wheat straw, with a recovery of $60 \%$ and $80 \%$ of lignin and hemicellulose, respectively [75]. A highly pure xylan (94\%) from corn fiber was extracted using different alkali solutions such as ammonium hydroxide, calcium hydroxide and potassium hydroxide [76]. Autohydrolysis combined with diluted acid hydrolysis are used frequently to enhance the enzymatic digestibility of cellulose for the subsequent production of glucose or ethanol [77]. Other frequent process is the use of autohydrolysis combined with an acid posthydrolysis step for the preparation of a suitable fermentation media for posterior conversion to xylose or xylitol. In this process, after the autohydrolysis step, diluted sulfuric acid is added to the solution and it was observed that it improves the fermentation [78-81]. 


\subsubsection{Mechanism of acid hydrolysis of hemicelluloses}

Besides degradation by enzymatic attack, chemical acidic hydrolysis is the essential and most typical degradation reaction of glycosidically linked glycosides, di-, oligo- and polysaccharides. The main molecular mechanism of acidic hydrolysis is outlined in Figure 1.14

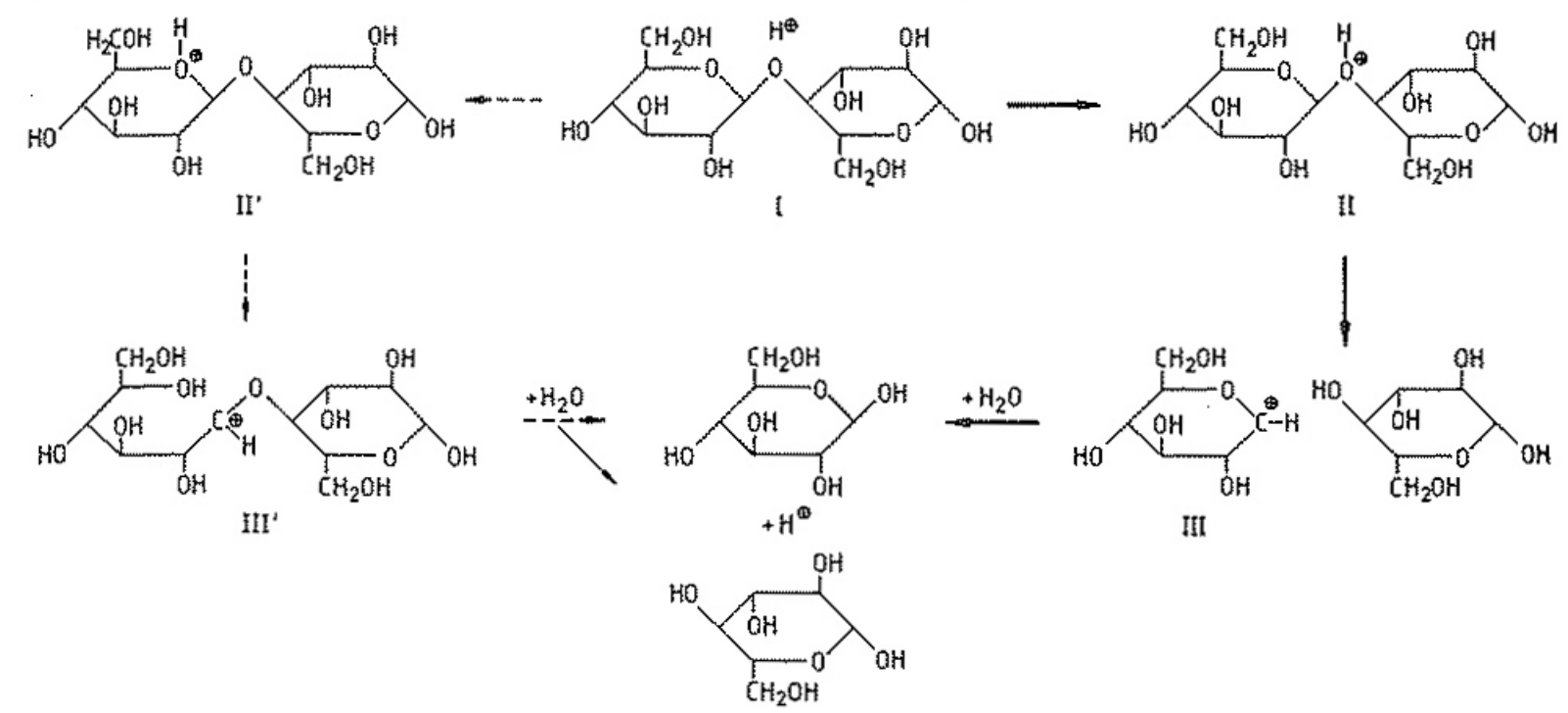

Figure 1.14. Mechanism of acid hydrolysis of glycosidic linkages [44]. $\rightarrow$ Dominant pathway.

Acidic hydrolysis, leading finally to a fission of glycosidic bonds, proceeds in three steps. In the first step the proton of the catalyzing acid interacts rapidly with the glycosidic oxygen linking two sugar units (I), forming a so-called conjugate acid (II). This step is followed by a slow cleavage of the C-O bond yielding an intermediate cyclic carbonium cation (III). The protonation may also occur at the ring oxygen (II'), resulting in a ring opening and a non-cyclic carbonium cation (III'). It is not clear which type of carbonium ion is most likely to be formed, but probably both modifications of protonation takes place. The tautomeric carbonium-oxonium occurs in a half chair conformation as demonstrated in Figure 1.15, and the carbonium cation initiates finally rapid addition of a water molecule, resulting in the stable end product and release of the proton. 


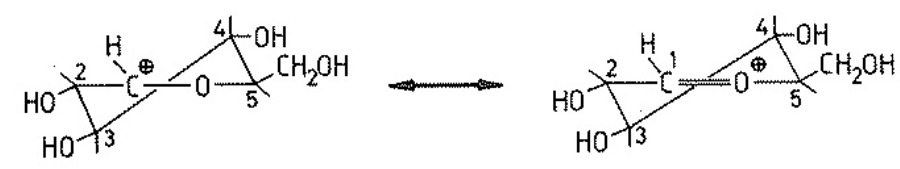

Figure 1.15. Half-chair conformation of the tautomeric carbonium-oxonium ion pair [44].

In the case of solvolysis with acid-containing solvents in the presence or absence of water, the cleavage of glycosidic linkages is mainly governed by the type of solvent. The non-aqueous solvents which are miscible with water, such ethanol or dioxane, may act as reaction partners (e.g. ethanol) or not (e.g. dioxane), but generally solvolytic effects improve the cleavage rate of glycosidic bonds.

The factors that influence the hydrolysis kinetics and the overall course of degradation concerns both on the acidic medium and the characteristics of the sample. The hydrolyzing medium can be characterized by the kind of acid, its concentration, $\mathrm{pH}$, acid strength, temperature and pressure of reaction. With regard to the sample, the most important factors are the phase state, the physical structure and accessibility (in the case of homogeneous or heterogeneous hydrolysis), the conformation effects, structure and substituents. The hydrolysis of glycosidic bonds usually follows a first order reaction, but the hydrolysis rate depends on the parameters of the acid and the sample.

Dehydration reactions typically occur during thermal treatments of polysaccharides, and they are also unavoidable side reactions under acidic hydrolysis conditions, causing a decomposition of hydrolyzed sugars. The acid-catalyzed dehydration under mild conditions leads to the formation of anhydro sugars with intramolecular glycosidic linkages, resulting from the elimination of a water molecule from two hydroxyl groups (e.g. 1,6-anhydroglucose). As these glycosidic linkages can easily be hydrolyzed, a series of further degradation products may be formed, part of them being aromatic and condensed compounds. The most important degradation products are the cyclic compounds furfural (formed from pentoses and uronic acids), and hydroxymethylfurfural (HMF) (formed from hexose sugars, like glucose) (Figure 1.16). High yields of these compounds are obtained using concentrated acids at elevated temperatures. 

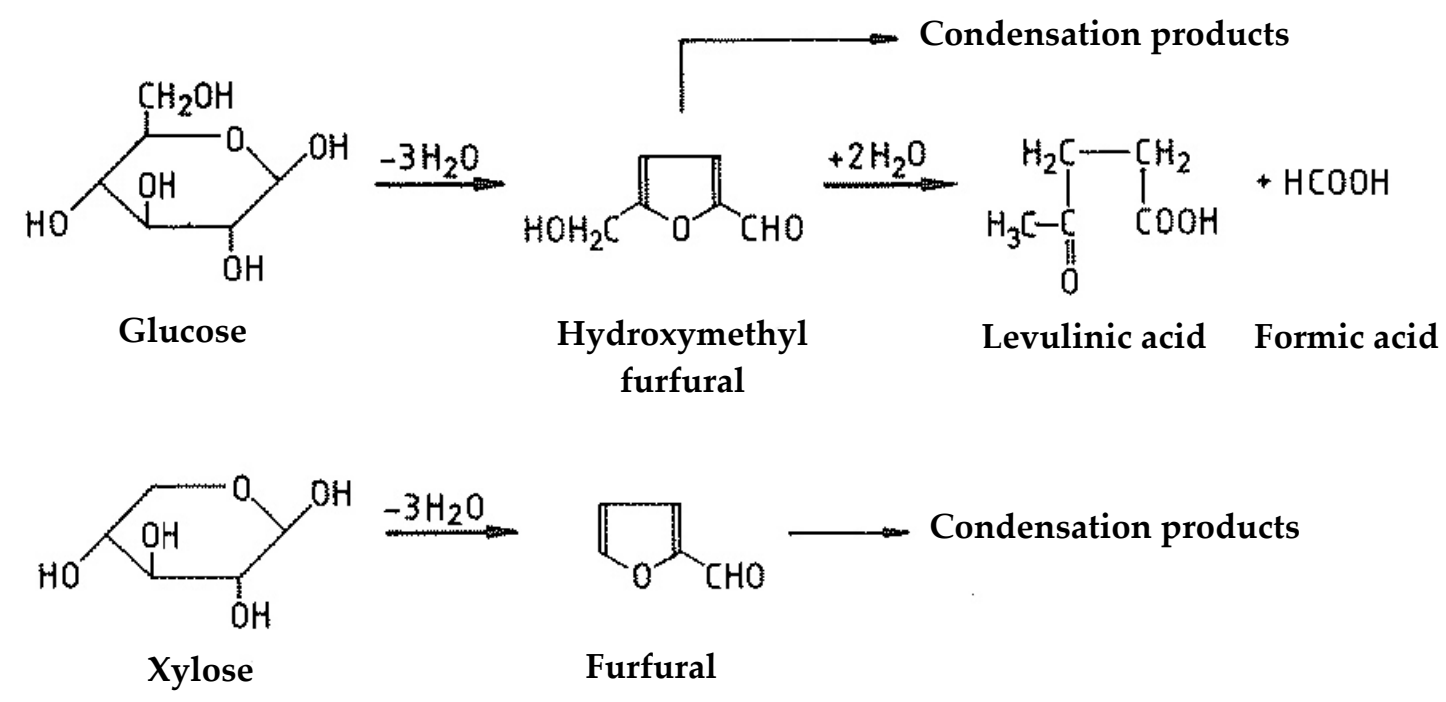

Figure 1.16. Formation of furfural, hydroxymethylfurfural, levulinic acid and formic acid from monosaccharides in acidic medium.

The oxidation reactions involving polysaccharides and sugars in acidic medium are important, occurring simultaneously with hydrolytic degradation during acidic pulping and bleaching processes. In principle the hydroxyl groups of the sugar units and the reducing end groups of di-, oligo or polysaccharides may be subjected to oxidative attack. The converted groups are aldehyde, keto and carboxyl groups. The ring structure can be preserved or destroyed by cleavage of the ring oxygen bond or C$\mathrm{C}$ bonds. Important final degradation acids are uronic acids, aldonic acids, and aldaric acids. Pentonic acids are formed by decarboxylation of hexuronic acids.

\subsubsection{Mechanism of alkaline hydrolysis of hemicelluloses}

The alkaline degradation of cellulose and polyoses is an essential factor in kraft and soda pulping, oxygen delignification, and hot alkali purification in dissolving pulp manufacture [44].

Initial reactions are solvation of hydroxyl groups by hydroxyl ions causing a swollen state. At elevated temperatures, the polysaccharides are attacked by strong alkali solutions with a large number of reactions taking place. The most important ones are dissolution of undegraded polysaccharides, peeling of end-groups with formation of alkali stable end-groups, alkaline hydrolysis of glycosidic bonds and acetyl groups, and degradation and decomposition of dissolved polysaccharides, hydrolyzed 
fragments, and peeled monosaccharides. The most important reactions are the peeling and hydrolytic ones.

At temperatures of about $100^{\circ} \mathrm{C}$, the degradation of polysaccharide chains starts from the existing reducing end-groups by the so-called peeling reaction (primary peeling). At temperatures above $150^{\circ} \mathrm{C}$ chains are split by alkaline hydrolysis. Thus new reducing end-groups are formed, which are also subject to endwise degradation (secondary peeling). The peeling reaction of polysaccharides involves the elimination of reducing end-groups by a $\beta$-alkoxy elimination to various carboxylic acids, thus reducing the chains by one monomeric unit at a time. The reaction mechanism of endwise degradation is outlined in Figure 1.17.

The initial step is an isomerization of the reducing end-group (I) to a ketose (II), which is in equilibrium with the corresponding 2,3-enediol. These structures are alkalilabile, and the C4-substituents are cleaved, leading to a new reducing end of the shortened polysaccharide chain and to the eliminated end-group (III). The latter is tautomerized to a dicarbonyl compound (IV). The main reaction of the deliberated endgroup corresponds to a benzilic acid rearrangement in the alkaline medium to yield isosaccharinic acid (3-deoxy-2-C-hydroxymethyl aldonic acid) (V) (gluco-isosaccharinic acid in the case of cellulose and mannan; xylo-isosaccharinic acid in the case of xylan). Other possible final degradation products are lactic acid (VI) or 2-hydroxy-butanoic acid and 2,5-dihydroxypentanoic acid, respectively. The polyoses are peeled much more than cellulose, being xylan more stable than glucomannans, which is attributed (for birchwood xylan) to the stabilizing effect of the galacturonic acid side-groups adjacent to the reducing end of the xylan chain. The easy cleavage of arabinose sidegroups in softwood xylans also has a stabilizing effect against alkaline peeling, since with the loss of the side group an alkali-stable metasaccharinic acid end-group is formed.

The endwise degradation finishes when a competing reaction takes place (see Figure $1.17-\mathrm{b}$ ). The most important stopping reaction is initiated by $\beta$-hydroxy elimination at the C4-position to a tautomeric intermediate, which is converted to an alkali-stable metasaccharinic acid end-group (3-deoxyaldonic acid) (VIII). Other possible end-group formation is C2-methylglyceric acid (IX). Other acids are formed during this alkaline degradation, like formic acid and acetic acid (this last comes from 
the deacetylation of hardwood xylans). The dissolved, deacetylated xylan chains are known to be redeposited on the fibres.

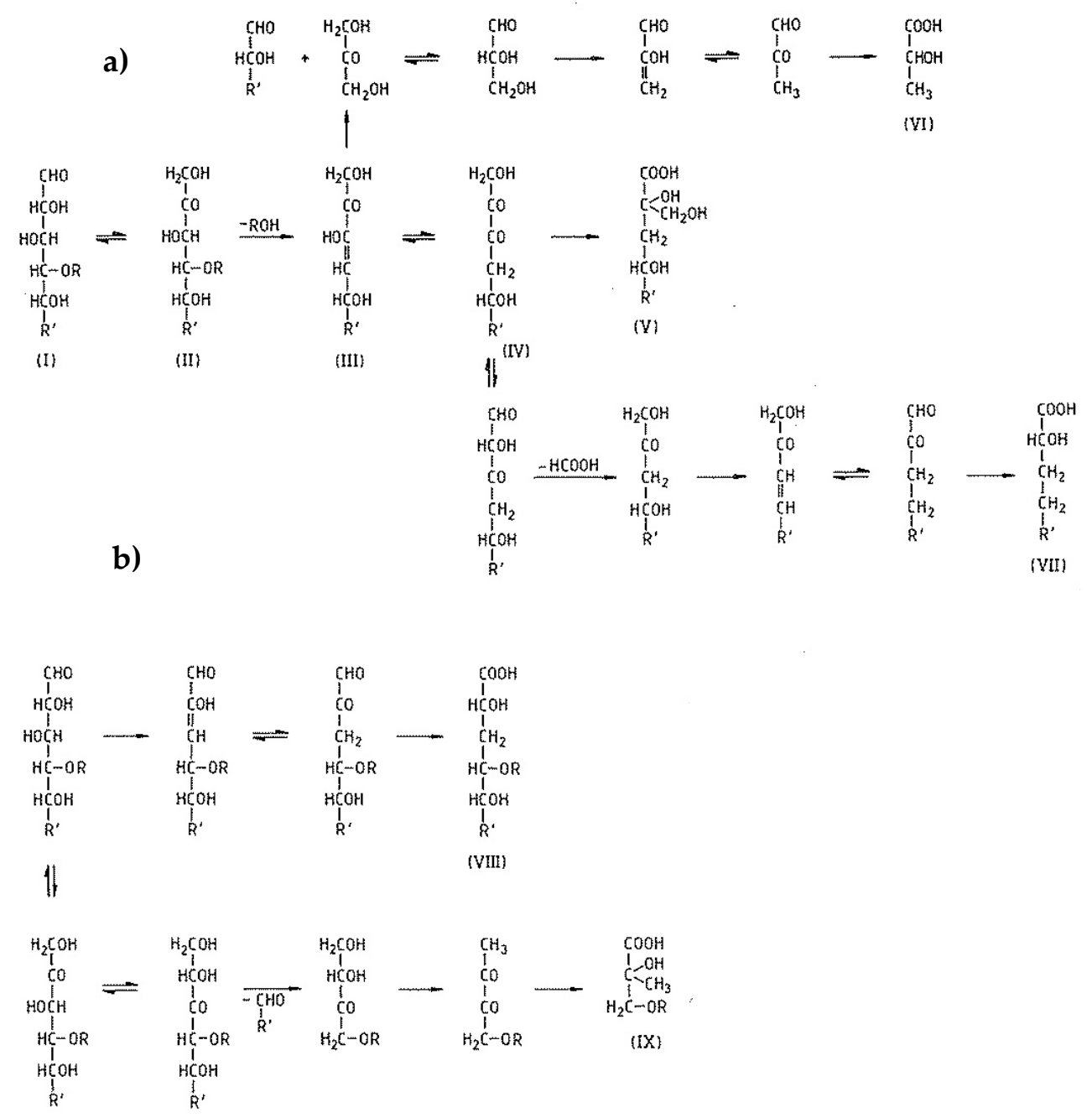

Figure 1.17. Endwise degradation of polysaccharides [44]. a) reactions involved in peeling, b) main stopping reactions. R: Polysaccharide chain, $\mathrm{R}^{\prime}: \mathrm{CH}_{2} \mathrm{OH}$ (for cellulose and mannan), and $\mathrm{H}$ (for xylan).

In addition to the peeling of end-groups, alkaline hydrolysis (depolymerization) of polysaccharides becomes important at temperatures of about $170^{\circ} \mathrm{C}$. The probable mechanism of alkaline hydrolysis, occurring much more slowly than the acidic hydrolysis, is outlined in Figure 1.18. The glycosidic linkage is cleaved by elimination of the alkoxy group ( $\beta$-elimination) after ionization of the hydroxyl group at C2 and formation of an 1,2-epoxide (oxirane structure). The hydrolytic cleavage results in a 
new reducing end-group, or possibly an 1,6-anhydride end is formed, which is easily degraded.

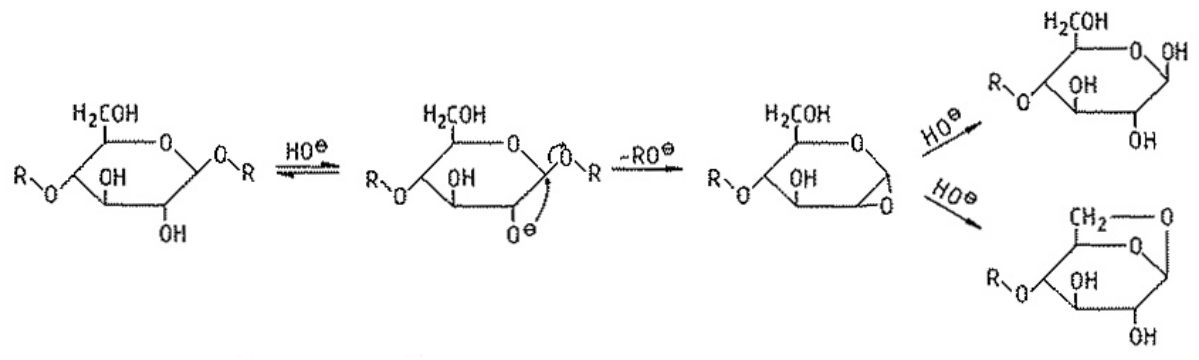

Figure 1.18. Hydrolysis of glycosidic bonds in alkaline medium.

\subsubsection{Enzymatic treatments}

Combination of enzymatic treatments with autohydrolysis or steam treatments are frequently used for the production of fermentation media. In this way, a xylosecontaining fermentation media was obtained by enzymatic posthydrolysis of oligomers produced from corncob autohydrolysis, achieving a conversion of $80 \%$ of the original xylan [82]. In other case, sulfuric acid impregnation of almond shells was combined with steam explosion, followed by an enzymatic posthydrolysis step, for the production of xylose. This process demonstrated to be more effective than the usual acidic treatment for the recovery of xylose [83]. The combination of steam pretreatment followed by enzymatic hydrolysis of birchwood [84], aspenwood [85] or brassica carinata [86] was used to enhance the enzymatic hydrolysis and to increment the conversion of celluloses and hemicelluloses. A total integrated process [87] was applied to the fractionation of several hardwoods, consisting in a steaming step for the solubilization of hemicelluloses with water. The hemicelluloses were purified and hydrolyzed with immobilized enzymes for their conversion firstly into xylose, and finally to xylitol. The remaining fibre was extracted several times with $90 \%$ dioxane, separating the lignin from the cellulose. The cellulose remaining was hydrolyzed for the production of glucose and finally of ethanol. In other case, ethanol was produced from lignocellulosic materials by a simultaneous saccharification and fermentation process with Kluyveromyces marxianus [88]. 
Enzymes are macromolecular proteins with a defined supramolecular structure containing an active center, which is generally situated in a hole. The group of enzymes comprises a large number of various biocatalysts, which accelerate and control biochemical reactions [44], possessing the advantage that many of them show a high specificity, i.e. their action is restricted to certain molecules or molecular structures, which is never attained by artificial catalysts. Enzymes are often called according to the molecule on which they act or according to their action, whereby the suffix -ase is used. An international system of classification divides enzymes according to their function:

$\square$ Oxidoreductases: effect redox reactions and act on alcoholic hydroxyl groups, keto groups, double bonds, C-N linkages, etc.

$\square$ Transferases: transfer functional groups such as C1-groups, aldehyde, keto, acyl and glycosyl groups, etc.

$\checkmark$ Hydrolases: cleave hydrolytically esters, glycosides, peptides, etc.

$\square$ Lyases, effect additions at $\mathrm{C}=\mathrm{C}, \mathrm{C}=\mathrm{O}$, and $\mathrm{C}=\mathrm{N}$ double bonds.

$\square$ Isomerases: catalyze isomeration reactions.

Ligases: effect the formation of new bonds during ATP cleavage.

The main enzymes acting on hemicelluloses are hydrolases, known as hemicellulolytic enzymes or hemicellulases.

Enzymes are produced within the cells but they may also act outside the cell, and they can be separated from the cells without losing their reactivity. Thus enzymatic reactions can be carried out in a cell-free medium. Depending on their place of reaction the enzymes are subdivided into endoenzymes, which act within the cells and control processes of the internal metabolism, and exoenzymes, which are excreted by the cell for the degradation of an insoluble substrate to soluble products, which are able to diffuse through the cell membrane.

Knowing the composition of the major hemicelluloses, it could be predicted that a variety of enzymes would be required for the efficient degradation of these materials $[89,90]$; indeed, the list of enzymes known to be involved in hemicellulose breakdown 
is already quite lengthy. In figure 1.19 an example of the action of different enzymes is given.

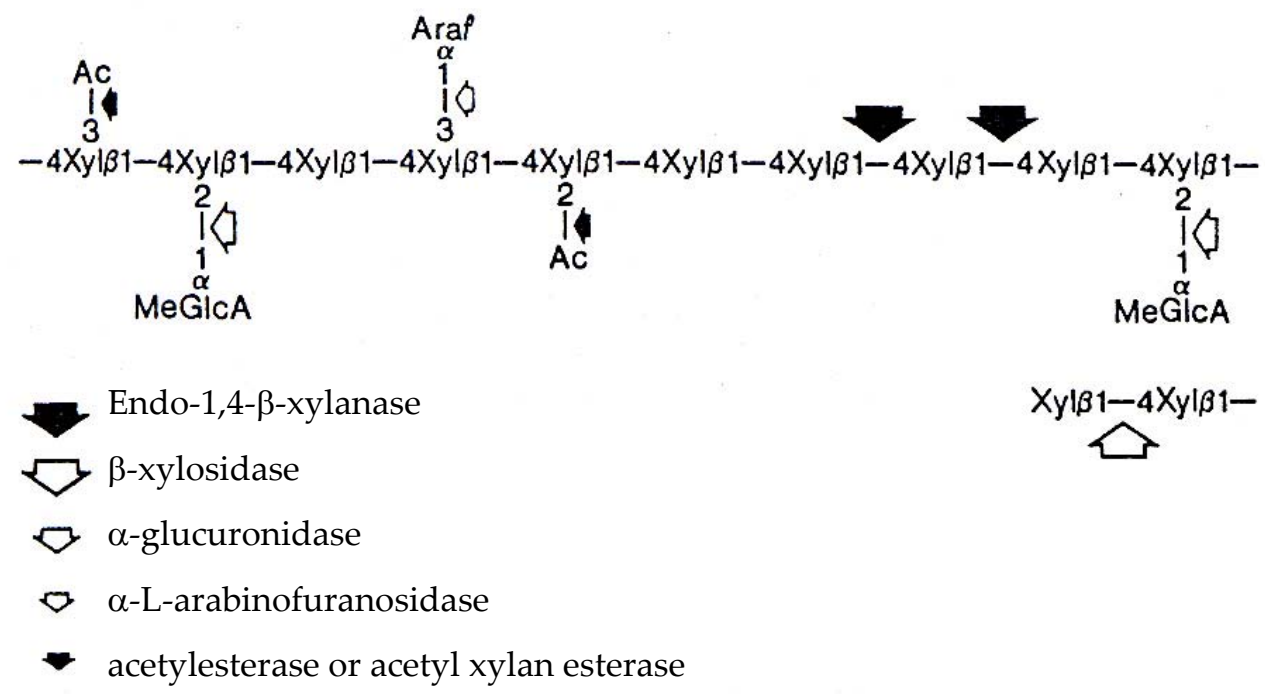

Figure 1.19. An hypothetical plant heteroxylan fragment and the sites of attack by xylanolytic enzymes [91].

The main enzymes involved in the degradation of xylans are endoxylanases, $\beta$ xylosidases and arabinofuranosidases.

$\square \quad$ Endo-1,4- $\beta$-D-xylanase

Fungal and bacterial endoxylanases are almost exclusively single subunit proteins with molecular weight (MW) values ranging from 8500 to $85000 \mathrm{~g} / \mathrm{mol}$. An endo- $\beta-1,4-x y l a n a s e$ catalyze the hydrolysis of xylans and xylo-oligosaccharides, with the exception of xylobiose. The efficiency of this enzyme for the hydrolysis of xylan decreases with the MW decrement. In general, endo-acting enzymes do not readily attack complex polysaccharides because such substances lack uninterrupted (unsubstituted) sequences of similar sugars and linkages. Most xylanases fall into this category in which they are generally found to hydrolyze main chain linkages at unsubstituted regions of the substrate to yield xylo-oligomers, longer xylooligosaccharides and substituted xylo-oligomers.

In contrast to those enzymes that act only at uninterrupted sequences, there are several examples of endoxylanases that cleave main chain linkages, only in the 
immediate vicinity of substituted regions. In relation to the hydrolysis of the backbone of susceptible substrates, all endo- $\beta-1,4$-xylanases appropriately characterized up to date have been found to be specific for the $\beta-1,4$-linkage, even when acting on mixed linkage substrates. Thus, endoxylanases have been classified as debranching or nondebranching depending on whether or not they liberate free arabinose in addition to cleaving main chain linkages.

$\square \quad \beta$-Xylosidases

These enzymes may be monomeric, dimeric, or tetrameric, with MW values ranging from 26000 to $360000 \mathrm{~g} / \mathrm{mol}$. They are produced by a variety of bacteria and fungi and may be found in the culture fluid, associated with the cell wall, or both. Many have transferase activity, in addition to direct hydrolase action, and exhibit relaxed specificity for both, the sugar and the linkage. True $\beta$-xylosidases cleaves artificial $\beta$-xylosides and unsubstituted $\beta$-1,4-linked xylo-oligosaccharides, including xylobiose. Action against xylo-oligomers proceeds with the preferential removal of xylose residues from the non-reducing end of such substrates, and affinity normally increases with the MW decrement. Moreover, $\beta$-xylosidases generally exhibits little or no action against polymeric xylans. $\beta$-xylosidases may be distinguished from the less commonly found exoxylohydrolase by virtue of the fact that the latter preferentially removes xylose from the non-reducing ends of xylans and xylo-oligomers (affinity should increase with the DP increment) with inversion of configuration.

$\nabla \alpha$-arabinofuranosidases

Most arabinosidases exist as monomers, but dimeric, tetrameric and octameric forms have also been found. Reported molecular weight values of the native enzymes range from 53000 to $495000 \mathrm{~g} / \mathrm{mol}$. The investigated enzymes release arabinose from various substrates, but there is evidence of preference for particular linkages. Moreover, arabinose containing oligosaccharides rather than polysaccharides are generally the preferred substrates.

\subsubsection{Mechanism of enzymatic hydrolysis}

For most enzymes that degrade polysaccharides, the hemicellulases act on the substrate both exo and endohydrolytically [92]. An exoenzyme degrades polyoses through successive separation of the monosaccharidic or oligosaccharidic units, 
whereas splitting occurs stepwise, usually from the non-reducing end of the polysaccharide chain. The endoenzymes act randomly, inducing multiple hydrolysis, which is accompanied by a pronounced decrease of the substrate polymerization degree. The polymer is therefore degraded progressively into shorter chains, up to products (usually monosaccharides and disaccharides) that cannot split further.

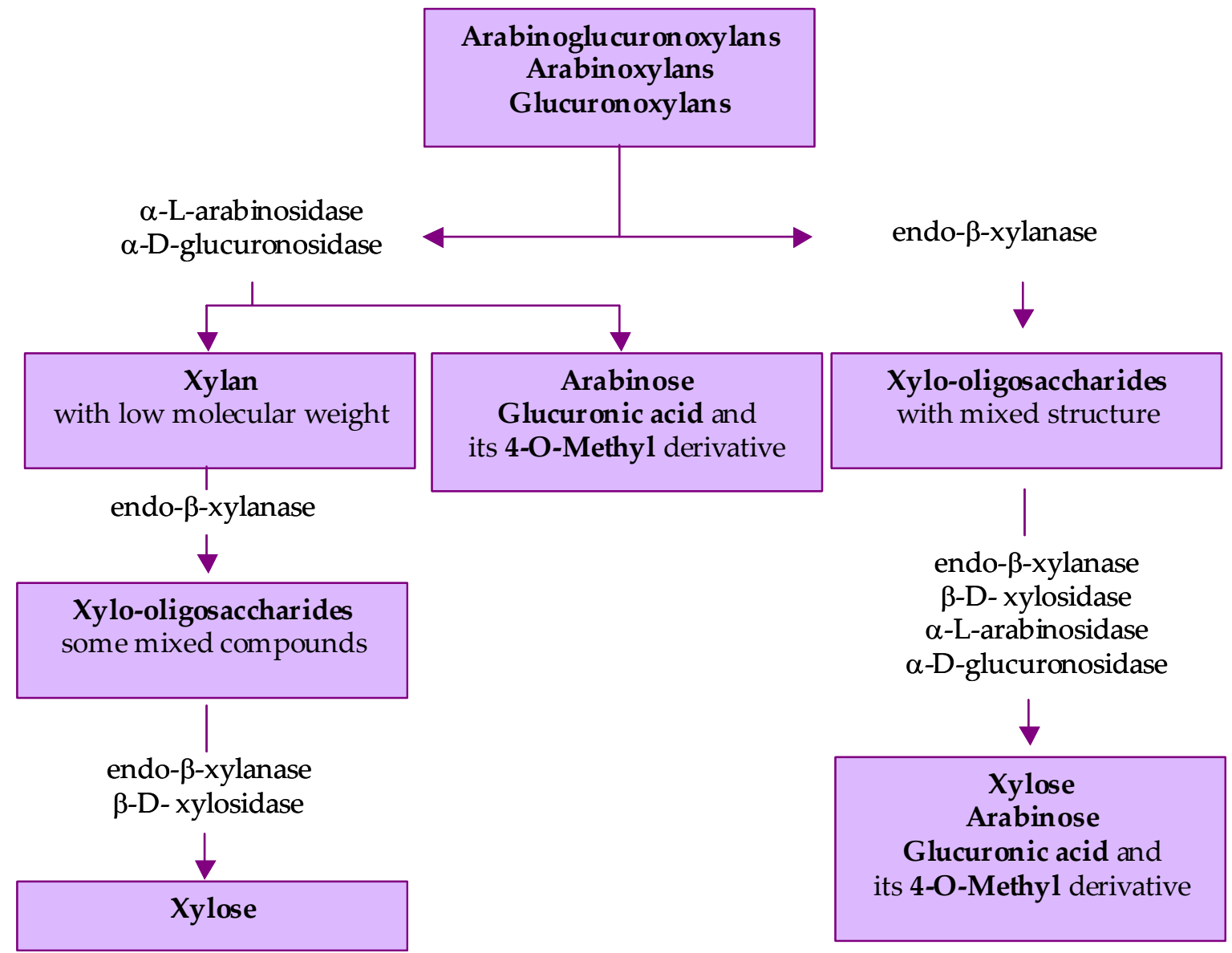

Figure 1.20. Activity mechanism of the different enzymes on arabinoglucuronoxylan, arabinoxylan, and glucuronoxylan [92].

An example of the pathway through which fungal enzymes act on hemicelluloses is given in Figure 1.20, including the following steps:

1. The attack of exoglycosidases, occurring prior to that of hemicellulases (xylanases, galactanases, and $\beta$-mannanases). They induce separation of branches, accompanied by opening and exposure of the glycan's chains for subsequent reactions. In this way, degradation will occur more easily, as a result of reducing the steric hindrance induced by the lateral chains. 
2. The action of endohemicellulases on glycan's chain, being nonbranched or with reduced branching. From this reaction, oligosaccharides with mixed structure may also result to be subsequently split, either by exoglycosidases or by endohemicellulases.

The efficient and extensive hydrolysis of hemicelluloses requires the cooperative or synergistic interactions of a variety of main-chain and side-chain cleaving enzymes of different specificities [89]. Synergy is observed when the amount of products formed by two or more enzymes acting together exceeds the arithmetic sum of the products formed by the action of each individual enzyme. Homosynergy is defined as the synergistic or cooperative interaction between two or more different types of side chain-cleaving enzyme. Heterosynergy is defined as the synergistic interaction between a side chain and a main chain-cleaving enzyme. The action of one type of enzyme preventing the action of a second is known as "antisynergy".

\subsubsection{Organosolv treatments}

For the production of glucuronoarabinoxylans from wheat bran, a process formed by a combination of a purification step (boiling 70\% ethanol) followed by removal of extractable arabinoxylans by extraction with water was proposed at pilot scale [93]. In this case, the final product was precipitated with ethanol and it had a purity of $70-80 \%$. In another example, several hemicellulosic products from wheat straw were obtained using a combination of several steps, mainly the extraction with dimethylsulfoxide (DMSO) followed by extraction with potassium hydroxide and sodium borate [94]. The delignification of wheat straw using a mixture of carboxylic acids and peroxoacids was useful as a bleaching step prior to pulping process for the cellulose production. In this case, the process for the production of cellulose was an organosolv process using a mixture of acetic acid/ formic acid/ water [95]. The cell wall material from Chinese shrubs Haloxylon ammodendron and Elaeagnus angustifolia was fractionated by two successive extractions with ethanol/water (60:40, v/v) under acidic conditions, finding that $84 \%$ and $88 \%$ of the original hemicelluloses were solubilized [96]. Steaming process and organosolv process (using a mixture of ethyleneglycol water) were compared for the production of cellulose from wheat straw. The results showed that the steaming extraction produces a cellulose with low hemicellulose and 
high lignin content, being susceptible of enzymatic treatments. The organosolv process produces cellulose with low hemicellulose and lignin contents [97].

Based on the main characteristics of the processes used commonly for the production of xylo-oligosaccharides, autohydrolysis reaction was chosen mainly because of its easy application, no use of toxic compounds, no handling of enzymes, no recovery of catalyst, etc. The description of the reaction procedure and the results obtained are given in the next chapters.

\subsection{RECOVERY AND PURIFICATION OF OLIGOSACCHARIDES}

The purification of oligosaccharides solutions is a complex problem, particularly when they come from hydrothermal processing. A variety of strategies have been proposed for refining the crude liquors, to remove undesired compounds and to separate oligosaccharides with a certain molecular weight [8]. Depending on the degree of purity desired, it is possibly that a sequence of several physicochemical treatments may need applied.

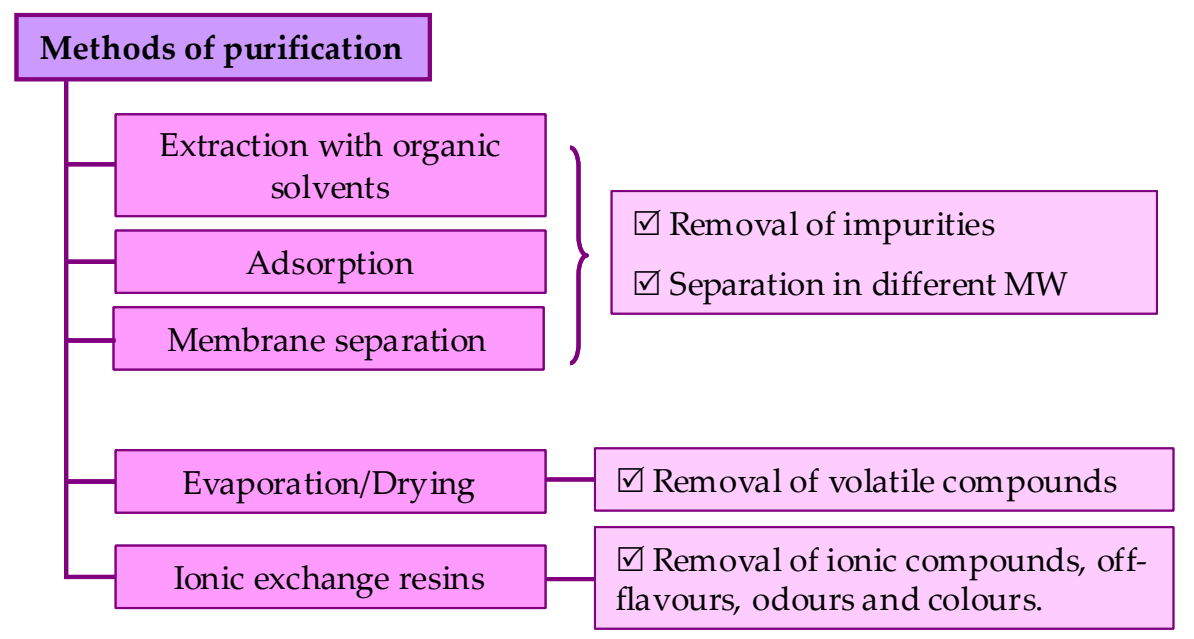

Figure 1.21. Main methods used for the purification of oligosaccharides.

The development of applications for hemicellulose-derived oligosaccharides requires good knowledge and control over their chemical composition, structure, purity and molar mass distribution. These properties are determined by the nature of the raw material, but they are also strongly influenced by the processes used to isolate 
and purify the oligosaccharides. Figure 1.21 shows the most important methods used for the purification of xylo-oligosaccharides.

\subsubsection{Extraction with organic solvents}

When the liquor obtained by mild hydrolysis of lignocellulosic materials is used subsequently in a fermentation step, the microorganisms growing on wood hydrolysates show low productivity because of the presence of inhibitory byproducts formed during the saccharification step. Several groups of microbial inhibitors have been identified in wood hydrolysates: inhibitors derived from the metals or minerals in wood, or hydrolysis equipment; products formed by decomposition of carbohydrates (including furfural, hydroxymethylfurfural and acetic acid); and lignin degradation products and compounds derived from wood extractives, which are mainly composed of phenolic compounds. Extraction with organic solvents has been used to remove most of these compounds, and it has several interesting features mainly because of their easy recovery owing to their low boiling point $[98,99]$. Several solvents have been used to recover compounds with antioxidant activity, for example, apolar solvents like ethers and ketones are the most employed for the removal of phenolics from water. The solvent extraction was used to obtain detoxified fermentation media and polyphenols with antioxidant activity from hemicellulosic wood hydrolysates. In this case, ethyl acetate and diethyl ether were tested under a variety of operational conditions allowing a recovery up to $84 \%$ of the initial lignin-derived compounds, which have shown antioxidant activity. The extracted hydrolysates yielded xylose solutions allowing a fermentative production of xylitol [19]. The same solvents (ethyl acetate and diethyl ether) were used also for the isolation of antioxidants from natural resources, removing polyphenols from water [20-22]. Ethyl ether seems to be the best pretreatment for the production of xylitol, when is compared with chloroform, ethyl acetate, trichloroethylene, diethyl ether and hexane [23]. Starting from dry fractions of hemicellulose extracts, organic acids (such as formic, acetic or propionic) have been proposed also to purify the xylan-degradation products. The water concentration should be limited in order that the impurities remain soluble in the solvent while avoiding appreciable solubilization of the hemicellulose $[8,100]$. Other organic solvents (such as alcohols and acetone) have been proposed for the recovery of hemicellulosedegradation products. As examples, ethanol and a mixture of ethanol and n-butanol were used for the purification of green fluorescent protein yielding good results [101]. 
Ethanol was also the preferred agent used for the precipitation of hemicelluloses in hemicellulose-containing caustic liquors [102]. Acetone, ethanol, and 2-propanol demonstrated to be equally effective for the precipitation of hemicelluloses from autohydrolysis liquors extracted with ethyl acetate [22].

\subsubsection{Adsorption processes}

Purification of oligosaccharides containing liquors was made by using adsorbents such as activated carbons, acid clay, bentonite, diatomaceous earth, aluminium hydroxide or oxide, titanium, silica and porous synthetic materials. A process for the decolorization of sugar syrups was proposed using a synthetic polymeric functionalized adsorbent, which comprises a highly crosslinked macroporous styrenic copolymer functionalized with weakly ionizing functional groups [103]. Also a combined process based in the utilization of activated carbons followed by elution with ethanol allows to recover oligosaccharides based on their molecular weight [8]. Adsorption in charcoal was applied to xylose-containing solutions obtained from acid prehydrolysis of Eucalyptus wood, to remove ligninderived compounds that limit the potential of hydrolysates for making fermentation media for the production of xylitol [104]. Adsorption on Amberlite XAD-2 (a polymeric adsorbent, hydrophobic crosslinked polystyrene copolymer) was widely used to adsorb soluble organic compounds from aqueous streams and organic solvents. It was used previously to separate impurities and purify xylo-oligosaccharides from phenolic compounds [105-107]. Treatment with activated carbon has been shown to be an effective process for removing impurities from carbohydrate products, having been tested for the recovery of xylitol from the fermented hydrolyzated of sugarcane bagasse [108], for the selective recovery of ferulic acid from hydrolyzates of sugar-beet pulps $[109,110]$, for the separation of maltopentaose from other maltooligosaccharides [111], and for the decolorization of sugar solutions [112] and xylo-oligosaccharides [113]. However, so far there has been no detailed study of the performance of activated carbons for the removal of lignin-derived impurities from crude xylo-oligosaccharide solutions or of the characteristics of the carbons that favor the selective adsorption of lignin-related impurities. 


\subsubsection{Membrane separation processes}

Several methods have been tested for the separation of hemicelluloses and oligosaccharides based on the molecular weight. Gel filtration was applied for the separation of oligomers from steam-treated spruce wood, with the objective of remove low molecular weight material derived from lignin hydrolysis. The recovery of oligosaccharides was between $90-100 \%$, but the reduction of the lignin fraction was not complete [114]. Nanofiltration was studied with model sugar solutions (mono, di and trisaccharide mixture) and commercial galacto-oligosaccharide mixture in a crossflow filtration unit. Temperature, pressure and concentration of the sugars have significant effects in the rejection of the sugar components of the solution. Continuous diafiltration demonstrated that this purification method is satisfactory for the recovery of oligosaccharides (98\% recovery) [115, 116]. Based in the same principle, nanofiltration was used for the purification of fructo-oligosaccharides, finding that the process was dependent on the operation mode, but it was possible to obtain above a $90 \%$ syrup purity [117]. Nanofiltration in diafiltration mode was also used for the separation of monosaccharides from inorganic electrolytes in solution, finding that the monosaccharides and the bivalent anions with few hundred units of MW can be separated from the univalent anions with few 10-folds of MW [118]. Nanofiltration and ultrafiltration with polymeric membranes were tested for the separation of non-sucrose compounds from the syrup of sugar-beet processing. The objective was to remove mainly coloured compounds and reduce the turbidity, finding that with a membrane with molecular weight cut off (MWCO) of $0.5 \mathrm{kDa}$ was possible to remove between $76 \%$ and $80 \%$ of them [119]. In other case, nanofiltration with polymeric membranes was used for the concentration of apple and pear juice at low pressures [120]. Crossflow microfiltration was also tested for the clarification of diffusion juices in the industry [121]. Oligosaccharides derived from milk were separated by using nanofiltration [122, 123], and ultrafiltration was used for the separation of lactose from milk proteins [124]. A combination of nanofiltration with ultrafiltration was used also to separate the high molar mass fraction from the low molar mass fraction of pectate oligosaccharides from lettuce [125]. In recent studies ultrafiltration has been shown to be an effective process for the purification of XOs obtained by autohydrolysis of corncobs [113], and for the fractionation of XOs produced by enzymatic hydrolysis of wheat flour [126]. An ultrafiltration membrane reactor was tested for the enzymatic hydrolysis of beechwood xylan to have the reaction step with the simultaneous 
separation into two streams, being one of them the permeate having the oligosaccharides mixture [127]. The same concept was applied to the enzymatic depolymerization of a dextran using an endodextranase [128], for the production of chitooligosaccharides [129, 130], and for the enzymatic hydrolysis of lactose [131].

\subsubsection{Evaporation and drying processes}

Vacuum evaporation can be one stage in the processing of oligosaccharides solutions from hydrothermal processing. Besides the expected increment in concentration, evaporation allows the removal of acetic acid and flavors or their precursors, which can be responsible of off-flavors [8]. Spray-drying and liophilization are widely used for the recovery of hemicellulose oligomers in powder form [40,114].

\subsubsection{Ionic exchange resins}

The ionic exchange resins are useful for desalination, but show limited ability for retaining coloured compounds [8]. Ionic exchange resins were used for the recovery of lactic acid from pretreated wood. In this case the lactic acid was present in a simultaneous saccharification and fermentation media, and it was quantitatively recovered by using anion resins in $\mathrm{OH}^{-}$form. The capacity of the resins tested remained constant in a fixed bed operation after successive cycles of loading and regeneration, being the best the Amberlite IRA 400 and Amberlite IRA 900 [132]. Ionic exchange treatment, combined with steam-stripping (removal of impurities by volatilization with steam) and carbon treatment, with or without an additional bleaching step (such as chlorite salts, hypochlorite salts, chlorine dioxide, ozone, etc), demonstrated to be effective for the removal of off-flavors, odors and/or colours from polysaccharides mixture [133]. The combination of cation exchange resins with ultrafiltration and the bleaching step was proposed also for the isolation of oligosaccharides from steam-exploded biomass [52]. 


\subsection{REFERENCES}

1. Crittenden, R. \& Playne, M. Production, properties, and applications of food-grade oligosaccharides. Trends in Food Science and Technology, 1996, 7: p. 353-361.

2. Rodriguez, R., Jimenez, A., Fernandez-Bolanos, J., Guillen, R., \& Heredia, A. Dietary fibre from vegetable products as source of functional ingredients. Trends in Food Science \& Technology, 2006, 17 (1): p. 3-15.

3. Cummings, J., Edmond, L., \& Magee, E. Dietary carbohydrates on health: do we still need the fibre concept? Clinical Nutrition Supplements, 2004, 1 (2): p. 5 - 17.

4. Gibson, G. Fibre and effects on probiotics (the prebiotic concept). Clinical Nutrition Supplements, 2004, 1 (2): p. 25 - 31.

5. Izumo, Y. \& Kojo, A. 2003, 2003048901: Japan.

6. Nishihara, M., Nagao, Y., \& Shimizu, K. in 8th Int. Symposium on Wood and Pulping Chemistry. 1995. Helsinki.

7. Christakopoulos, P., Katapodis, P., Kalogeris, E., Kekos, D., Macris, B.J., Stamatis, H., \& Skaltsa, H. Antimicrobial activity of acidic xylo-oligosaccharides produced by family 10 and 11 endoxylanases. International Journal of Biological Macromolecules, 2003: p. 171 - 175.

8. Vazquez, M., Alonso, J., Dominguez, H., \& Parajó, J. Xylo-oligosaccharides: manufacture and applications. Trends in Food Science and Technology, 2000, 11: p. 387-393.

9. Fooks, L. \& Gibson, G. In vitro investigations of the effect of probiotics and prebiotics on selected human intestinal pathogens. FEMS Microbiology Ecology, 2002, 39: p. 67 - 75.

10. Fooks, L. \& Gibson, G. Mixed culture fermentation studies on the effects of synbiotics on the human intestinal pathogens Campylobacter jejuni and Escherichia coli. Anaerobe, 2003, 9: p. 231 $-242$.

11. Kontula, P., von Wright, A., \& Mattila-Sandholm, T. Oat bran b-gluco- and xylooligosaccharides as fermentative substrates for lactic acid bacteria. International Journal of Food Microbiology, 1998, 45: p. 163 - 169.

12. Hudson, M. \& Marsh, P. Carbohydrate metabolism in the colon, in Human colonic bacteria-Role in nutrition, physiology and pathology, G. Gibson and G. Mac Farlane, Editors. 1995, CRC Press: Boca Raton, FL. p. 61 - 73.

13. Zampa, A., Silvi, S., Fabiani, R., Morozzi, G., Orpianesi, C., \& Cresci, A. Effects of different digestible carbohydrates on bile acid metabolism and SCFA production by human gut micro-flora grown in an in vitro semi-continuous culture. Anaerobe, 2004, 10: p. 19 - 26. 
14. Hsu, C., Liao, J.W., Chung, Y.C., Hsieh, C.P., \& Chan, Y.C. Xylooligosaccharides and fructooligosaccharides affect the intestinal microbiota and precancerous colonic lesion development in rats. Journal of Nutrition, 2004, 134 (6): p. 1523 - 1528.

15. Yuan, X., Wang, J., \& Yao, H. Feruloyl oligosaccharides stimulate the growth of Bifidobacterium bifidum. Anaerobe, 2005, 11: p. 225-229.

16. Wollowski, I., Rechkemmer, G., \& Pool - Zobel, B. Protective role of probiotics and prebiotics in colon cancer. American Journal of Clinical Nutrition, 2001, 73: p. 451 - 455.

17. Manning, T. \& Gibson, G. Prebiotics. Best Practice \& Research Clinical Gastroenterology, 2004, 18 (2): p. 287 - 298.

18. Ziemer, C. \& Gibson, G. An overview of probiotics, prebiotics and synbiotics in the functional food concept: perspectives and future strategies. International Dairy Journal, 1998, 8: p. 473-479.

19. Cruz, J., Domínguez, J., Domínguez, H., \& Parajó, J. Solvent extraction of hemicellulosic wood hydrolysates: a procedure useful for obtaining both detoxified fermentation media and polyphenols with antioxidant activity. Food Chemistry, 1999, 67: p. 147-153.

20. Moure, A., Cruz, J., Franco, D., Domínguez, J., Sineiro, J., Domínguez, H., Nuñez, M., \& Parajó, J. Natural antioxidants from residual sources. Food Chemistry, 2001, 72: p. 145-171.

21. Garrote, G., Cruz, J., Domínguez, H., \& Parajó, J. Valorisation of waste fractions from autohydrolysis of selected lignocellulosic materials. Journal of Chemical Technology and Biotechnology, 2003, 78: p. 392-398.

22. Vazquez, M., Garrote, G., Alonso, J., Dominguez, H., \& Parajo, J.C. Refining of autohydrolysis liquors for manufacturing xylooligosaccharides: evaluation of operational strategies. Bioresource Technology, 2005, 96 (8): p. 889 - 896.

23. Parajó, J.C., Dominguez, H., \& Dominguez, J. Xylitol production from Eucalyptus wood hydrolysates extracted with organic solvents. Process Biochemistry, 1997, 32 (7): p. 599 - 604.

24. Stone, A., Melton, D., \& Lewis, M. Structure-function relations of heparin-mimetic sulfated xylan oligosaccharides: inhibition of Human Immunodeficiency Virus-1 infectivity in vitro. Glycoconjugate Journal, 1998, 15: p. 697-712.

25. Damonte, E., Matulewicz, M., Cerezo, A., \& Coto, C. Herpes simplex virus-inhibitory sulfated xylogalactans from the red seaweed Nothogenia fastigiata. Chemotherapy, 1996, 42 (1): p. 57 - 64.

26. Pujol, C., Matulewicz, M., Cerezo, A., \& Damonte, E. Inhibitory action of an algal derived xylomannan on glycoprotein $C$ mediated biological properties of Herpes simplex virus. Phytomedicine, 1998, 5 (3): p. 205 - 208.

27. Muto, S., Niimura, K., Oohara, M., Oguchi, Y., Matsunaga, K., Hirose, K., Kakuchi, J., Sugita, N., Furusho, T., Yoshikumi, C., \& Takahashi, M. Polysaccharides and antiviral drugs containing the same as active ingredient. 1992, US 5089481: United States.

28. Ando, H., Ohba, H., Sakaki, T., Takamine, K., Kamino, Y., Morikawi, S., Bakalova, R., Uemura, Y., \& Hatate, Y. Hot-compressed-water decomposed products from bamboo manifest a 
selective cytotoxicity against acute lymphoblastic leukemia cells. Toxicology in Vitro, 2004, 18: p. 765 - 771.

29. Suwa, Y., Koga, K., Fujikawa, S., Okazaki, M., Irie, T., \& Nakada, T. Bifidobacterium bifidum proliferation promoting composition containing xylooligosaccharide. 1999, US 5939309: United States.

30. DeMichele, S., Garleb, K., McEwen, J., \& Fuller, M. Nutritional product for a person having ulcerative colitis. 1999, US 5952314.

31. Campbell, J., Fahey, G., DeMichele, S., \& Garleb, K. Metabolic characteristics of healthy adult males as affected by ingestion of a liquid nutritional formula containing fish oil, oligosaccharides, gum arabic and antioxidant vitamins. Food and Chemical Toxicology, 1997, 35: p. 1165-1176.

32. Dohnalek, M., Ostrom, K., \& Hilty, M. Use of indigestible oligosaccharides to prevent gastrointestinal infections and reduce duration of diarrhea in humans. 1998, US 5827526: United States.

33. Wolf, B., Garleb, K., Campbell, S., Meulbroek, J., Wheeler, K., \& Walton, J. Oral dehydration solution containing indigestible oligosaccharides. 1998, US 5733579: United States.

34. Dohnalek, M., Ostrom, K., \& Hilty, M. Use of indigestible oligosaccharides to reduce the incidence of otitis media in humans. 1998, US 5849324: United States.

35. Garcia, R., Toshiyuki, N., Praxedes, A., Raffin, F., Moura, T., \& Egito, S. Preparation of micro and nanoparticles from corn cobs xylan. Polymer Bulletin, 2001, 46: p. 371 - 379.

36. Vandamme, T., Lenourry, A., Charrueau, C., \& Chaumeil, J. The use of polysaccharides to target drugs to the colon. Carbohydrate Polymers, 2002, 48: p. 219 - 231.

37. Glasser, W., Jain, R., \& Sjostedt, M. Thermoplastic pentosan-rich polysaccharides from biomass. 1995, US 5430142: United States.

38. Wallace, D., Reich, C., Shargill, N., Vega, F., \& Osawa, A. Fragmented polymeric compositions and methods for their use. 2000, US 6063061.

39. Gabrielii, I. \& Gatenholm, P. Preparation and properties of hydrogels based on hemicellulose. Journal of Applied Polymer Science, 1998, 69: p. 1661 - 1667.

40. Gabrielii, I., Gatenholm, P., Glasser, W., Jain, R., \& Kenne, L. Separation, characterization and hydrogel-formation of hemicellulose from aspen wood. Carbohydrate Polymers, 2000, 43: p. 367 374.

41. Boderke, P., Manero, J., \& Filbey, J. Nanoparticles comprising polyelectrolyte complex of polycation, polyanion and biologically active agent, especially useful for controlled drug release on oral administration. 1999, DE 19810965: Germany.

42. Söderqvist Lindblad, M., Ranucci, E., \& Albertsson, A. Biodegradable polymers from renewable sources. New hemicellulose-based hydrogels. Macromolecular Rapid Communications, 2001, 22: p. 962 - 967. 
43. Ebringerová, A., Hromádková, Z., \& Heinze, T. Hemicellulose. Advances in Polymer Science, 2005, 186: p. 1 - 67.

44. Fengel, D. \& Wegener, G. Wood: Chemistry, Ultrastructure, Reactions. 1989, Berlin - New York: Walter de Gruyter.

45. Shimizu, K. Chemistry of Hemicelluloses, in Wood and Cellulosic Chemistry, D. Hon and N. Shiraishi, Editors. 1990, Marcel Dekker: New York.

46. Montané, D., Salvadó, J., Farriol, X., Vidal, P., Jollez, P., \& Chornet, E. Polysaccharides from biomass via thermomechanical process, in Polysaccharides: Structural diversity and functional versatility, S. Dumitriu, Editor. 1998, Marcel Dekker: New York. p. 1069 - 1086.

47. Hromádková, Z., Kováciková, J., \& Ebringerová, A. Study of the classical and ultrasoundassisted extraction of the corncob xylan. Industrial Crops and Products, 1999, 9: p. 101-109.

48. Ebringerová, A. \& Hromádková, Z. The effect of ultrasound on the structure and properties of the water-soluble corn hull heteroxylan. Ultrasonics Sonochemistry, 1997, 4: p. 305 - 309.

49. Ebringerová, A., Hromádková, Z., Alfödi, J., \& Hríbalová, V. The inmunologically active xylan from ultrasound-treated corncobs: extractability, structure and properties. Carbohydrate Polymers, 1998, 37: p. 231-139.

50. Ebringerová, A., Hromádková, Z., Hríbalová, V., \& Mason, T. Effect of ultrasound on the inmunogenic corn cob xylan. Ultrasonics Sonochemistry, 1997, 4: p. 311 - 315.

51. Jacobs, A., Palm, M., Zacchi, G., \& Dahlman, O. Isolation and characterization of water-soluble hemicelluloses from flax shive. Carbohydrate Research, 2003, 338: p. 1869 - 1876.

52. Dhara, K., Glasser, W., Kaar, W., Palmer, J., \& Rauschen, N. Isolation of oligosaccharides from biomass. 1991, WO 9118000.

53. Overend, R. \& Chornet, E. Fractionation of lignocellulosics by steam-aqueous pretreatment. Phil. Trans. R. Soc. Lond., 1987, 321: p. 523-536.

54. Garrote, G., Domínguez, H., \& Parajó, J. Hydrothermal processing of lignocellulosic materials. Holz als Roh - und Werkstoff, 1999, 57: p. 191-202.

55. Kabel, M., Carvalheiro, F., Garrote, G., Avgerinos, E., Koukios, E., Parajó, J., Gírio, F., Schols, H., \& Voragen, A. Hydrothermally treated xylan rich by-products yield different classes of xylo-oligosaccharides. Carbohydrate Polymers, 2002, 50: p. 47-56.

56. Parajó, J., Garrote, G., Cruz, J., \& Dominguez, H. Production of xylooligosaccharides by autohydrolysis of lignocellulosic materials. Trends in Food Science and Technology, 2004, 15 $(115-120)$.

57. Garrote, G., Domínguez, H., \& Parajó, J. Mild autohydrolysis: an environmentally friendly technology for xylooligosaccharide production from wood. Journal of Chemical Technology and Biotechnology, 1999, 74: p. 1101-1109. 
58. Garrote, G., Domínguez, H., \& Parajó, J. Autohydrolysis of corncob: study of non-isothermal operation for xylooligosaccharide production. Journal of Food Engineering, 2002, 52: p. 211-218.

59. Carvalheiro, F., Esteves, M., Parajo, J.C., Pereira, H., \& Gírio, F. Production of oligosaccharides by autohydrolysis of brewery's spent grain. Bioresource Technology, 2004, 91: p. 93 - 100.

60. Yang, R., Xu, S., Wang, Z., \& Yang, W. Aqueous extraction of corncob xylan and production of xylooligosaccharides. Lebensmittel - Wissenschaft u Technologie, 2005, 38: p. 377 - 382.

61. Aoyama, M., Seki, K., \& Saito, N. Solubilization of bamboo grass xylan by steaming pretreatment. Holzforshung, 1995, 49: p. 193-196.

62. Brownell, H., Yu, E., \& Saddler, J. Steam explosion pretreatment of wood: effect of chip size, acid, moisture content, and pressure drop. Biotechnology and Bioengineering, 1986, 28: p. 792-801.

63. Montané, D., Salvadó, J., Farriol, X., \& Chornet, E. The fractionation of almond shells by thermo-mechanical aqueous phase (TM-AV) pretreatment. Biomass and Bioenergy, 1993, 4 (6): p. $427-437$.

64. De Bari, I., Viola, E., Barisano, D., Cardinale, M., Nanna, F., Zimbardi, F., Cardinale, G., \& Braccio, G. Ethanol production at flask and pilot scale from concentrated slurries of steam-exploded aspen. Industrial and Engineering Chemistry Research, 2002, 41 (7): p. 1745 - 1753.

65. Heitz, M., Capek-Ménard, E., Koeberle, P., Gagné, J., Chornet, E., Overend, R., Taylor, J., \& $\mathrm{Yu}, \mathrm{E}$. Fractionation of Populus Tremuloides at the Pilot Plant scale: optimization of steam pretreatment conditions using the Stake II Technology. Bioresource Technology, 1991, 35: p. 2332.

66. Jollez, P., Chornet, E., \& Overend, R. Steam aqueous fractionation of sugar cane bagasse: an optimization study of process conditions at the pilot plant level., in Advances in Thermochemical Biomass Conversion, B.A.a.P.C.a.H. A.V. Bridgewater, Editor. 1994: London. p. 1659-1669.

67. Liu, C. \& Wyman, C. The effect of flow rate of very dilute sulfuric acid on xylan, lignin, and total mass removal from corn stover. Industrial and Engineering Chemistry Research, 2004, 43: p. $2781-2788$.

68. Chen, R., Lee, Y., \& Torget, R. Kinetic and modelling investigation on two-stage reverse flow reactor as applied to dilute-acid pretreatment of agricultural residues. Applied Biochemistry and Biotechnology, 1996, 57/58: p. 133 - 146.

69. Montané, D., Salvadó, J., Torras, C., \& Farriol, X. High-temperature dilute-acid hydrolysis of olive stones for furfural production. Biomass and Bioenergy, 2002, 22: p. 295-304.

70. Martínez, J., Granado, J., Montané, D., Salvadó, J., \& Farriol, X. Fractionation of residual lignocellulosics by dilute-acid prehydrolysis and alkaline extraction: Application to almond shells. Bioresource Technology, 1995, 52: p. 59-67.

71. Montané, D., Farriol, X., Salvadó, J., Jollez, P., \& Chornet, E. Fractionation of wheat straw by steam-explosion pretreatment and alkali delignification. Cellulose pulp and byproducts from hemicellulose and lignin. Journal of Wood Chemistry and Technology, 1998, 18 (2): p. 171191. 
72. Montané, D., Farriol, X., Salvadó, J., Jollez, P., \& Chornet, E. Application of steam explosion to the fractionation and rapid vapor-phase alkaline pulping of wheat straw. Biomass and Bioenergy, 1998, 14 (3): p. 261-276.

73. Montané, D., Salvadó, J., \& Farriol, X. Fractionation of wheat straw via steam explosion pretreatment. Characteristics of the lignin obtained by alkali delignification of the steamed straw. Holzforshung, 1997, 51 (2): p. 135-141.

74. Methacanon, P., Chaikumpollert, O., Thavorniti, P., \& Suchiva, K. Hemicellulosic polymer from Vetiver grassand its physichochemical properties. Carbohydrate Polymers, 2003, 54: p. 335 -342 .

75. Sun, R., Lawther, J., \& Banks, W. Influence of alkaline pre-treatments on the cell wall components of wheat straw. Industrial Crops and Products, 1995, 4: p. 127-145.

76. Hespell, R. Extraction and characterization of hemicellulose from the corn fiber produced by cornwet milling processes. Journal of Agricultural and Food Chemistry, 1998, 46: p. 2615-2619.

77. Martínez, J., Reguant, J., Montero, M., Montané, D., Salvadó, J., \& Farriol, X. Hydrolytic pretreatment of softwood and almond shells. Degree of Polymerization and Enzymatic digestibility of the cellulose fraction. Industrial and Engineering Chemistry Research, 1997, 36 (3): p. 688696.

78. Cruz, J., Domínguez, J., Domínguez, H., \& Parajó, J. Preparation of fermentation media from agricultural wastes and their bioconversion into xylitol. Food Biotechnology, 2000, 14 (1 - 2): p. $79-97$.

79. Rivas, B., Domínguez, J., Domínguez, H., \& Parajó, J. Bioconversion of posthydrolysed autohydrolysis liquors: an alternative for xylitol production from corn cobs. Enzyme and Microbial Technology, 2002, 31: p. 431-438.

80. Garrote, G., Domínguez, H., \& Parajó, J. Manufacture of xylose-based fermentation media from corncobs by posthydrolysis of autohydrolysis liquors. Applied Biochemistry and Biotechnology, 2001, 95: p. 195-207.

81. Garrote, G., Domínguez, H., \& Parajó, J. Generation of xylose solutions from Eucalyptus globulus wood by auto hydrolysis-posthydrolysis processes: Posthydrolysis kinetics. Bioresource Technology, 2001, 79: p. 155-164.

82. Vazquez, M., Alonso, JL, Dominguez, H, and Parajó, JC. Production of xylose-containing fermentation media by enzymatic post-hydrolysis of oligomers produced by corn cob autohydrolysis. World Journal of Microbiology and Biotechnology, 2001, 17: p. 817-822.

83. Pou-Ilinas, J., Canellas, J., Driguez, H., Excoffier, G., \& Vignon, M. Steam pretreatment of almond shells for xylose production. Carbohydrate Research, 1990, 207: p. 126-130.

84. Puls, J., Poutanen, K., Körner, H., \& Viikari, L. Biotechnical utilization of wood carbohydrates after steaming pretreatment. Applied Microbiology and Biotechnology, 1985, 22: p. 416-423.

85. Brownell, H. \& Saddler, J. Steam pretreatment of lignocellulosic material for enhanced enzymatic hydrolysis. Biotechnology and Bioengineering, 1987, 29: p. 228-235. 
86. Ballesteros, I., Oliva, J.M., Negro, M.J., Manzanares, P., \& Ballesteros, M. Enzymic hydrolysis of steam exploded herbaceous agricultural waste (Brassica carinata) at different particule sizes. Process Biochemistry, 2002, 38 (2): p. 187-192.

87. Shimizu, K., Sudo, K., Ono, H., Ishihara, M., Fujii, T., \& Hishiyama, S. Integrated process for total utilization of wood components by steam explosion pretreatment. Biomass and Bioenergy, 1998, 14 (3): p. 195 - 203.

88. Ballesteros, M., Oliva, J.M., Negro, M.J., Manzanares, P., \& Ballesteros, I. Ethanol from lignocellulosic materials by a simultaneous saccharification and fermentation process (SFS) with Kluyveromyces marxianus CECT 10875. Process Biochemistry, 2004, 39 (12): p. 1843-1848.

89. Coughlan, M., Tuohy, M., Filho, E., Puls, J., Claeyssens, M., Vrsanská, M., \& Hughes, M. Enzymological aspects of microbial hemicellulases with emphasis on fungal systems, in Hemicelluloses and Hemicellulases, M. Coughlan and G. Hazlewood, Editors. 1993, Portland Press: Cambridge. p. 53 - 84.

90. Puls, J. \& Schuseil, J. Chemistry of hemicelluloses: Relationship between hemicellulose structure and enzymes required for hydrolysis, in Hemicellulose and Hemicellulases, M. Coughlan and G. Hazlewood, Editors. 1993: London. p. 1 - 27.

91. Biely, P. Biochemical aspects of the production of microbial hemicellulases, in Hemicellulose and Hemicellulases, M. Coughlan and G. Hazlewood, Editors. 1993, Portland Press: London. p. $29-51$.

92. Popa, V. Enzymatic hydrolysis of hemicelluloses and cellulose, in Polysaccharides: Structural Diversity and Functional Versatility, S. Dumitriu, Editor. 1998, Marcel Dekker: Quebec. p. 969 - 1006.

93. Hollman, J. \& Lindhauer, M. Pilot-scale isolation of glucuronoarabinoxylans from wheat bran. Carbohydrate Polymers, 2005, 59 (2): p. 225 - 230.

94. Lawther, J., Sun, R., \& Banks, W. Extraction, fractionation and characterization of structural polysaccharides from wheat straw. Journal of Agricultural and Food Chemistry, 1995, 43: p. 667-675.

95. Kham, L., Le Bigot, Y., Delmas, M., \& Avignon, G. Delignification of wheat straw using a mixture of carboxylic acids and peroxoacids. Industrial Crops and Products, 2005, 21 (1): p. 9 15.

96. Sun, X., Sun, R., Lu, Q., Xu, F., \& Lin, L. Fractional isolation and physicho-chemical characterization of hemicelluloses by a two-stage treatment from Haloxylon ammodendron and Elaeagnus angustifolia. Journal of Agricultural and Food Chemistry, 2002, 50: p. 6400 - 6407.

97. Puls, J., Gast, D., \& Körner, H. Characterization of straw cellulose after steaming and organosolv pretreatment, in New Approaches to Research on Cereal Carbohydrates, R.D.H.a.L. Munck, Editor. 1985, Elsevier Science Publishers B.V.: Amsterdam, Netherlands. p. 305-312.

98. Vegas, R., Alonso, J.L., Domínguez, H., \& Parajó, J.C. Manufacture and refining of oligosaccharides from industrial solid wastes. Industrial and Engineering Chemistry Research, 2005, 44: p. $614-620$. 
99. Vegas, R., Alonso, J., Domínguez, H., \& Parajo, J.C. Processing of rice husk autohydrolysis liquors for obtaining food ingredients. Journal of Agricultural and Food Chemistry, 2004, 52: p. $7311-7317$.

100. Schweiger, R. Refining of Hemicelluloses. 1973, US 3716526: USA Patent.

101. Yakhnin, A., Vinokurov, L., Surin, A., \& Alakhov, Y. Green fluorescent protein purification by organic extraction. Protein Expression and Purification, 1998, 14: p. 382 - 386.

102. Sihtola, H. Method for the removal of hemicellulose from hemicellulose-containing caustic liquors. 1976, US 3935022: United States.

103. L'Hermine, G. \& Lundquist. Decolorization of sugar syrups using functionalized adsorbents. 1998, EP 0882803.

104. Parajó, J., Domínguez, H., \& Domínguez, J. Study of charcoal adsorption for improving the production of Xylitol from wood hydrolysates. Bioprocess Engineering, 1995, 16: p. 39-43.

105. Bunzel, M., Allerdings, E., Sinwell, V., Ralph, J., \& Steinhart, H. Cell wall hydroxycinnamates in wild rice (Zizania aquatica L.) insoluble dietary fibre. European Food Research and Technology, 2002, 214: p. 482 - 488.

106. Saulnier, L., Vigouroux, J., \& Thibault, J. Isolation and partial characterization of feruloylated oligosaccharides from maize bran. Carbohydrate Research, 1995, 272: p. 241 - 253.

107. McCallum, J., Taylor, I., \& Towers, G. Spectrophotometric assay and electrophoretic detection of trans-feruloyl esterase activity. Analytical Biochemistry, 1991, 196: p. 360 - 366.

108. Gurgel, P., Mancilla, I.M., Peçanha, R.P., \& Siquiera, J.F.M. Xylitol recovery from fermented sugarcane bagasse hydrolyzate. Bioresource Technology, 1995, 52: p. 219 - 223.

109. Couteau, D. \& Mathaly, P. Fixed-bed purification of ferulic acid from sugar-beet pulp using activated carbon: optimization studies. Bioresource Technology, 1998, 60: p. 17 - 25.

110. Couteau, D. \& Mathaly, P. Purification of ferulic acid by adsorption after enzymatic release from sugar-beet pulp extract. Industrial Crops and Products, 1997, 6: p. 237 - 252.

111. Lee, J.W., Kwon, T.O., \& Moon, I.S. Adsorption of monosaccharides, disaccharides, and maltooligosaccharides on activated carbon for separation of maltopentaose. Carbon, 2004, 42: $\mathrm{p}$. $371-380$.

112. Ahmedna, M., Marshall, W., \& Rao, R.M. Surface properties of granular activated carbons from agricultural by-products and their effects on raw sugar decolorization. Bioresource Technology, 2000, 71: p. $103-112$.

113. Yuan, Q.P., Zhang, H., Qian, Z.M., \& Yang, X.J. Pilot-plant production of xylo-oligosaccharides from corncob by steaming, enzymatic hydrolysis and nanofiltration. Chemical Technology and Biotechnology, 2004, 79: p. 1073-1079.

114. Palm, M. \& Zacchi, G. Separation of hemicellulosic oligomers from steam - treated spruce wood using gel filtration. Separation and Purification Technology, 2004, 36: p. 191 - 201. 
115. Goulas, A., Kapasakalidis, P., Sinclair, H., Rastall, R., \& Grandison, A. Purification of oligosaccharides by nanofiltration. Journal of Membrane Science, 2002, 209: p. 321 - 335.

116. Goulas, A., Grandison, A., \& Rastall, R. Fractionation of oligosaccharides by nanofiltration. Journal of the Science and Agriculture, 2003, 83: p. 675 - 680.

117. Li, W., Li, J., Chen, T., \& Chen, C. Study on nanofiltration for purifying fructo-oligosaccharides. I. Operation modes. Journal of Membrane Science, 2004, 245: p. 123 - 129.

118. Wang, X., Zhang, C., \& Ouyang, P. The possibility of separating saccharides from a $\mathrm{NaCl}$ solution by using nanofiltration in diafiltration mode. Journal of Membrane Science, 2002, 204: p. 271 - 281.

119. Gyura, J., Seres, Z., Vatai, G., \& Molnár, E. Separation of non-sucrose compounds from the syrup of sugar-beet processing by ultra- and nanofiltration using polymer membranes. Desalination, 2002, 148: p. 49 - 56.

120. Warczok, J., Ferrando, M., López, F., \& Güell, C. Concentration of apple and pear juices by nanofiltration at low pressures. Journal of Food Engineering, 2004, 63 (1): p. 63-70.

121. Lutin, F., Bailly, M., \& Bar, D. Process improvements with innovative technologies in the starch and sugar industries. Desalination, 2002, 148: p. 121 - 124.

122. Leiva, M. \& Guzman, M. Formation of oligosaccharides during enzymic hydrolysis of milk whey permeates. Process Biochemistry, 1995, 30 (8): p. 757 - 762.

123. Sarney, D., Hale, C., Frankel, G., \& Vulfson, E. A novel approach to the recovery of biologically active oligosaccharides from milk using a combination of enzymatic treatment and nanofiltration. Biotechnology Bioengineering, 2000, 69: p. 461 - 467.

124. Chen, C., Hsu, C., \& Chiang, B. Optimization of the enzymic process for manufacturing lowlactose milk containing oligosaccharides. Process Biochemistry, 2002, 38: p. 801-808.

125. Iwasaki, K. \& Matsubara, Y. Purification of pectate oligosaccharides showing root-growthpromoting activity in lettuce using ultrafiltration and nanofiltration membranes. Journal of Bioscience and bioengineering, 2000, 89 (5): p. 495 - 497.

126. Swennen, K., Courtin, C.M., Van der Bruggen, B., Vandecasteele, C., \& Delcour, J.A. Ultrafiltration and ethanol precipitation for isolation of arabinoxylooligosaccharides with different structures. Carbohydrate Polymers, 2005, 62: p. 283 - 292.

127. Freixo, M. \& Pinho, M. Enzymatic hydrolysis of beechwood xylan in a membrane reactor. Desalination, 2002, 149: p. 237 - 242.

128. Mountzouris, K., Gilmour, S., Grandison, A., \& Rastall, R. Modeling of oligodextran production in an ultrafiltration stirred-cell membrane reactor. Enzyme and Microbial Technology, 1999, 24: p. 75 - 85.

129. Jeon, Y. \& Kim, S. Continuous production of chitooligosaccharides using a dual reactor system. Process Biochemistry, 2000, 35: p. 623-632. 
130. Jeon, Y. \& Kim, S. Production of chitooligosaccharides using an ultrafiltration membrane reactor and their antibacterial activity. Carbohydrate Polymers, 2000, 41: p. 133 - 141.

131. Petzelbauer, I., Splechtna, B., \& Nidetzky, B. Development of an ultrahigh-temperature process of the enzymatic hydrolysis of lactose. III. Utilization of two thermostable b-glycosidases in a continuous ultrafiltration membrane reactor and galacto-oligosaccharide formation under steadystate conditions. Biotechnology Bioengineering, 2002, 77: p. 394 - 404.

132. Moldes, A., Alonso, J., \& Parajó, J. Resin selection and single step production and recovery of lactic acid from pretreated wood. Applied Biochemistry and Biotechnology, 2001, 95 (2): p. 6981.

133. Eden, J., Kasica, J., Walsh, L., Rutenberg, M., Lacourse, N., Solarek, D., \& Koubek, T. Purification of polysaccharides. 1998, US Patent 5756721. 
AUTOHYDROLYSIS OF AGRICULTURAL BY-PRODUCTS FOR THE PRODUCTION OF XYLO-OLIGOSACCHARIDES.

Debora Alcida Nabarlatz

ISBN: 978-84-690-7617-0 / DL: T.1385-2007

2. MATERIALS AND METHODS 


\subsection{AUTOHYDROLYSIS REACTION}

As established in the scope of the thesis, the purpose was to evaluate several lignocellulosic materials coming from biomass (like agriculture residues) to obtain xylo-oligosaccharides with potential applications in the food and pharmaceutical field. First of all, the objective was to evaluate the products obtained and their distribution when the biomass is processed by using hydrothermal treatment (autohydrolysis reaction). For this purpose, the autohydrolysis reaction was studied first at small scale using corncobs and almond shells as the source for the production of xylooligosaccharides. The fractions of the solid (cellulose, lignin and xylan remaining), and the products obtained in the liquid (xylo-oligosaccharides, monomers and degradation compounds) were quantified. In the case of the xylo-oligosaccharides, not only their composition was studied, but also the molar mass distribution was related to the temperature and time of reaction. Finally the process was made in a higher volume reactor $(10 \mathrm{~L})$ to obtain sufficient amount of xylo-oligosaccharides to be used in the subsequent purification and / or recovery steps.

\subsubsection{Autohydrolysis reaction at small scale}

The experiments at small scale by using a batch tubing-bomb reactor system were performed for two different raw materials, corncobs (CC) and almond shells (AS). The reactor was a $25 \mathrm{~mm}$ O.D. stainless steel vessel with a volume of $25 \mathrm{~mL}$ (see Figure 2.1).

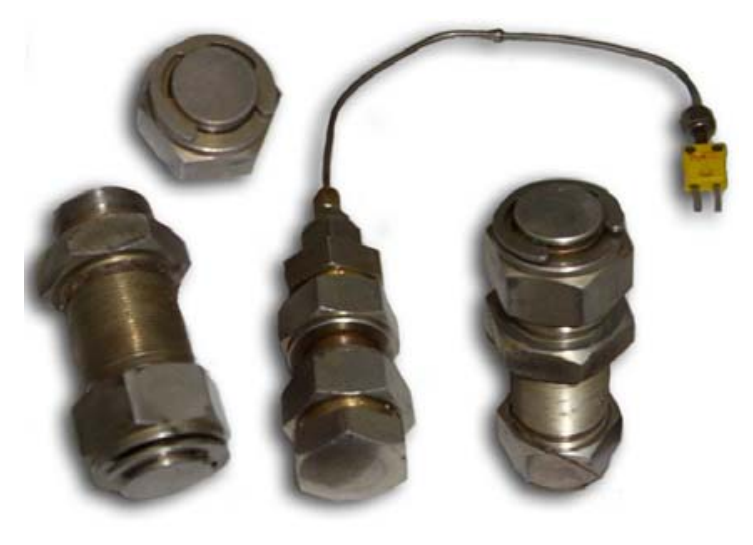

Figure 2.1. Small reactors. 
The reactors (6 units) were mounted horizontally on a support and then immersed in an oil bath, which was previously heated to the desired reaction temperature. An 1/16-inch K-type thermocouple was mounted in another reactor filled only with water to record the temperature-time history of each experiment. A typical temperature profile for the autohydrolysis reaction experiments is shown in Figure 2.2.

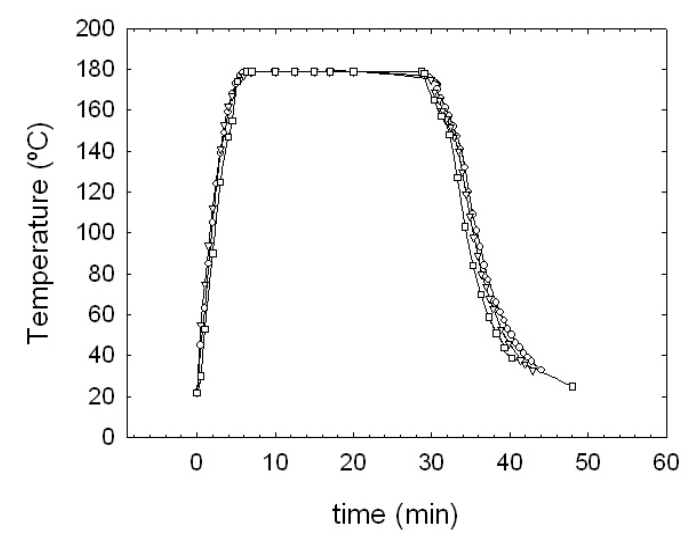

Figure 2.2. Typical temperature profile for the experiments in the $10 \mathrm{~L}$ reactor.

The temperatures and times tested are detailed in Table 1, and the range of temperatures tested was based on literature data [1]. Quadruplicate experiments for $\mathrm{CC}$ were performed at $179^{\circ} \mathrm{C}$ and 3 different reaction times to evaluate the typical dispersion of the results. In the case of AS, triplicate experiments were performed at $169^{\circ} \mathrm{C}$ and at 5 different reaction times to evaluate the typical dispersion of the results. All the experiments were performed at nominal solids concentration of $11 \%$ ( $8 \mathrm{~g}$ of water per gram of dry solid). In each experiment the reactor was loaded with an amount of solid equivalent to around $2.5 \mathrm{~g}$ of dry material and $20 \mathrm{~mL}$ of deionized water. After that, the reactors were sealed and mounted in the support. As soon as the reactors were immersed in the oil bath, the temperature acquisition was started. At the end of the reaction time, the reactors were extracted from the oil bath and immediately immersed in cold water to quench the reaction products. After cooling, the reactors were opened and the reaction product was filtered to recover the solid residue, which was washed with warm water (three consecutive washings with $15 \mathrm{~mL}$ ) and dried at $105^{\circ} \mathrm{C}$. The liquid from each reactor and the washings were mixed and stored for further analysis, as detailed in the section 2.5.6.1. 


\begin{tabular}{|c|c|c|c|c|}
\hline \multicolumn{5}{|c|}{ Temperature $\left({ }^{\circ} \mathrm{C}\right)$} \\
\hline 150 & 159 & 169 & 179 & 190 \\
\hline \multicolumn{5}{|c|}{ Reaction times at constant temperature (min) } \\
\hline 7.2 & 9.2 & 6.4 & 6.6 & 8.7 \\
\hline 29.0 & 20.8 & 12.4 & 9.6 & 10.1 \\
\hline 50.8 & 32.3 & 18.3 & 12.6 & 11.6 \\
\hline 72.6 & 43.9 & 24.3 & 15.6 & 13.0 \\
\hline 94.3 & 55.5 & 30.3 & 18.5 & 14.5 \\
\hline 116.1 & 67.0 & 36.2 & 21.5 & 15.9 \\
\hline 143.4 & 81.5 & 43.7 & 25.3 & 17.7 \\
\hline 170.6 & 96.0 & 51.2 & 29.0 & 19.6 \\
\hline 225.0 & 124.9 & 66.1 & 36.5 & 23.2 \\
\hline 279.5 & 153.8 & 81.0 & 43.9 & 26.8 \\
\hline 334.0 & 182.7 & 95.9 & 51.4 & 30.4 \\
\hline
\end{tabular}

Table 2.1. Times of reaction at constant temperature tested for the experiments at small scale.

\subsubsection{Autohydrolysis reaction in the $10 \mathrm{~L}$ reactor}

The autohydrolysis reaction at larger scale was studied using six different raw materials, corncobs (CC), almond shells (AS), olive stones (OS), rice husks (RH), and the straw of wheat (WS) and barley (BS). The experiments were performed using a $10 \mathrm{~L}$ stirred batch reactor (see Figure 2.3) that was constructed of ANSI 304-L and 316-L stainless steel by EMMSA (Tarragona, Spain).

The reactor was equipped with a variable speed Magnedrive II stirrer (Autoclave Engineers, USA), an internal coil for heating and cooling, and a thermocouple for temperature acquisition along the experiment. Heating was provided by a stream of saturated steam (at $40 \mathrm{bar}$ ), through the inner coil at a pressure adequate (10 bar) to maintain the desired temperature inside the reactor $(7$ bar gives an inside temperature of $\left.179^{\circ} \mathrm{C}\right)$. When the target reaction time was reached $(29 \mathrm{~min})$ the flow of steam was stopped and tap water was circulated through the inner coil to quench the reaction mixture. Once cooled, the reactor was depressurized through a valve on the cover and it was emptied into a $50 \mathrm{~L}$ polypropylene container through a 1 " ball valve located at 
the bottom of the vessel. The solid residue was extracted completely and the reactor was thoroughly washed with deionized water $(1 \mathrm{~L})$, mixing the washings with the liquid product (LP). After the completion of the reaction, the solid hydrolysis residue was separated from the liquid phase by filtration, washed with warm water $\left(50^{\circ} \mathrm{C}\right.$, two consecutive washings with $1 \mathrm{~L}$ each), and dried at room temperature. The final volume of the liquid product obtained by combining the liquid phase and washing water was measured and $100 \mathrm{~mL}$ were taken for analysis, as detailed in the section 2.5.6.1.

The experiments for all samples were carried out in deionized water at $179^{\circ} \mathrm{C}$ and $29 \mathrm{~min}$ of reaction, following the optimal conditions founded in the previous experiments done at laboratory scale for the autohydrolysis of CC and AS. The concentration of solids in the reactor varied depending on the porosity and density of the different raw materials to have the better mixing inside the reactor. For AS, OS and $\mathrm{RH}$ the concentration was the highest, $14.3 \%$ (833 $\mathrm{g}$ of material per $5 \mathrm{~L}$ of water) because they are dense materials. For CC it was reduced to $11.1 \%$ (625 g of dry solid per $5 \mathrm{~L}$ of water), and for BS and WS to $5.7 \%$ (300 g of dry solid with $5 \mathrm{~L}$ of water) due that they are porous, low density materials.
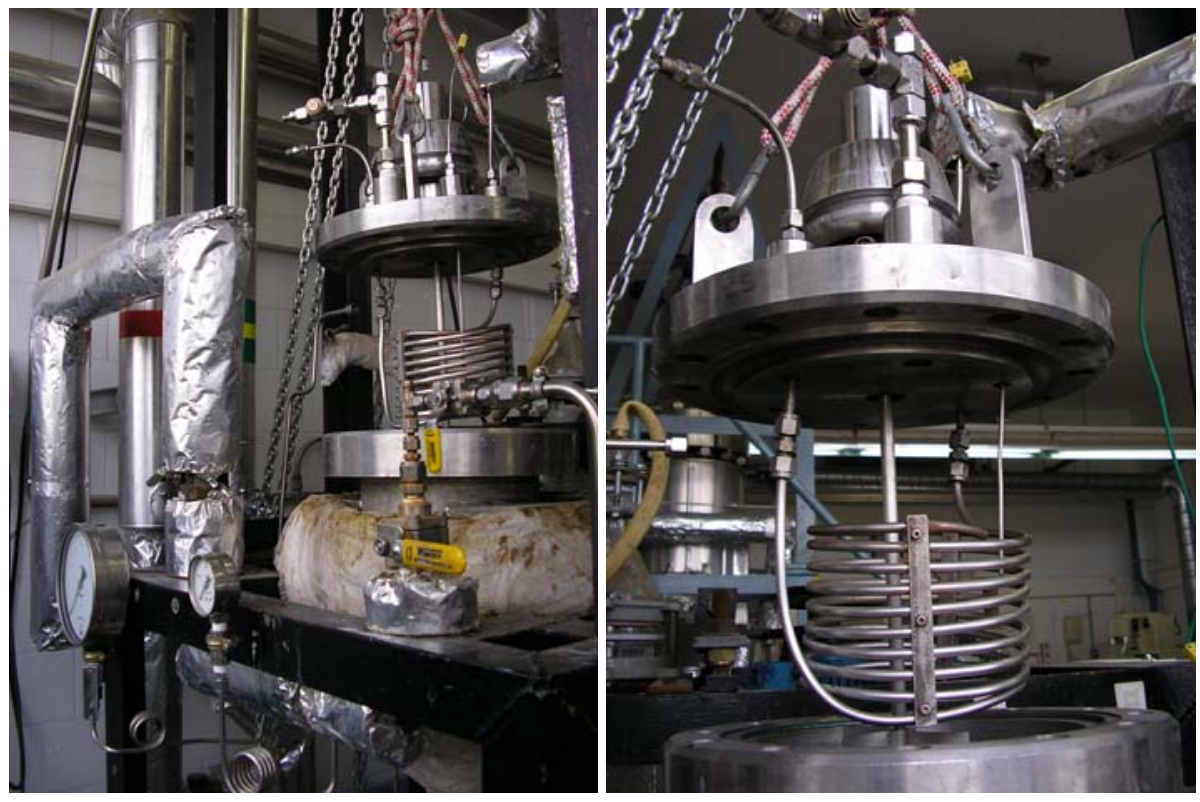


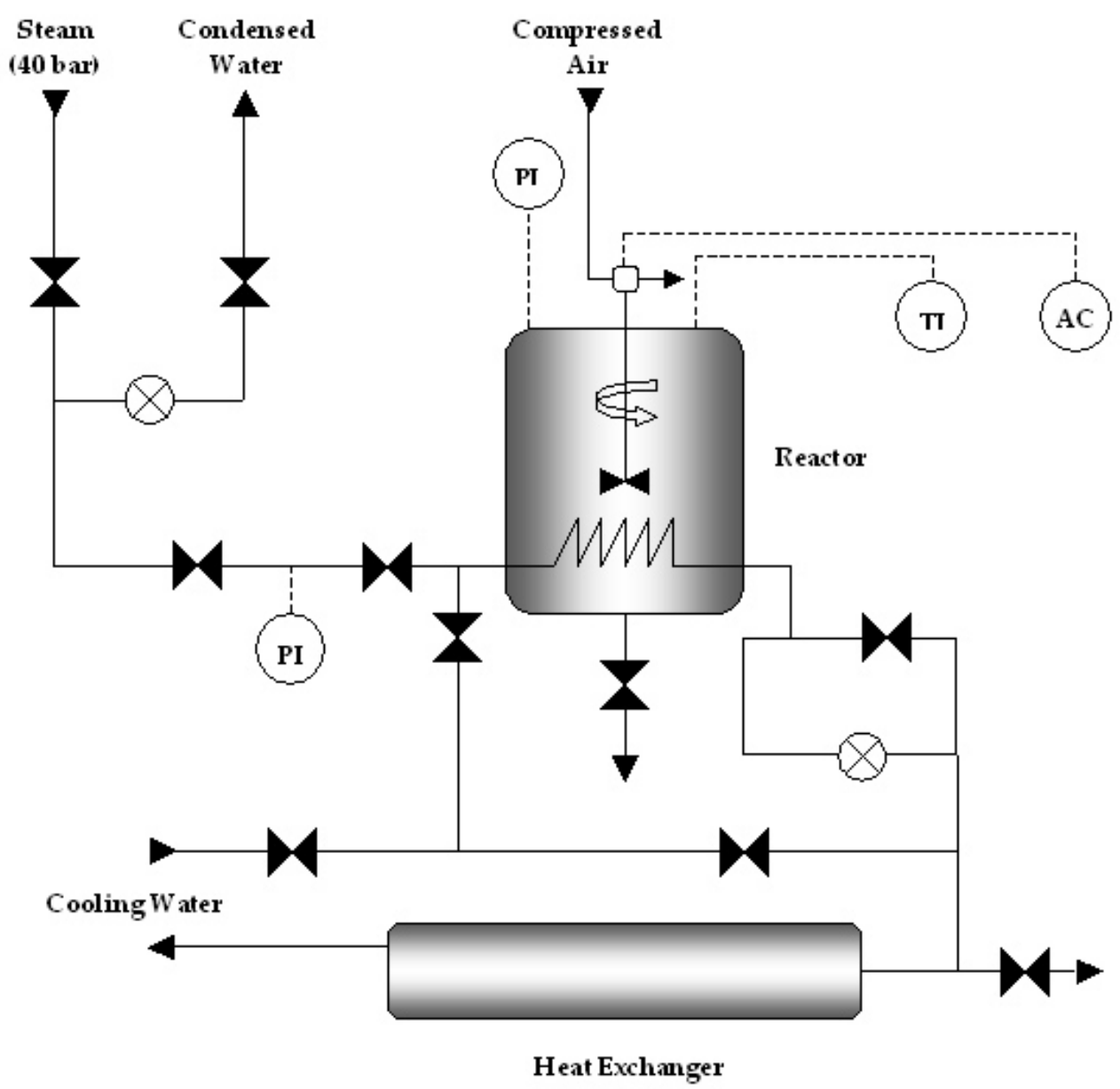

Figure 2.3. Scheme of the $10 \mathrm{~L}$ reactor system. Previous page: Pictures of the reactor system.

\subsubsection{Analysis of the samples}

\subsubsection{Analysis of the raw materials}

Samples of corncobs (CC), wheat straw (WS), barley straw (BS), rice husks (RH) and olive stones (OS) were collected in the northeast of Spain. Almond shells (AS) were purchased from MIMSA S.A. (Lleida, Spain). The samples of CC, WS, BS and RH were milled to pass through a $1 \mathrm{~mm}$ screen, while OS and AS were milled and sieved to 300 $\mathrm{mm}$.

The moisture content of the raw materials was determined by the standard method 2.5.2. The ash content in the original, non-extracted material was measured by the ASTM D-1102-84 standard method (see section 2.5.1). The organic extractives were removed according to a modification of the ASTM D-1107-84 standard method (see 
section 2.5.3). The samples, now free of extractives were analyzed for carbohydrates, acetyl groups and klason lignin (see section 2.5.4).

\subsubsection{Analysis of the solid residue obtained after the reaction}

The solid residues that remain after the autohydrolysis reaction were dried and weighted to determine the solubilized portion, and then were analyzed for its content of carbohydrates and acetyl groups by HPLC, and Klason lignin by gravimetry (see section 2.5.4). The calculation procedure used for quantification is described below.

The percentage of solubilized solid after the autohydrolysis reaction (SB) was calculated following Equation 2.1, where DS is the mass of original dry solid (g) and DSR is the mass of dry solid remaining after hydrolysis (g).

$$
S B=\left[\frac{D S-D S R}{D S}\right] \cdot 100
$$

The cellulose and lignin content were calculated in two different ways: as function of the original dry solid (Equation 2.2), and as function of the original component in raw material (Equation 2.3). SOL_OMi corresponds to the $\mathrm{wt} \%$ of component $\mathrm{i}$ in the hydrolyzed solid, based on $100 \mathrm{~g}$ of original dry material; SB is the $w t \%$ of solubilized solid; SOL_OC i is the $w t \%$ of component $i$ in the hydrolyzed solid, based on $\%$ of component $\mathrm{i}$ in raw material; SOL_RAW $\mathrm{is}$ the $\mathrm{w} \mathrm{t} \%$ of component $\mathrm{i}$ in raw material. COMP is the mass of component $\mathrm{i}(\mathrm{g})$ in dry basis obtained by HPLC analysis in the case of glucose and by weight in the case of Klason lignin.

$$
\begin{aligned}
& S O L_{-} O M_{i}=\left[\frac{C O M P_{i}}{S}\right] \cdot(100-S B) \\
& S O L_{-} O C_{i}=\frac{S O L_{-} O M_{i}}{S O L_{-} R A W_{i}} \cdot 100
\end{aligned}
$$

In the case of xylan, it was calculated separately for each component (xylose, arabinose and acetic acid). Equation 2.4 was used to calculate the xylan composition as percentage of original dry solid, and Equation 2.5 was used to calculate the xylan composition as $\mathrm{wt} \%$ of the xylan in raw material. Equation 2.6 allows to calculate the total xylan remaining in the solid based on original xylan in the raw material, as sum of 
their components. Equation 2.7 represents the composition (in percentage of each component) of the xylan that remains in the solid.

$$
\begin{aligned}
& X Y L_{-} O M_{i}=\frac{C O M P_{i}}{S} \cdot(100-S B) \\
& X Y L_{-} O X_{i}=\frac{X Y L_{-} O M_{i}}{S O L_{-} R A W_{X y l a n}} \cdot 100 \\
& X Y L_{-} R E=\sum X Y L_{-} O X_{i} \\
& X Y L_{-} R E_{-} C O M P_{i}=\frac{X Y L_{-} O M_{i}}{\sum X Y L_{-} O M_{i}} \cdot 100
\end{aligned}
$$

In these equations, $\mathrm{XYL}$ _OMi is the $w \mathrm{t} \%$ of component $\mathrm{i}$ (xylose, arabinose or acetic acid) in the hydrolyzed solid, based on $100 \mathrm{~g}$ of original dry material; XYL_OX $\mathrm{X}_{\mathrm{i}}$ is the $\mathrm{wt} \%$ of component $\mathrm{i}$ (xylose, arabinose or acetic acid) in the hydrolyzed solid, based on original xylan; XYL_RE is the total xylan remaining in the hydrolyzed solid based on original xylan; XYL_RE_COMP is the $w t \%$ of component $\mathrm{i}$ (xylose, arabinose or acetic acid) in the xylan remaining in the hydrolyzed solid, and SOL_RAW is the wt $\%$ of component $i$ in raw material calculated as a sum of the corresponding percentages of xylose, arabinose and acetic acid.

\subsubsection{Analysis of the autohydrolysis liquor}

The volume of the liquid phase (sample + washings) obtained after the autohydrolysis reaction and the final $\mathrm{pH}$ of the mixture were measured. A sample of the liquid product was analyzed by HPLC directly to quantify the free monosaccharides, acetic acid, furfural and HMF, and by GPC to determine the molar mass distribution of the xylo-oligosaccharides formed during autohydrolysis. Another sample was analyzed by posthydrolysis (see section 2.5.6.1) to convert XOs to their constitutive monomers, and then it was analyzed by HPLC to quantify the total amount of XOs in the liquid product.

The amount of each component (xylose, arabinose and acetic acid) in xylooligosaccharides was calculated with Equation 2.8 as percentage of original material and with Equation 2.9 as percentage of original xylan. The total yield of xylooligosaccharides was calculated as a sum of xylose, arabinose and acetyl groups with 
Equation 2.10. OLIG_OMi corresponds to the wt\% of component i (xylose, arabinose or acetic acid) that form part of xylo-oligosaccharides, based on $100 \mathrm{~g}$ of original dry material; OLIG_OX $\mathrm{i}$ is the wt\% of component $\mathrm{i}$ (xylose, arabinose or acetic acid) that form part of xylo-oligosaccharides, based on original xylan; OLIG_TOT is the total amount of xylo-oligosaccharides based on original xylan; DS is the mass of original dry solid $(\mathrm{g})$; COMP $\mathrm{i}$ is the mass of component $\mathrm{i}(\mathrm{g})$ in dry basis obtained by HPLC analysis for glucose, xylose, arabinose and acetic acid, and SOL_RAW is the wt\% of component $\mathrm{i}$ in raw material calculated as a sum of the corresponding percentages of xylose, arabinose and acetic acid.

$$
\begin{aligned}
& O L I G_{-} O M_{i}=\frac{C O M P_{i \text { posthydrolysis }}-C O M P_{\text {ihydrolysis }}}{D S} \cdot 100 \\
& O L I G_{-} O X_{i}=\frac{O L I G_{-} O M_{i}}{S O L_{-} R A W_{\text {Xylan }}} \cdot 100 \\
& O L I G_{-} \text {TOT }=\sum O L I G_{-} O X_{i}
\end{aligned}
$$

The composition of xylo-oligosaccharides in percentage for each component was calculated with Equation 2.11, where OLIG_COMPi represents the composition of oligosaccharides in $\mathrm{wt} \%$ (for xylose, arabinose and acetic acid).

$$
O L I G_{-} \mathrm{COMP}_{i}=\frac{O L I G_{-} O X_{i}}{O L I G_{-} \mathrm{TOT}} \cdot 100
$$

The monomers and its degradation products presents in hydrolysis liquor were calculated as percentage of original material with Equation 2.12. In the case of xylose, arabinose, acetic acid and furfural, their percentage was calculated as $w \mathrm{t} \%$ of original xylan using Equation 2.13. In the case of glucose and HMF they were calculated as $\mathrm{wt} \%$ of original glucose using Equation 2.14. MON_OC $\mathrm{i}_{\mathrm{i}}$ is the $\mathrm{w} t \%$ of monomers presents in the autohydrolysis liquor (glucose and HMF), based on original cellulose; MON_OMi corresponds to the $\mathrm{wt} \%$ of monomers presents in the autohydrolysis liquor (glucose, xylose, arabinose) and furfural, acetic acid, and HMF, based on $100 \mathrm{~g}$ of original dry material, and MON_OX $\mathrm{X}_{\mathrm{i}}$ is the $\mathrm{wt} \%$ of monomers presents in the autohydrolysis liquor (xylose, arabinose and acetic acid), based on the original xylan. DS is the mass of original dry solid $(\mathrm{g})$; $\mathrm{COMP}_{\mathrm{i}}$ is the mass of component $\mathrm{i}(\mathrm{g})$ in dry basis obtained by 
HPLC analysis for glucose, xylose, arabinose, acetic acid, furfural and HMF, and SOL_RAW is the $w t \%$ of component $i$ in raw material.

$$
\begin{aligned}
& M O N_{-} O M_{i}=\frac{C O M P_{i h y d r o l y s i s}}{D S} \cdot 100 \\
& M O N_{-} O X_{i}=\frac{M O N_{-} O M_{i}}{S O L_{-} R A W_{\text {Xylan }}} \cdot 100 \\
& M O N_{-} O C_{i}=\frac{M O N_{-} O M_{i}}{S O L_{-} R A W_{\text {Cellulose }}} \cdot 100
\end{aligned}
$$

\subsection{PURIFICATION OF THE XYLO-OLIGOSACCHARIDES}

Besides of the autohydrolysis reaction and its effect on the xylo-oligosaccharides obtained, the second step was to test several purification and recovery methods to determine their effects in the product obtained. In this way, several methods were studied: the separation using polymeric membranes, the adsorption using activated carbons, the precipitation with ethanol, and the enzymatic membrane reactors (EMRs).

\subsubsection{Ultrafiltration using polymeric membranes}

\subsubsection{Retention of impurities and separation of different molecular weight fractions}

The polymeric membranes were tested to eliminate low molecular weight material and/or to separate different molecular weight fractions of xylooligosaccharides. Ultrafiltration experiments were carried out using flat sheet polymeric membranes with different molecular weight cut off (MWCO). The xylooligosaccharides used for the experiment were obtained by autohydrolysis (at $179^{\circ} \mathrm{C}$ and 29 min of reaction) of almond shells in the $10 \mathrm{~L}$ reactor and after that they were recovered by spray drying process. The samples of the recovered xylo-oligosaccharides were dissolved in deionized water at a concentration of $20 \mathrm{~g} / \mathrm{L}$, which is close to the typical xylo-oligosaccharides concentration in the autohydrolysis liquor. Around 0.1 $\mathrm{g} / \mathrm{L}$ of sodium azide $\left(\mathrm{NaN}_{3}\right)$ was added to prevent the growth of microorganisms 
during the filtration tests. $2 \mathrm{~L}$ of solution were prepared and used for each experiment. The ultrafiltration was studied in the bench-scale unit schematized in Figure 2.4.

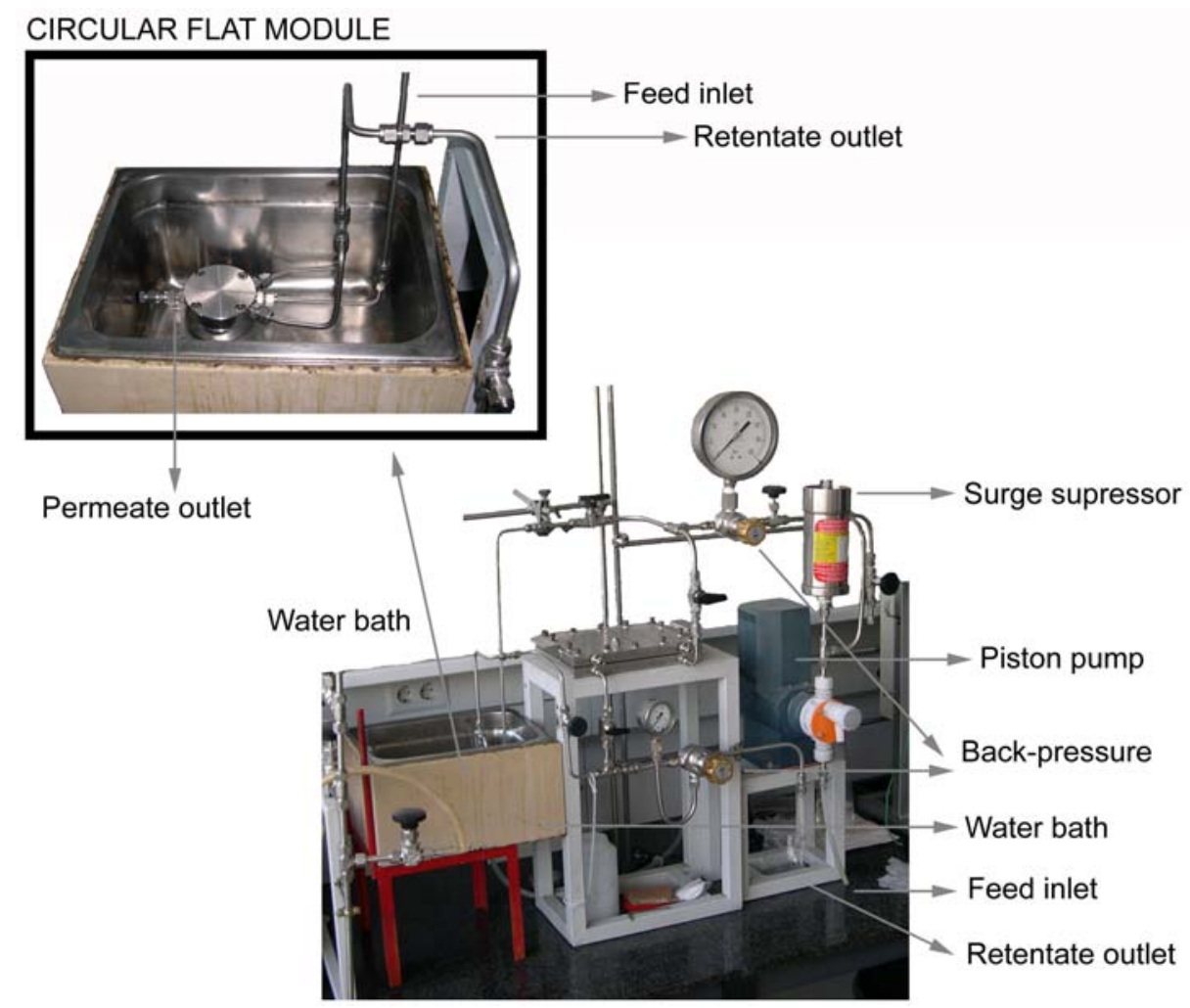

Figure 2.4. Equipment used for the membrane separation process.

The flat-sheet samples of the G-series thin-film ultrafiltration membranes with different molecular weight cut-off (MWCO) were provided by Osmonics (USA), with the corresponding MWCO: GE (1.0 kDa), GH (2.5 kDa), GK (3.5 kDa) and GM (8.0 $\mathrm{kDa}$ ). These membranes have applications in chemical purification, color and TOC reduction, process-stream separations, and oil-water separation. Prior to utilization, the membranes were cut to the size appropriated for the operation and soaked in demineralized water.

The flat-sheet membranes were first tested individually on a high-pressure cell $\left(1.257 \cdot 10^{-3} \mathrm{~m}^{2}\right.$ of effective membrane area, see Figure 2.5$)$. First of all, they were tested using deionized water to determine the fluxes of water and calculate the permeability of the membrane. A pulse pump (Prominent Vario, Prominent, Germany) with a flow of $28 \mathrm{~L} / \mathrm{h}$ was used, combined with a surge suppressor (Hidracar, Spain) to eliminate the pulse effects. The trans-membrane differential pressure was adjusted at 2.6 to 9 bar 
by means of a back-pressure regulator (Veriflo, Parker, USA), and after the system reached a stable state the flux of water was measured. After that, the system was emptied and filled with the solution. Again the trans-membrane differential pressure was adjusted at 2.6 to 9 bar by means of a back-pressure regulator, but in this case the permeate was recycled to the feed tank during the experiment to maintain a constant volume and concentration of solute. Once the flux had stabilized, several samples of around $2.0 \mathrm{~mL}$ of filtrate and permeate were collected for further analysis. The samples were filtered through a $0.22 \mu \mathrm{m}$ filter, and were analyzed by GPC as described in the analytical procedures section. All experiments were performed at a fluid temperature of $25 \pm 1^{\circ} \mathrm{C}$, which was maintained by circulating water from a thermostatic bath through the jacket of the feed reservoir.
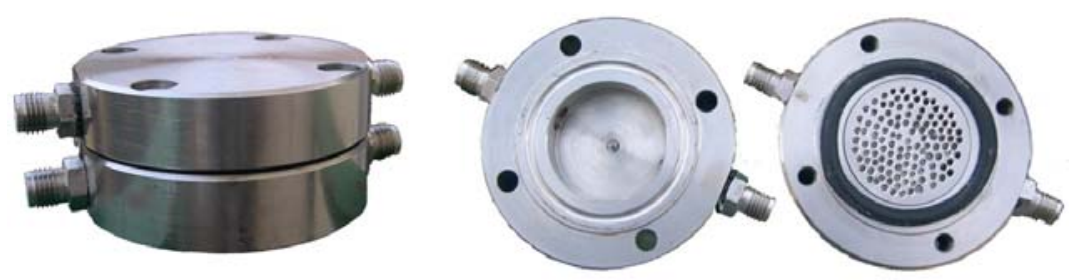

Figure 2.5. Module used for the separation using polymeric membranes.

\subsubsection{Fouling experiments}

For the experiments dealing with membranes fouling, the GE membrane (1 kDa in MWCO) was tested. The solution of xylo-oligosaccharides was prepared in the same way as before. In this case again the membrane was tested with deionized water to determine the original permeability. The pressure was adjusted at 5 bar and the temperature was maintained at $25 \pm 1{ }^{\circ} \mathrm{C}$. After the measurements, the system was emptied and filled again with the solution, and the conditions of temperature and pressure were set as before. Because of the flux of permeate was low, it was collected and weighted in a scale throughout all the experiment, and the time was registered. Fractions of permeate ( $5 \mathrm{~g}$ each) were collected and further analyzed as described in the analytical procedures section. The experiment was carried out for 5 hours. After this time the system was emptied, washed slightly with deionized water, and the permeability of the membrane was checked again by measuring the new permeate flux of water at the same conditions. 
The selectivity of the membrane was defined as the relationship between the dimensionless concentrations of lignin products and xylo-oligosaccharides in the permeate according to Equation 2.15, where CLP-feed and Cxo-feed are the total concentrations of lignin-related products and XOs in the feed and $\mathrm{C}_{\mathrm{LP}}$ and $\mathrm{CxO}_{\mathrm{O}}$ are their concentrations in the permeate. Rejection curves were calculated from the GPC elugrams of the xylo-oligosaccharides collected at the lowest flux of permeate by Equation 2.16, where Robs, $\mathrm{M}$ is the retention for a xylo-oligomer with a molar mass of $\mathrm{M}$, and $\mathrm{CXO}-$ feed,M and $\mathrm{CXO}, \mathrm{M}$ are its concentration in the feed and permeate, respectively.

$$
\begin{aligned}
& S_{L P / C H}=\frac{\left(C_{L P} / C_{L P-F e e d}\right)}{\left(C_{X O} / C_{X O-\text { feed }}\right)} \\
& R_{o b s, M}=1-\frac{C_{X O, M}}{C_{X O-\text { feed }, M}}
\end{aligned}
$$

\subsubsection{Adsorption on activated carbon}

For the purification of the xylo-oligosaccharides three samples of commercial activated carbons (NORIT, Netherlands) were tested: ROX 0.8 (AC-1), PAC200 (AC-2) and Darco 12x40 (AC-3). ROX 0.8 is an extruded granular activated carbon used for decoloring starch hydrolyzates and sugars. PAC200 is a powdered carbon used for removing taste, odor and color from water and industrial process applications. The $12 \times 40$ carbon is a general-purpose granular carbon grade used in a variety of applications including purification of fine chemicals and food. The xylooligosaccharides used for the experiments were obtained by autohydrolysis (at $179^{\circ} \mathrm{C}$ and 29 min of reaction) of almond shells in the $10 \mathrm{~L}$ reactor. Two kinds of experiments were made, being the first one the equilibrium experiments to determine the equilibrium adsorption for the different carbons tested. In this case, the xylooligosaccharides after the autohydrolysis reaction were dried by spray-drying process, and after that dissolved in a known concentration for the experiments. For the second type of experiments, only one carbon was chosen to test it in a middle scale column, and the xylo-oligosaccharides solution was used directly as it comes from the reactor. The retention of the lignin-derived impurities was related to the characteristics of the carbon used, and also to the possibility that they are covalently bounded to xylooligosaccharides molecules. 


\subsubsection{Equilibrium tests}

For the equilibrium experiments, ROX 0.8 and Darco $12 \times 40$ were grounded and sieved to $0.2 \mathrm{~mm}$, while PAC 200 was used directly. In the column tests, all carbons were used as received. The surface characteristics of the carbons were determined in samples of pulverized carbon according to the methods detailed in the analytical methods section.

Adsorption equilibrium was measured in a batch system. A sample of the xylooligosaccharides recovered by spray drying was dissolved in deionized water at a concentration of $20 \mathrm{~g} / \mathrm{L}$. Samples of $10 \mathrm{~mL}$ of this solution were placed in $20 \mathrm{~mL}$ test tubes and the activated carbon was added, in amounts that varied from 15 to $500 \mathrm{mg}$. The tubes were capped and placed in a water bath at $30^{\circ} \mathrm{C}$, attached perpendicularly with clamps to a horizontal revolving shaft that had a rotating speed of $2 \mathrm{rpm}$. After 24 $\mathrm{h}$ the tubes were removed from the bath and the mixture was centrifuged at $4000 \mathrm{rpm}$ for $20 \mathrm{~min}$ to separate the activated carbon. A sample of the supernatant liquid was filtered through a $0.22 \mu \mathrm{m}$ nylon syringe filter, placed in an encapsulated vial and stored at $5^{\circ} \mathrm{C}$ until by HPLC/ GPC as described in the analytical procedures section below.

\subsubsection{Adsorption on activated carbon in a column}

Column tests were performed at room temperature $\left(21 \pm 1^{\circ} \mathrm{C}\right)$ using around $22 \mathrm{~g}$ of granular activated carbon (ROX 0.8) packed on a $55 \mathrm{~mL}$ column (20 mm inner diameter x $180 \mathrm{~mm}$ length), made of metacrylate tube and PVC fittings. This carbon was selected because of its slightly better selectivity toward lignin adsorption and because it was readily available in granular form and more suitable for column packing than AC-2 and AC-3. The latter contained fines and caused problems during operation due to the entrainment of carbon particles and because it led to larger pressure drops across the bed.

Activated carbon was submerged in boiling water for $15 \mathrm{~min}$ to remove air and fine particles and then extracted and poured into the column, which had previously been filled with water to avoid entrapping air in the carbon bed. The column had wire mesh plates at both ends to prevent the entrainment of carbon particles and was operated in up flow mode to reduce channeling. In this case it was used a second batch of xylo-oligosaccharides solution that was prepared by autohydrolysis reaction (having 
a total concentration of solids of $35.2 \mathrm{~g} / \mathrm{L}$ ) and it was used directly as it comes from the reactor. The solution was fed at $6 \mathrm{~mL} / \mathrm{min}$ with a Watson-Marlow 313F peristaltic pump (Watson-Marlow Bredel, USA), which led to a residence time of $0.15 \mathrm{~h}$. At the end of the experiment the feed stream was switched to deionized water for $1 \mathrm{~h}$ to clean the column. The product was collected in four fractions - from 0 to $2 \mathrm{~h}$ ( $1^{\text {st }}$ fraction, 13.1 bed volumes), from 2 to $4 \mathrm{~h}$ ( $2^{\text {nd }}$ fraction, 26.2 bed volumes), from 4 to $5.5 \mathrm{~h}$ ( $3^{\text {rd }}$ fraction, 36 bed volumes), and the washing solution- and the dissolved solids in each fraction were recovered by lyophilization. Also, samples of $2 \mathrm{~mL}$ were withdrawn from the outlet stream throughout the experiment, filtered through a $0.22 \mu \mathrm{m}$ nylon filter, and analyzed by GPC/HPLC to determine the instantaneous composition of the product stream, as described in the analytical procedures section.

\subsubsection{Characterization of the activated carbon}

The characterization of the activated carbon was made by courtesy of Mrs. Vannessa Torné and Dr. Vannessa Fierro (Wood Biopolymers Group, Universitat Rovira i Virgili, Spain). The surface area and porosity of the activated carbons were determined from their nitrogen adsorption-desorption isotherms obtained at $77 \mathrm{~K}$ in an ASAP 2020 surface analyzer (Micromeritics, USA). The samples were previously degassed at $523 \mathrm{~K}$ for several hours. $\mathrm{N}_{2}$ adsorption data for $P / P_{0}$ from $10^{-5}$ to 0.99 were analyzed according to (i) the BET method [2] for calculating the specific surface area, $S_{\text {BET }}$ and (ii) the $\alpha$ s method [3] using Carbopack F Graphitized Carbon Black as reference material to calculate the ultramicromicropore volume [4] (pore diameter < $0.8 \mathrm{~nm}), \mathrm{V}_{\alpha, \text { umic. }}$ The total pore volume, $\mathrm{V}_{0.99}$, was calculated from nitrogen adsorption at a relative pressure of 0.99 . The average pore diameter was calculated from the total pore volume and the surface area using Equation 2.17.

$$
\bar{d}_{p}=4 \frac{V_{0.99}}{S_{B E T}}
$$

The point of zero charge (PZC) was determined by mass titration [5]. Various amounts of activated carbon were added to a $10 \mathrm{~mL}$ solution of $0.1 \mathrm{M} \mathrm{NaCl}$ to obtain mixtures with $0.05,0.1,0.5,1.0$, and $10 \%$ of carbon by weight. The bottles were sealed to eliminate any contact with air and stirred overnight. The equilibrium $\mathrm{pHs}$ of the suspensions were measured after $24 \mathrm{~h}$ of contact time. The PZC value of the activated carbon was taken as the equilibrium $\mathrm{pH}$ of the suspension with the highest 
concentration of carbon when the change in $\mathrm{pH}$ with carbon concentration was low. Methylene Blue $\left(\mathrm{C}_{16} \mathrm{H}_{18} \mathrm{ClN}_{3} \mathrm{~S} \cdot 2 \mathrm{H}_{2} \mathrm{O}, \mathrm{MB}\right)$ serves as a model compound for checking the adsorption of medium size organic molecules from aqueous solutions. A $50 \mathrm{~mL}$ portion of a $3.2 \mathrm{mM}$ solution of MB (Scharlau Chemie, SPAIN) and approximately $50 \mathrm{mg}$ of activated carbon were used in adsorption experiments. The solutions were stirred overnight and filtered to remove the activated carbon in suspension before analysis. The equilibrium concentration of $\mathrm{MB}$ in the solution was measured by spectrophotometry at $664.8 \mathrm{~nm}$ in a Dinko Instruments 8500 spectrometer (Dinko Instruments, SPAIN). The amount adsorbed was calculated from the change in concentration of the solution. The iodine number was provided by NORIT. The oxygenated acid surface groups were determined according to the method of Boehm [6], and the basic groups were determined by titration with hydrochloric acid. A $25 \mathrm{mg}$ portion of carbon was mixed with $25 \mathrm{~mL}$ of each of the following solutions: $0.1 \mathrm{~N}$ sodium hydroxide, $0.1 \mathrm{~N}$ sodium carbonate, $0.1 \mathrm{~N}$ sodium bicarbonate, $0.1 \mathrm{~N}$ sodium ethoxide and $0.05 \mathrm{~N}$ hydrochloric acid. The vials were sealed and stirred for $48 \mathrm{~h}$, and the solutions were filtered. Samples of $5 \mathrm{~mL}$ were taken, and they were titrated with $0.05 \mathrm{~N} \mathrm{HCl}$ or $0.1 \mathrm{~N} \mathrm{NaOH}$ to determine the excess of base or acid, respectively. The number of acidic sites of each type was calculated under the assumptions that sodium ethoxide neutralize all the acidic groups (i.e., the carboxylic, phenolic, lactonic and carbonyl groups), that $\mathrm{NaOH}$ neutralizes the carboxylic, phenolic, and lactonic groups, $\mathrm{Na}_{2} \mathrm{CO}_{3}$ neutralizes the carboxylic and lactonic groups, and that $\mathrm{NaHCO}_{3}$ neutralizes only the carboxylic groups. The number of surface basic sites was calculated from the amount of $\mathrm{HCl}$ consumed by the activated carbon.

\subsubsection{Precipitation with a non solvent}

Alcoholic precipitation was applied to several samples of xylo-oligosaccharides solutions obtained by autohydrolysis of corncobs and almond shells at small scale. The precipitation was carried out with ethanol addition (96\%, Panreac). An aliquot of the liquid product $(1 \mathrm{~mL})$ was taken and mixed with $7 \mathrm{~mL}$ of ethanol. The mixture was centrifuged at $4000 \mathrm{rpm}$ for $5 \mathrm{~min}$ and the liquid was decanted. The precipitate was washed with ethanol, centrifuged again in the same conditions, and dried under vacuum at room temperature. The powder recovered was weighted, dissolved in deionized water and a sample was taken and analyzed by GPC as described in the analytical methods section. The yield of precipitated oligosaccharides is calculated 
with Equation 2.18 as function of original dry material and with Equation 2.19 as function of original xylan,

$$
\begin{aligned}
& \text { PREC_OM }=\frac{P O}{D S} \cdot 100 \\
& P R E C_{-} O X=\frac{P R E C_{-} O M}{S O L_{-} R A W_{X y l a n}} \cdot 100
\end{aligned}
$$

where PREC_OM is the yield of precipitated oligosaccharides based on $100 \mathrm{~g}$ of original dry material, PREC_OX is the yield of precipitated oligosaccharides based on original xylan, DS is the mass of dry solid (g), PO is the mass of oligosaccharides precipitated (g), and SOL_RAW is the \% of component $\mathrm{i}$ in xylan, which is calculated as a sum of the corresponding percentages of xylose, arabinose and acetic acid in raw material.

The percentage of lignin present in precipitated oligosaccharides is calculated with Equation 2.20,

$$
L O=\frac{B}{P O / V} \cdot 100
$$

where $B$ is the concentration of lignin obtained by spectrophotometry $(\mathrm{g} / \mathrm{L}), \mathrm{PO}$ is the mass of oligosaccharides precipitated $(\mathrm{g})$, and $\mathrm{V}$ the dilution volume (L).

\subsubsection{Enzymatic membrane reactors}

The term Enzymatic Membrane Reactors (EMRs) means that the hydrolytic reaction and purification step are combined in a single unit. For this purpose, a membrane with an enzyme adsorbed on it was tested for the hydrolysis and continuous separation of dextrans.

The enzymatic membrane reactors (EMRs) were obtained from home-made precursor polymeric membranes, synthesized from $15 \% \mathrm{w} / \mathrm{w}$ polysulfone (PSf) in dimethyl formamide (DMF) as solvent, and water in the coagulation bath (non solvent), by courtesy of Dr. Carles Torras (Wood Biopolymers Group, Universitat Rovira I Virgili, Spain). The enzyme (purchased from Sigma Aldrich, commercial 
dextranase) was adsorbed on a commercial activated carbon (Norit Darco 12x40, with a superficial area of $650 \mathrm{~m}^{2} / \mathrm{g}$ and total pore volume of $0.93 \mathrm{~mL} / \mathrm{g}$ ). For the adsorption experiments, several ratios enzyme/carbon $(1,2,3,5$ and $10 \mathrm{~mL}$ of enzyme in $10 \mathrm{~mL}$ of total solution and $50 \mathrm{mg}$ of carbon) at three different $\mathrm{pHs}(3,5$ and 7$)$, were tested to determine the maximum amount of enzyme adsorbed. The amount of enzyme adsorbed was checked by Elemental Analysis. The activity of the enzyme before and after the adsorption process was tested by analyzing samples of hydrolyzed dextrans (MW 40 kD, Sigma Aldrich) by GPC as indicated in section 2.5.16.2.

The complex enzyme - carbon was added into the polymeric solution. In a first stage of the work, two membrane layers, physically joined, were used to perform the reaction and the separation. The first layer corresponded to the composite membrane containing the enzyme described before. The second layer was a commercial membrane (Osmonics GE Series, MWCO $1 \mathrm{kDa}, 2.5 \mathrm{kDa}$ and $8 \mathrm{kDa}$ ). The experimental device used was the same described for the experiments with polymeric membranes (see Figure 2.4 and 2.5). A pulse pump with a flow of $28 \mathrm{~L} / \mathrm{h}$ was used, combined with a surge suppressor used to eliminate the pulse effects. A back pressure controller was used to maintain the trans-membrane pressure constant at 2 bar. The circular flatmembrane module, housing the EMR, was immersed in a water bath and maintained at $50^{\circ} \mathrm{C}$ to ensure the optimal temperature for the enzyme activity at the EMR. A solution of dextran $(40 \mathrm{kDa})$ at a concentration $1.5 \mathrm{~g} / \mathrm{L}$ was fed to test the functioning of the EMR. Samples of the retentate and the permeate were collected and analyzed by GPC as described in section 2.5.16.2.

\subsection{RECOVERY OF THE XOS}

\subsubsection{Spray-drying}

The autohydrolysis liquor coming from the $10 \mathrm{~L}$ reactor was processed by spraydrying to recover the xylo-oligosaccharides in powder form. The equipment used was an were dried by atomization using a Büchi Mini Spray Dryer B-290 (see Figure 2.6.) (purchased from Masso Analítica, Barcelona, Spain).

The air flow rate in the atomizer nozzle was $473 \mathrm{~L} / \mathrm{h}$, and the liquid flow was 8 $\mathrm{mL} / \mathrm{min}$. The drying air stream has a flow of $38 \mathrm{~m}^{3} / \mathrm{h}$ with an inlet and outlet 
temperature of $150^{\circ} \mathrm{C}$ and $85^{\circ} \mathrm{C}$ respectively. This procedure removed water and most of the volatile impurities, like furfural and acetic acid, leaving dry xylooligosaccharides that still contained all non-volatile impurities, like monosaccharides, organic extractives, lignin-derived phenolics and inorganic salts.
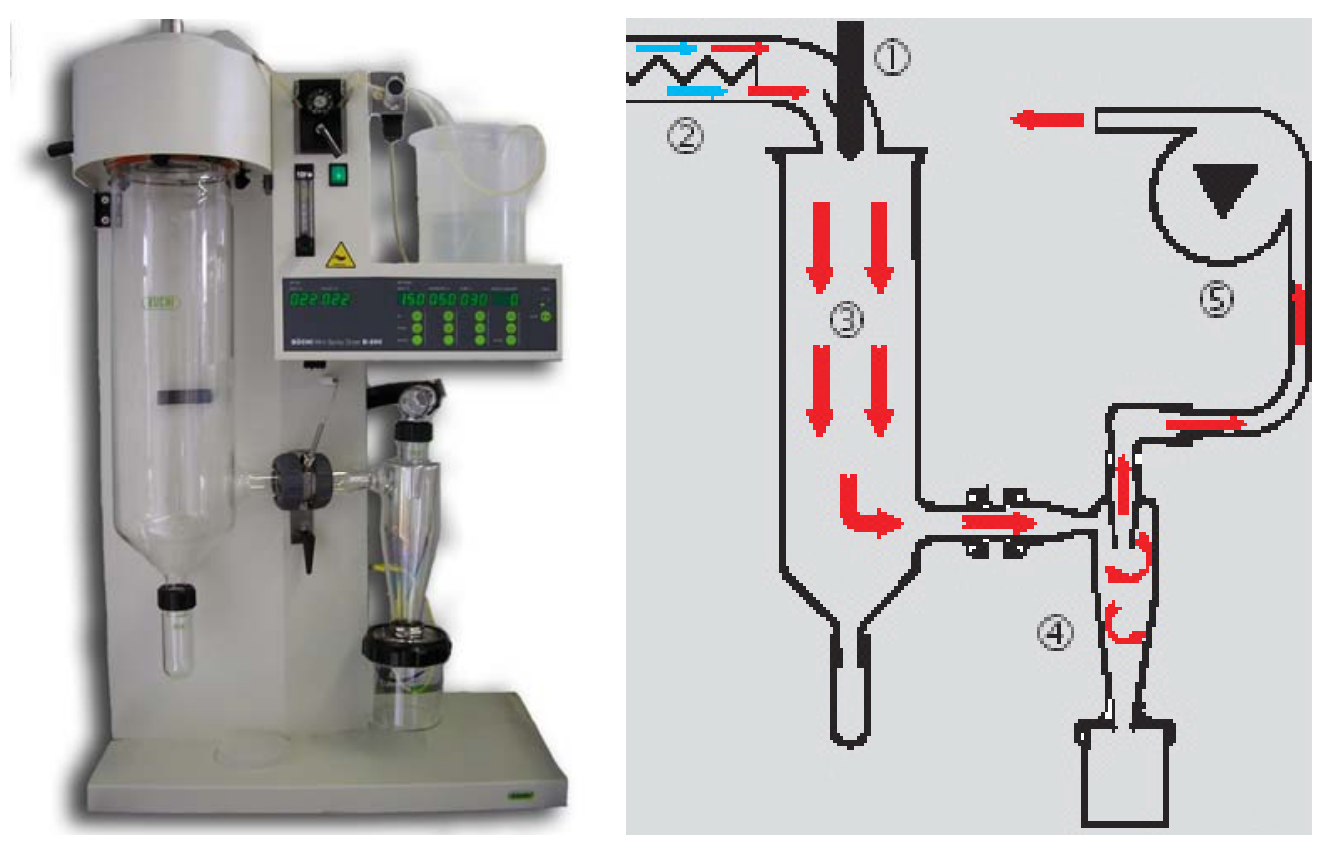

Figure 2.6. Left. Spray drying equipment. Right. Scheme of the spray drying process (from Büchi): 1. Dispersion of the liquid into small drops; 2. Heating of the desiccant air; 3. Drying of the drops and obtention of the solid particles; 4 . Separation of the particles in the cyclone; 5. Aspirator.

\subsubsection{Lyophilization}

Samples of the liquor containing xylo-oligosaccharides were also dried by lyophilization process using an Armfield Lyophilization Equipment (purchased from Prodel S.A., Madrid, Spain), equipped with a high vacuum pump JAVAC (Brook Crompton Betts Pty.) (see Figure 2.7).

The lyophilization process was used mainly when the amount of sample was small, and to compare with the recovery with the spray drying process. The conditions used were a vacuum pressure of $0.5 \mathrm{mbar}$ and a temperature of $-40^{\circ} \mathrm{C}$. 


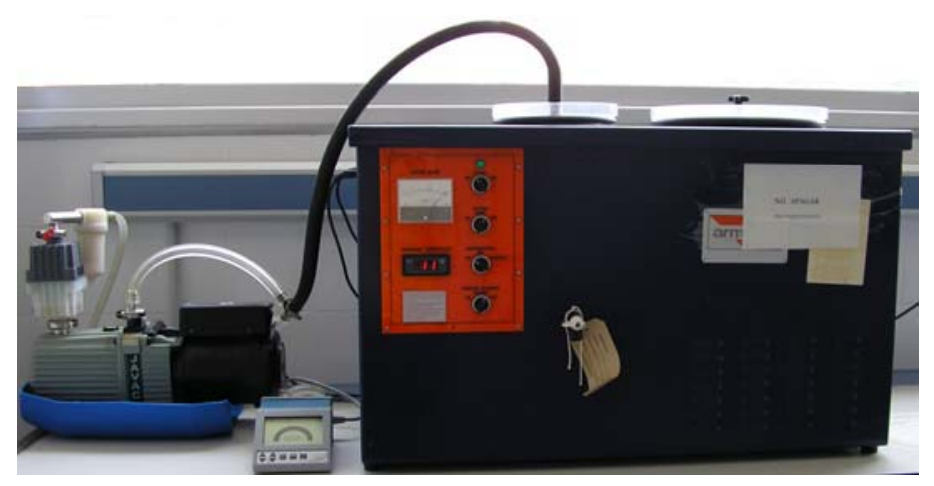

Figure 2.7. Lyophilization equipment.

\subsection{PREPARATIVE PROCEDURES}

Some procedures were required to prepare the samples for certain analytical techniques, like the dialysis prior to NMR analysis or purification with the Amberlite XAD - 2 resin for the identification of phenolics. The experiments described in Sections 2.4.2. for the preparative procedures, and in Sections 2.5.7., 2.5.9.2., 2.5.11., 2.5.12., and 2.5.13. for the analytical methods were carried out in the Institute of Chemistry, Slovak Academy of Sciences, Bratislava, Slovakia.

\subsubsection{Dialysis process used for purification of SXOs}

Dialysis was used to purify the XOs from salts, ions, and low molecular weight material. The spray-dried XOs samples (SXOs) were purified by dialysis to prepare them for the NMR analysis. Solutions of SXOs in deionized water at concentrations 20 $\mathrm{g} / \mathrm{L}$ with CC and AS and $40 \mathrm{~g} / \mathrm{L}$ with OS, WS, BS and RH, were exhaustively dialyzed using a cellulose membrane (estimated MWCO of $12.4 \mathrm{kDa}$, Sigma Aldrich) (see Figure 2.8). The retentate obtained was recovered by lyophilization yielding samples of dialyzed xylo-oligosaccharides (DXOs), which were further analyzed by GPC and NMR. The permeate was collected and concentrated under vacuum in a rotavapour system at temperature below $40^{\circ} \mathrm{C}$, and after that was lyophilized to recover the low molecular weight material in solid form. 


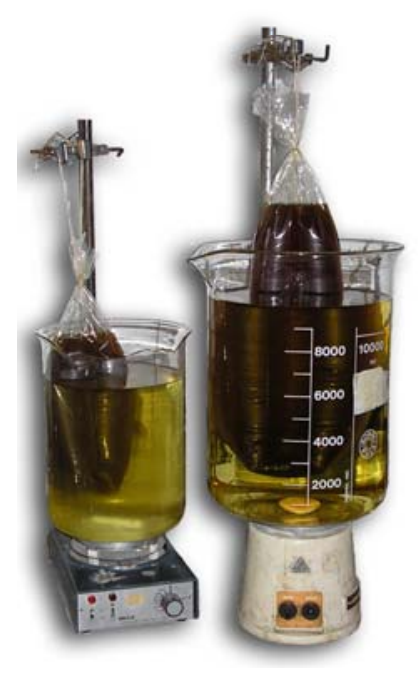

Figure 2.8. Dialysis process used for purification of xylo-oligosaccharides.

For the preparation of the dialysis bag, the dialysis tubing was cut for the desired volume, filled with distilled water and washed, and after that filled with the solution. The bag is placed in a recipient with distilled water. The retentate remained inside the bag, and the low molecular weight material (ions, salts, and other compounds) diffused to the water outside the bag. To control the progress of the dialysis, the water was changed after $24 \mathrm{~h}$, and the conductivity of the diffusate was measured. The process was repeated until the conductivity remained constant and near to that of original water.

\subsubsection{Purification with Amberlite XAD - 2 resin}

The resin used was Amberlite XAD - 2 (purchased from Supelco). This kind of resin is a polymeric adsorbent, hydrophobic crosslinked polystyrene copolymer, supplied as $20-60$ mesh size white insoluble beads. The resin is widely used to adsorb soluble organic compounds from aqueous streams and organic solvents. This resin was used previously to separate impurities and purify xylo-oligosaccharides from phenolic compounds [7-9].

The process was made in batch form and the resin was washed with distilled water (3 times) under stirring in a beaker, in sufficient amount to form a bed volume of $50 \mathrm{~mL}$. The diffusate obtained after dialysis treatment of SXOs from corncobs was weighted and dissolved in $150 \mathrm{~mL}$ of distilled water. $20 \mathrm{~mL}$ of the solution was applied 
to the resin, stirred and decanted. The supernatant liquid was separated and collected. After that the resin was washed with water $(150 \mathrm{~mL})$, with a solution of $\mathrm{MeOH}:$ Water (50:50) $(150 \mathrm{~mL})$, and with $\mathrm{MeOH}(150 \mathrm{~mL})$. Each time the resin was washed under stirring, decanted, and the supernatant liquid was collected. An aliquot of each fraction was separated and dried under vacuum for quantification. After weighting, each fraction was dissolved in distilled water and analyzed by Paper Chromatography in both solvent systems (neutral and acidic one). The different fractions were also analyzed in a UV spectrometer to measure the global absorbance at $280 \mathrm{~nm}$ and 360 $\mathrm{nm}$. The absorbance of each fraction was compared with blank (water, in the first two cases, water-methanol (50:50) in the second case and methanol in the third). To compare and see the shift in the signal that indicates the presence of phenolic compounds, three drops of $10 \mathrm{wt} \% \mathrm{NaOH}$ were added to each solution, and the absorbance was measured again after $10 \mathrm{~min}$, and $2 \mathrm{~h}$ of reaction. In this case the same blanks were prepared adding also the drops of alkali.

The phenolic acid content was measured also after alkalinization. Some drops of $2 \mathrm{M} \mathrm{NaOH}$ were added to the fractions from water washing and from $\mathrm{MeOH}$ :Water (50:50) washing, until $\mathrm{pH}$ around 13, and the reaction proceeded at room temperature for $2 \mathrm{~h}$. After that, the reaction was stopped and the liquid was washed under stirring (2 times) with diethylether to separate the phenolics presents in solution. The system separated in two phases, and the fractions were collected and dried. The water part was dried under vacuum, and the residue was analyzed by Paper Chromatography to identify changes in sugar composition. The ether part was dried under flushing with $\mathrm{N}_{2}$, and the solid was analyzed by FTIR (Fourier Transformed Infrared Spectroscopy).

\subsection{ANALYTICAL METHODS}

\subsubsection{Ash content determination (ASTM D-1102-84)}

To determine the ash content, $2 \mathrm{~g}$ of the dried sample were put in a melting pot and heated at $600^{\circ} \mathrm{C}$ during $3-4 \mathrm{~h}$, after that cooled under vacuum and weighted. The process was repeated until obtain a constant weight. Triplicate analysis were performed. 


\subsubsection{Moisture content determination}

To determine the moisture content, the samples $\left(2 \mathrm{~g}\right.$ each) were dried at $105^{\circ} \mathrm{C}$ until constant weight. Triplicate analysis were performed.

\subsubsection{Removal of the organic extractives (ASTM D-1107-84 modified)}

The dried raw material was treated with a mixture of ethanol-toluene (according to a modification of the ASTM D-1107-84 standard method in which benzene is replaced by toluene), to remove the organic extractives.

The extraction was carried out in a Soxhlet extraction system. $3 / 4$ of the Soxhlet cartridges volume was filled with the dried samples, and the organic solution used for the extraction was a mixture ethanol/toluene $(1: 2 \mathrm{v} / \mathrm{v})$. The extraction was carried out overnight and then the cartridge was washed with $96 \%$ ethanol and dried in an oven at $105^{\circ} \mathrm{C}$. The extraction solvent was evaporated in an oven at $60^{\circ} \mathrm{C}$, and the extractive was also quantified. The raw material now free of extractives was analyzed by the Klason lignin analysis (see section 2.5.4).

\subsubsection{Determination of the Klason lignin (ASTM D 1106-84)}

The analysis was performed by quantitative hydrolysis of the solid in $72 \% \mathrm{H}_{2} \mathrm{SO}_{4}$. For this purpose, $0.3 \mathrm{~g}$ of the dry solid were put in a beaker and $3 \mathrm{~mL}$ of $24.1 \mathrm{~N} \mathrm{H}_{2} \mathrm{SO}_{4}$ were added, leaving it under manual stirring at $30^{\circ} \mathrm{C}$ during $60 \mathrm{~min}$. The solution was then diluted to $4 \% \mathrm{H}_{2} \mathrm{SO}_{4}$ (by adding $84 \mathrm{~mL}$ of deionized water) and the reaction continued at $120^{\circ} \mathrm{C}$ for $45 \mathrm{~min}$. Then the solution was cooled, filtered and the liquid was collected. The volume of the liquid was measured and a sample of this acidic solution was then filtered through a $0.22 \mu \mathrm{m}$ syringe filter and analyzed by HPLC as described below to determine the carbohydrates content. The solid was washed with deionized water until neutral $\mathrm{pH}$, dried at $105^{\circ} \mathrm{C}$ and weighted to determine the Klason lignin content. 


\subsubsection{Analysis of the XOs recovered}

The xylo-oligosaccharides recovered by spray-drying or lyophilization processes (SXOs) were analyzed to determine their sugar composition, ashes and lignin content. The analysis of the neutral sugar composition of the xylo-oligosaccharides obtained by spray-drying process samples was made by posthydrolysis of the dried sample (see section 2.5.6.2). The lignin associated to the SXOs was measured gravimetrically as acid-resistant lignin, and acid-soluble lignin was estimated by using the standard method (see section 2.5.8). The ash content in the SXOs samples was determined by standard procedure (see section 2.5.1).

\subsubsection{Posthydrolysis reaction for the quantification of total monomers}

\subsubsection{Posthydrolysis of samples from autohydrolysis liquor}

A sample of the liquid product $(5 \mathrm{~mL})$ obtained after the autohydrolysis reaction was mixed with $1 \mathrm{~mL}$ of $5 \mathrm{~N} \mathrm{H}_{2} \mathrm{SO}_{4}$ and hydrolyzed at $120^{\circ} \mathrm{C}$ for $45 \mathrm{~min}$ to convert $\mathrm{XOs}$ to their constitutive monomers, and then was analyzed by HPLC to quantify the total amount of XOs in the LP.

\subsubsection{Posthydrolysis of SXOs and DXOs}

To determine the global composition of the xylo-oligosaccharides obtained after spray-drying or lyophilization process, posthydrolysis was performed by dissolving 3 $\mathrm{g}$ of the dried xylo-oligosaccharides in $180 \mathrm{~mL}$ of $0.416 \mathrm{M} \mathrm{H}_{2} \mathrm{SO}_{4}$, followed by hydrolysis at $120^{\circ} \mathrm{C}$ for $45 \mathrm{~min}$. After that, the solution obtained was filtrated and a sample of the liquid was filtered using a $0.22 \mu \mathrm{m}$ syringe filter to analyze it by HPLC.

\subsubsection{Total hydrolysis for the production of alditols and quantification by GC}

Total hydrolysis of the xylo-oligosaccharides from corncobs and almond shells after spray-drying (SXOs) and after dialysis treatment (DXOs) was made adding 4.5 $\mathrm{mL}$ of $2 \mathrm{M}$ TFA (trifluoroacetic acid) to $6 \mathrm{mg}$ of the Xos. The flasks were sealed, and maintained at $105^{\circ} \mathrm{C}$ for $24 \mathrm{~h}$ to assure complete hydrolysis. After the hydrolysis, the 
flasks were opened, diluted with distilled water, and concentrated in the rotavapour system together with water (coevaporation) to remove the acetic acid. This process was repeated until no acetic acid was present.

After concentration, the hydrolysate was dissolved in distilled water and passed through an ionic exchange resin to separate neutral compounds from acidic compounds. The resin was purchased from Fluka, Dowex 2 × 8 200/400, (strongly basic anion exchange resin). The resin was washed with distilled water until neutral $\mathrm{pH}$. The hydrolysate was passed through the column, and then eluted several times with distilled water. This eluate (containing only the neutral compounds) was recovered, concentrated under vacuum, dried, and weighted to quantify the neutral sugars recovered. The neutral sugars were detected by paper chromatography (neutral system), and after, that they were reduced for GC (Gas Chromatography). Then the resin was washed with $4 \mathrm{M} \mathrm{CH}_{3} \mathrm{COOH}$, to recover the acidic compounds (again it was concentrated until dryness and weighted). The acidic compounds were detected by paper chromatography, in the acidic solvent system.

The reduction of neutral compounds was made to allow the detection of the neutral compounds by GC. $1 \mathrm{~mL}$ of distilled water was added under stirring to the neutral compounds (around $6 \mathrm{mg}$ ) recovered from ionic exchange resin. After that, 20 $\mathrm{mg}$ of $\mathrm{NaBH}_{4}$ were dissolved in $1.5 \mathrm{~mL}$ of distilled water (total volume $2.5 \mathrm{~mL}$ ), added slowly to the previous solution, and the reduction proceeded for $4 \mathrm{~h}$. The flasks were covered to avoid light. A cation exchanger (Dowex Type 50 WX8, mesh $200-400, \mathrm{H}$ form) was added until neutral $\mathrm{pH}$ to stop the reaction. The liquid was filtrated, recovered and concentrated in the rotavapour system to remove water. After that it was washed with methanol to remove the boric acid and the liquid was concentrated until dryness. When the flasks were dried they were weighted to quantify the reduced sugars (alditols) (around $2 \mathrm{mg}$ ). These sugars were converted into alditol trifluoroacetates, by reaction with $0.1 \mathrm{~mL}$ of trifluoroacetic anhydride (with a trace amount of pyridine) at room temperature for 2 hours. After that, the solution was analyzed by GC analysis, injected directly into the capillary column. Gas Chromatography analysis was conducted on Hewlett-Packard 5890 Series II chromatograph equipped with a PAS-1701 column $(0.32 \mathrm{~mm} \times 25 \mathrm{~m})$ at a temperature program of $110-125^{\circ} \mathrm{C}\left(2^{\circ} \mathrm{C} / \mathrm{min}\right)$ to $165^{\circ} \mathrm{C}\left(20^{\circ} \mathrm{C} / \mathrm{min}\right)$ and a flow rate of hydrogen of $20 \mathrm{~mL} / \mathrm{min}$. 


\subsubsection{Determination of the acid - soluble lignin}

The method for the quantification of the acid-soluble lignin residues is based on the Tappi T 250 standard method for acid - soluble lignin. The absorbance of the solution at $205 \mathrm{~nm}$ was measured in a Dinko Instruments 8500 spectrometer (Dinko Instruments, SPAIN). The calibration curve was made using vanillic acid as standard (Merck). All analyses were performed in triplicate.

\subsubsection{Determination of uronic acid}

\subsubsection{Determination by colorimetry}

The determination of uronic acids in quantitative form was made following the method by Blumenkrantz [10]. For this purpose, $1.2 \mathrm{~mL}$ of a solution $0.0125 \mathrm{M} \mathrm{Na}_{2} \mathrm{~B}_{2} \mathrm{O}_{4}$ in concentrated $\mathrm{H}_{2} \mathrm{SO}_{4}$ were added to $0.2 \mathrm{~mL}$ of the sample conveniently diluted. The tubes were capped and refrigerated in crushed ice. The mixture was shaken by hand and the tubes were heated in a water bath at $100^{\circ} \mathrm{C}$ for $5 \mathrm{~min}$. After that, they were cooled in a water-ice bath, and were added $20 \mu \mathrm{L}$ of a solution of m-hydroxydiphenyl (Sigma Aldrich) $(0.15 \%$ of m-hydroxydiphenyl prepared in $0.5 \% \mathrm{NaOH})$. The tubes were shaken and within $5 \mathrm{~min}$ the absorbance at $520 \mathrm{~nm}$ was measured in a Dinko Instruments 8500 spectrometer (Dinko Instruments, SPAIN). The calibration curve was made using D-glucuronic acid as standard (Sigma Aldrich). Because carbohydrates produces a pinkish cromogen with the solution of sulfuric acid/tetraborate at $100^{\circ} \mathrm{C}$, a blank sample was run without addition of the solution of m-hydroxydiphenyl, which was replaced by $20 \mu \mathrm{L}$ of $0.5 \% \mathrm{NaOH}$, and the absorbance was substracted from the total absorbance.

\subsubsection{Determination by potentiometry}

For the uronic acids quantification, the SXOs and DXOs were purified in different ways prior to the potentiometric titration to eliminate salts and ions that could interfere in the analysis.

$1 \mathrm{~g}$ of SXOs and $200 \mathrm{mg}$ of DXOs were washed with $3 \times 100 \mathrm{~mL}$ of an acidified ethanol solution $(800 \mathrm{~mL}$ of $96 \%$ ethanol, $160 \mathrm{~mL}$ of distilled water and $10 \mathrm{~mL}$ of concentrated $\mathrm{HCl}$ ) under stirring. After that, it was decanted, and the liquid was 
discarded. The remaining XOs were washed with an ethanolic solution $(800 \mathrm{~mL}$ of $96 \%$ ethanol and $160 \mathrm{~mL}$ of distilled water) to remove the $\mathrm{HCl}$. After the washings, the collected XOs were dissolved in $100 \mathrm{~mL}$ of distilled water, and were applied to a cation exchange column. The resin used was Dowex Type 50WX8, mesh $200-400$ (purchased from Serva). The resin was washed with distilled water $(3 \times 100 \mathrm{~mL}$ each), to remove the XOs from the column. All the fractions were collected, concentrated under vacuum and lyophilized.

To compare the effectiveness of the washing with ethanol, the SXOs (around 500 $\mathrm{mg}$ ) were applied directly to the cation exchange column, and eluted in the same way as described previously. After that, the solution was concentrated under vacuum and lyophilized.

The XOs after lyophilization were weighted precisely, and dissolved in $50 \mathrm{~mL}$ of distilled water (that was boiled previously to remove carbonic acid). The solution was maintained closed to avoid absorption of $\mathrm{CO}_{2}$. The samples were valorated with $0.1 \mathrm{M}$ $\mathrm{KOH}$ until neutral $\mathrm{pH}$. The volume of $\mathrm{KOH}$ consumed was proportional to the amount of uronic acid present in the sample (identified as 4-O-methylglucuronic acid).

\subsubsection{Determination of ferulic acid}

The determination of ferulic acid was made following the method by Saulnier [8], in which the ferulic acid is determined by spectrophotometry. $0.1 \mathrm{~mL}$ of the solution conveniently diluted are mixed with a buffer $\mathrm{pH} 10(0.1 \mathrm{M}$ sodium tetraborate $-0.1 \mathrm{M}$ glycine, then adjusted to $\mathrm{pH} 10$ adding concentrated $\mathrm{NaOH}$ ). The proportion of free and esterified ferulic acid is calculated from the absorptions (A) at $375 \mathrm{~nm}$ and $345 \mathrm{~nm}$ using a Dinko Instruments 8500 spectrometer (Dinko Instruments, SPAIN), assuming the following molar absorption coefficients $(1 / \mathrm{M} \mathrm{cm}): \varepsilon 345=19662, \varepsilon 375=7630$ for free ferulic acid; and $\varepsilon^{\prime}{ }_{345}=23064, \varepsilon^{\prime}{ }_{375}=31430$ for esterified ferulic acid. The corresponding concentrations for both free $[\mathrm{FA}]_{\mathrm{f}}$ and esterified $[\mathrm{FA}]_{\mathrm{e}}$ ferulic acid were calculated using the next equations:

$$
[F A]_{e}=\frac{\left(A_{375} \times \varepsilon_{345}\right)-\left(A_{345} \times \varepsilon_{375}\right)}{\left(\varepsilon_{375}^{\prime} \times \varepsilon_{345}\right)-\left(\varepsilon_{345}^{\prime} \times \varepsilon_{375}\right)}
$$




$$
[F A]_{f}=\frac{A_{345}-\left(\varepsilon_{345}^{\prime} \times[F A]_{e}\right)}{\varepsilon_{345}}
$$

\subsubsection{Procedure for the solvent extraction - Determination of phenolic acid}

Samples (100 mg) of SXO and DXO from almond shells were dissolved in distilled water $(40 \mathrm{~mL})$ under stirring for $2 \mathrm{~h}$. The insoluble part was separated by centrifugation at 10,000 rpm for $10 \mathrm{~min}$, and it was dissolved in methanol yielding, after centrifugation of insoluble material and evaporation of the methanol, fraction MeS. The aqueous supernatant was treated successively with three portions $(20 \mathrm{~mL})$ of ethyl acetate. The aqueous phase yielded after evaporation the purified fraction $\mathrm{PuXO}$ and the organic phase the soluble phenolic fraction EAS.

Spray dried xylo-oligosaccharides (from corncobs and almond shells) were treated with alkali to isolate phenolic acid [8]. Around $500 \mathrm{mg}$ of each raw material reacted with $10 \mathrm{~mL}$ of $10 \% \mathrm{NaOH}$ at room temperature for $2 \mathrm{~h}$. After that time, the reaction was stopped by addition of $6 \mathrm{M} \mathrm{HCl}$ until $\mathrm{pH}$ around 2. The liquid was extracted with diethylether (2 times) and the ether extract was dried under vacuum for further analysis by FTIR (Fourier Transformed Infrarred Spectroscopy).

\subsubsection{Deacetylation reaction}

Samples of dialyzed XOs (DXOs) from corncobs and almond shells were deacetylated with alkali, after dialyzed, lyophilized and analyzed by NMR to detect if there were changes in the spectra that allowed to deduce the position of the acetyl substituents. For this purpose, $200 \mathrm{mg}$ of DXOs were dissolved in $40 \mathrm{~mL}$ of distilled water under stirring, adding $40 \mathrm{~mL}$ of $0.2 \mathrm{M} \mathrm{NaOH}$. The final solution was maintained into the fridge for $18-24 \mathrm{~h}$ (overnight). After that, the solution was neutralized with 1 and $0.1 \mathrm{M} \mathrm{HCl}$ until $\mathrm{pH} 7$, and the neutral solution was dialyzed with distilled water (Membra-Cel Dialysis Tubing, MWCO $3500 \mathrm{Da}$ ) according to the method explained in the section 2.4.1. The final solution was lyophilized, yielding sample De- $\mathrm{XO}$, and sended to NMR analysis. 


\subsubsection{Methods for qualitative identification}

\subsubsection{Descending Paper Chromatography}

Descending Paper Chromatography (PC) was used to identify neutral sugars and acids in qualitative form. The PC was performed on paper Whatman № 1 , in the following solvent systems: System 1 (to identify neutral sugars) was 8:2:1 ethylacetate (EtOAc) - pyridine - water; System 2 (to identify acidic compounds) was 18:3:1:4 EtOAc - acetic acid - formic acid - water. The dots were put in the paper, dried, and the papers were placed into the solvent system. After $24 \mathrm{hs}$, the paper was extracted from the solvent system, dried in air, and detected. In both systems, the detection was based on anilinium hydrogenphtalate $(8.3 \mathrm{~g}$ phtalic acid, $4.6 \mathrm{~mL}$ of aniline, $500 \mathrm{~mL}$ of acetone), by drying first in air, and after that heating for $5 \mathrm{~min}$ in an oven at $105^{\circ} \mathrm{C}$. It was possible to identify neutral sugars such as galactose, glucose, mannose, arabinose, xylose, rhamnose, (in crescent mobility), and the acidic compounds such as glucuronic acid and galacturonic acid (by comparison with standards).

\subsubsection{TLC (Thin Layer Chromatography)}

TLC was used to detect the presence of monomers and oligomers in the diffusate from dialysis of xylo-oligosaccharides. TLC was made on Silufol plates (purchased from Cavalier, Czech Republic), and on Silica Gel 60 (from Merck) № 105553 (25 TLC aluminium sheets $20 \times 20 \mathrm{~cm}$ ). The plates were prepared with standards, and the solution from the diffusate from dialysis of corncobs and almond shells, in the next solvent systems: 1) butanol: formic acid: water (2:3:1), and 2) propanol: water: methanol (2:1:1). After that, the plates were sprayed with $20 \%\left(\mathrm{NH}_{4}\right)_{2} \mathrm{SO}_{4}$ with nitrogen as carrier, being the resultant spots were visualized by charier.

\subsubsection{Antioxidant activity of xylo-oligosaccharides}

The antioxidant capacity of the xylo-oligosaccharides was measured according to the analysis TEAC (Trolox Equivalent Antioxidant Capacity // Assay) described elsewhere [11], (by courtesy of Mrs. Aleksandra Rozek and Dr. Monserrat Ferrando, GITA, Universitat Rovira i Virgili, Spain). The antioxidant standard used was Trolox (6-hydroxy-2,5,7,8-tetramethylchroman-2-carboxylic acid). A solution $2.5 \mathrm{mM}$ of Trolox 
was prepared in $5 \mathrm{mM}$ phosphate buffered saline (PBS), $\mathrm{pH} 7.4$ to be used as standard. A stock solution was also prepared dissolving ABTS, 2,2'-azinobis(3ethylbenzothiazoline-6-sulfonic acid) diammonium salt in water to a $7 \mathrm{mM}$ concentration. The radical cation ABTS ${ }^{-}+$was produced by reacting ABTS stock solution with $2.45 \mathrm{mM}$ potassium persulfate $\left(\mathrm{K}_{2} \mathrm{~S}_{2} \mathrm{O}_{8}\right)$ (final concentration) and allowing the mixture to stand in the dark at room temperature for $12-16 \mathrm{~h}$ before use. According to the method, the ABTS ${ }^{-+}$solution was diluted with PBS, pH 7.4, until it gave an absorbance of $0.72( \pm 0.02)$ at $734 \mathrm{~nm}$ and equilibrated at $30^{\circ} \mathrm{C}$. $20 \mu \mathrm{L}$ of the sample conveniently diluted were taken and mixed with the stock solution of (ABTS ${ }^{\bullet+}$ $+\mathrm{K}_{2} \mathrm{~S}_{2} \mathrm{O}_{8}+\mathrm{PBS}$ ) until a final volume of $2 \mathrm{~mL}$. The absorbance of the mixture was measured at $734 \mathrm{~nm}$ and $30^{\circ} \mathrm{C}$ at 0 and $5 \mathrm{~min}$, respectively, using the stock solution $\left(\mathrm{ABTS}^{\bullet}+\mathrm{K}_{2} \mathrm{~S}_{2} \mathrm{O}_{8}+\mathrm{PBS}\right)$ as blank. The average absorbance was calculated by the next equation:

$\Delta A=\frac{A b s_{t=0 \min }-A b s_{t=5 \min }}{A b s_{t=0 \text { min }}}-A b s_{\text {blank }}$

The concentration equivalent to $\mu \mathrm{M}$ of Trolox was calculated according to the next equation:

$C_{\text {Trolox }}\left[\frac{\mu m o l}{L}\right]=27.535 \times \Delta A(\%)+44.625$

\subsubsection{Mitogenic and comitogenic activity testing}

The assays are based on the modified Iribe method elaborated for muramyl glycopeptides [12], described in more detail in the literature [13]. The experiments were developed by courtesy of the Institute of Chemistry of the Slovak Academy of Sciences, Bratislava, Slovak Republic. Rat thymocytes (strain Wistar, males weighting about $200 \mathrm{~g}$ ) in RPMI-1640 medium supplemented with 5\% fetal calf serum were cultivated at $1.5 \times 10^{6}$ cells in $0.2 \mathrm{~mL}$ per well either without or with $25 \mu \mathrm{g} / \mathrm{mL}$ of the Tmitogen phytohaemagglutinin (PHA). Test compounds were added at final concentrations of $10,30,100,300$, and $1000 \mu \mathrm{g} / \mathrm{mL}$. After $72 \mathrm{~h}$ of cultivation, thymocyte proliferation was measured by incorporation of ${ }^{3} \mathrm{H}$-thymidine, expressed in counts per minute (cpm). In each of 4 - 7 independent experiments, mean cpm for each set of 4 replicates were used to calculate the stimulation indices (SI). The direct mitogenic effect 
was expressed as $\mathrm{SI}_{\mathrm{mit}}=$ mean $\mathrm{cpm}$ for test compound / mean cpm for the control without stimulant. The comitogenic effect was expressed as SIcomit $=$ mean $\mathrm{cpm}$ (test compound + PHA) / mean cpm for PHA. The mean cpm for control cultures without any addition was $\varnothing 948$ (704-1143). For cultures incubated with PHA, the mean cpm was $\varnothing 1331$ (1081 - 1601). As positive control was used the mitogenic corncob arabinoglucuronoxylan [14] (from the Institute of Chemistry, SAS, Bratislava, Slovakia). The possible contamination of the DXO with endotoxin was checked in a parallel test performed in the presence of polymyxin B, which inhibits the biological effects of endotoxin including its mitogenic activity. It was negative for all tested compounds.

\subsubsection{Instrumental methods}

\subsubsection{High Pressure Liquid Chromatography Analysis}

High-pressure liquid chromatography (HPLC) analysis was used to quantify acetic acid, monosaccharides, furfural, and hydroxymethylfurfural (HMF). The analysis was done with an Agilent 1100 series chromatograph (Agilent, USA), using a Bio-Rad HPX $87 \mathrm{H}$ column at $30^{\circ} \mathrm{C}$ (Bio-Rad Laboratories, USA) (see Figure 2.9).

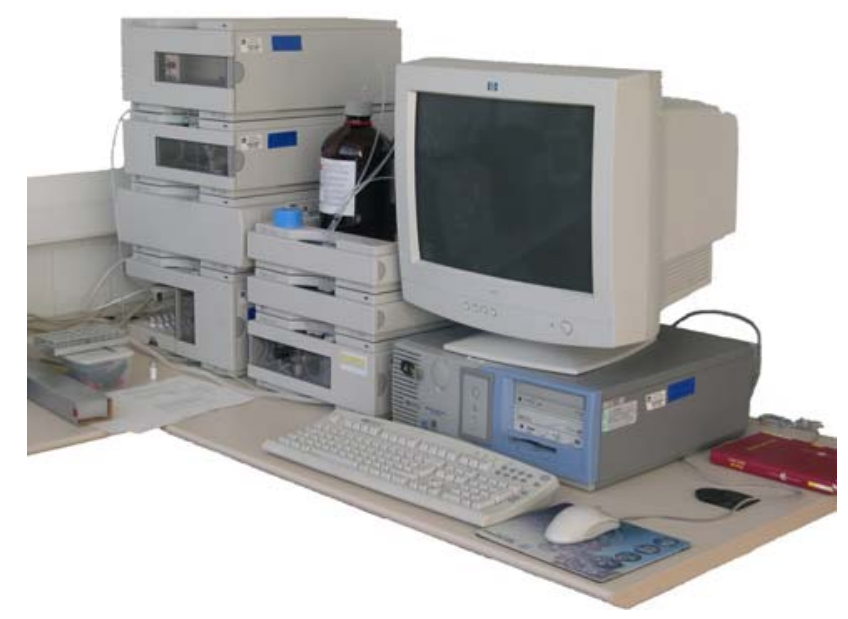

Figure 2.9. Equipment used for HPLC/GPC. 


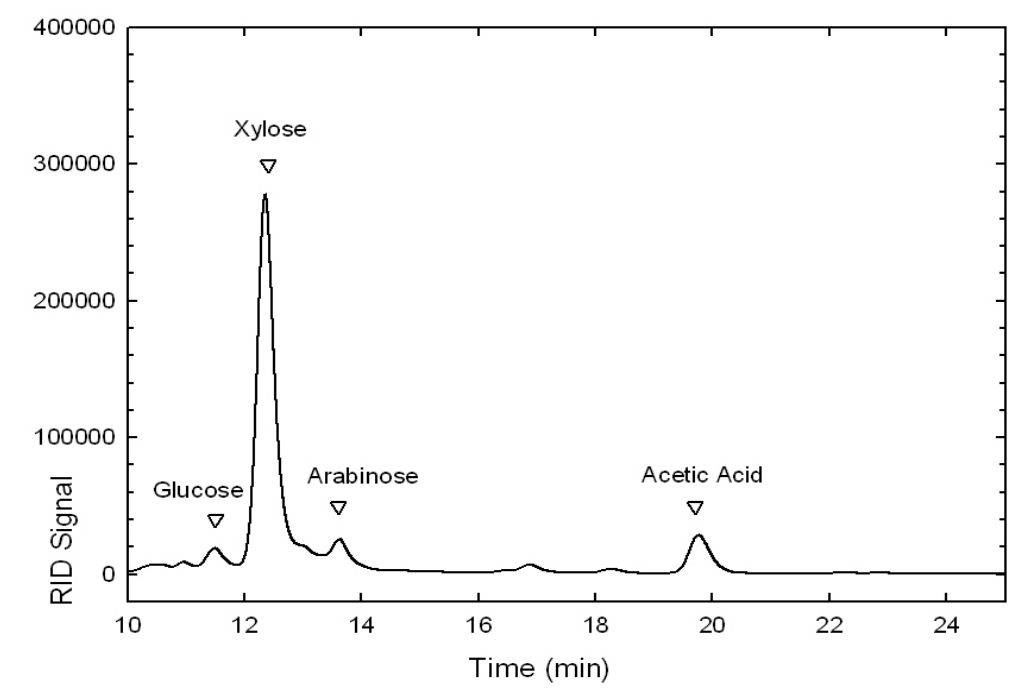

a)

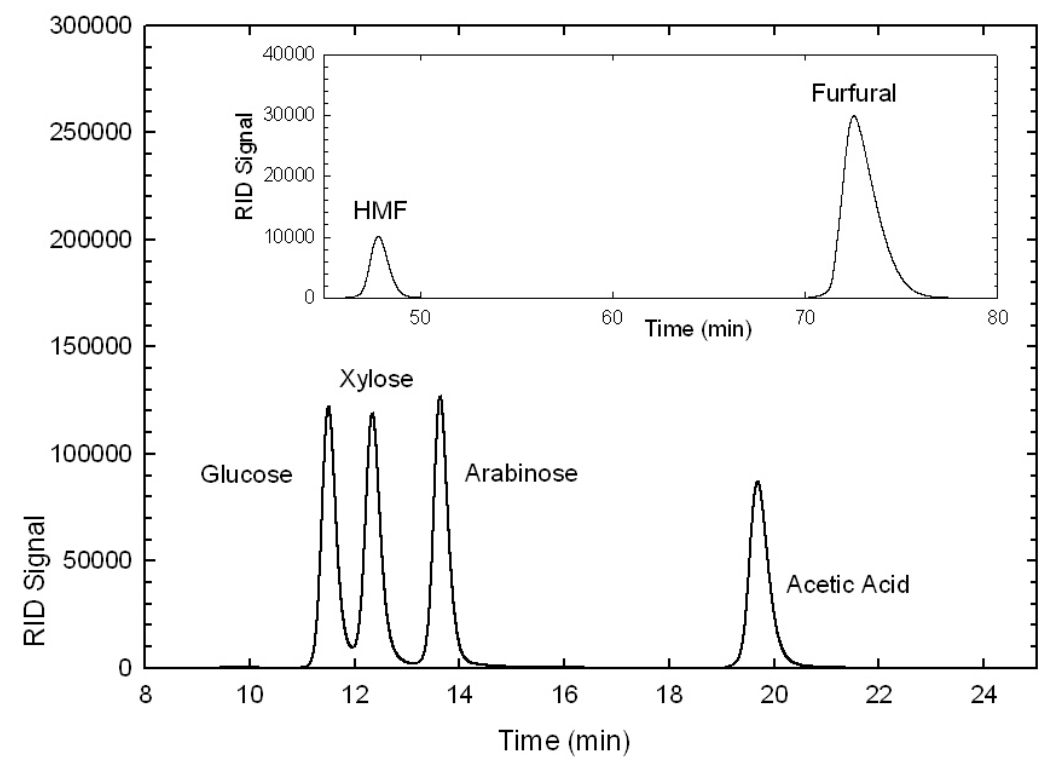

Figure 2.10. a) Chromatogram obtained with the RID detector for a sample of autohydrolysis liquor of almond shells after posthydrolysis treatment. b) Chromatogram obtained for the analysis of the different standards used.

The solvent was $0.005 \mathrm{M} \mathrm{H}_{2} \mathrm{SO}_{4}$ and flow rate $0.5 \mathrm{~mL} / \mathrm{min}$. Before measurements, all the samples $(2 \mathrm{~mL})$ were filtered through a $0.22 \mu \mathrm{m}$ filter. An ultraviolet diode-array detector and a refractive index (RI) detector were connected in series. The UV detector was used to quantify furfural and HMF in the samples that contained low 
concentrations of these compounds, while the RI detector was used for the samples with high concentrations. This detector was also used to quantify carbohydrates.

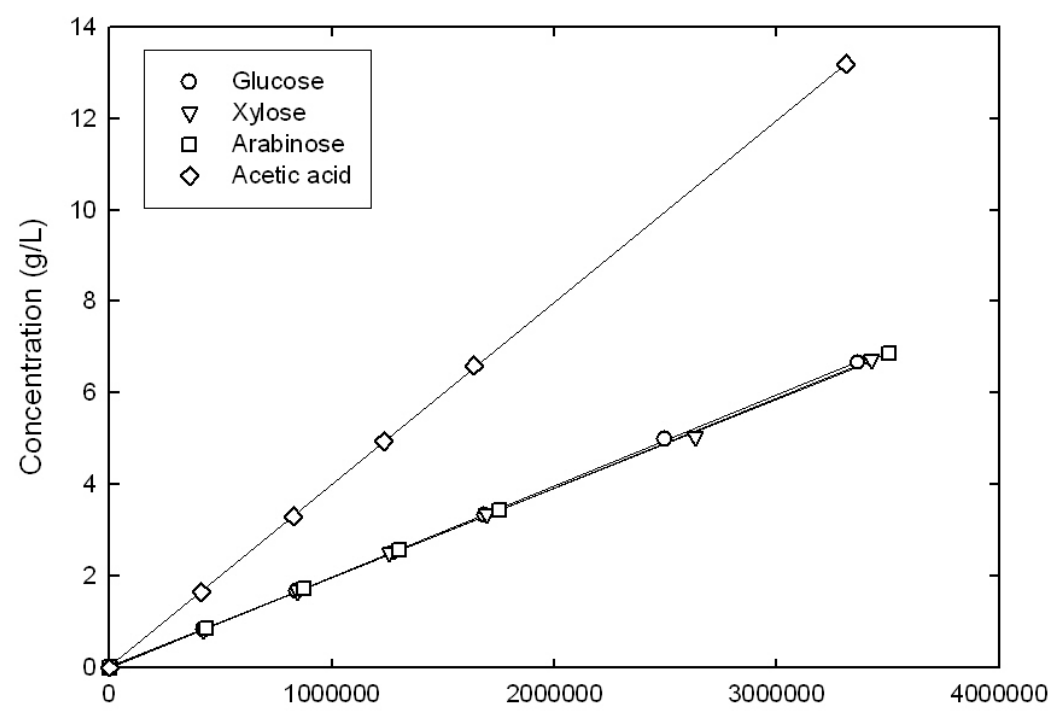

a) Area

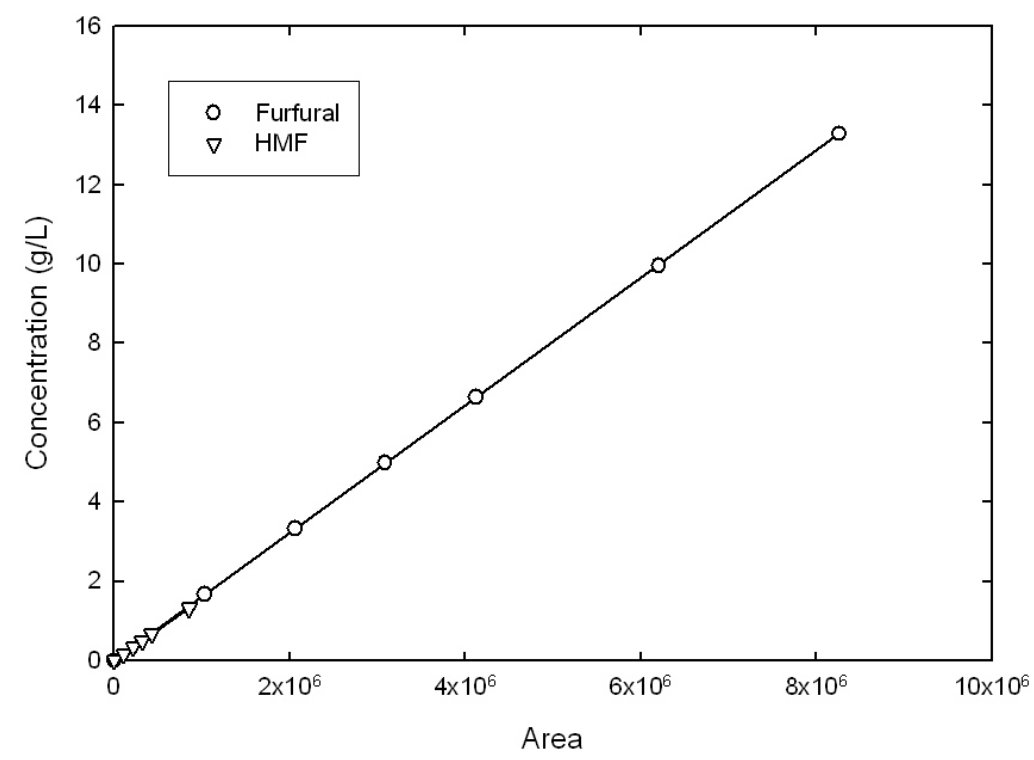

Figure 2.11. a) Calibration curve for the standards of glucose, xylose, arabinose and acetic acid obtained with the RID detector. b) Calibration curve for the standards HMF and furfural obtained with the RID detector. 
The system was calibrated with glucose, xylose, arabinose, acetic acid, furfural and HMF standards (Sigma-Aldrich). Examples of the chromatograms obtained with the HPLC and the calibration curves obtained are shown in Figure 2.10.

\subsubsection{Gel Permeation Chromatography}

The molar mass distribution of xylo-oligosaccharides was determined by Gel Permeation Chromatography (GPC) using the same chromatograph as in HPLC, and the GPC add-on of the LC Chemstation software (purchased from Agilent, Barcelona, Spain). The GPC analysis was performed with a TSKGel G3000PWXL column (Toso Haas, Japan; purchased from Teknokroma, Barcelona, SPAIN) at $25^{\circ} \mathrm{C}$ using as solvent $0.05 \mathrm{M} \mathrm{KNO}_{3}$, containing $83 \mathrm{mg} / \mathrm{L} \mathrm{NaN}_{3}$, at a flow rate $0.5 \mathrm{~mL} / \mathrm{min}$. The system was calibrated with xylose, glucose and low polydispersity standards of maltooligosaccharides and dextrans (Fluka). Calculations of the molar mass distribution were performed using the Agilent Chemstation GPC add-on software. Figure 2.12 shows a typical molar mass distribution obtained by GPC, corresponding to a mixture of XOs obtained after autohydrolysis of almond shells, and recovered by spray drying process.

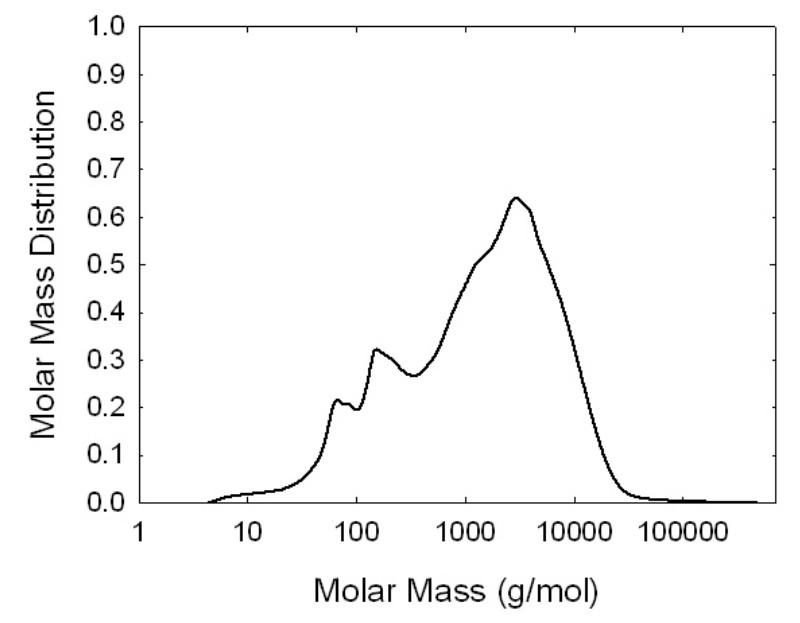

Figure 2.12. Typical Molar Mass Distribution (MMD), obtained for a mixture of XOs from almond shells after spray-drying process.

Figure 2.13 shows the calibration curve obtained for the different standards tested. 
The samples from autohydrolysis liquor were analyzed directly, and in the case of samples from SXOs and DXOs, solutions $(2 \mathrm{~g} / 100 \mathrm{~mL})$ were prepared by dissolving the dried sample in deionized water. In all the cases a sample of $1.2 \mathrm{~mL}$ of the filtered liquid was mixed with $0.2 \mathrm{~mL}$ of a solution $0.35 \mathrm{M} \mathrm{KNO}_{3}$, containing $581 \mathrm{mg} / \mathrm{L} \mathrm{NaN}$. For samples coming from the ultrafiltration or adsorption experiments they already contained $\mathrm{NaN}_{3}$, and for this reason to $1 \mathrm{~mL}$ of the sample were added $0.2 \mathrm{~mL}$ of $\mathrm{KNO}_{3}$ $0.3 \mathrm{M}$. The samples coming from enzymatic membrane reactors were analyzed directly.

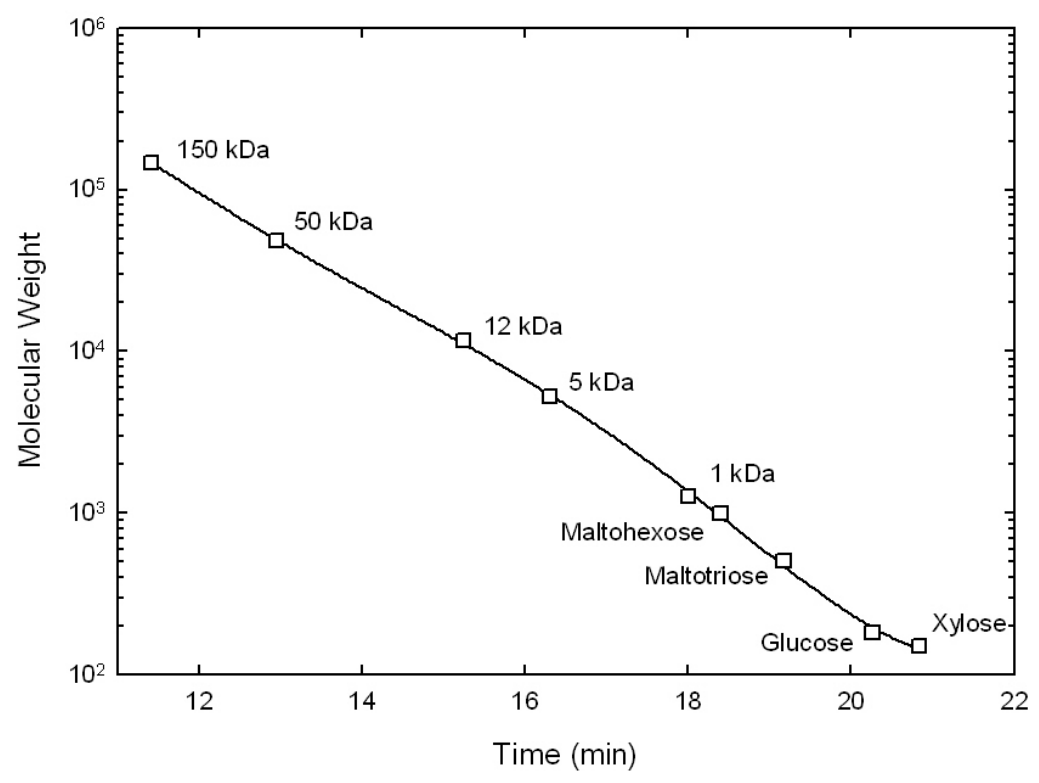

Figure 2.13. Calibration curve for GPC analysis (the line is a polynomial regression of order 5).

\subsubsection{Nuclear Magnetic Resonance (NMR) analysis}

The NMR analyses were performed on $10 \mathrm{mg}$ of dry DXOs dissolved in $0.75 \mathrm{~mL}$ $\mathrm{D}_{2} \mathrm{O}$ (99.96\%, Sigma Aldrich). The ${ }^{1} \mathrm{H}$ spectra were obtained using a Varian Mercury VX400 spectrometer at $400 \mathrm{MHz}$, and the ${ }^{13} \mathrm{C}$ NMR spectra were measured in a Varian Gémini 300 spectrometer at $300 \mathrm{MHz}$. The ${ }^{1} \mathrm{H}$ NMR spectra were recorded using a $75^{\circ}$ pulse of $12 \mathrm{~ms}$, a spectral width of $4500 \mathrm{~Hz}$ and a repetition time of $15 \mathrm{~s}$. All spectra were acquired at ambient temperature. The proton-detected heteronuclear single quantum (HSQC) spectra were recorded over a spectral width ( $\left.\mathrm{t}_{1}\right)$ of $14600 \mathrm{~Hz}$ and a width ( $\mathrm{t}_{2}$ ) of $3600 \mathrm{~Hz}$, with a $2048 \times 1024$ matrix, and 0.125 transients per increment. 
The delay between transients was $15 \mathrm{~s}$ and the delay for polarization transfer was set to $140 \mathrm{~Hz}\left({ }^{1} \mathrm{H}{ }^{13} \mathrm{C}\right.$ coupling constant).

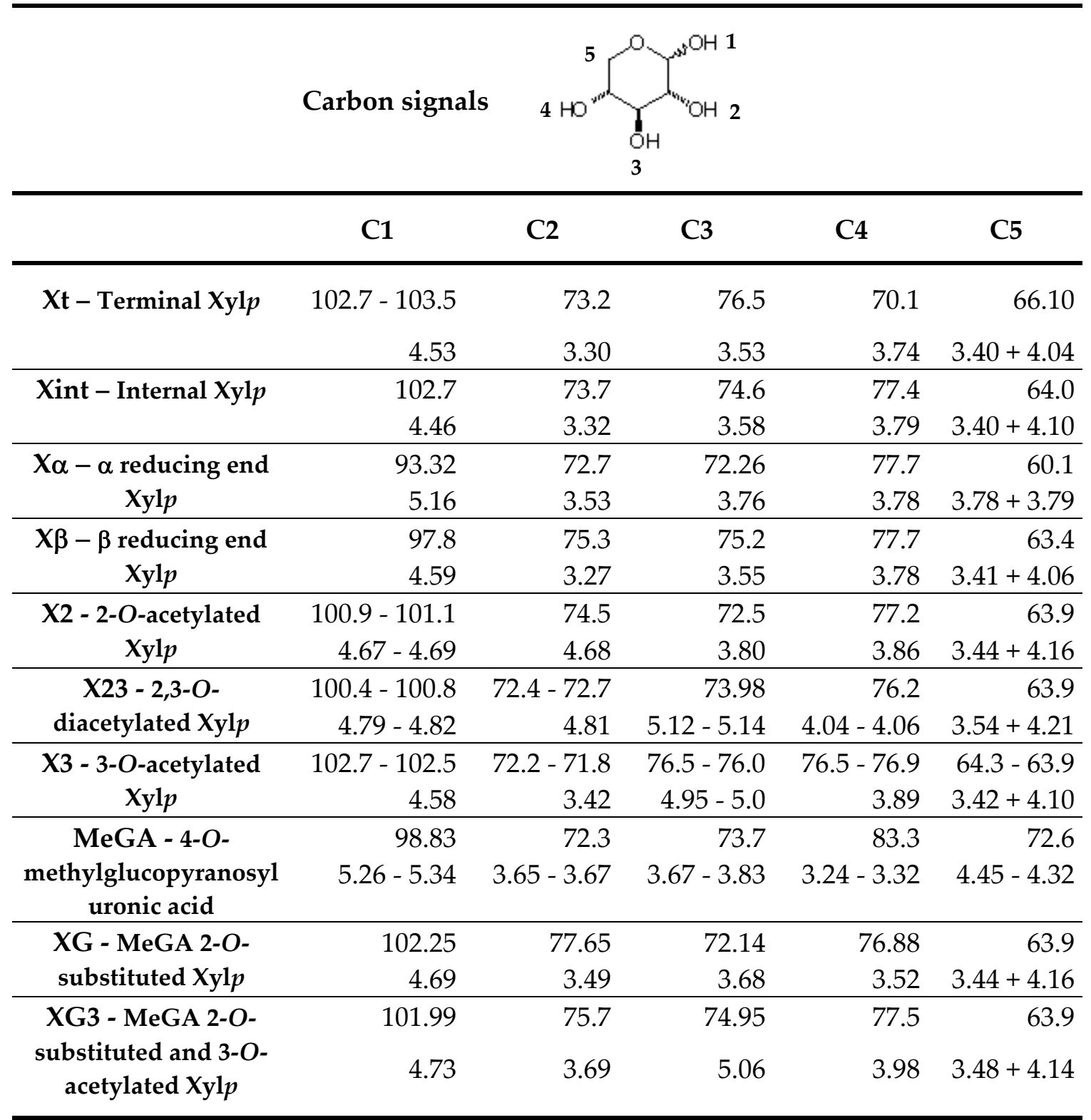

Table 2.2. Assignments for the ${ }^{13} \mathrm{C}$ signals (up) and ${ }^{1} \mathrm{H}$ signal (down) for each different carbon in the molecule.

Table 2.2 shows the assignments of the different signals obtained for the xylose molecules substituted and not substituted in the NMR spectra, based on literature data $[15,16]$. The following designations are used: $X i n t, X t, X \alpha$ and $X \beta$ : non-acetylated internal, non-reducing terminal, and reducing $\alpha$ and $\beta$ terminal $\mathrm{Xyl} p$ residues. $\mathrm{X}$ 3: 3-O- 
acetylated Xylp; X2: 2-O-acetylated Xylp; X23: 2,3-O-diacetylated Xylp; XG: MeGA 2-Osubstituted Xylp; XG3: MeGA 2-O-substituted and 3-O-acetylated Xylp; MeGA: 4-Omethylglucopyranosyl uronic acid.

a)

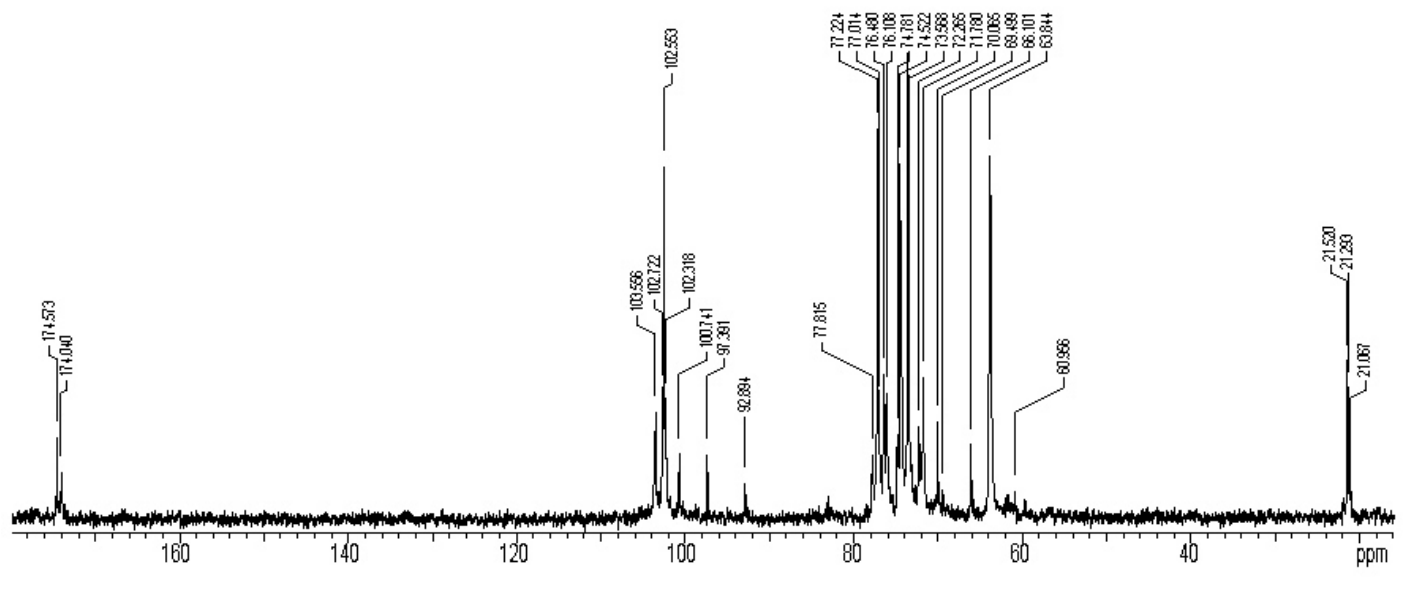

b)

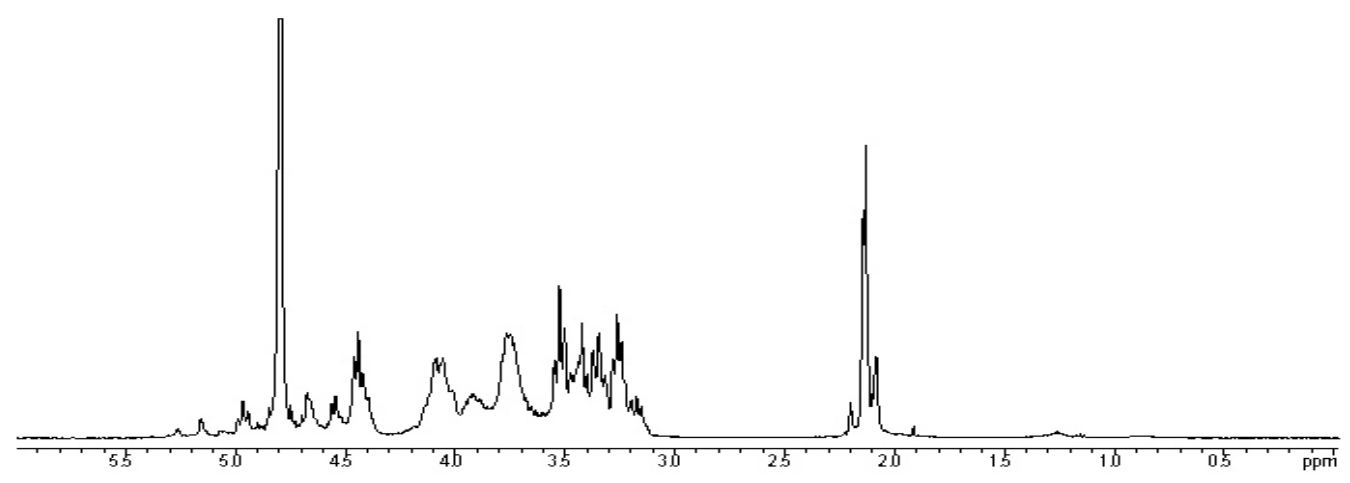

c)

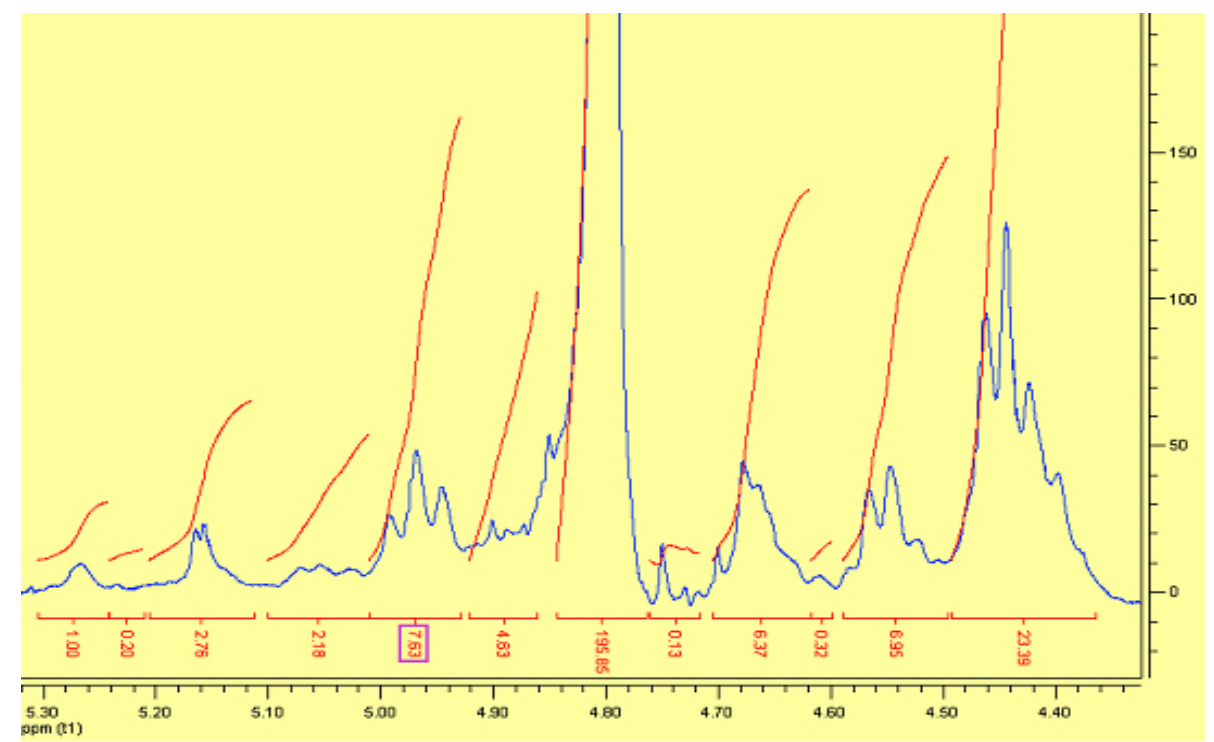




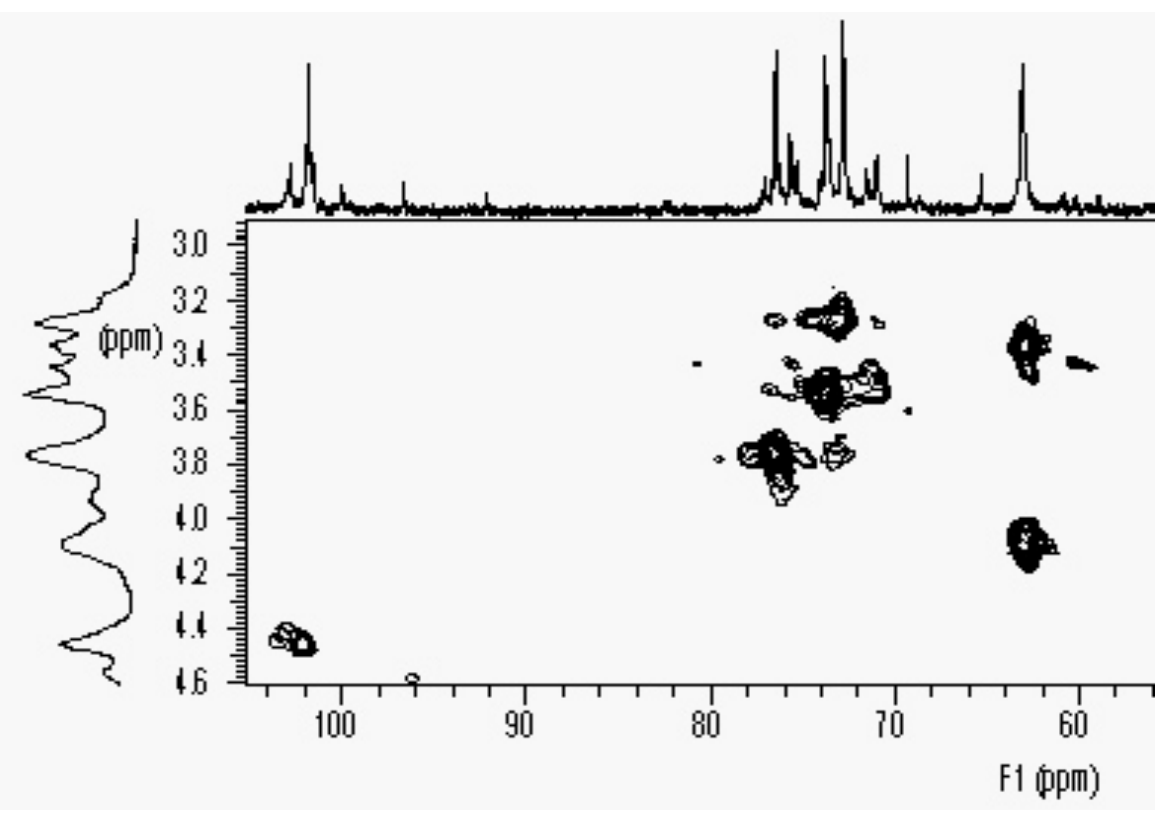

d)

Figure 2.14. Different spectra for DXOs from almond shells. Previous page: a) ${ }^{13} \mathrm{C}$ spectra. b) ${ }^{1} \mathrm{H}$ spectra. c) Integrated areas of the anomeric region of ${ }^{1} \mathrm{H}$ spectra, used for the calculation of the acetylation degree. Up: d) HSQC spectra of almond shells.

Some typical ${ }^{13} \mathrm{C}$ and ${ }^{1} \mathrm{H}$ spectra can be observed in Figure $2.14 \mathrm{a}-\mathrm{b}$, in this case for DXOs from almond shells. Figure 2.14 - c shows the assignments in the ${ }^{1} \mathrm{H}$ anomeric region used for the calculation of the acetylation degree for DXOs from almond shells. In this case the software used for the calculation of the integrated areas was Mestre $\mathrm{C} v$. 2.0.1. (Mestrelab Research, A Coruña, Spain).

The acetylation degree of the different samples was calculated in two different ways [16-18]. The first one we used was calculated with Equation 2.25, calculating the areas of acetylated and non acetylated xylose units in the anomeric region; and the second one was calculated with Equation 2.26 by using the total area of acetylated units and dividing it by the total carbohydrate area.

$$
\begin{aligned}
& D S A c=\frac{\sum \text { Acetylated Xyl }}{\sum(\text { Acetylated Xyl }+ \text { Non Acetylated Xyl })} \\
& D S A c=\frac{\sum \text { Acetyl signals }}{\sum \text { Total carbohydrate signals }}
\end{aligned}
$$




\subsubsection{FT-IR and MALDI-TOF Mass Spectrometry}

The measurements were made by courtesy of Dr. V. Sasinková from the Institute of Chemistry, Bratislava, Slovak Republic.

Fourier-transformed infrared (FT-IR) spectra (in KBr pellets) were obtained on a NICOLET Magna 750 spectrometer with a DTGS detector and OMNIC 3.2 software using 128 scans at a resolution of $4 \mathrm{~cm}^{-1}$. NMR spectra were recorded in $\mathrm{D}_{2} \mathrm{O}$ at 27 and $60{ }^{\circ} \mathrm{C}$ on an FT NMR Bruker AVANCE DPX 300 spectrometer $\left({ }^{1} \mathrm{H}\right.$ at $300.13 \mathrm{MHz}$ and ${ }^{13} \mathrm{C}$ at $75.46 \mathrm{MHz}$ ) equipped with a selective unit and gradient enhanced spectroscopy

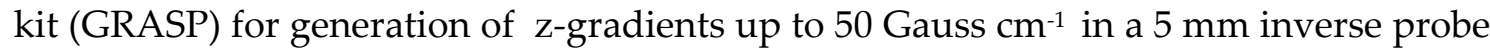
kit. Chemical shifts of signals were referenced to internal acetone (2.225 and 31.07 ppm for ${ }^{1} \mathrm{H}$ and ${ }^{13} \mathrm{C}$, respectively). The data matrix for 2D-NMR experiments was processed with squared sine function, using Bruker software XWIN-NMR version 1.3. The mass spectra were measured using the MALDI TOF IV (Shimadzu, Kratos Analytical) instrument. Samples were irradiated by $337 \mathrm{~nm}$ photons from nitrogen laser. 2,5Dihydroxybenzoic acid (DHB) was used as a matrix. The samples (1 mg) were dissolved in $1 \mathrm{~mL}$ of the mixture acetonitrile/water $(1: 1, \mathrm{v} / \mathrm{v})$. For the spot preparation, a mixture of $1 \mu \mathrm{L}$ of the matrix DHB with $10 \mathrm{pmol} / \mu \mathrm{L}$ analyte solution was used. Accelerating voltages applied for the MS measurements were $5 \mathrm{kV}$. 


\subsection{REFERENCES}

1. Garrote, G., Domínguez, H., \& Parajó, J. Autohydrolysis of corncob: study of non-isothermal operation for xylooligosaccharide production. Journal of Food Engineering, 2002, 52: p. 211-218.

2. Brunauer, S., Emmett, P.H., \& Teller, E. Adsorption of gases in multimolecular layers. Journal of the American Chemical Society, 1938, 60: p. 309 - 319.

3. Sing, K.S.W. The use of physisorption for the characterization of microporous carbons. Carbon, 1989, 27: p. 5 - 11.

4. Kruk, M., Li, Z.J., Jaroniec, M., \& Betz, W.R. Nitrogen adsorption study of surface properties of graphitized carbon blacks. Langmuir, 1999, 15: p. 1435 - 1441.

5. Noh, J.S. \& Schwarz, J.A. Effect of $\mathrm{HNO}_{3}$ treatment on the surface acidity of activated carbons. Carbon, 1990, 28: p. 675 - 682.

6. Boehm, H.P. Chemical identification of surface groups. Advances in Catalysis, 1966, 1: p. 179 287.

7. Bunzel, M., Allerdings, E., Sinwell, V., Ralph, J., \& Steinhart, H. Cell wall hydroxycinnamates in wild rice (Zizania aquatica L.) insoluble dietary fibre. European Food Research and Technology, 2002, 214: p. 482 - 488.

8. Saulnier, L., Vigouroux, J., \& Thibault, J. Isolation and partial characterization of feruloylated oligosaccharides from maize bran. Carbohydrate Research, 1995, 272: p. 241 - 253.

9. McCallum, J., Taylor, I., \& Towers, G. Spectrophotometric assay and electrophoretic detection of trans-feruloyl esterase activity. Analytical Biochemistry, 1991, 196: p. 360 - 366.

10. Blumenkrantz, N. \& Asboe-Hansen, G. New method for quantitative determination of uronic acids. Analytical Biochemistry, 1973, 54: p. 484-489.

11. Re, R., Pellegrini, N., Proteggente, A., Pannala, A., Yang, M., \& Rice-Evans, C. Antioxidant activity applying an improved ABTS radical cation decolorization assay. Free Radical Biology \& Medicine, 1999, 26 (9 - 10): p. 1231 - 1237.

12. Iribe, H. \& Koga, T. Augmentation of the proliferation response of thymocytes to phytohemagglutinin by the muramyl dipeptide. Cell Immunology, 1984, 88: p. 9 - 15.

13. Ebringerová, A., Kardosová, A., Hromadková, Z., Malovíkova, A., \& Hribalová, V. Immunomodulatory activity of acidic xylans in relation to their structural and molecular properties. International Journal of Biological Macromolecules, 2002, 30 (1): p. 1-6.

14. Kacuráková, M., Capek, P., Sasinková, V., Wellner, N., \& Ebringerová, A. FT-IR study of plant cell wall model compounds: pectic polysaccharides and hemicelluloses. Carbohydrate Polymers, 2000, 43 (2): p. 195-203.

15. Kardosová, A., Matulová, M., \& Malovíková, A. (4-O-Methyl-a-D-glucurono)-D-xylan from Rudbeckia fulgida, var. sullivantii (Boynton et Beadle). Carbohydrate Research, 1998, 308: p. 99 $-105$. 
16. Teleman, A., Lundqvist, J., Tjerneld, F., Stalbrand, H., \& Dahlman, O. Characterization of acetylated 4-O-methylglucuronoxylan isolated from aspen employing ${ }^{1} \mathrm{H}$ and ${ }^{13} \mathrm{C} \mathrm{NMR}$ spectroscopy. Carbohydrate Research, 2000, 329: p. 807 - 815.

17. Gröndahl, M., Teleman, A., \& Gatenholm, P. Effect of acetylation on the material properties of glucuronoxylan from aspen wood. Carbohydrate Polymers, 2003, 52: p. 359 - 366.

18. Teleman, A., Tenkanen, M., Jacobs, A., \& Dahlman, O. Characterization of O-acetyl-(4-Omethylglucurono)xylan isolated from birch and beech. Carbohydrate Research, 2002, 337: p. 373 - 377. 
AUTOHYDROLYSIS OF AGRICULTURAL BY-PRODUCTS FOR THE PRODUCTION OF XYLO-OLIGOSACCHARIDES.

Debora Alcida Nabarlatz

ISBN: 978-84-690-7617-0 / DL: T.1385-2007

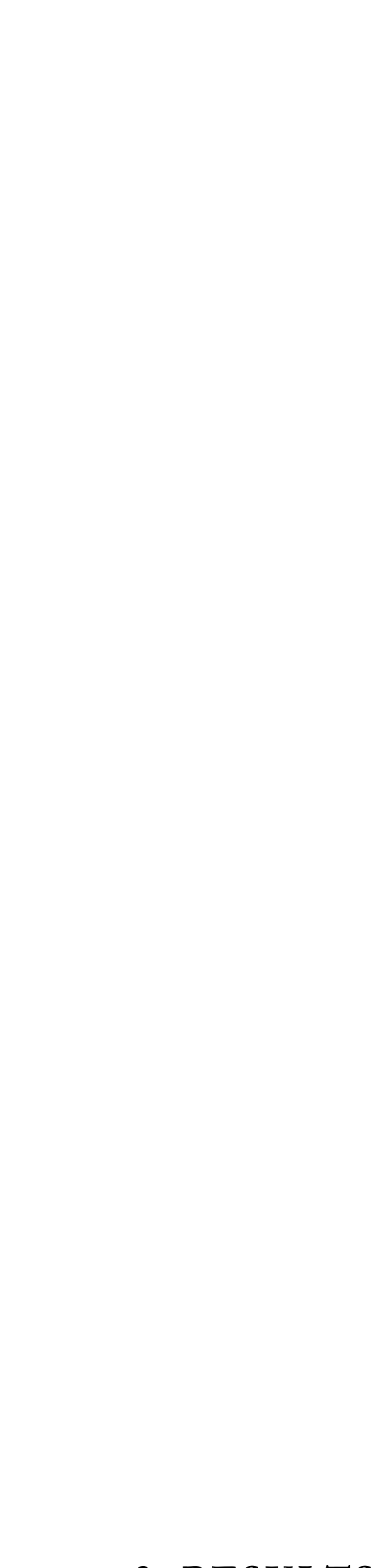

\section{AND DISCUSSION}

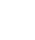


According to the objectives of this thesis, autohydrolysis was evaluated for the production of xylo-oligosaccharides from several agriculture residues, typical from the Mediterranean region of Spain. Autohydrolysis was studied in small reactors to test different temperatures and reaction times. For these experiments, corncobs (CC) and almond shells (AS) were used as raw material. The remaining fractions of cellulose, lignin and xylan in the solid, and the products obtained in the liquid (xylooligosaccharides, monomers and degradation compounds) were quantified. In the case of the xylo-oligosaccharides, not only their composition was studied, but also the molar mass distribution was related to the reaction parameters (temperature and time of reaction). A kinetic model that explain the behavior of the xylan during the autohydrolysis, was proposed and validated in each case. For the production of a high amount of xylo-oligosaccharides, the experiments were scaled up in a $10 \mathrm{~L}$ batch reactor. Six raw materials were tested, corncobs, almond shells, olive stones, rice husks, and the straws of wheat and barley. At this stage, the objectives were to check the reaction conditions and validate the kinetic model, and also produce enough amounts of xylo-oligosaccharides to explore the possibilities of recovery and purification in subsequent steps. The structure of the xylo-oligosaccharides obtained from each different raw material was determined. Between them, xylo-oligosaccharides from almond shells were characterized more deeply, because of the interest of the raw material as a promising source for their production.

Besides the autohydrolysis reaction and its effect on the xylo-oligosaccharides obtained, several purification methods were tested to determine the possibilities of application and their effects in the product obtained: the precipitation with ethanol, the adsorption with activated carbons, and the separation using polymeric membranes.

The first one, the precipitation with ethanol, was used to recover quantitatively the xylo-oligosaccharides presents in the autohydrolysis liquor. The amount of residual lignin present in the xylo-oligosaccharides mixture was also quantified. The fractionation of the xylo-oligosaccharides according to their molar mass appears feasible through selective extraction with solvent mixtures of different compositions and polarities. This seems to be a promising method for the recovery, fractionation and at the same time purification of the oligosaccharides obtained.

The second purification method tested was the adsorption of impurities in activated carbon. For this purpose, three commercial activated carbons were evaluated, 
and the xylo-oligosaccharides used were obtained from almond shells by autohydrolysis reaction at pilot scale. Two levels of experiments were made, being the first one the equilibrium experiments to determine the equilibrium adsorption for the different carbons tested. For the second level experiments, only one carbon was chosen for the experiments in a column. The retention of the lignin-derived impurities was related to the characteristics of the carbon used, and also to the possibility that they are covalently bounded to xylo-oligosaccharides molecules.

The third method tested was the purification by using commercial thin-film polymeric membranes. Its aim was to test several membranes to eliminate low molecular weight material and/or also to separate different molecular weight fractions of xylo-oligosaccharides. The results describe the differences in the selectivity for the retention of the xylo-oligosaccharides and also for the impurities associated with lignin.

There are also some preliminary studies from which the results are still under preparation. One of them is the purification by using enzymatic membranes. Previous studies demonstrated that it was possible to obtain low molecular weight oligosaccharides and separate them in the same step by immobilizing the enzyme in the membrane, being the reaction and separation produced at the same time [1]. The preliminary results indicates that is possible to immobilize endodextranase on activated carbon, incorporating this enzyme-carbon complex inside the membrane. Other preliminary studies about the possible applications of the xylo-oligosaccharides obtained were made, in which it was evaluated the immunomodulatory activity of the xylo-oligosaccharides from almond shells, and the antioxidant activity of xylooligosaccharides from different resources.

The presentation and discussion of the main results are developed in the following sections, and they are the basis of the papers that have already been published in peer-reviewed journals [2-7], and others that are currently submitted or under preparation. 


\subsection{AUTOHYDROLYSIS OF CORNCOBS AND ALMOND SHELLS}

\subsubsection{Raw material composition}

The composition of the native raw materials, corncobs (CC) and almond shells (AS) was analyzed as described in the experimental section, and the results are detailed in Table 3.1.

\begin{tabular}{lcccc} 
& \multicolumn{2}{c}{ Corncobs } & \multicolumn{2}{c}{ Almond shells } \\
\cline { 2 - 5 } Composition (\% dry basis) & Average & $\begin{array}{c}\text { Confidence } \\
\text { interval }\end{array}$ & $\begin{array}{c}\text { Average } \\
\text { Confidence } \\
\text { interval }\end{array}$ \\
\hline Ash & 1.14 & 0.03 & 2.83 & 0.07 \\
EtOH/Toluene extractives & 2.1 & 0.5 & 5.0 & 0.4 \\
Klason lignin & 18.7 & 0.4 & 27.4 & 1.4 \\
Glucan* & 38.5 & 0.3 & 26.8 & 0.6 \\
Xylan* & 29.5 & 0.7 & 26.1 & 0.8 \\
Arabinan* & 3.3 & 0.3 & 2.4 & 0.3 \\
Acetyl & 4.0 & 0.4 & 4.0 & 0.9 \\
Other (by difference) & 6.2 & - & 5.5 & - \\
Arabinan/xylan (mol/mol) & $1: 8.9$ & - & $1: 9.3$ & - \\
Acetyl/xylan (mol/mol) & $1: 3.4$ & - & $1: 15.2$ & - \\
\hline
\end{tabular}

Table 3.1. Average chemical composition and confidence interval $(\alpha=0.025)$ of the batch of corncobs and almond shells used for this study. * Anhydrous monosaccharides.

For CC, the amounts of lignin and cellulose, measured as Klason lignin and glucan, respectively, were $18.7 \%$ and $38.5 \%$ of the total material. In the case of AS, the lignin content is higher, near to $27.4 \%$, and the cellulose (glucan) content is lower $(26.8 \%)$. The hemicellulose fraction, considered as xylan, represented $36.8 \%$ of the CC 
and $32.5 \%$ of AS. The composition of the xylan was anhydroxylose $(29.5 \%)$, anhydroarabinose (3.3\%) and acetyl groups (4.0\%) for CC, and anhydroxylose $(26.1 \%)$, anhydroarabinose $(2.4 \%)$ and acetyl groups $(4.0 \%)$ for AS. The composition of the material was similar to others reported in the literature [8].

\subsubsection{Composition of the solid residue after autohydrolysis}

Figure 3.1 shows the fraction of the constitutive biopolymers that remains in the solid residue after autohydrolysis at the different reaction conditions tested.
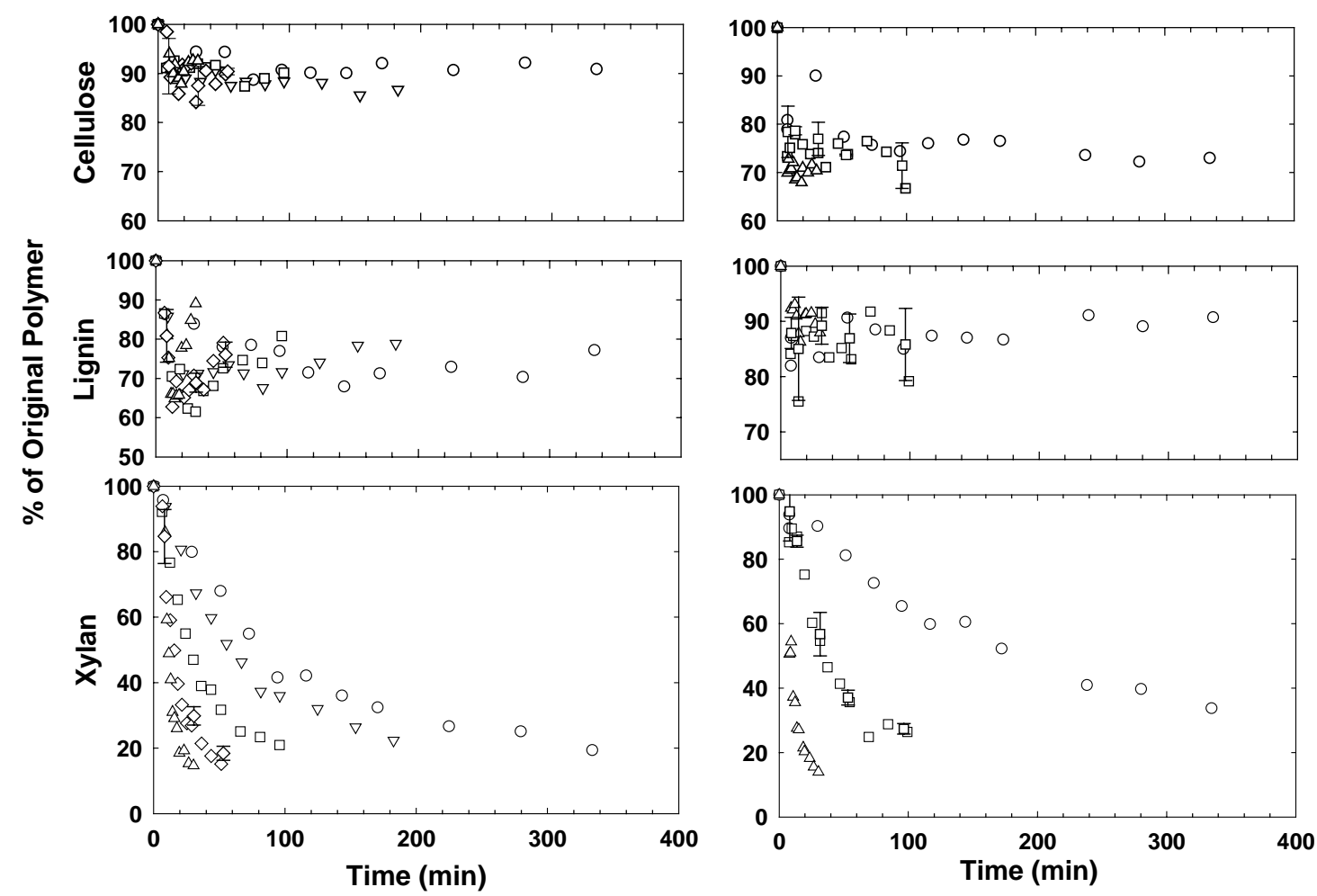

Figure 3.1. Composition of the solid residue after the reaction from corncobs (left) and almond shells (right), for different temperatures as function of the reaction time: cellulose (as \% of original cellulose), lignin (as \% of original lignin) and xylan (as \% of original xylan): $150^{\circ} \mathrm{C} O$, $159^{\circ} \mathrm{C} \nabla, 169^{\circ} \mathrm{C} \square, 179^{\circ} \mathrm{C} \diamond, 190^{\circ} \mathrm{C} \triangle$. Error bars represent the $95 \%$ confidence interval for selected experiments $\left(\right.$ at $179^{\circ} \mathrm{C}$ for corncobs and $169^{\circ} \mathrm{C}$ for almond shells, respectively). 
Each product (cellulose, lignin and xylan) is presented as \% of the original polymer for CC (left) and AS (right). As can be observed, in the case of cellulose, around $90 \%$ remained unaltered for CC. The reaction conditions does not affect this behavior. In the case of $\mathrm{AS}$, this percentage was lower, varying between $70-80 \%$, again independent of the reaction conditions. In both cases, the amount of the cellulose recovered in the solid was significant, so can be considered that the cellulose remaining in the solid could be separated in subsequent processes, for example for the preparation of fermentation broths, production of bio-ethanol, etc.

The lignin remaining in the solid shows a different behavior. In the case of CC, the lignin that remained after the reaction varied between $60-80 \%$ of the original, showing an important depolymerization. In the case of AS, the lignin content remaining was higher, varying between $80-95 \%$ of the original. In both cases it was independent of the time and temperature of the reaction. The lignin depolymerization can be related to the lignin and organic extractives content present in the original raw material. In CC, the percentage of lignin in the raw material accounted up to $18.7 \%$, while in AS accounted up to $27.4 \%$. The organic extractives content was around $2.1 \%$ for $\mathrm{CC}$, and $5 \%$ for AS. That indicates that the increase in the lignin and organic extractives content of the solid contributes making the material less accessible to the reaction, yielding less lignin-derived products in the liquid. This aspect is important because these products derived from lignin constitutes impurities in the xylooligosaccharides that possibly have to be removed in subsequent purification steps.

The hemicelluloses remaining in the solid (considered as xylan) showed similar behavior for both raw materials. For the largest times at each temperature, it was possible to solubilize up to $80 \%$ of the original xylan, remaining only $20 \%$ in the solid. For the temperatures between $190^{\circ} \mathrm{C}$ and $169^{\circ} \mathrm{C}$, the levels of xylan fell very rapidly, and around $80 \%$ of the xylan reacted for times less than $100 \mathrm{~min}$. In the case of lower temperatures $\left(150^{\circ} \mathrm{C}\right.$ and $\left.159^{\circ} \mathrm{C}\right)$, the solubilization was slower, and it takes much more time to reach similar levels (between $200 \mathrm{~min}$ and $350 \mathrm{~min}$ of reaction). These results showed good agreement with the trends reported for the autohydrolysis of annual plants, agriculture residues and hardwoods, both in hydrothermal processes [9-11] and steam-explosion processes [12-14].

Xylan was considered to be formed by anhydroxylose, anhydroarabinose and acetyl groups. The composition of the native xylan for CC was calculated from the 
chemical composition of the raw material: $80 \%$ in anhydroxylose, $9 \%$ in anhydroarabinose and $11 \%$ in acetyl groups. In the case of AS, the xylan composition was approximately $85 \%$ anhydroxylose, $6 \%$ anhydroarabinose, and $9 \%$ acetyl groups. Figure 3.2 shows that the partially hydrolyzed xylan was enriched in anhydroxylose units to around $90 \%$, for both raw materials, and this enrichment was more or less independent of the reaction conditions.
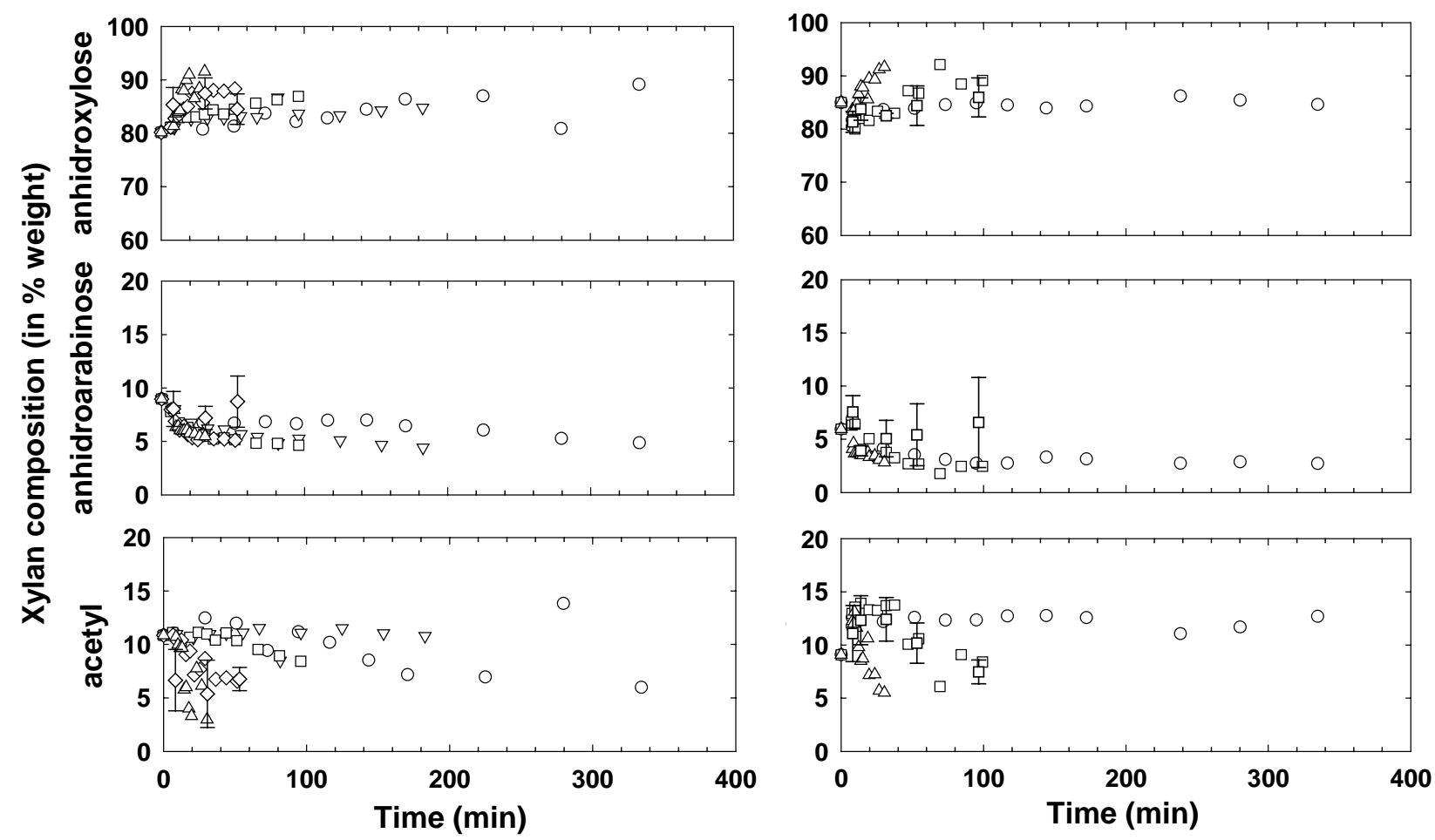

Figure 3.2. Variation in the composition of the xylan remaining in the solid residue after the reaction, for different temperatures as function of the reaction time: anhydroxylose, anhydroarabinose and acetyl (as wt.\% of xylan). Corncobs (left), and almond shells (right): $150^{\circ} \mathrm{C} O, 159^{\circ} \mathrm{C} \nabla, 169^{\circ} \mathrm{C} \square, 179^{\circ} \mathrm{C} \diamond$ and $190^{\circ} \mathrm{C} \triangle$. Error bars represent the $95 \%$ confidence interval for selected experiments (at $179^{\circ} \mathrm{C}$ for corncobs and $169^{\circ} \mathrm{C}$ for almond shells, respectively).

Anhydroarabinose content decreased until 5\% for CC and $2-3 \%$ for AS. The proportion of the acetyl groups also decreased, until a final content of around $5 \%$ for both raw materials, because they were liberated and catalyzed the hydrolysis reaction. This fact can be evidenced by the $\mathrm{pH}$ of the final liquid mixture. It decreased with the increase of time at a certain temperature (Figure 3.3). For CC, the $\mathrm{pH}$ decreased until 
3.3 for the maximal reaction time (below $100 \mathrm{~min}$ ) for temperatures between 169 $190^{\circ} \mathrm{C}$. For lower temperatures, the reaction seemed to be not so strong, reaching a $\mathrm{pH}$ of 3.5 for the maximal reaction time at $159^{\circ} \mathrm{C}$ and 3.8 for $150^{\circ} \mathrm{C}$. For $\mathrm{AS}$, the $\mathrm{pH}$ was not so acidic, reaching in all the cases a $\mathrm{pH}$ of around 4 for the maximal reaction time at all the temperatures tested. This indicated that with the increase in temperature, or at a certain temperature, with the increase of the reaction time, more acetyl groups were hydrolyzed yielding acetic acid, which decreased the $\mathrm{pH}$ of the liquid.
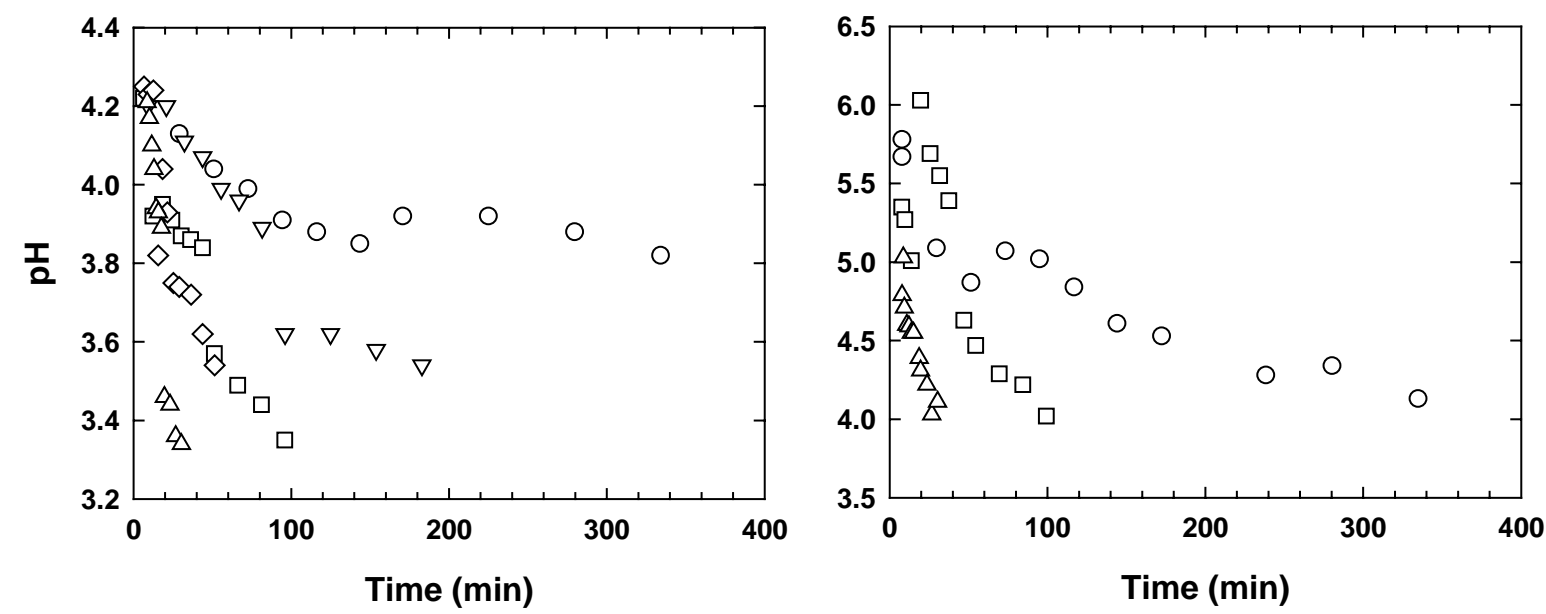

Figure 3.3. $\mathrm{pH}$ of the resultant liquid after the reaction, as function of temperature and reaction time. Corncobs (left), and almond shells (right): $150^{\circ} \mathrm{C} \bigcirc, 159^{\circ} \mathrm{C} \nabla, 169^{\circ} \mathrm{C} \square, 179^{\circ} \mathrm{C} \diamond$ and $190^{\circ} \mathrm{C} \triangle$.

Figure 3.4 shows the yield of the different cellulose products in the hydrolysis liquor, such as gluco-oligosaccharides (GOs), glucose and its degradation product, hydroxymethylfurfural (HMF). The yield of GOs was around $4 \%$ for CC, and $2 \%$ for AS, independently of the temperature or reaction time. The yield of glucose was between $4-6 \%$ of the cellulose in CC, with small influence of the reaction parameters. In the case of AS, the yield of glucose was dependant of the reaction parameters, showing a decrease in the glucose content from $2 \%$ until $0.5-1 \%$, at $20 \mathrm{~min}$ for $190^{\circ} \mathrm{C}$ and $330 \mathrm{~min}$ for $150^{\circ} \mathrm{C}$. The yield of $\mathrm{HMF}$ increased, reaching $1.5 \%$ of the original cellulose for CC, and almost $1 \%$ for AS. That behavior indicated that some low molecular weight cellulose was readily depolymerized, and was converted to GOs and glucose, which was then dehydrated to HMF in the liquid phase. 

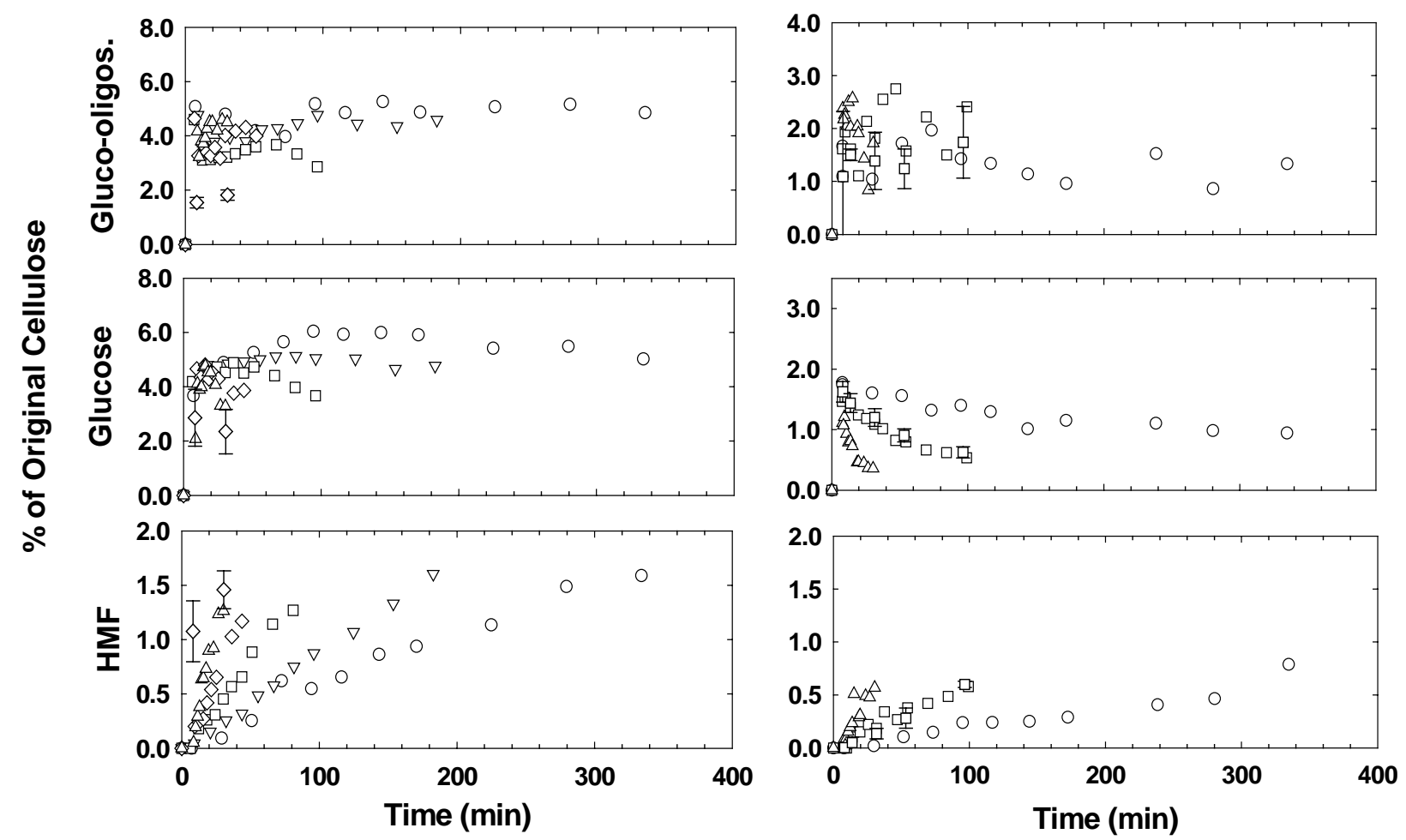

Figure 3.4. Distribution of the cellulose products in the liquid after the reaction (as \% of the original cellulose), as function of temperature and reaction time: gluco-oligosaccharides, glucose and HMF. Corncobs (left), and almond shells (right): $150^{\circ} \mathrm{C} O, 159^{\circ} \mathrm{C} \nabla, 169^{\circ} \mathrm{C} \square$,

$179^{\circ} \mathrm{C} \diamond$ and $190^{\circ} \mathrm{C} \triangle$. Error bars represent the $95 \%$ confidence interval for selected experiments (at $179^{\circ} \mathrm{C}$ for corncobs and $169^{\circ} \mathrm{C}$ for almond shells, respectively).

\subsubsection{Autohydrolysis of corncobs}

\subsubsection{Product distribution and reaction pathway}

Figure 3.5 shows the evolution of the fractional yield of the xylan remaining in the hydrolyzed lignocellulosic with reaction time for the five temperatures tested. As expected, the amount of xylan decreased continuously with time and the rate of hydrolysis was accelerated by temperature. The fractional yield of xylan in the solid decreased to around $20 \%$ in $300 \mathrm{~min}$ at $150^{\circ} \mathrm{C}$, while it took only $20 \mathrm{~min}$ to reach the same conversion at $190^{\circ} \mathrm{C}$. The composition of the xylan remaining in the solid changed as the hydrolysis reaction progressed. 

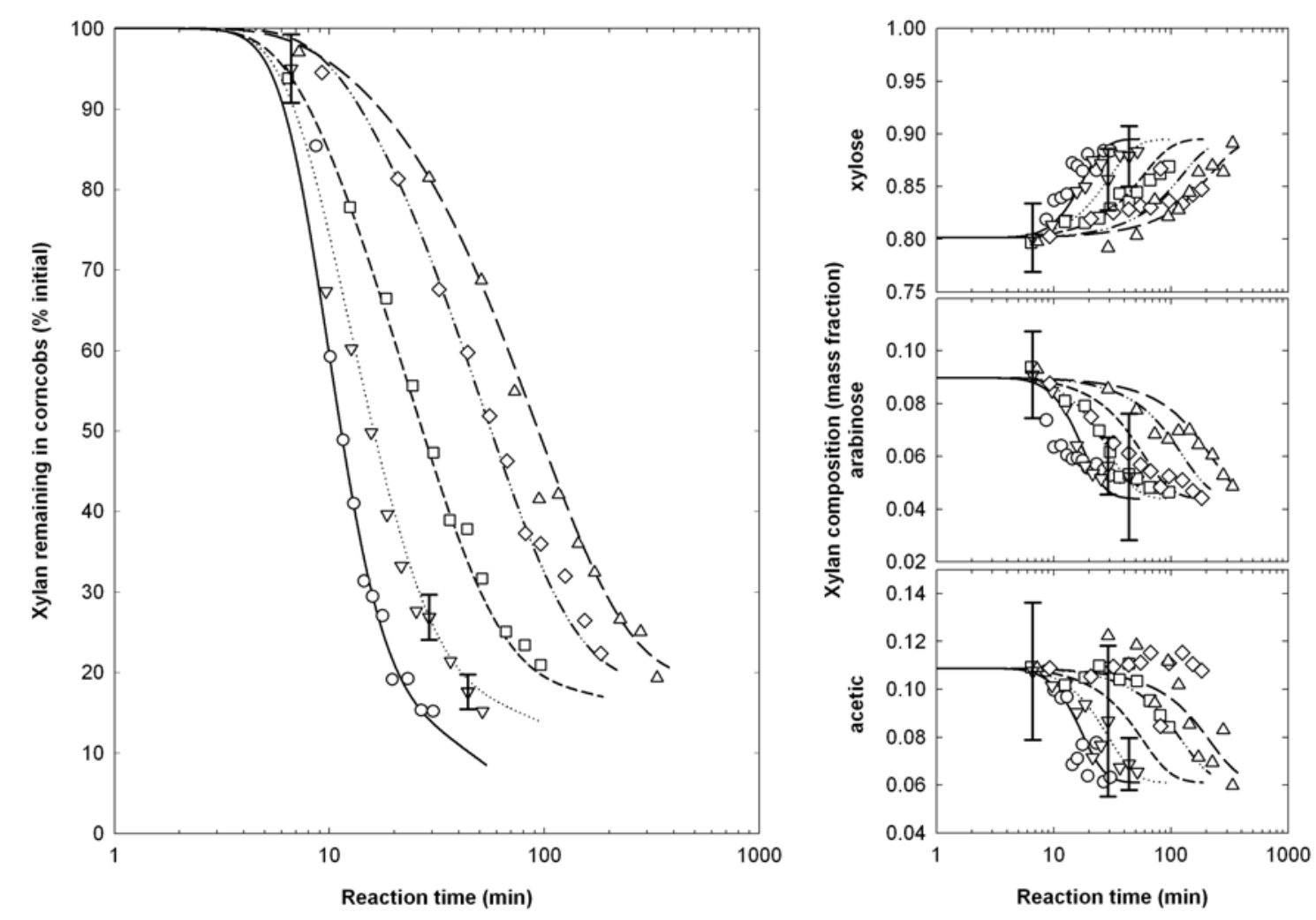

Figure 3.5. Yield and compositions of the xylan remaining in the hydrolyzed corncobs at autohydrolysis temperatures of $150^{\circ} \mathrm{C}(\triangle ;---), 159^{\circ} \mathrm{C}(\diamond ;-\cdot-\cdot \cdot \cdot), 169^{\circ} \mathrm{C}(\square ;------), 179^{\circ} \mathrm{C}(\nabla$; …...) and $190^{\circ} \mathrm{C}(\mathrm{O} ;-\longrightarrow)$. Points with error bars correspond to quadruplicate experiments for the $169^{\circ} \mathrm{C}$ series. Lines show the values calculated with the kinetic model using the best-fit parameters.

Figure 3.5 shows that the fraction of xylose increased from 0.801 for xylan in unreacted corncobs to around 0.890 for the samples hydrolyzed in the longest experiments, whereas the contents of arabinose and acetyl decreased from 0.090 to 0.045 and 0.109 to 0.065 , respectively, at all temperatures. However, the dispersion of the composition was high. Xylan hydrolysis proceeds through depolymerization to water-soluble xylo-oligosaccharides, which are also made up of xylose as the main component, arabinose and acetyl groups. 

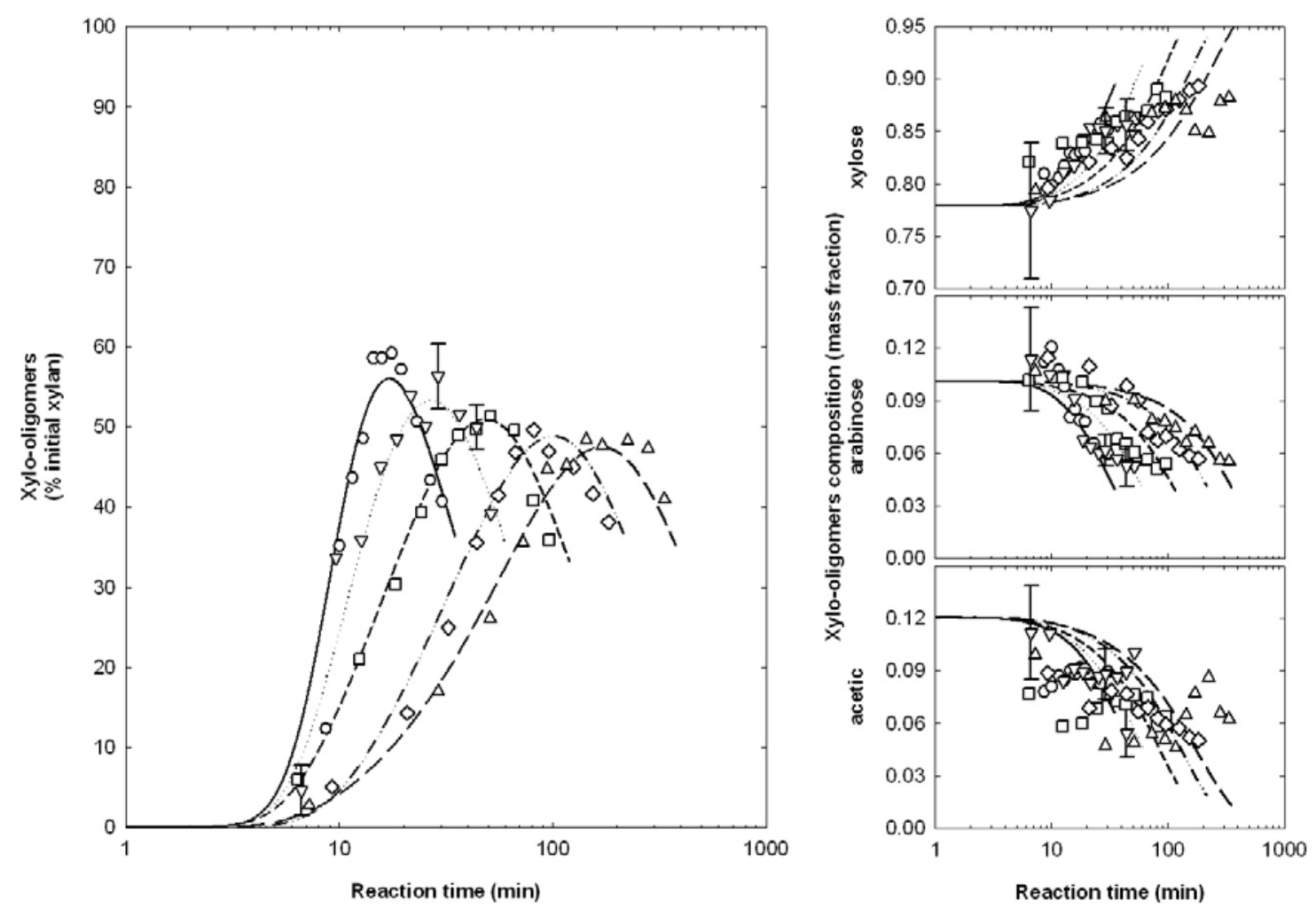

Figure 3.6. Yield and compositions of the xylo-oligosaccharides from corncobs at autohydrolysis temperatures of $150^{\circ} \mathrm{C}(\triangle ;---), 159^{\circ} \mathrm{C}(\diamond ;-\cdot-\cdot \cdot), 169^{\circ} \mathrm{C}(\square ;------), 179^{\circ} \mathrm{C}(\nabla$; …...) and $190^{\circ} \mathrm{C}(\mathrm{O} ;-$ - $)$. Points with error bars correspond to quadruplicate experiments for the $169^{\circ} \mathrm{C}$ series. Lines show the values calculated with the kinetic model using the best-fit parameters.

Figure 3.6 shows the yield of the xylo-oligosaccharides measured in the aqueous phase at the five reaction temperatures. The maximum yield was close to $50 \%$ of the xylan in corncobs at $150^{\circ} \mathrm{C}$ after $200 \mathrm{~min}$ of hydrolysis. Higher temperatures slightly favored an increase in the yield of xylo-oligosaccharides and it reached a maximum of $58 \%$ at $190^{\circ} \mathrm{C}$ and $15 \mathrm{~min}$ of hydrolysis. The chemical composition of the xylooligosaccharides was also dependent on reaction temperature and time. Extending the hydrolysis time at constant temperature produced xylo-oligosaccharides with higher content of xylose and a smaller presence of arabinose and acetyl groups.

Finally, Figure 3.7 shows the yields of the monomer products formed by the hydrolysis of the oligomers, xylose, arabinose and acetic acid, and furfural from the dehydration of both monosaccharides. The yields of all products increased steadily with time at all temperatures except for arabinose, which reached a maximum at a high 
hydrolysis time when its rate of degradation to furfural was greater than its rate of formation.
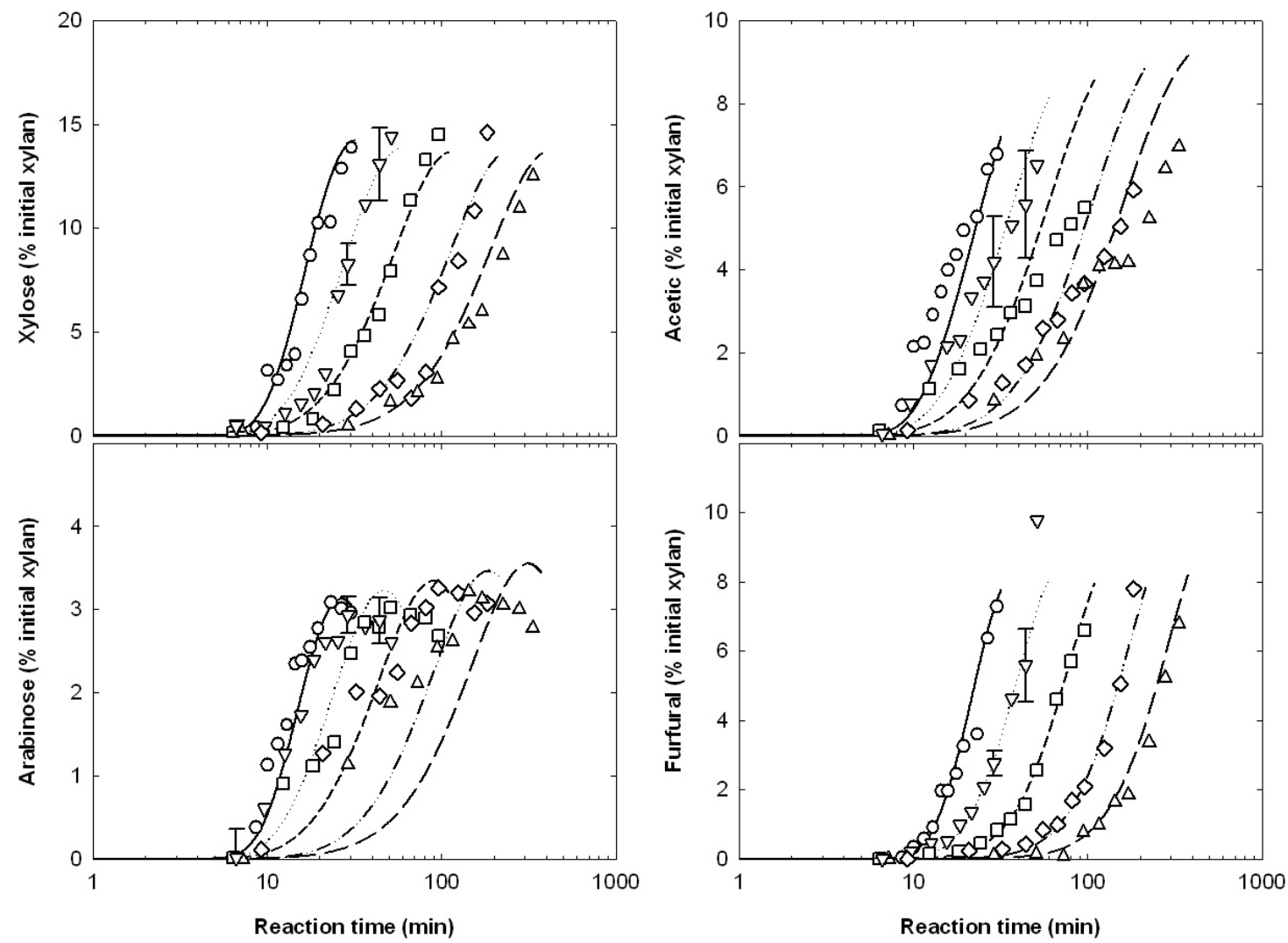

Figure 3.7. Yields of xylose, arabinose, acetic acid and furfural during corncobs autohydrolysis at $150^{\circ} \mathrm{C}(\triangle ;---), 159^{\circ} \mathrm{C}(\diamond ;-\cdot-\cdot \cdot), 169^{\circ} \mathrm{C}(\square ;-----), 179^{\circ} \mathrm{C}(\nabla ; \cdots \cdots \cdot)$ and $190^{\circ} \mathrm{C}(\bigcirc ;--)$. Points with error bars correspond to quadruplicate experiments for the $169^{\circ} \mathrm{C}$ series. Lines show the values calculated with the kinetic model using the best-fit parameters.

The change in composition of the xylan remaining in the hydrolyzed corncobs during hydrolysis can be explained by two limiting situations:

1. The cleavage reactions of acetyl and arabinose, which are lateral chains in the native xylan from corncobs, are much faster than the depolymerization of the backbone xylose chain. Therefore, most arabinose and acetic acid is formed directly from xylan in the solid, and the composition of the xylan remaining in the solid changes with time. 
This also changes the composition of the xylo-oligosaccharides that are formed as the hydrolysis proceeds.

2. Native xylan is heterogeneous in composition and can be considered to be made up of at least two different fractions. Each fraction has a different composition and a different susceptibility toward the hydrolysis reaction. In this case, high-molar-mass xylo-oligosaccharides readily evolve from xylan and are then hydrolyzed in the liquid phase to xylose, arabinose and acetic acid. Because the two fractions of xylan have different rates of hydrolysis, they solubilize at different rates and cause the apparent change in composition of the xylan that remains in the solid. Because the unhydrolyzed xylan is richer in xylose as the hydrolysis proceeds, it is concluded that the xylan fraction with the higher contents of arabinose and acetyl is depolymerized to xylo-oligosaccharides and solubilized more easily.

If the first explanation is true, is expected that the yields of arabinose and acetic acid to rise sharply at the beginning of the reaction. However, HPLC analyses of the soluble products showed that acetyl and arabinose are found preferentially in the oligomers rather than as free monomers. This agrees with the results for paper birch autohydrolysis, which showed that the rate for direct deacetylation of xylan was negligible compared with that for the formation of xylo-oligosaccharides above $150^{\circ} \mathrm{C}$ [15]. Furthermore, the xylo-oligosaccharides obtained at the shortest reaction times showed a lower content of xylose and higher proportions of arabinose and acetyl groups than the average composition of the xylan in corncobs shown in Table 3.1. This indicates that the xylo-oligosaccharides formed at the beginning of the reaction did not lose a significant amount of lateral chains.

The GPC analyses of the soluble products for the experiments at short reaction times were used to determine the molar mass distribution of the xylo-oligosaccharides (see Figure 3.8). 


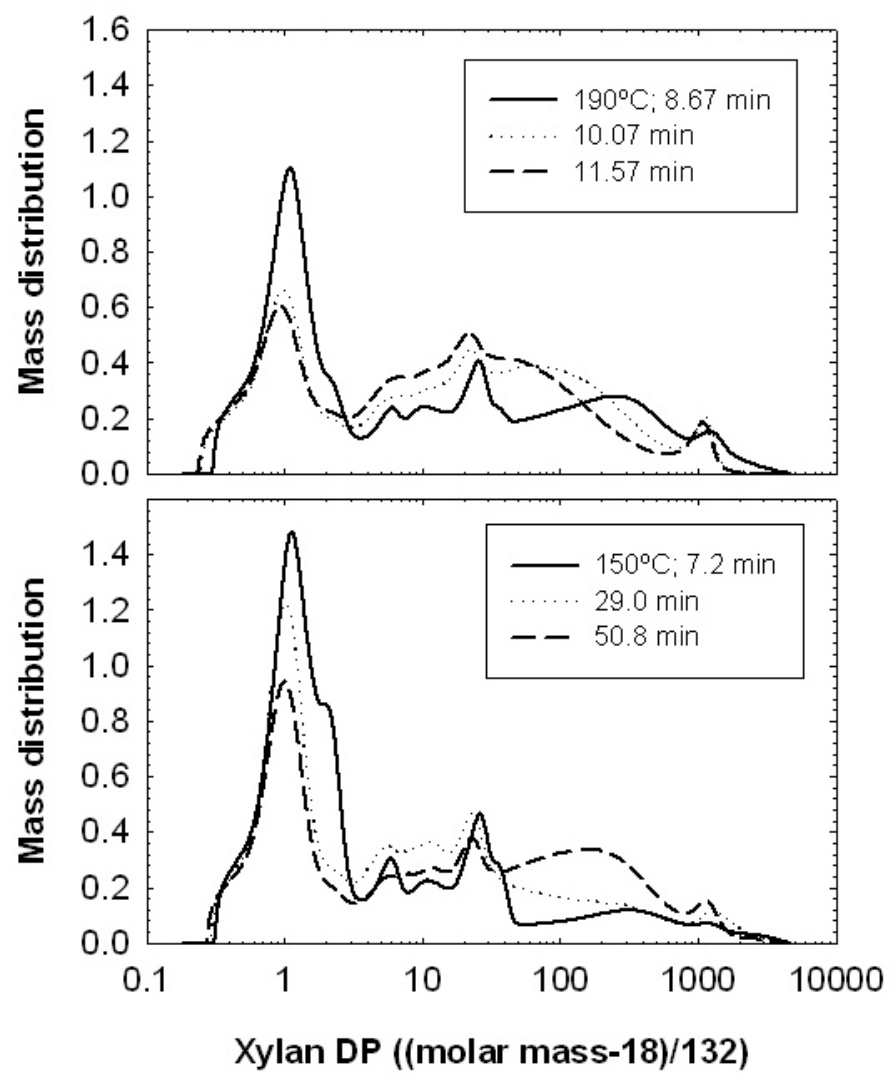

Figure 3.8. Molar mass distributions of the soluble products for the experiments performed at $190^{\circ} \mathrm{C}$ (top) and $150^{\circ} \mathrm{C}$ (bottom), and short reaction times. The degree of polymerization of xylan was calculated by assuming a monomer molar mass of $132 \mathrm{~g} / \mathrm{mol}$ (anhydrous xylose and arabinose). Degrees of polymerization below 1 indicates species with lower molar masses, such as acetic acid and furfural.

The degree of polymerization (DP) shown in the molar mass distributions was calculated assuming that the molar mass of the monomer was $132 \mathrm{~g} / \mathrm{mol}$, which is the molar mass of an anhydrous pentose (xylose and arabinose). This is only an approximate value, therefore, because the presence of the acetyl groups is not considered. This analysis indicates that the molar mass distribution of the oligomers is very broad and that large oligomers are solubilized significantly even at a very short reaction time. It must also be considered that the large peak at low DP observed for the experiments at the shortest reaction time is essentially caused by the extractives and other low-molar-mass components of the native corncobs rather than by monosaccharides or acetic acid derived from xylan, which, according to data in Figure 3.7, still present very low yields. It can therefore be concluded that native xylan (Xy) can be described by two fractions with different compositions and reactivities, as can 
be seen in the reaction pathway proposed in Figure 3.9. The first fraction, $X y_{1}$, has a higher content of arabinose and acetyl groups than the less reactive fraction, $X y_{2}$, and it is assumed to be more reactive and to depolymerize faster during autohydrolysis. Both xylans are hydrolyzed to a mixture of water-soluble oligomers, $X O$, which are then hydrolyzed in the liquid phase to monomers: xylose $(X y l)$, arabinose (Ara) and acetic acid (Ace). Xylose and arabinose dehydrate to furfural (Fur), which is unstable at the reaction conditions and forms condensation and degradation products $(C D P)$.
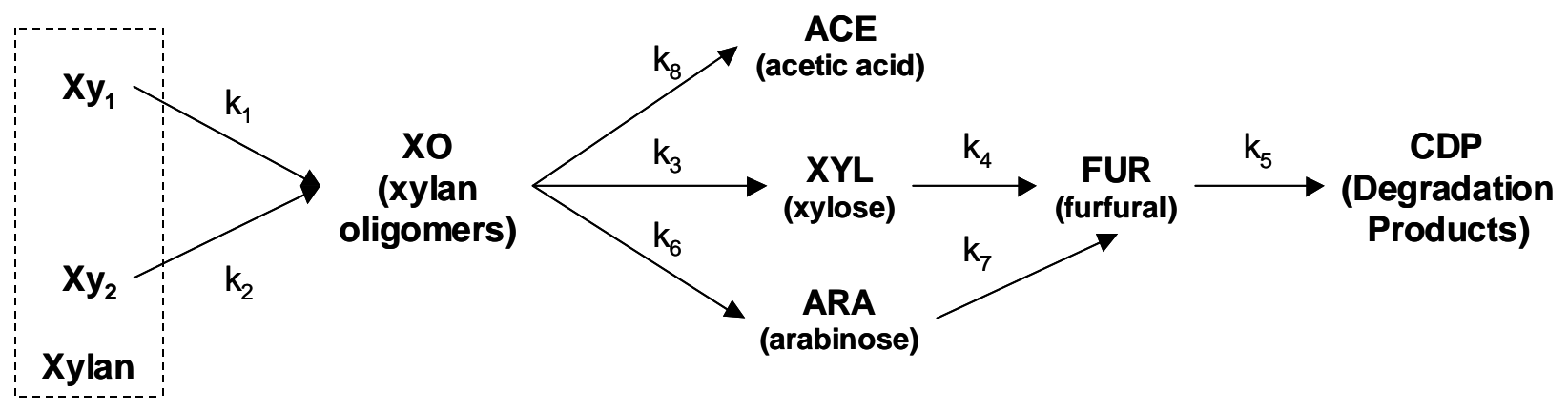

Figure 3.9. Reaction pathway for xylan autohydrolysis from corncobs.

This is a simplified reaction pathway as arabinose and acetic acid will probably be formed directly from xylan to a certain extent, and furfural has been reported to be formed by direct dehydration of small xylo-oligosaccharides. However, it provides a qualitative explanation of the experimental results obtained. The apparent heterogeneity of xylan and the different rates of hydrolysis for the two xylan fractions are probably caused by a varying degree of association with lignin and cellulose in the cell-wall structure. Models based on two xylan fractions conveniently describe this polymer for the purpose of kinetic modeling and have been widely used for the hydrolysis of hardwoods [16-18] and annual plants [8, 17].

\subsubsection{Kinetics of xylan depolymerization}

The autohydrolysis of hemicelluloses has received considerable attention, and several reaction schematics and kinetic models are available in the literature. A simple approach is to use severity parameters that measure the intensity of the reaction conditions by lumping time, temperature, and acid concentration into a single parameter (severity) that is then used to correlate the yields of the different products 
[19-24]. Another approach is to use formal kinetics to describe the behavior of the system according to reaction pathways inferred from experimental data. Most models consider a sequence of consecutive hydrolysis reactions: hemicellulose in the solid biomass is hydrolyzed to soluble oligomers, which are further depolymerized in the aqueous phase to monosaccharides. Xylose and arabinose are also dehydrated to furfural, and the six-carbon monosaccharides are degraded to hydroxymethylfurfural (HMF). Finally, furfural and HMF are converted into condensation and degradation products [15]. The hydrolytic reactions are initiated by the hydronium cation formed by water dissociation, and further accelerated once free uronic acids and acetic acid are formed by the hydrolysis of the uronic and acetyl groups in hemicellulose. Some models propose two types of hemicellulose in the solid with different reactivities towards hydrolysis [16-18, 25]. Other models include the existence of two fractions of oligomers in solution with different molar masses [26]. All kinetic models consider a homogeneous system with pseudo-first-order reactions. However, in all of the kinetic models thus far presented in the literature, xylan is loosely defined as the total amount of pentoses present in the product fractions, but the composition of the native xylan and the changes in the composition of the xylan that remains in the solid and of the xylo-oligosaccharides during hydrolysis are not taken into account. The kinetic model developed here is more rigorous because accounts for the changes in the compositions of xylan and the xylo-oligosaccharides. Xylan is considered to be a polymer made up of three constitutive monomers: xylose, arabinose and acetic acid. Clearly, xylan also contains variable amounts of uronic acids, but they were not measured and are not included in the results. However, the kinetic model can be easily modified to account for the presence of uronic acids in native xylan, in the xylo-oligosaccharides, and as free monomeric products. The experiments on the autohydrolysis of corncobs were developed in quasi-isothermal tubing-bomb reactors, and provided information about variations in the yield and composition of both the xylan in the solid and the xylooligosaccharides that are formed as primary products during autohydrolysis, and these data were used to estimate the parameters of the kinetic model.

The reaction pathway in Figure 3.9 was used to develop a model for the kinetics of xylan depolymerization. The model assumes that the composition of each of the two xylan fractions in the lignocellulosic does not change with conversion, that there is no direct formation of monomers (i.e. xylose, arabinose and acetic acid) from xylan in the lignocellulosic solid, that monomers are formed solely by depolymerization of the 
oligomers, and that the rates of monomer formation from the oligomers are independent of the molar mass, structure and composition of the oligomers. If a first order dependency of the reaction rates with concentration is considered, the individual mass balances for the reactive species in the system are described by Equations 3.1 to 3.9. $C_{j}$ denotes the concentration of the species $j$ expressed as a mass percent of the initial xylan that has been converted into the species $j$, and the average composition of the oligomers is expressed by $x_{\mathrm{XO}-\mathrm{X} y \mathrm{l},} x_{\mathrm{XO}-\mathrm{Ara}}$ and $x_{\mathrm{XO}-\mathrm{Ace}}$, which are the mass fractions of anhydroxylose, anhydroarabinose, and acetyl, respectively, in the oligomers. The specific reaction rates, $k_{i}$, vary with temperature following the Arrhenius relationship (Equation 3.10).

$$
\begin{aligned}
& C_{X y}=C_{X y_{1}}+C_{X y_{2}} \\
& \frac{d C_{X y_{1}}}{d t}=-k_{1} C_{X y_{1}} \\
& \frac{d C_{X y_{2}}}{d t}=-k_{2} C_{X y_{2}} \\
& \frac{d C_{X O}}{d t}=k_{1} C_{X y_{1}}+k_{2} C_{X y_{2}}-\left(k_{3} X_{X O-X y l}+k_{6} X_{X O-A r a}+k_{8} X_{X O-A c e}\right) C_{X O} \\
& \frac{d C_{X y l}}{d t}=k_{3} X_{X O-X y l} C_{X O}-k_{4} C_{X y l} \\
& \frac{d C_{A r a}}{d t}=k_{6} x_{X O-A r a} C_{X O}-k_{7} C_{A r a} \\
& \frac{d C_{\text {Ace }}}{d t}=k_{8} X_{X O-A c e} C_{X O} \\
& \frac{d C_{\text {Fur }}}{d t}=k_{4} C_{X y l}+k_{7} C_{\text {Ara }}-k_{5} C_{\text {Fur }} \\
& \frac{d C_{C D P}}{d t}=k_{5} C_{F u r} \\
& k_{i}=k_{i 0} \exp \left(\frac{-E_{a i}}{R T(t)}\right)
\end{aligned}
$$


To solve this set of equations, is necessary to know how the average composition of the xylo-oligosaccharides ( $x$ xO-Xyl, $x$ xO-Ara and $x$ xO-Ace) changes with time. Equation 3.4 is therefore replaced by Equations 3.4.1 to 3.4.4, which are the individual balances for anhydrous xylose, arabinose, and acetyl in the oligomers.

$$
\begin{aligned}
& C_{X O}=C_{X O-X y l}+C_{X O-A r a}+C_{X O-A c e} \\
& \frac{d C_{X O-X y l}}{d t}=k_{1} X_{X y_{1}-X y l} C_{X y_{1}}+k_{2} X_{X y_{2}-X y l} C_{X y_{2}}-k_{3} X_{X O-X y l} C_{X O} \\
& \frac{d C_{X O-A r a}}{d t}=k_{1} X_{X y_{1}-A r a} C_{X y_{1}}+k_{2} X_{X y_{2}-A r a} C_{X y_{2}}-k_{6} X_{X O-A r a} C_{X O} \\
& \frac{d C_{X O-A c e}}{d t}=k_{1} X_{X y_{1}-A c e} C_{X y_{1}}+k_{2} X_{X y_{2}-A c e} C_{X y_{2}}-k_{8} X_{X O-A c e} C_{X O}
\end{aligned}
$$

The average composition of the oligomers is expressed as mass fractions by Equations 3.11 to 3.13 .

$$
\begin{aligned}
& x_{X O-X y l}=\frac{C_{X O-X y l}}{C_{X O-X y l}+C_{X O-A r a}+C_{X O-A c e}} \\
& x_{X O-A r a}=\frac{C_{X O-A r a}}{C_{X O-X y l}+C_{X O-A r a}+C_{X O-A c e}} \\
& x_{X O-A c e}=\frac{C_{X O-A c e}}{C_{X O-X Y l}+C_{X O-A r a}+C_{X O-A c e}}
\end{aligned}
$$

The set of equations can now be solved numerically provided that the temperature profile and the initial boundary conditions are known. Specifically, these are the amounts of each type of xylan present in the native corncobs, $\left(\mathrm{C}_{x y 1}[0]\right.$ and $\left.C_{X y 2}[0]\right)$ and the compositions of both xylan fractions ( $x_{X y 1-X y l} x_{X y 2}-X_{y} l, x_{X y 1-A r a}, x_{X} y 2-A r a$, $x_{X y 1-A c e}$ and $\left.x_{X y 2-A c e}\right)$. Obviously, these data are unknown because the analysis of the corncobs provides only the total amount of xylan $\left(C_{X y}[0]\right)$ and its composition $\left(x_{X y-X y l}[0]\right.$, $\left.x_{X y-A r a[0],} x_{X y-A c e}[0]\right)$, which is the average of the two xylan fractions. The average composition of xylan is related to the average compositions of xylan fractions by Equations 3.14 to 3.16 . 


$$
\begin{aligned}
& x_{X y-X y l}=\frac{C_{X y_{1}} X_{X y_{1}-X y l}+C_{X y_{2}} x_{X y_{2}-X y l}}{C_{X y_{1}}+C_{X y_{2}}} \\
& x_{X y-A r a}=\frac{C_{X y_{1}} x_{X y_{1}-A r a}+C_{X y_{2}} x_{X y_{2}-A r a}}{C_{X y_{1}}+C_{X y_{2}}} \\
& x_{X y-A c e}=\frac{C_{X y_{1}} x_{X y_{1}-A c e}+C_{X y_{2}} x_{X y_{2}-A c e}}{C_{X y_{1}}+C_{X y_{2}}}
\end{aligned}
$$

The experimental data were used to fit the unknown parameters in the model by means of the least-squares objective function $F$ defined by Equation 3.17, where $n$ is the number of experimental data points and the first term accounts for the concentrations of all species measured experimentally (Xy, XO, Xyl, Ara, Ace, Fur and $C D P$ ), the second term includes the composition of the xylan oligomers, and the third term expresses the average composition of the xylan remaining in the hydrolyzed lignocellulosic. The superscript * denotes experimental values, whereas the other terms are model predictions. Optimization was performed using the non-isothermal data from all the experiments with a Newton-type minimization algorithm that allowed to calculate the optimal values for the frequency factors ( $k_{1}$ to $\left.k_{8}\right)$ and activation energies ( $E_{a 1}$ to $\left.E_{a 8}\right)$ of the rate constants, the composition of each xylan fraction ( $x_{X y 1-X y l,} x_{X y 2-X y l}$, $x_{X y 1-A r a}, x_{X y 2-A r a}, x_{X y 1-A c e}$ and $\left.x_{X y 2-A c e}\right)$ and the fraction of each xylan type in the corncobs $\left(C_{x y 1}[0]\right.$ and $\left.C_{x y 2}[0]\right)$. Integration of the ordinary differential equations that describe the system was performed numerically with a Runge-Kutta algorithm. The temperature time profile recorded experimentally for each data point was used to integrate the ordinary differential equations. Several restrictions were included in the model to avoid convergence to unreal solutions (Equations 3.18 to 3.21 ).

$$
\begin{aligned}
& F=\sum_{h=1}^{n}\left[\sum_{i=1}^{7}\left(\frac{C_{h, i}-C_{h, i}^{*}}{100}\right)^{2}+\sum_{j=1}^{3}\left(x_{X O-h, j}-x_{X O-h, j}^{*}\right)^{2}+\sum_{k=1}^{3}\left(x_{X y-h, k}-x_{X y-h, k}^{*}\right)^{2}\right] \\
& k_{0 j}>0 \text { and } E_{a j}>0 \quad \text { for } \mathrm{j}=1-8 \\
& C_{X y_{2}}[0]=C_{X y}[0]-C_{X y_{1}}[0] \\
& x_{X y_{1}-\text { Ace }}=1.0-\left(x_{X y_{1}-X y l}+x_{X y_{1}-\text { Ara }}\right)
\end{aligned}
$$




$$
x_{X y_{2}-A c e}=1.0-\left(x_{X y_{2}-X y l}+X_{X y_{2}-A r a}\right)
$$

Figures 3.5 - 3.7 compare the experimental yield of the products and the values calculated with the model for the experiments at 150,159, 169, 179 and $190^{\circ} \mathrm{C}$. Figure 3.5 shows that the yield of xylan that remains in the hydrolyzed solid is accurately predicted by the model, as there is a good agreement between the experimental data and the model at all temperatures. The model also gives a fair description of the composition of the unreacted xylan. Figure 3.6 compares the experimental yield of xylo-oligosaccharides with the model calculations. The model predicts the general trends of the changes in the composition of the xylo-oligosaccharides with time, but there is limited agreement with the experiments because of the scatter of the experimental data. Figure 3.7 compares the experimental yields of xylose, arabinose, acetic acid, and furfural with those calculated with the model. Again, the model is in good agreement with the experimental data at all reaction temperatures. It can therefore be concluded that the model presented here is suitable for describing the kinetics of the reactions involved in xylan autohydrolysis and that it correctly describes the changes in the compositions of xylan and its oligomers during the reaction.

The reaction parameters were calculated according to the model, and the results are presented in Table 3.2, which reports the optimal values for the activation energies and the frequency factors. Table 3.3 lists the amount of each type of xylan and the corresponding compositions. The activation energy for xylan hydrolysis was 127 $\mathrm{kJ} / \mathrm{mol}$ for the most reactive xylan. This is close to the value of $125 \mathrm{~kJ} / \mathrm{mol}$ reported for corncob autohydrolysis when two types of hydrolysable xylan were assumed [8], and falls within the values of 126 and $156 \mathrm{~kJ} / \mathrm{mol}$ reported for the dilute acid hydrolysis of white birch wood [16]. The least reactive xylan had an activation energy of $251 \mathrm{~kJ} / \mathrm{mol}$, which is substantially higher than the value of $186 \mathrm{~kJ} / \mathrm{mol}$ reported in another study [8]. The activation energies for xylose and arabinose formation by the hydrolysis of the xylo-oligosaccharides were 119 and $106 \mathrm{~kJ} / \mathrm{mol}$, respectively, and the activation energies for their dehydration to furfural were $122 \mathrm{~kJ} / \mathrm{mol}$ for xylose and $125 \mathrm{~kJ} / \mathrm{mol}$ for arabinose. Some values reported for the dehydration of xylose to furfural are 109 $\mathrm{kJ} / \mathrm{mol}$ for the autohydrolysis of corncobs [26], $113 \mathrm{~kJ} / \mathrm{mol}$ for the dilute acid hydrolysis of pure xylose [27], and $128 \mathrm{~kJ} / \mathrm{mol}$ for the dilute acid hydrolysis of xylooligosaccharides from corncobs [28]. The activation energy for the disappearance of furfural was $132 \mathrm{~kJ} / \mathrm{mol}$, and the deacetylation of the xylan oligomers had an activation 
energy of $65.1 \mathrm{~kJ} / \mathrm{mol}$, which is virtually identical to the value of $66.4 \mathrm{~kJ} / \mathrm{mol}$ that was reported for the deacetylation of corncob xylo-oligosaccharides in acidic media [28].

\begin{tabular}{ccc}
\hline$k_{j}\left(\mathbf{m i n}^{-1}\right)$ & $E_{a j}(\mathbf{k J} / \mathbf{m o l})$ & $\ln \left(k_{0 j} / \mathbf{m i n}^{-1}\right)$ \\
\hline$k_{1}$ & 127.3 & 31.52 \\
$k_{2}$ & 251.7 & 61.41 \\
$k_{3}$ & 119.0 & 27.55 \\
$k_{4}$ & 122.5 & 29.36 \\
$k_{5}$ & 132.0 & 32.48 \\
$k_{6}$ & 106.2 & 25.08 \\
$k_{7}$ & 125.2 & 29.82 \\
$k_{8}$ & 65.1 & 14.18 \\
\hline
\end{tabular}

Table 3.2. Best-fit values for the activation energies and the frequency factors of rate constants $\mathrm{k}_{1}$ to $\mathrm{k}_{8}\left(\mathrm{~min}^{-1}\right)$.

The amounts of each xylan type in the native corncobs were estimated to be $80.3 \%$ for type- 1 xylan and $19.7 \%$ for the less reactive type-2. The average mass composition of the most reactive type- 1 xylan was $77.9 \%$ xylan (anhydroxylose), $10.1 \%$ arabinan (anhydroarabinose) and $12.0 \%$ acetyl. The low reactivity xylan (type-2) had $89.5 \%$ xylan, around $4.4 \%$ arabinan and $6.1 \%$ of acetyl.

\begin{tabular}{lcc}
\hline & Xylan type 1 & Xylan type 2 \\
\hline Content (\% of xylan) $-C_{X y j}[0]$ & 80.3 & 19.7 \\
Anhydroxylose $-x_{X y j-X y l}$ & 0.779 & 0.895 \\
Anhydroarabinose $-x_{X y j-A r a}$ & 0.101 & 0.044 \\
Acetyl $-x_{X y j-A c e}$ & 0.120 & 0.061 \\
\hline
\end{tabular}

Table 3.3. Best-fit values for the amounts and compositions of the two types of xylan in native corncobs. 


\subsubsection{Autohydrolysis of almond shells}

\subsubsection{Product distribution and reaction pathway}

Xylans are polyoses that are formed by a homopolymer backbone of xylose units. Several functional groups (uronic acids, arabinose, galactose, and acetyl and ferulic acids) can be attached to the xylan backbone in variable amounts, which results in the large diversity of xylan structures found in plants [29, 30]. Xylan was considered to be a polymer made up of three constitutive monomers: xylose, arabinose and acetic acid. Xylan from almond shells should contain variable amounts of glucuronic and ferulic acids as well, but it was no possible to measure them accurately, and they were not included in the results. Consequently, the quantity of xylan in the hydrolyzed solid and the yield of xylo-oligosaccharides were calculated from the amounts of anhydrous xylose, arabinose and acetic acid determined by quantitative hydrolysis and HPLC analysis.
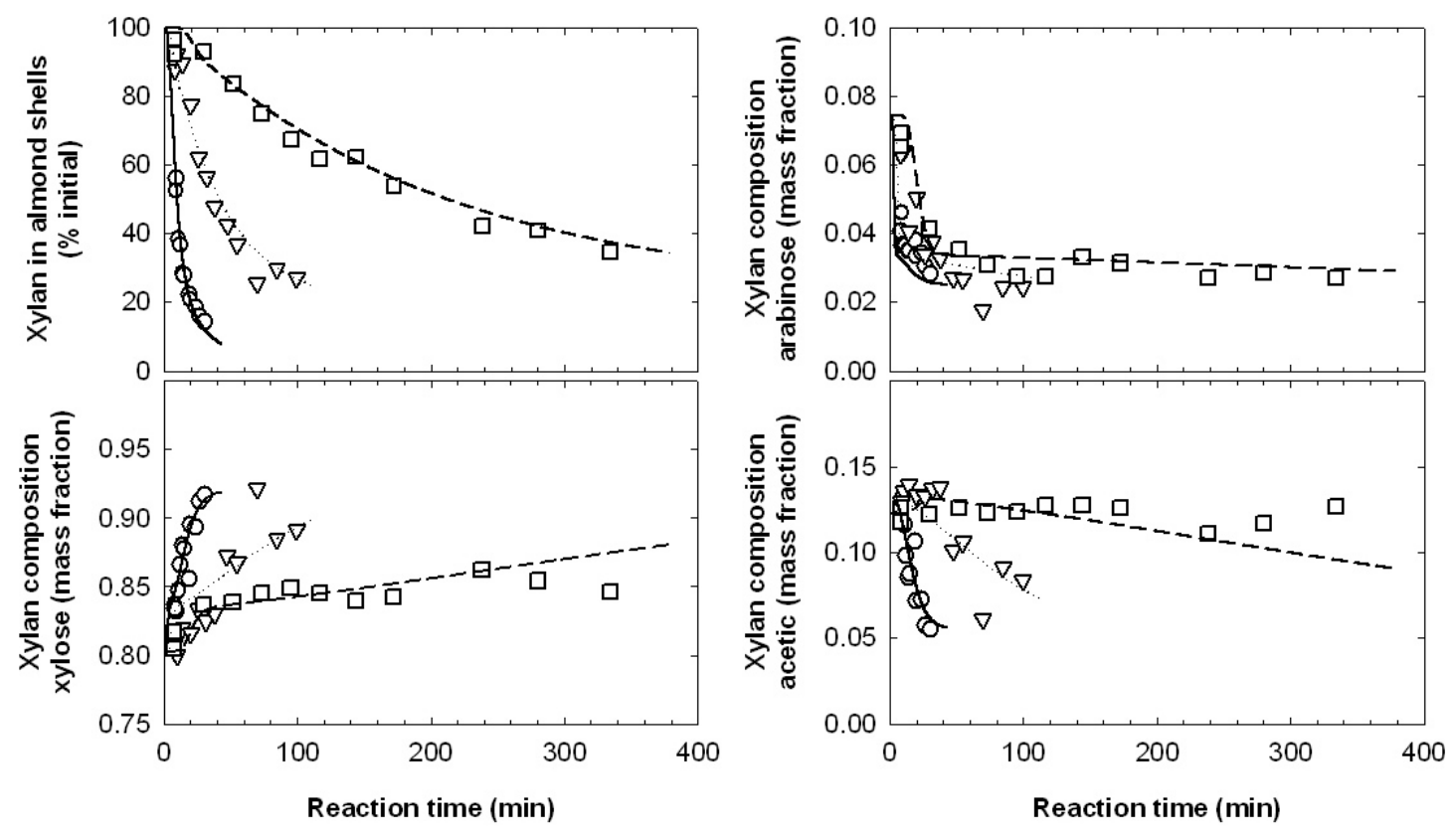

Figure 3.10. Amount and composition of the unreacted xylan remaining in the hydrolyzed

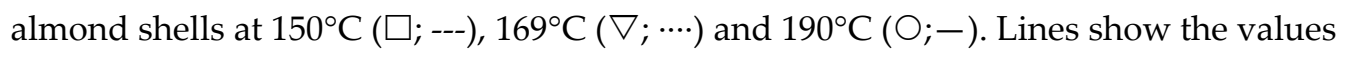
calculated with the kinetic model using the best-fit parameters. The amount of xylan is expressed as percentage of the xylan in native almond shells, while the composition is expressed as mass fraction of the remaining xylan. 
Figure 3.10 shows the xylan that remains in the hydrolyzed almond shells at the three temperatures tested, expressed as fraction of the initial xylan in the untreated almond shells. Xylan decreased to $35 \%$ of the initial composition in $335 \mathrm{~min}$ at $150^{\circ} \mathrm{C}$, while it took only $13 \mathrm{~min}$ to reach the same conversion at $190^{\circ} \mathrm{C}$. After $30 \mathrm{~min}$ at the latter temperature, only $15 \%$ of the initial xylan remained in the hydrolyzed solid. The composition of the xylan changed as the hydrolysis progressed. In general, the mass fraction of xylose in xylan increased while that of arabinose decreased. Acetyl groups reached a maximum at an intermediate hydrolysis time.
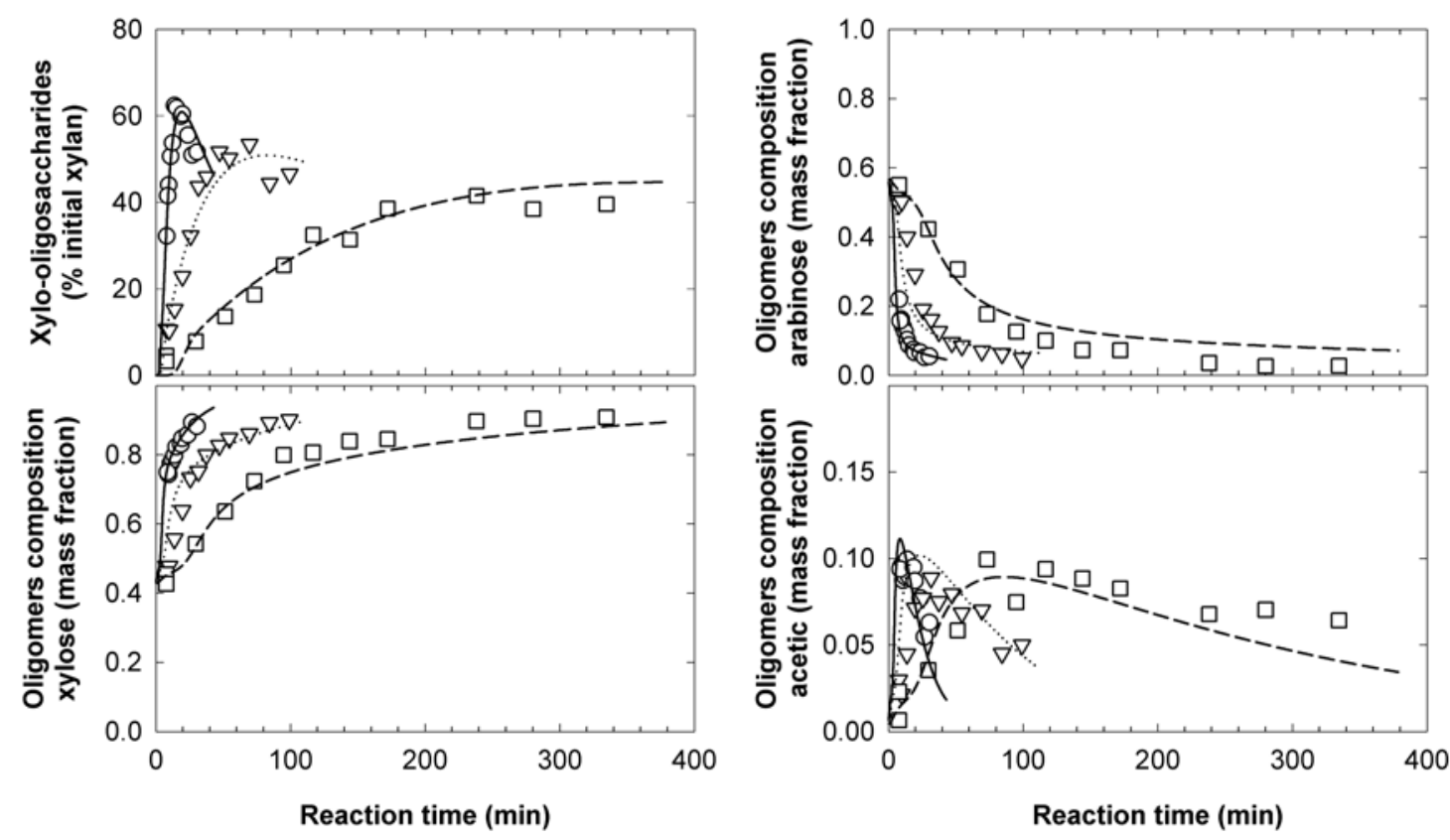

Figure 3.11. Yield and composition of the xylo-oligosaccharides at $150^{\circ} \mathrm{C}(\square ;---), 169^{\circ} \mathrm{C}(\nabla ; \cdots)$ and $190^{\circ} \mathrm{C}(\mathrm{O} ;-)$. Lines show the values calculated with the kinetic model using the best-fit parameters. The yield of xylo-oligosaccharides is expressed as percentage of the xylan in native almond shells, while the composition is expressed as mass fraction of the xylo-oligosaccharides.

The yield of the xylo-oligosaccharides measured in the aqueous phase at the three reaction temperatures is shown in Figure 3.11, expressed as percentage of the xylan in the untreated almond shells. The maximum yield at $150^{\circ} \mathrm{C}$ was $\sim 42 \%$ after 300 min of hydrolysis. Higher temperature favored an increase in the yield of xylooligosaccharides, which reached a maximum of $63 \%$ at $190^{\circ} \mathrm{C}$ and $19 \mathrm{~min}$ of hydrolysis. The chemical composition of the xylo-oligosaccharides was also influenced by 
temperature and time. Those produced at short reaction time had a high content of arabinose, but it decreased to much lower values after a few minutes of hydrolysis. The content of xylose increased steadily with reaction time, and acetyl groups reached a maximum along hydrolysis.

Figure 3.12 shows the molar mass distribution of the xylo-oligosaccharides at selected times of hydrolysis for the experiments at $150^{\circ} \mathrm{C}, 169^{\circ} \mathrm{C}$ and $190^{\circ} \mathrm{C}$. The normalized areas of the molar mass distribution plots were multiplied by the yield of xylo-oligosaccharides of each experiment for better interpretation. The GPC analysis only provided a qualitative description of the molar mass distribution of the xylooligosaccharides since it was performed on samples of the hydrolysis liquid and it accounts for all soluble products. This includes xylo-oligosaccharides, but it also includes monosaccharides and their degradation products, lignin-derived products, and other constituents of the almond shells such as inorganic salts, organic extractives and minor amounts of protein and pectin, which are solubilized during hydrolysis. The latter are present in almond shells at typical levels of $1.0 \%$ and $0.58 \%$, respectively [31].

At the beginning of the hydrolysis process, the soluble products comprised a wide range of molar masses. After $7.8 \mathrm{~min}$ at $150^{\circ} \mathrm{C}$ the xylo-oligosaccharides had a very wide mass distribution that covered from 0.1 to $1000 \mathrm{kDa}$, and shown four characteristic peaks at 248, 3.9, 1.6 and $0.235 \mathrm{kDa}$. The high molar mass peak at $248 \mathrm{kDa}$ decreased because of the hydrolysis of the solubilized xylo-oligosaccharides as the reaction proceeded, but there were some oligomers of molar mass $>200 \mathrm{kDa}$ present even at a very long reaction time $\left(230 \mathrm{~min}\right.$ at $\left.150^{\circ} \mathrm{C}\right)$. This means that a small fraction of high molar mass xylo-oligosaccharides was formed during most of the extent of the reaction. However, the molar mass distribution of the oligomers narrowed as the hydrolysis advanced. At $150^{\circ} \mathrm{C}$ and 95 min most of the xylo-oligosaccharides had a molar mass $<100 \mathrm{kDa}$; there was a new and broad peak around $20 \mathrm{kDa}$, and the peaks at 3.9, 1.6 and $0.235 \mathrm{kDa}$ had also gained in area. These peaks shifted toward lower molar masses as the hydrolysis went longer. The $20 \mathrm{kDa}$ peak shifted to $16 \mathrm{kDa}$ at 117 min and to $10 \mathrm{kDa}$ at $172 \mathrm{~min}$. For the longest experiment, $335 \mathrm{~min}$, this peak had disappeared. The peaks at 3.9 and $1.6 \mathrm{kDa}$ shifted toward 3.7 and $1.2 \mathrm{kDa}$, respectively. 

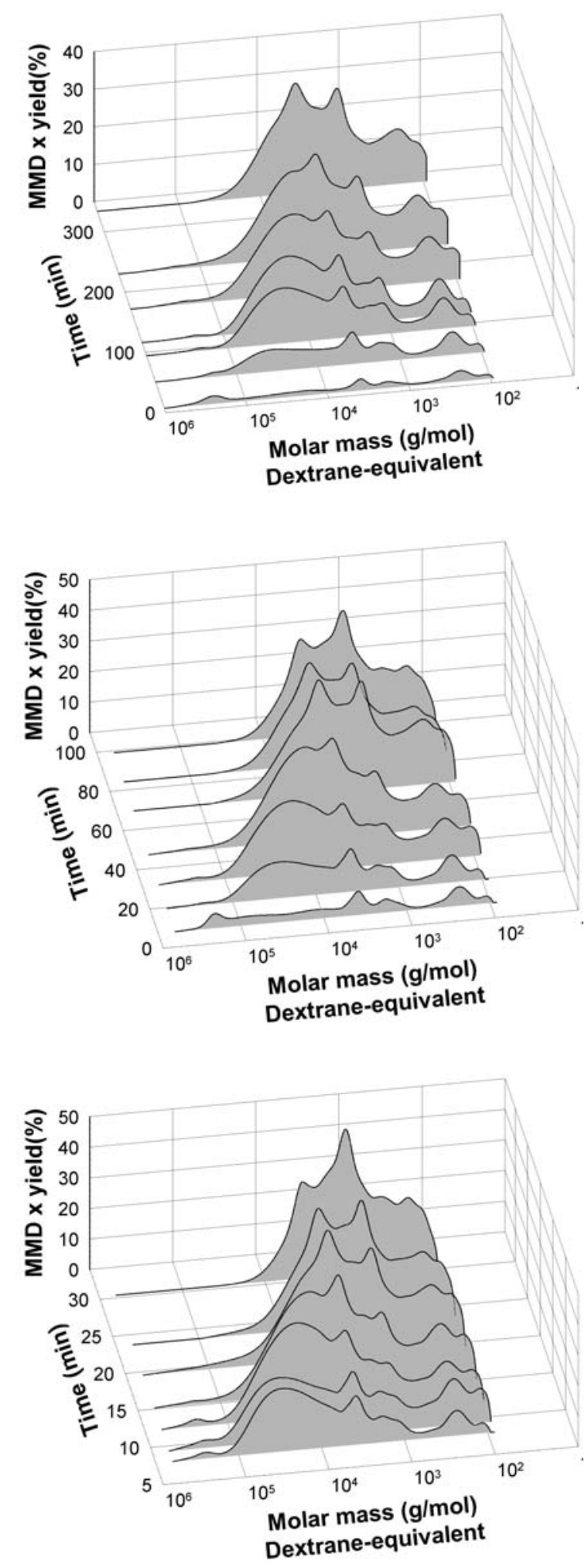

Figure 3.12. Change in the molar mass distribution of the xylo-oligosaccharides during autohydrolysis at $150^{\circ} \mathrm{C}$ (top), $169^{\circ} \mathrm{C}$ (middle) and $190^{\circ} \mathrm{C}$ (bottom). Areas of the distribution are proportional to the yield on xylo-oligosaccharides. 
The persistence and increase in importance of the peaks at $3.9-3.7$ and $1.6-1.2$ $\mathrm{kDa}$ along the reaction suggest that the hydrolysis of xylo-oligosaccharides is not a completely random bond scission, but that some structures and fragments of the polymer chains are more resilient to hydrolysis and are the most probable hydrolysis products. Assuming that the oligomer chains are formed entirely by C5 monosaccharides, those molar masses correspond to approximate degrees of polymerization of around $30-28$ and $12-9$. The experiments at $169^{\circ} \mathrm{C}$ and $190^{\circ} \mathrm{C}$ show the same trends that have been inferred for the experiments at $150^{\circ} \mathrm{C}$. In fact, the evolution of the molar mass distribution was noticeably the same regardless of temperature, and the products with molar masses of around 3.9-3.7, $1.6-1.2$ and $0.235 \mathrm{kDa}$ were always favored over other molar masses.

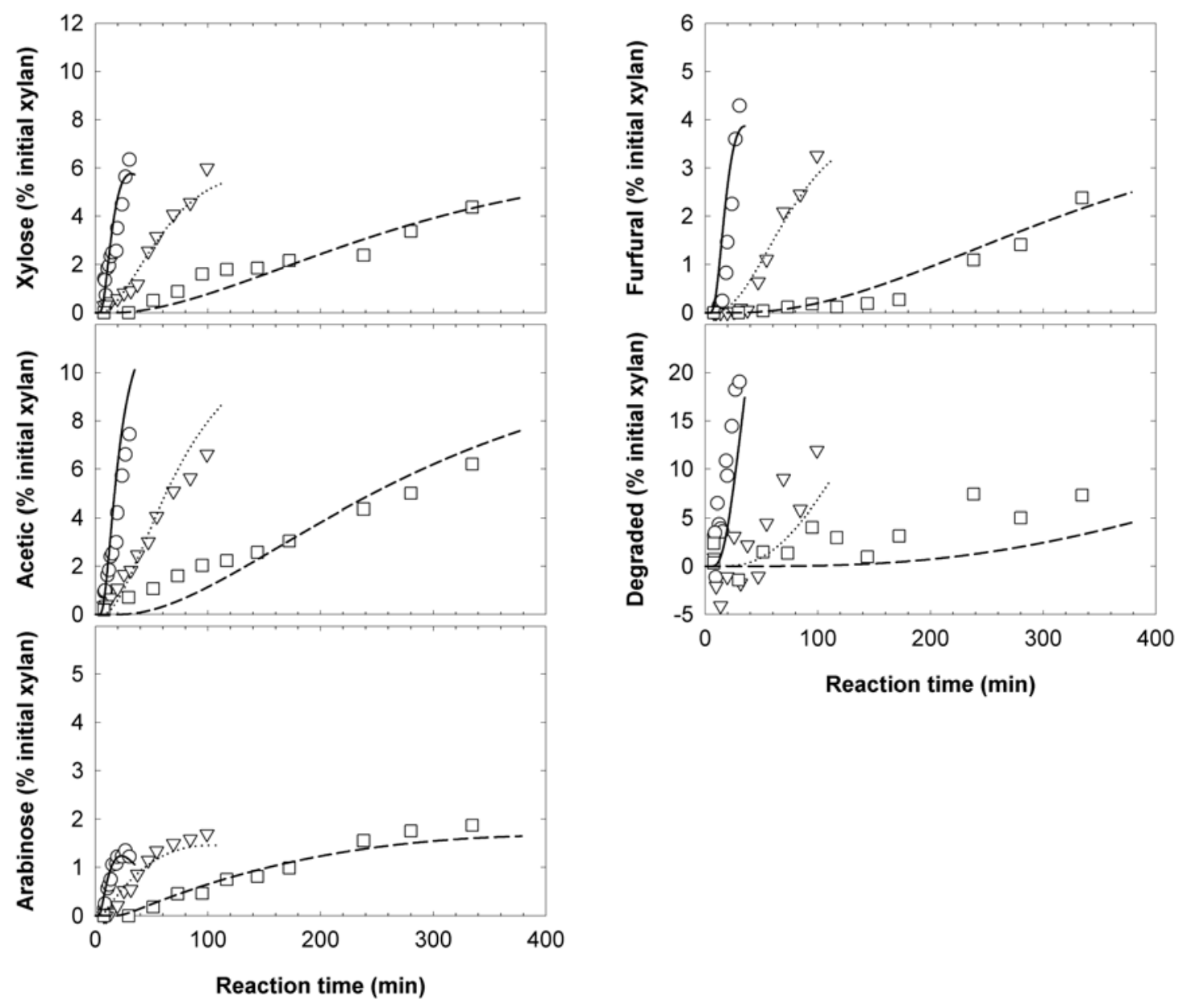

Figure 3.13. Yields of xylose, acetic acid, arabinose and furfural, and the amount of degraded xylan at $150^{\circ} \mathrm{C}(\square ;---), 169^{\circ} \mathrm{C}(\nabla ; \cdots)$ and $190^{\circ} \mathrm{C}(\mathrm{O} ;-)$. Lines show the values calculated with the kinetic model using the best-fit parameters. The yield of products is expressed as percentage of the xylan in native almond shells. 
Figure 3.13 shows the yields of monomer products formed by the hydrolysis of the xylo-oligosaccharides: acetic acid, xylose, arabinose, and furfural from the dehydration of both monosaccharides. Their yields increased steadily with time at all temperatures except for that of arabinose, which approached a maximum at a high hydrolysis time, when its rate of degradation to furfural was larger than its rate of formation. All these products also appear in the molar mass distribution plots in Figure 3.12 as the peak at $0.1-0.2 \mathrm{kDa}$. The amount of xylan that was degraded to other products, also shown in Figure 3.13, was determined by difference from a mass balance on xylan. The amount of degradation products increased continuously with the time of reaction, although the degradation was more severe at $190^{\circ} \mathrm{C}$ than at the lower temperatures.

\subsubsection{Kinetics of xylo-oligosaccharides formation}

The reaction pathway in Figure 3.14 was used to model the kinetics of depolymerization of xylan from almond shells.
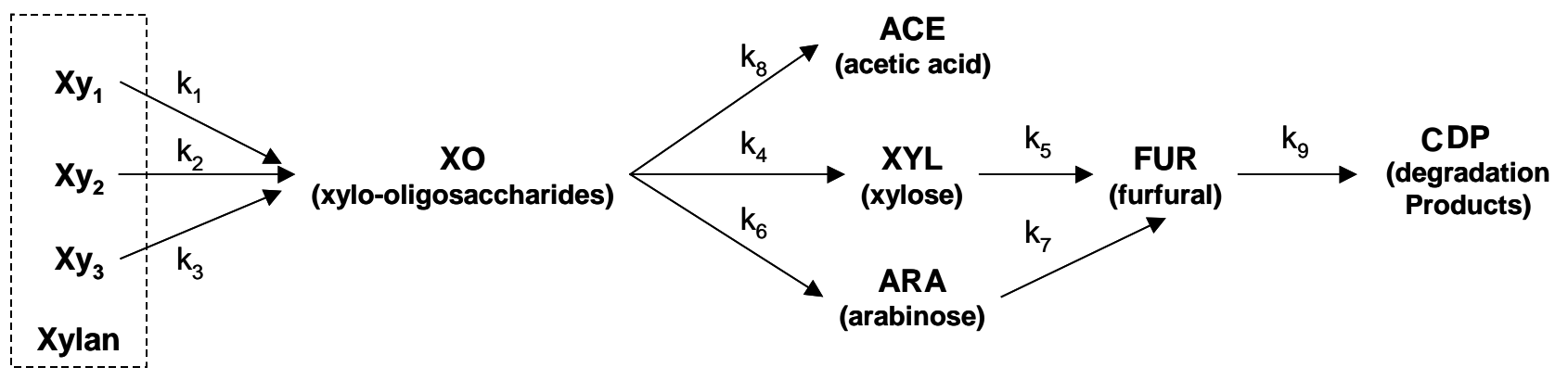

Figure 3.14. Reaction pathway for the autohydrolysis of xylan from almond shells.

Based on the kinetic model proposed for corncobs, a modification was made to explain the differences in the behaviour for this material. Here, xylan was considered to be formed by three different fractions, with different reactivities towards hydrolysis, and subsequently different reaction velocities. This modification was made due that the previous kinetic model, which proposed that the xylan was formed by two different fractions (the more reactive with higher contents of arabinose and acetyl groups), was not able to explain the large percentage of arabinose in the xylooligosaccharides produced at short reaction time and the rapid change in the composition of the oligosaccharides. Kinetic models based on the existence of two xylan fractions have been used for the hydrolysis of hardwoods [16-18] and annual 
plants $[8,17]$. Since each fraction has a distinct rate of hydrolysis, they solubilize at a different velocity and cause the change of the composition of the xylan that remains in the solid. Because the non-hydrolyzed xylan is richer in xylose as the hydrolysis proceeds, it was concluded that the xylan fraction with the higher content of arabinose and acetyl groups is solubilized more easily. However, a model with only two types of xylan could not explain the large percentage of arabinose in the xylo-oligosaccharides produced at short hydrolysis time and the rapid change in the composition of the oligomers. In fact, the fraction of arabinose in the xylo-oligosaccharides at a short reaction time is well above the average composition of the xylan in almond shells, shown in Table 3.1. It was included a third type of xylan which, according to experimental data, should be only a small fraction of the whole xylan but very rich in arabinose. In fact, this third type of "xylan" is probably another arabinose-rich hemicellulose or pectin. A content of $0.58 \%$ of pectin in almond shells has been reported [31]. This could be explained by the fact that dicotyl plants like hardwoods and herbs (almond shells is a hardwood fruit) contains 4-O-methylglucuronoxylans, whereas in monocotyl plants (like grasses and cereals) the xylans contain arabinose and glucuronic acid as side chains [32]. For this reason, arabinose usually found in hydrolysates of extracted hemicelluloses from dicotyl plants might originate from contaminating pectic polysaccharides comprising arabinan and/or arabinogalactan side chains.

According to the model, the xylan fractions $\left(X y_{1}, X y_{2}\right.$ and $\left.X y_{3}\right)$ are hydrolyzed to a mixture of water-soluble oligomers, $X O$, which are then hydrolyzed in the liquid phase to monomers: xylose $(X y l)$, arabinose $(A r a)$ and acetic acid (Ace). Xylose and arabinose dehydrate to furfural (Fur), which is unstable at the reaction conditions and forms condensation and degradation products $(C D P)$. The model assumes the following: (1) the composition of each of the three xylan fractions in the lignocellulosic does not change with conversion; (2) there is no direct formation of monomers (i.e. xylose, arabinose and acetic acid) from xylan in the lignocellulosic solid; (3) monomers are solely formed by depolymerization of the xylo-oligosaccharides; and (4) the rates of monomer formation from the xylo-oligosaccharides are independent of the molar mass, the structure, and the composition of the xylo-oligosaccharides. This is a simplified reaction pathway since some xylose, arabinose and acetic acid may evolve directly from xylan in the solid. Also, furfural has been reported to be formed by direct dehydration of small xylo-oligosaccharides. This model provides a quantitative 
explanation of the experimental data. However, the heterogeneity of xylan and the different rates of hydrolysis for each xylan fraction can be attributed to real structural differences in xylan but also to a variable degree of association between xylan and lignin and cellulose in the cell wall structure.

The individual mass balances for a perfectly mixed batch reactor and the stoichiometric relationships, Equations 3.22 to 3.31, were derived from the reaction pathway in Figure 3.14. The reactions were assumed to be pseudohomogeneous, irreversible and first order, with rate constants following the Arrhenius-type dependency on temperature. $C_{i}$ denotes the concentration of the species $i$, expressed as mass $\%$ of the initial xylan that has been converted into the species $i$. The chemical species were xylan $(X y)$, the three individual xylan fractions $\left(X y_{1}, X y_{2}\right.$ and $\left.X y_{3}\right)$, xylooligosaccharides (XO), xylose (Xyl), arabinose (Ara), acetic acid (Ace), furfural (Fur), and degradation products $(C D P)$. The composition of xylan and xylo-oligosaccharides along hydrolysis are expressed as mass fractions by $x_{x O-j}$ and $x_{X y-k}$, where the three possible values for sub index $j$ are anhydrous xylose, arabinose, and acetyl, and the sub index $k$ denotes the type of xylan (from 1 to 3 ).

The experimental yields of hydrolysis products and the compositions of xylan and xylo-oligosaccharides were used to fit the unknown parameters of the model, which were the activation energies $\left(E_{a j}\right)$ and the frequency factors $\left(k_{0 j}\right)$ for the rate constants $\left(k_{1}, \ldots, k_{j}, \ldots, k_{9}\right)$, the composition of each xylan type $\left(x_{x y 1-X y l}, x_{X y 2-X y l}, x_{X y 3}-x_{y} l, x_{x y 1-}\right.$ Ara, $x_{X y 2-A r a} x_{X y 3-A r a}, x_{X y 1-A c e}, x_{X y 2-A c e}$ and $\left.x_{X y 3-A c e}\right)$, and the fraction of each xylan type in the almond shells ( $\mathrm{C}_{x_{y 1}}[0], \mathrm{Cx}_{x_{2}}[0]$ and $\left.\mathrm{C}_{x_{3}}[0]\right)$. The best-fit values for the parameters of the model were calculated by minimization of a least-squares objective function (Equation 3.32), where $\alpha, \beta$ and $\lambda$ are weighting factors and the sub index $h$ is the number of the experiment. Since the experiments were non-isothermal because of the relatively long time required for heating the reactor up, the temperature-time profile recorded for each experimental data point was used to integrate the set of ordinary differential equations. The complete details of the model and the optimization procedure are the same for the kinetic model for corncobs.

$$
\begin{aligned}
& C_{X y}=C_{X y_{1}}+C_{X y_{2}}+C_{X y_{3}} \\
& \frac{d C_{X y_{1}}}{d t}=-k_{1} C_{X y_{1}}
\end{aligned}
$$




$$
\begin{aligned}
& \frac{d C_{X y_{2}}}{d t}=-k_{2} C_{X y_{2}} \\
& \frac{d C_{X y_{3}}}{d t}=-k_{3} C_{X y_{3}} \\
& \frac{d C_{X O}}{d t}=k_{1} C_{X y_{1}}+k_{2} C_{X y_{2}}+k_{3} C_{X y_{3}}-\left(k_{4} X_{X O-X y l}+k_{6} X_{X O-A r a}+k_{8} X_{X O-A c e}\right) C_{X O} \\
& \frac{d C_{X y l}}{d t}=k_{4} x_{X O-X y l} C_{X O}-k_{5} C_{X y l} \\
& \frac{d C_{A r a}}{d t}=k_{6} X_{X O-A r a} C_{X O}-k_{7} C_{A r a} \\
& \frac{d C_{A c e}}{d t}=k_{8} X_{X O-A c e} C_{X O} \\
& \frac{d C_{\text {Fur }}}{d t}=k_{5} C_{X y l}+k_{7} C_{\text {Ara }}-k_{9} C_{F u r} \\
& \frac{d C_{C D P}}{d t}=k_{9} C_{F u r} \\
& F=\sum_{h=1}^{n}\left[\sum_{i=1}^{7}\left(\frac{C_{h, i}-C_{h, i}^{*}}{\alpha_{i}}\right)^{2}+\sum_{j=1}^{3}\left(\frac{x_{X O-h, j}-x_{X O-h, j}^{*}}{\beta}\right)^{2}+\sum_{k=1}^{3}\left(\frac{x_{X y-h, k}-x_{X y-h, k}^{*}}{\lambda}\right)^{2}\right]
\end{aligned}
$$

Table 3.4 shows the best-fit values for the activation energies and the frequency factors, and Table 3.5 shows the optimal values for the amount of each type of xylan in almond shells and their compositions. The most reactive xylan accounted for $8.1 \%$ of the whole, and it was formed by arabinose (58.2\%) and xylose (41.8\%). Autohydrolysis of this type of xylan had an activation energy of $143 \mathrm{~kJ} / \mathrm{mol}$. The xylan type with an intermediate reactivity represented $68.6 \%$ of the total, and it was formed by $80.8 \%$ of anhydroxylose, $3.2 \%$ of anhydroarabinose, and $16 \%$ of acetyl, while the activation energy for conversion into xylo-oligosaccharides was $156 \mathrm{~kJ} / \mathrm{mol}$. The less reactive xylan was $23.3 \%$ of the total. It was formed by $92.0 \%$ of anhydroxylose, $2.5 \%$ of anhydroarabinose, and 5.5\% of acetyl, and the activation energy for its autohydrolysis was $249 \mathrm{~kJ} / \mathrm{mol}$. The activation energies for the hydrolysis of the xylo-oligosaccharides 
to xylose and arabinose were 124.9 and $119.0 \mathrm{~kJ} / \mathrm{mol}$, respectively, and the activation energies for their dehydration to furfural were $136.9 \mathrm{~kJ} / \mathrm{mol}$ for xylose and $144.4 \mathrm{~kJ} / \mathrm{mol}$ for arabinose. The activation energy for the disappearance of furfural was $132 \mathrm{~kJ} / \mathrm{mol}$, and the deacetylation of the xylo-oligosaccharides had an activation energy of 95.8 $\mathrm{kJ} / \mathrm{mol}$.

\begin{tabular}{ccc}
\hline$k_{j}\left(\mathrm{~min}^{-1}\right)$ & $E_{a j}(\mathrm{~kJ} / \mathrm{mol})$ & $\ln \left(k_{0 j} / \mathrm{min}^{-1}\right)$ \\
\hline$k_{1}$ & 142.5 & 39.07 \\
$k_{2}$ & 155.7 & 38.76 \\
$k_{3}$ & 248.9 & 61.17 \\
$k_{4}$ & 124.9 & 28.42 \\
$k_{5}$ & 136.9 & 33.68 \\
$k_{6}$ & 119.0 & 27.60 \\
$k_{7}$ & 144.4 & 35.37 \\
$k_{8}$ & 95.8 & 22.52 \\
$k_{9}$ & 132.0 & 32.93 \\
\hline
\end{tabular}

Table 3.4. Best-fit values for the activation energy and the frequency factor of the rate constants $\mathrm{k}_{1}$ to $\mathrm{k}$.

\begin{tabular}{lccc}
\hline & \multicolumn{3}{c}{ Xylan } \\
\cline { 2 - 4 } & Type 1 & Type 2 & Type 3 \\
\hline Content (\% of xylan) $-C_{X y j[}[0]$ & 8.1 & 68.6 & 23.3 \\
Anhydroxylose $-x_{x y j-X y l}$ & 0.418 & 0.808 & 0.920 \\
Anhydroarabinose $-x_{X y j-A r a}$ & 0.582 & 0.032 & 0.025 \\
Acetyl $-x_{X y j-A c e}$ & 0.000 & 0.160 & 0.055 \\
\hline
\end{tabular}

Table 3.5. Best-fit values for the amount and composition of the three types of xylan in native almond shells. 
Figures 3.10, 3.11 and 3.13 compare the experimental yields of the products and the values calculated with the model for the experiments at $150^{\circ} \mathrm{C}, 169^{\circ} \mathrm{C}$ and $190^{\circ} \mathrm{C}$. The model predicts accurately the yield of xylo-oligosaccharides and the amount of xylan remaining in the hydrolyzed almond shells, as well as their composition. Also, it gives a fair description for the yields of monomer products. It, therefore, be concluded that the model presented here is suitable for describing the kinetics of the reactions involved in xylan autohydrolysis and that it correctly describes the changes to the composition of xylan and its oligomers during the reaction.

\subsubsection{Large-scale experiments}

The purpose of the large-scale experiments was to test the performance of the kinetic model, and to produce larger batches of xylo-oligosaccharides solution for the study of the recovery by spray drying and testing of purification sequences. Four experiments were carried out in the $10 \mathrm{~L}$ stirred batch reactor at $179^{\circ} \mathrm{C}$ and a nominal residence time of $29 \mathrm{~min}$ (including the heating period but not the cooling down), using a dry almond shells concentration of $14.3 \%$. In each experiment the reactor was loaded with $0.93 \mathrm{~kg}$ of almond shells (9.0\% moisture) and $4.94 \mathrm{~kg}$ of deionized water. The time-temperature history of each experiment was recorded, and it was used to estimate the yield and composition of the xylo-oligosaccharides and the yield of monomer products.

Figure 3.15 shows the amount of xylan remaining in the hydrolyzed almond shells, the yield of xylo-oligosaccharides, the composition of xylan and xylooligosaccharides, and the yields of xylose, arabinose, acetic acid, and furfural, for the experiments and the kinetic model. The dispersion among the experimental values from the four experiments was caused by differences in the evolution of temperature along each experiment, especially during the heating and cooling periods. This also originated the differences among the values calculated with the kinetic model, which used the temperature profile recorded for each experiment to calculate the yield and composition of the products. Comparison between the experimental data and the results from the model shows a good agreement, except for the yield of acetic acid that was slightly underestimated by the model. However, the discrepancies are of the same level as the scattering that is normally encountered in experimental studies on the hydrolysis of lignocellulosics. This confirms the validity of the kinetic model for the description of the hydrolysis reaction. 


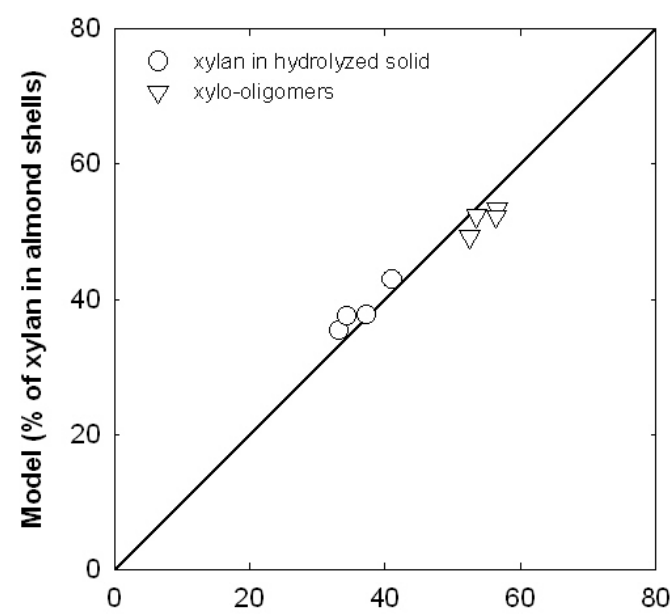

Experimental (\% of xylan in almond-shells)

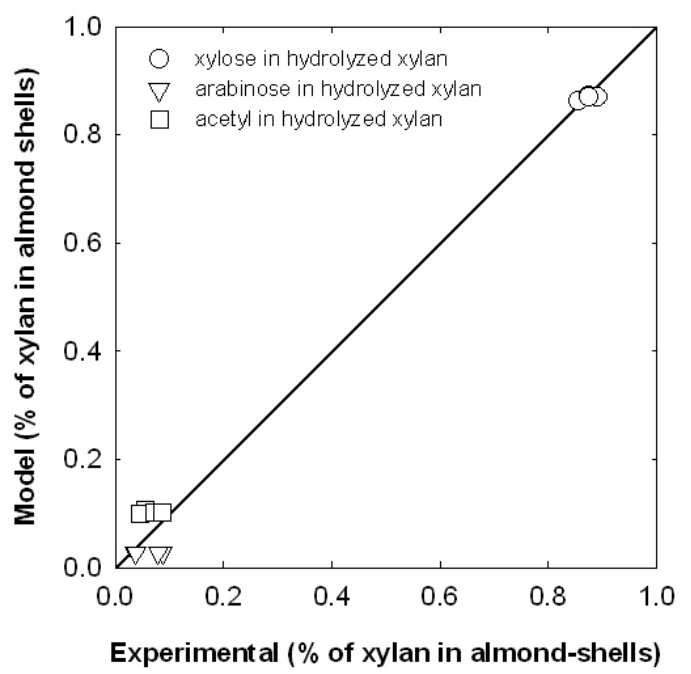

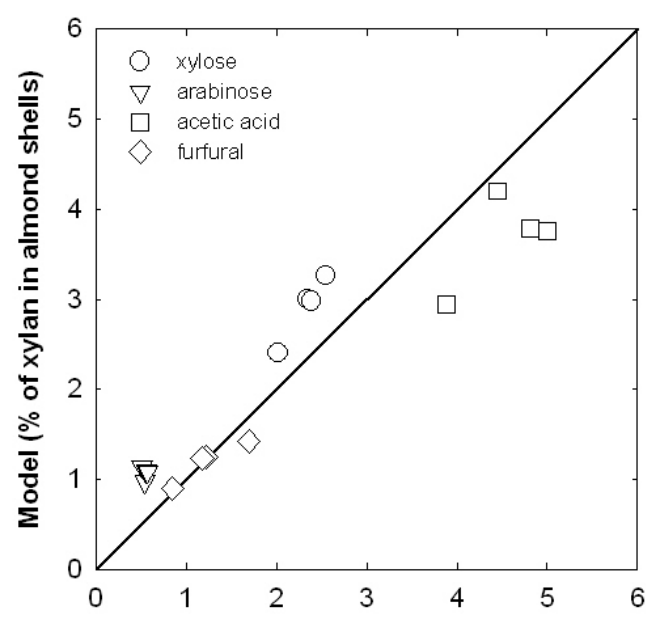

Experimental (\% of xylan in almond-shells)

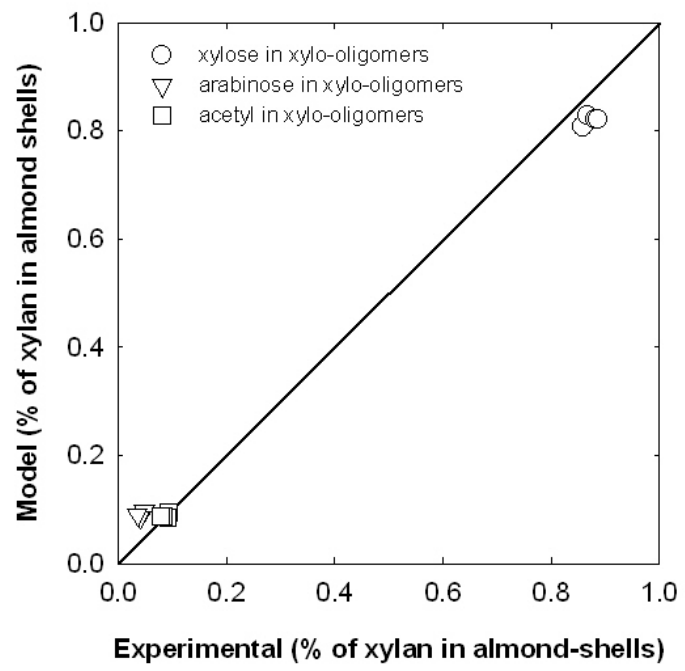

Figure 3.15. Autohydrolysis of almond shells in the $10 \mathrm{~L}$ stirred reactor at $179^{\circ} \mathrm{C}$. Comparison between the experimental yields and compositions and the values calculated with the kinetic model for xylan, xylo-oligosaccharides, and monomer products.

The xylo-oligosaccharides produced in the large-scale experiments were recovered from the hydrolysis liquor by spray drying. Figure 3.16 shows the average yields of the different streams for three of the experiments at $179^{\circ} \mathrm{C}$ and $29 \mathrm{~min}$ in the $10 \mathrm{~L}$ reactor. For an easier interpretation, all results have been scaled to a basis of 100 $\mathrm{kg}$ of dry almond shells entering the reactor. The composition of the solid powder recovered by spray drying shows that xylo-oligosaccharides only accounted for $57.9 \%$ of the mass. Monomer products accounted for $5.3 \%$ of the solid $(2.5 \%$ xylose, $1.5 \%$ 
arabinose, $1.1 \%$ glucose, and $0.17 \% \mathrm{HMF}$ ); no significant amounts of acetic acid or furfural were detected, while the ash content was $4.9 \%$.

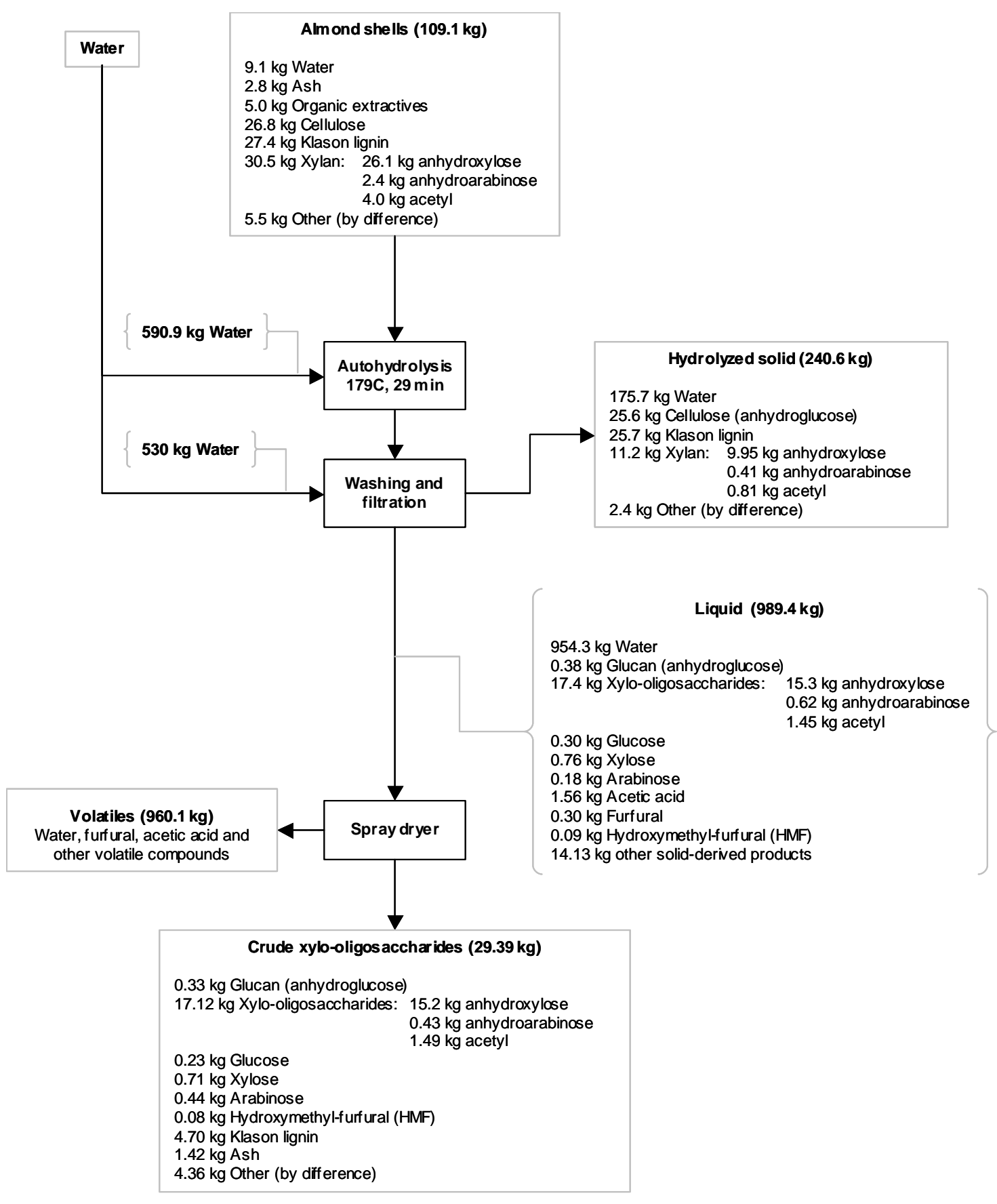

Figure 3.16. Yields and compositions for the autohydrolysis of almond shells at $179^{\circ} \mathrm{C}$ and 29 $\mathrm{min}$ and the recovery of the crude xylo-oligosaccharides by spray drying. Average results from three experiments have been scaled to a basis of $100 \mathrm{~kg}$ of dry almond shells entering the process. 
The quantitative acid hydrolysis of the crude xylo-oligosaccharides to measure their total content of monosaccharides produced $15.6 \%$ of acid-insoluble solid, which was associated to Klason-type lignin. Finally, 16.5\% of the solid was not identified. It was assumed to be formed by compounds from the almond shells that were solubilized during the autohydrolysis reaction, like extractives, low molar mass phenolics from lignin, and also byproducts from the degradation of monosaccharides and furfural.

The percentage of xylo-oligosaccharides in the non-volatile hydrolysis products for almond shells (57.9\%) agrees with that reported for rice husks $(54.8 \%$, including uronic acids) [33], and barley residues (46.3\%, including uronic acids) [34]. Recovery of the xylo-oligosaccharides by spray drying produced a decrease in their arabinose-toxylose ratio, from $4.3 \%$ in the autohydrolysis liquid product to $2.7 \%$ after spray drying, although the acetyl-to-xylose ratio remained almost unchanged. Also, there was a significant increase in the yield of arabinose monomer, from $0.17 \mathrm{~kg} /(100 \mathrm{~kg}$ dry almond shells) in the autohydrolysis liquor, to $0.44 \mathrm{~kg} /(100 \mathrm{~kg}$ dry almond shells $)$ in the solid recovered by spray drying. This indicates that the xylo-oligosaccharides are affected by temperature during drying and that the most labile bonds between arabinose and the xylan backbone are broken.

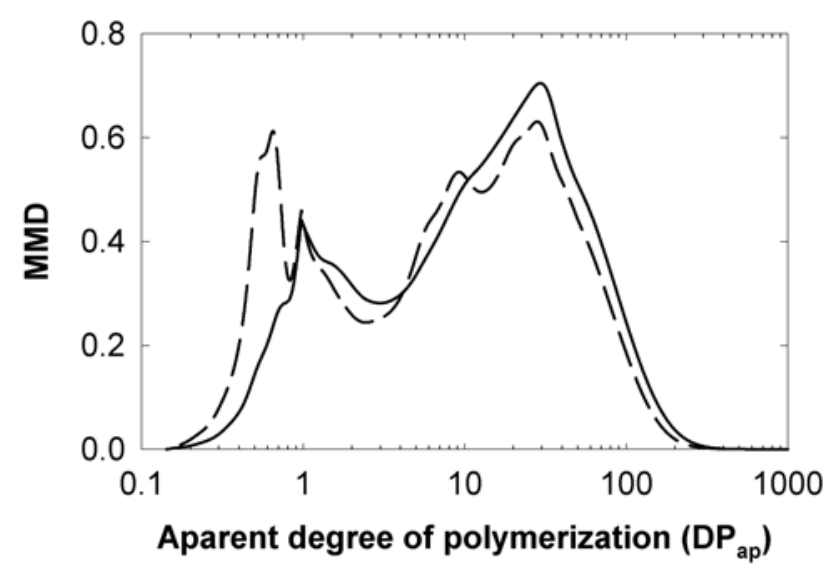

Figure 3.17. Molar mass distribution of the crude xylo-oligosaccharides in the autohydrolysis liquor (---), and after recovery by spray drying (-), determined by GPC. The system was calibrated with monodisperse dextrans, and the degree of polymerization (DP) was calculated with Equation 3.33. 
Figure 3.17 shows the molar mass distributions of the soluble products in the autohydrolysis liquor and the crude xylo-oligosaccharides recovered by spray drying, determined by GPC analysis. The molar mass distribution is plotted against the apparent degree of polymerization of the xylo-oligosaccharides $(D P)$, which was calculated from the GPC elugram according to Equation 3.33, assuming that all the solute is formed by monomers with the molar mass of anhydroxylose.

$$
D P=\frac{\text { Molar mass }-18}{132}
$$

The molar mass distribution of the soluble products in the autohydrolysis liquor shows a peak below an DP $\cong 1$, which corresponds to furfural, acetic acid, and other volatile and nonvolatile products with molar mass less than that of xylose. As expected, this peak almost disappears after spray drying because of the evaporation of the volatile compounds of the sample. The products in the autohydrolysis liquor also show a distinct peak at a DP $\cong 9$, which cannot be observed after spray drying, and that appears to be related to the loss of arabinose. It can be concluded, that the xylooligosaccharides rich in arabinose are partially depolymerized during spray drying, yielding arabinose monomer and xylo-oligosaccharides with a lower arabinose-toxylose ratio. The depolymerization does not affect the backbone xylose chain nor the acetyl groups, but affects the arabinan groups. In fact, the dextran-equivalent numberaverage $\left(\mathrm{Mn}_{\mathrm{n}}\right)$ and mass-average $\left(\mathrm{M}_{\mathrm{w}}\right)$ molar mass averages were 0.37 and $2.85 \mathrm{kDa}$ for the products in the autohydrolysis liquor, respectively, and 0.54 and $3.45 \mathrm{kDa}$ for the product from spray drying. This rise in the molar mass averages is attributed to the loss of volatile low-molar-mass products during drying, and demonstrates that the extent of thermal depolymerization during drying is very limited.

Almond shells have a high content of xylan and are an adequate feedstock for the production of xylo-oligosaccharides through autohydrolysis at a moderate temperature. Furthermore, the high density of almond shells allows processing of medium-density slurries (15 - 20\% of solids) during autohydrolysis, which gives concentrations of product in the aqueous solution higher than those for other lignocellulosics. However, the purity of the xylo-oligosaccharides produced by autohydrolysis is low, and their molar mass distribution is relatively broad. Therefore, it is necessary to develop a purification process to obtain a high-purity product with a composition and molar mass distribution controlled and repetitive. 


\subsection{AUTOHYDROLYSIS OF DIFFERENT AGRICULTURAL BY- PRODUCTS}

\subsubsection{Autohydrolysis-induced compositional changes}

As mentioned before, the autohydrolysis reaction was made using a $10 \mathrm{~L}$ reactor to have enough xylo-oligosaccharides that could be used in the subsequent purification steps. In this stage, six different agricultural residues were tested, and the yield, molar mass distribution, chemical composition and structure of the xylo-oligosaccharides was studied, and the results presented in the next subsections.

\subsubsection{Composition of the raw materials}

Table 3.6 shows the chemical composition of the different raw materials used in this study, namely corncobs (CC), wheat straw (WS), barley straw (BS), rice husks (RH), olive stones (OS), and almond shells (AS).

\begin{tabular}{lcccccc}
\hline & CC & AS & OS & WS & BS & RH \\
\hline Ash & $1.14 \pm 0.03$ & $2.83 \pm 0.07$ & $2.80 \pm 0.04$ & $6.39 \pm 0.04$ & $6.13 \pm 0.05$ & $15.21 \pm 0.03$ \\
Extractives & $2.10 \pm 0.05$ & $5.0 \pm 0.4$ & $6.4 \pm 0.4$ & $6.5 \pm 0.8$ & $5.9 \pm 1.0$ & $2.4 \pm 0.3$ \\
Klason lignin & $18.7 \pm 0.4$ & $27.4 \pm 1.4$ & $31.3 \pm 0.1$ & $15.9 \pm 0.3$ & $16.7 \pm 0.3$ & $24.6 \pm 0.1$ \\
Glucose $^{\mathrm{a}}$ & $38.5 \pm 0.3$ & $26.8 \pm 0.6$ & $24.0 \pm 0.2$ & $31.5 \pm 4.2$ & $30.8 \pm 4.3$ & $29.7 \pm 4.3$ \\
Xylose $^{\mathrm{a}}$ & $29.5 \pm 0.7$ & $26.1 \pm 0.8$ & $23.3 \pm 0.1$ & $19.8 \pm 2.9$ & $19.8 \pm 2.8$ & $16.5 \pm 2.3$ \\
Arabinose $^{\mathrm{a}}$ & $3.3 \pm 0.3$ & $2.4 \pm 0.3$ & $1.4 \pm 0.03$ & $2.8 \pm 0.3$ & $3.0 \pm 0.5$ & $2.0 \pm 0.3$ \\
Acetyl groups $^{4.0 \pm 0.4}$ & $4.0 \pm 0.9$ & $3.1 \pm 0.4$ & $2.6 \pm 0.9$ & $2.5 \pm 0.8$ & $1.1 \pm 0.1$ \\
Others $^{\mathrm{b}}$ & 6.2 & 5.5 & 7.8 & 14.7 & 15.2 & 8.4 \\
Acetyl/Xylc & 0.29 & 0.34 & 0.28 & 0.29 & 0.28 & 0.15 \\
\hline
\end{tabular}

Table 3.6. Composition of the different raw materials (wt.\%), related to dry material, with confidence interval $(\alpha=0.025)$. ${ }^{a}$ Expressed as anhydrous units. ${ }^{\mathrm{b}}$ Calculated by difference. ${ }^{\mathrm{c}}$ Ratio in mol/mol. 
The major differences were found in the ash content, which was low in CC, AS and OS $(1-2.8 \%)$. Higher amounts of ash (around 6\%) were determined in WS and BS, and $\mathrm{RH}$ showed the highest content of about $15 \%$, in agreement with the significant occurrence of silicates in these and related plant tissues [35]. Organic extractives, including some phenolics, were higher in AS, OS, WS, and BS (5-6.5\%) than in CC and $\mathrm{RH}(\sim 2 \%)$. The degree of lignification estimated by the Klason lignin was about 16 $-19 \%$ in WS, BS and CC, higher in RH and AS (24 - 27\%), and particularly high in OS $(31.3 \%)$. Because of the presence of ash, Klason lignin analysis gave an overestimation of the lignin content. Therefore, the obtained values were corrected by the ash content of the Klason lignin [36]. The cellulose content estimated from the amount of glucose in the Klason lignin hydrolysate varied between $24 \%$ for OS and $38.5 \%$ for CC, and was lower for the more lignified biomass species. The content of xylan, estimated from the amounts of xylose, arabinose, and acetyl groups, was 36.8\% and 32.5\% for CC and AS respectively, and was lower for the other species, up to $19.7 \%$ for RH. However, besides arabinose and acetyl groups, xylan also contains variable amounts of glucuronic acid and some phenolic acids, which were not quantified by the used analytical procedures. Table 3.6 also reports on the acetyl-to-xylose mole ratios, which were 1:2.9 and 1:6.6 for AS and $\mathrm{RH}$, respectively, and around 1:3.5 for the other lignocellulosics.

\subsubsection{Cellulose component}

The effect of the autohydrolysis reaction on the cellulose component is shown in Figure 3.18, where the content of cellulose in the hydrolysis residue, and the glucooligosaccharides, glucose and hydroxymethylfurfural (HMF), the main product of glucose degradation by dehydration, in the liquid product are shown as \% of the cellulose present in the raw materials. All of them were detected by HPLC, as described before. Essentially, the cellulose remained in the hydrolysis residue and only a small part was depolymerized to oligomers and glucose and dissolved. However, it has to be noted that glucose and gluco-oligosaccharides might have released also from other cell wall components, such as hemicelluloses of the glucomannan, xyloglucan or mixed-linkage $\beta$-glucan types [32], what depends on the plant source. OS and AS, the most lignified materials, showed lower formation of gluco-oligosaccharides and glucose. This might be caused by the more dense and lignified structure of their cell 
wall, which hinders the hydrolysis and solubilization of the non-crystalline segments of the cellulose chains.

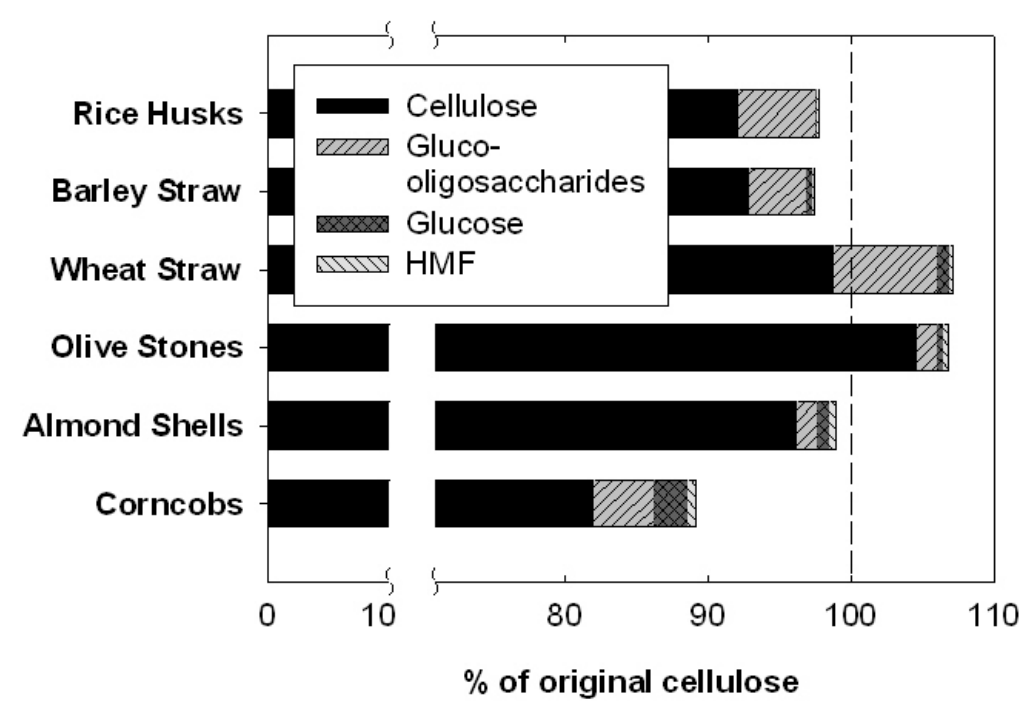

Figure 3.18. Distribution of cellulose among reaction products: hydrolysis residue (cellulose) and liquid products (gluco-oligosaccharides, glucose and HMF), expressed as \% of original cellulose in the different raw materials.

\subsubsection{Lignin component}

Lignin is partially depolymerized during autohydrolysis and a small fraction of the low molar mass phenolics dissolved. A part of lignin is known to be covalently bound to xylan, and phenolic acids, particularly ferulic acid, appears in side chains of heteroxylans from grasses and cereals, esterifying arabinose residues at position 5 [37]. Therefore, some xylo-oligosaccharides might contain such phenolics.

Figure 3.19 shows the distribution of lignin between the hydrolysis residue and the liquid phase, expressed as percentage of the amount of lignin and organic extractives present in the original material. Organic extractives have been included because they are also solubilized partially during autohydrolysis and, depending on their characteristics, appear as Klason lignin in the hydrolysis residue or as acidsoluble lignin dissolved in the aqueous phase. The lower solubilization of lignin was observed for OS and AS, regardless of their higher lignin content, which is coherent with a dense and closed cell-wall structure and a highly condensed lignin. On the 
contrary, lignin in the less lignified materials was more accessible towards hydrolysis and solubilization, especially for WS. The concentrations of lignin-derived products in the liquid phase at the end of the reaction were $0.30,0.28,0.20,0.18,0.17$ and $0.12 \%$ $\mathrm{w} / \mathrm{w}$ for CC, OS, AS, RH, WS and BS, respectively. The presence of lignin-derived species in the liquid product calls for the inclusion of additional purification treatments to isolate xylo-oligosaccharides with adequate purity, and well-defined and repetitive composition and molar mass. However, the lower the concentration of lignin products relative to that of xylo-oligosaccharides is in the autohydrolysis liquid, the simpler the purification sequence and the higher its effectiveness should be. Extraction with organic solvents, followed by a secondary treatment like ion exchange, lead the best results for the purification of xylo-oligosaccharides from rice husks, and from solid residues coming from the malting industry [33, 34, 38]. Adsorption onto activated carbons [39], and nanofiltration [40], are promising methods for the separation of lignin-derived compounds produced by autohydrolysis reaction.

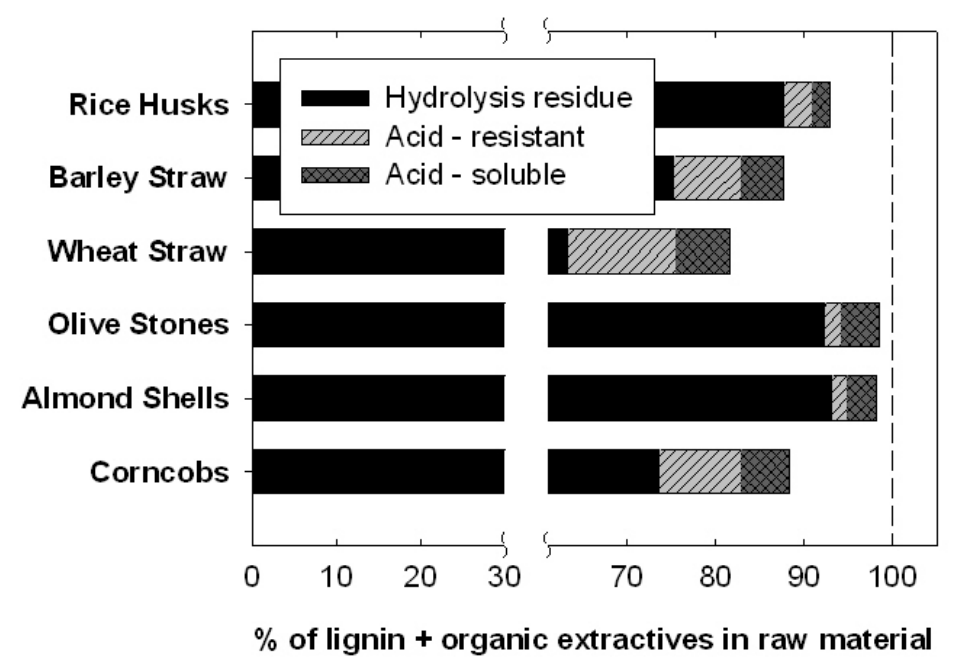

Figure 3.19. Distribution of lignin among reaction products: hydrolysis residue (Klason Lignin), and liquid products (acid - resistant and acid - soluble lignin), expressed as \% of original Klason lignin + organic extractives in the different raw materials.

\subsubsection{Xylan component}

Hemicelluloses are readily depolymerized and dissolved during autohydrolysis of lignocellulosics at the temperature used in this study. Xylan is the main component 
in the hemicelluloses of the six species tested. Xylan from monocotyl plants (grasses and cereals) contains arabinose, acetyl groups and glucuronic acid as side chains, but in dicotyl plants (hardwoods) xylan consists only of partially acetylated 4-Omethylglucuronoxylan chains [37]. Therefore, the arabinose found in the hydrolyzates of hemicelluloses extracted from almond shells and olive stones was probably originated from minor pectic polysaccharides comprising arabinan and/or arabinogalactan side chains. However, the term xylo-oligosaccharides (XOs) has been used to name the hemicellulose-derived oligosaccharides from autohydrolysis along this paper, and the possible arabinan-derived oligomers encountered in the case of AS and OS have been included as XOs for the purpose of calculating yields and average compositions.
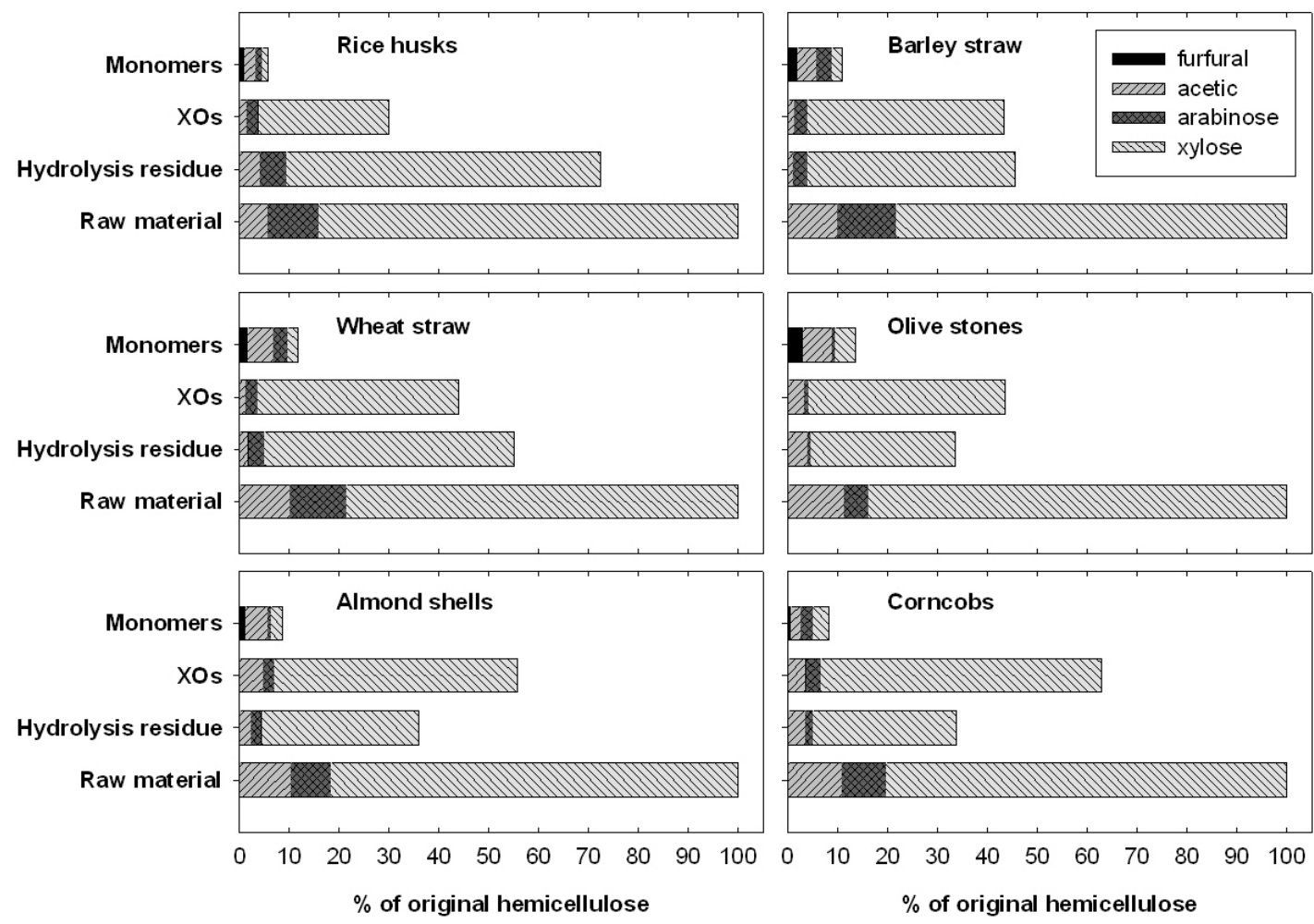

Figure 3.20. Hemicellulose in the raw material and its distribution between the hydrolysis residue and the non-dried liquid products (XOs, monosaccharides, acetic acid and furfural), expressed as $\%$ of original hemicellulose in the different raw materials.

Figure 3.20 shows the distribution of the main constituents of the hemicelluloses (xylose, arabinose and acetic acid) in the raw material, in the hydrolysis residue and in 
the liquid phase, for the six lignocellulosic species. Products from the hemicelluloses in the liquid phase were present in form of XOs, as free monomers, acetic acid and as furfural, the main decomposition product of pentoses. The hemicelluloses remaining in the hydrolysis residue were about 33 to $35 \%$ of the original for CC, AS and OS, and shows that around 65\% were solubilized. The depolymerization of WS and BS was not so effective, and about $45 \%$ and $55 \%$, respectively, of the hemicelluloses remained in the hydrolysis residue. In the case of $\mathrm{RH}$, the percentage was much higher, indicating that less than $30 \%$ was solubilized. These differences are closely related to the amount of acetyl groups that are present in the lignocellulosics, as shown in Table 3.6. The larger the amount of acetyl groups that were present in the raw material, the more acetic acid was liberated by cleavage of the acetyl groups and available to catalyze the depolymerization of hemicelluloses into XOs. This was corroborated with the final $\mathrm{pH}$ of the liquid product collected from the reactor, which was between 3.5 and 3.9 for the experiments with CC, AS and OS, and around 4.2 for WS, BS and RH. As seen in Figure 3.20, the composition of the hemicelluloses remaining in the hydrolysis residue was similar for all substrates, with xylose as the main component. In fact, the remaining hemicelluloses (expressed as the sum of xylose, arabinose and acetyl groups) were richer in xylose $(85-91 \%)$ than the native $(78-84 \%)$, showing that autohydrolysis preferentially released XOs that were rich in arabinose and acetyl groups [41]. The XOs recovered in the liquid product had a xylose content of 83 to 87 $\%$, which is below the value of the hemicellulose remaining in the hydrolysis residue, but higher than in native hemicelluloses.

The yield of XOs was around $60 \%$ of the original xylan content for CC, in agreement with previous studies done at laboratory scale [8]. The same agreement in the yields (55\%) was observed with AS. The yields for OS, WS, and BS were about $43 \%$ of the original xylan, while for RH it was only about 30\%. The composition of the xylooligosaccharides was close to that of the hemicelluloses that remained in the hydrolysis residue, accordingly with the preferential cleavage of acetyl groups and/or arabinose from the backbone of the xylan chains. The yields of arabinose and xylose in the liquid product were not high because they readily decomposed into furfural at the reaction conditions.

The composition of the XOs obtained after spray drying (SXOs) is shown in Table 3.7. The raw material that gave the highest content of SXOs in the powder product was AS (61\% of the product), followed by CC (59\%), OS (54\%), BS (47\%), WS and RH ( 
$42 \%)$. The latter two products showed a higher content of gluco-oligosaccharides, namely $13 \%$ and $15 \%$, respectively.

\begin{tabular}{|c|c|c|c|c|c|c|}
\hline Composition (wt.\%) a & $\mathrm{CC}$ & AS & OS & WS & BS & RH \\
\hline Gluco-oligosaccharides & 5.2 & 4.1 & 2.4 & 13.2 & 6.3 & 15.3 \\
\hline$\underline{\text { Xylo-oligosaccharides }}$ & 59.4 & $61.2^{\mathrm{b}}$ & $53.5^{\mathrm{b}}$ & 41.2 & 47.1 & 42.8 \\
\hline Xylose & 51.7 & 53.9 & 46.3 & 34.3 & 39.3 & 37.3 \\
\hline Arabinose & 3.3 & - & - & 4.4 & 4.8 & 3.5 \\
\hline Acetyl groups & 4.4 & 7.4 & 7.2 & 2.5 & 3.0 & 1.9 \\
\hline$\underline{\text { Arabinans }}$ & - & 3.9 & 1.2 & - & - & - \\
\hline \multicolumn{7}{|l|}{$\underline{\text { Monosaccharides }}$} \\
\hline Glucose & 2.4 & 0.8 & 0.3 & 0.8 & 0.5 & 0.5 \\
\hline Xylose & 2.9 & 2.6 & 4.2 & 0.9 & 1.4 & 2.0 \\
\hline Arabinose & 2.5 & 1.6 & 1.4 & 1.9 & 2.6 & 2.9 \\
\hline$\underline{\text { Acetic acid }}$ & 0.4 & 1.7 & 0.5 & 0.6 & 0.9 & 2.2 \\
\hline \multicolumn{7}{|l|}{ Degradation Products } \\
\hline $\mathrm{HMF}$ & 0.5 & 0.3 & 0.2 & 0.2 & 0.1 & 0.1 \\
\hline Furfural & 0.0 & 0.1 & 0.1 & 0.0 & 0.0 & 0.1 \\
\hline Acid-resistant lignin & 5.6 & 1.8 & 2.3 & 8.4 & 6.3 & 5.9 \\
\hline Acid-soluble lignin & 3.3 & 3.5 & 5.1 & 4.2 & 4.1 & 3.9 \\
\hline$\underline{\text { Ash }}$ & 4.0 & 7.0 & 7.3 & 14.2 & 15.4 & 13.6 \\
\hline$\underline{\text { Others }}^{\mathrm{c}}$ & 13.7 & 11.2 & 21.3 & 15.3 & 14.4 & 10.6 \\
\hline
\end{tabular}

Table 3.7. Composition of the spray - dried liquid product (SXOs). ${ }^{a}$ Related to dry material. ${ }^{b}$ Excluding anhydrous arabinose. ${ }^{c}$ Calculated by difference.

In the case of dicotyledonous plants, to whom almond and olive trees belong, arabinose was not considered as part of the xylo-oligosaccharides [32], and it was 
expressed as arabinan with a content of 3.9 and $1.2 \%$ for AS and OS respectively. The levels of acetic acid, furfural and HMF were negligible because they were evaporated during the spray-drying process. The products contained phenolics, determined as acid-resistant and acid-soluble lignin in amounts ranging from $1.8 \%$ and $3.5 \%$ in AS, to $8.4 \%$ and $4.2 \%$ in WS. As was mentioned before, the low lignin levels in the liquid products after the reaction are beneficial for the subsequent purification steps. The ash content of the powder products was in agreement with that of the raw materials (Table 3.8).

\subsubsection{Molar mass distribution of the xylo-oligosaccharides}

The molar mass distribution (MMD) obtained by GPC of the hydrolysis liquor (Figure 3.21) was similar for all XOs, showing several molecular peaks $\left(\mathrm{M}_{\mathrm{p}}\right)$ in various proportions.

About $1 / 3$ of the products were of very small molar mass $\left(\mathrm{M}_{\mathrm{p}} \sim 60\right.$ and $\left.300 \mathrm{~g} / \mathrm{mol}\right)$ including degradation products, and mono- and disaccharides. The rest comprises oligosaccharides $\left(\mathrm{M}_{\mathrm{p}} \sim 1000\right.$ and $\left.3000 \mathrm{~g} / \mathrm{mol}\right)$ and smaller proportions of polymeric xylan fragments with a broad range of molar masses from 6000 to $60000 \mathrm{~g} / \mathrm{mol}$, which were most pronounced in WS, BS and RH. OS and CC gave a higher proportion of low molecular weight products than AS, in agreement with the higher concentration of acetic acid in the reaction media. The spray-dried liquid products (SXOs) exhibited about the same MMD as the non-dried product. The main difference was a slight reduction of species with low molar masses (from 60 to $150 \mathrm{~g} / \mathrm{mol}$ ), due to the evaporation of furfural, acetic acid and other volatile compounds during drying. Figure 3.21 shows also that dialysis of SXOs effectively removed most of the low molar mass material. The resulting dialyzed xylo-oligosaccharides (DXOs) exhibited a low molecular mass with a narrower MMD, which show a single characteristic peak at $3500 \mathrm{~g} / \mathrm{mol}$ for CC and OS, $\sim 5000 \mathrm{~g} / \mathrm{mol}$ for AS, $\sim 5500 \mathrm{~g} / \mathrm{mol}$ for RH and BS, and $~$ $6500 \mathrm{~g} / \mathrm{mol}$ for WS, indicating a mixture of xylan oligomers and polymers. 


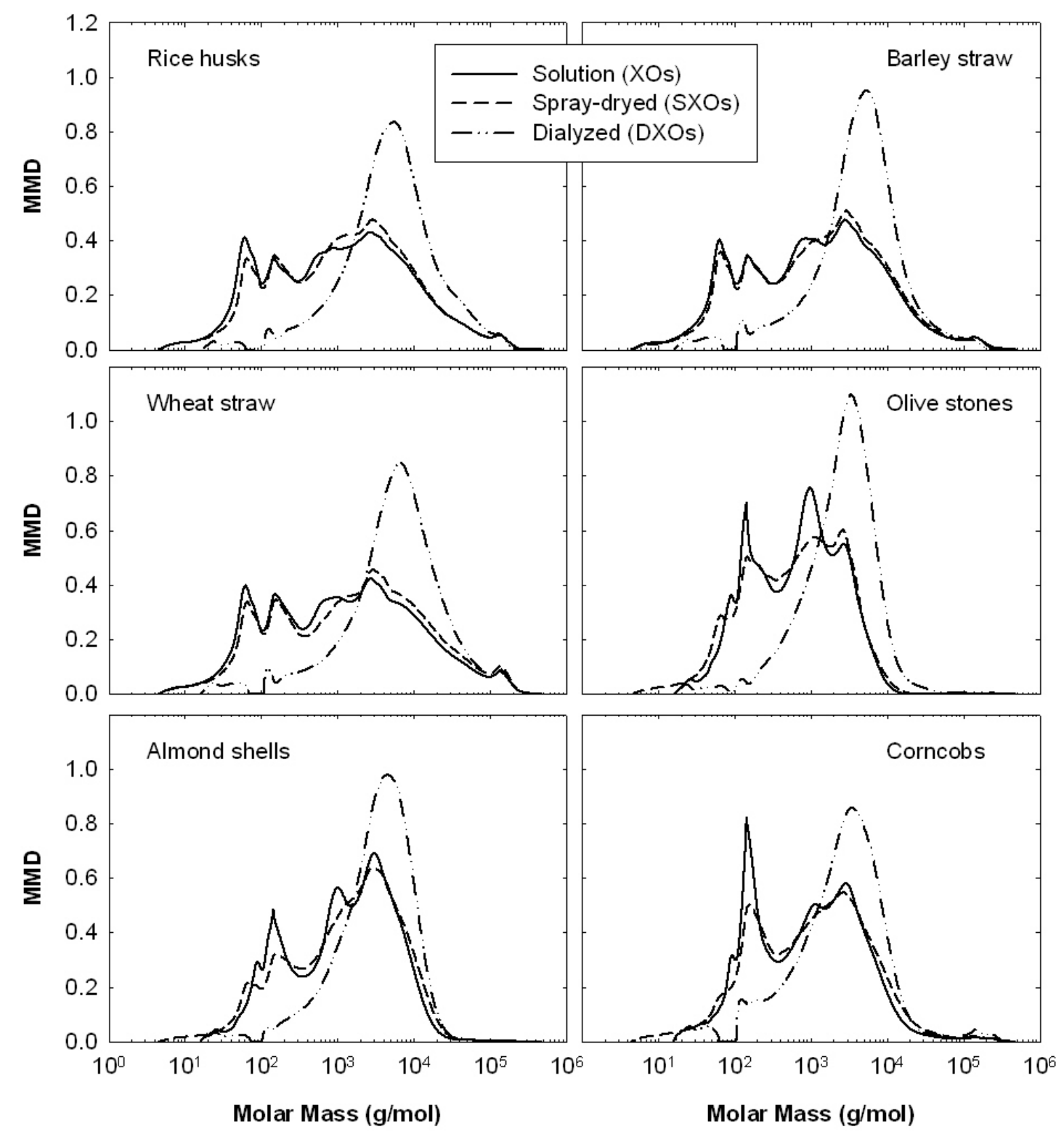

Figure 3.21. Molar mass distribution of the xylo-oligosaccharides in the non-dried liquid product (XOs), obtained after spray drying (SXOs) and obtained after dialysis (DXOs), for the six raw materials studied.

\subsubsection{Structural features of the xylo-oligosaccharides}

1D $\left({ }^{13} \mathrm{C}\right.$ and $\left.{ }^{1} \mathrm{H}\right)$ and 2D (HSQC) NMR spectra of the DXOs were collected in order to elucidate the structural features. The signals for ${ }^{13} \mathrm{C}$ and ${ }^{1} \mathrm{H}$ were assigned based on the HSQC spectra following published NMR data for xylo-oligosaccharides and glucuronoxylans [42-45]. 
As seen in Figure 3.22, the ${ }^{13} \mathrm{C}$ NMR spectral patterns of all six DXOs are the same, differing only in the intensity of the signals. The dominating five signals gave HSQC ${ }^{13} \mathrm{C} /{ }^{1} \mathrm{H}$ cross peaks at $\delta 102.57 / 4.45,73.6 / 3.28,74.6 / 3.54,77.3 / 3.76$ and 63.9/4.04+3.40, corresponding to C-1 - C-5 of 4-linked $\beta$ - Xyl $p$ residues. The cross peaks at $\delta$ 98.8/5.28 (C-1) and 83.1/3.19 (C-4) indicate the presence of $\alpha$-linked 4-Omethylglucuronic acid (MeGA) residues.

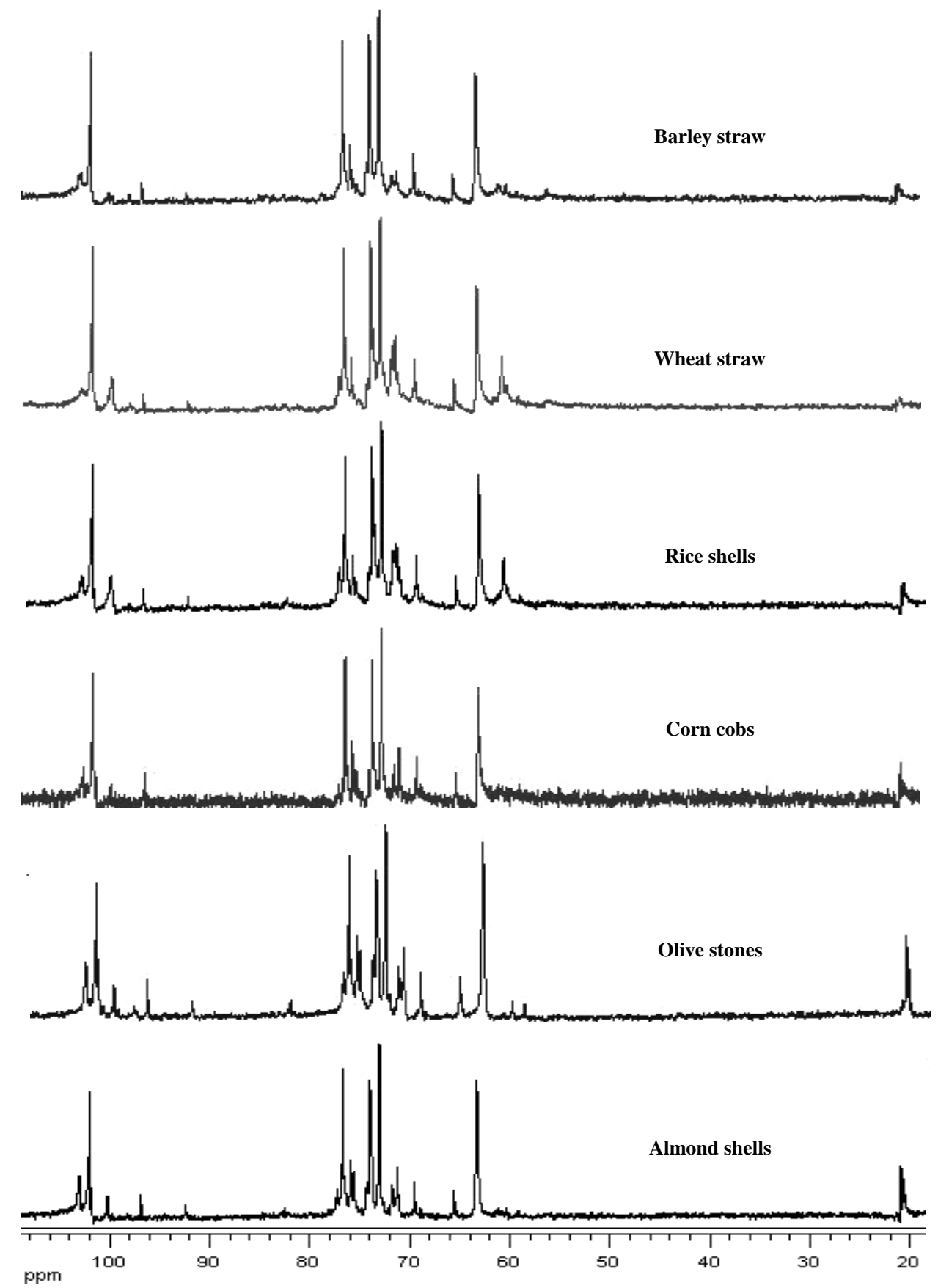

Figure 3.22. ${ }^{13} \mathrm{C}$ NMR spectra (in $\mathrm{D}_{2} \mathrm{O}$ ) of DXOs from various plant sources. 
In spite of the occurrence of low amounts of arabinose in all SXOs (Table 3.7), no signals were detected in the spectra corresponding to $\alpha$-Araf residues. These signals would appear in the downfield region at $107-110$ ppm, similarly as reported for the arabinose-containing heteroxylans [32]. Very probably, because of the low amount and variety of positions of $\alpha$-Araf residues in the DXOs as well as in contaminating fragments of pectic arabinans and arabinogalactans, released by the hydrothermal treatment, the arabinose signals were not detectable. In contrast to the DXOs from OS and AS, which are tissues of dicotyl plants containing 4-O-methylglucuronoxylans, $\alpha$ Araf residues could be expected in DXOs from CC, RH, BS and WS. The last are tissues of monocotyl plants, where arabinose represents a sugar constituent of the heteroxylan component [37]. The cross peaks at $\delta 100.6 / 5.38$ and 61.0/3.80+3.73 were not assigned because of lack of further information. They might correspond to $\alpha$-linked hexopyranose residues such as galactose, originating from side chains of the heteroxylan component and/or of contaminating cell wall hexoglycans [32].

The pattern of ${ }^{1} \mathrm{H}$ NMR of all DXOs spectra was similar (shown for OS and BS in Figure 3.23). The present acetyl groups gave $\mathrm{HSQC}{ }^{13} \mathrm{C} /{ }^{1} \mathrm{H}$ cross peaks at $\delta 22-20.7 / 2.22-2.10$. The average degree of substitution of the DXOs was calculated from the ${ }^{1} \mathrm{H}$ NMR spectra by dividing the area of the acetyl group signals by the cumulative signal of all carbohydrates [44, 46].

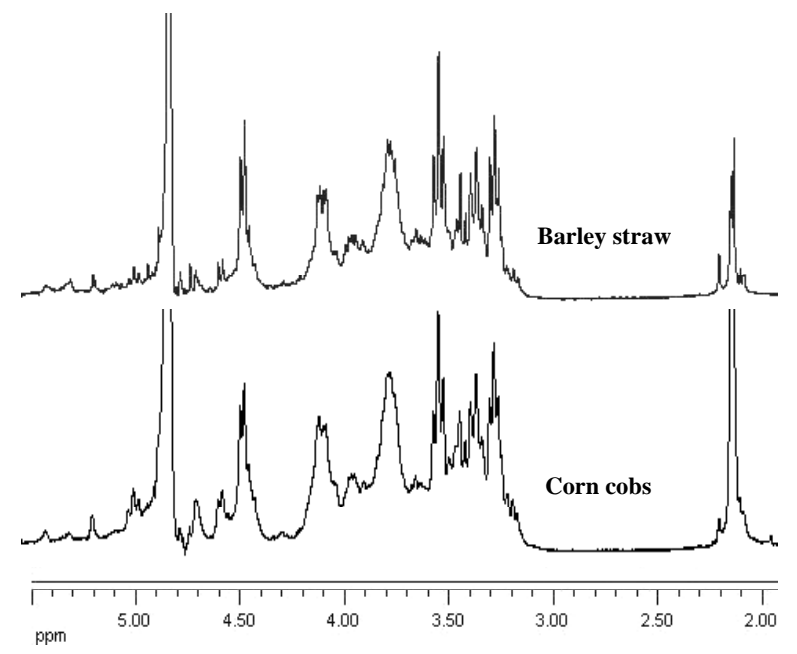

Figure 3.23. ${ }^{1} \mathrm{H}$ NMR spectra of XOs from barley straw and corncobs. 
The proportion of Xylp and MeGA residues as well as the location of the acetyl groups was elucidated by means of proton assignments in the anomeric region of the ${ }^{1} \mathrm{H}$ NMR HSQC spectra (demonstrated for OS in Figure 3.24). The obtained chemical shifts were in accord with values already published for hardwood 4-Omethylglucuronoxylans $[44,45]$. The relative proportions of $\mathrm{Xyl} p$ residues, free and $O-$ acetylated, were determined [45] by integrating the areas of the H-1 signals of internal, non-reducing and reducing terminal $\mathrm{Xyl} p(\underline{\mathrm{Xint}}, \mathrm{Xt}, \mathrm{X} \alpha, \mathrm{X} \beta)$, the H-2 signal from 2-Oacetylated $\mathrm{Xyl} p(\underline{\mathrm{X} 2})$, the $\mathrm{H}-3$ signals from 3-O-acetylated $\mathrm{Xyl} p(\underline{\mathrm{X} 3})$ and 2,3-Odiacetylated $\mathrm{Xyl} p(\underline{\mathrm{X} 23})$, and $\mathrm{Xyl} p$ bearing the 2-linked MeGA $(\underline{\mathrm{XG}})$. The proportion of MeGA was derived from its $\mathrm{H}-1$ signal area.

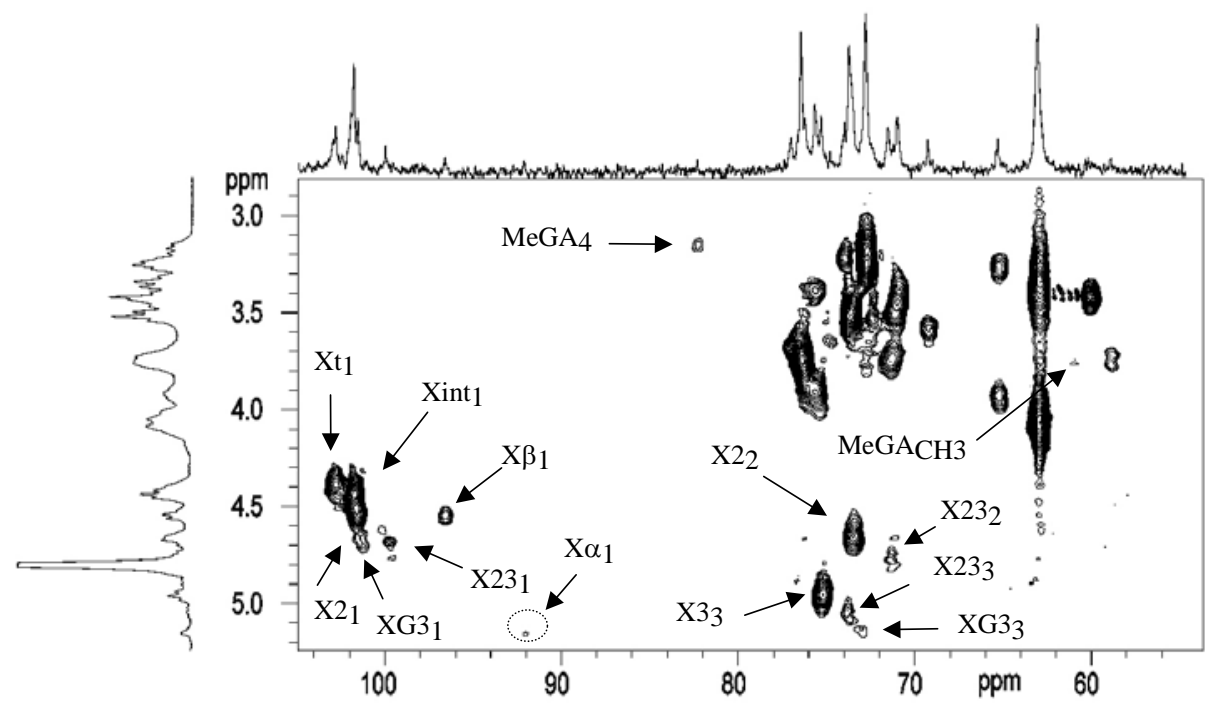

Figure 3.24. The 2D HSQC spectrum of DXOs from olive stones, illustrating MeGA residues and various $\mathrm{Xyl} p$ residues. The following designations are used: $\mathrm{X} 3$ : 3-O-acetylated Xyl $p ; \mathrm{X} 2: 2-$

O-acetylated Xylp; X23: 2,3-O-diacetylated Xylp; XG3: MeGA 2-O-substituted and 3-Oacetylated Xyl $p$; MeGA: 4-O-methylglucopyranosyl uronic acid; Xint, $\mathrm{Xt}, \mathrm{X} \alpha$ and $\mathrm{X} \beta$ : nonacetylated internal, non-reducing terminal, and reducing terminal Xylp residues. The subscript number corresponds to the $\mathrm{H}$ - and $\mathrm{C}$-atom.

The values of the average degree of acetylation estimated from the ${ }^{1} \mathrm{H}$ NMR spectral data and those obtained by quantitative HPLC analysis of the acetic acid liberated by the acid hydrolysis of SXOs are summarized in Table 3.8. The chemical analysis revealed that the SXOs from OS had the highest degree of acetylation (35\%), 
followed by AS (30\%) and CC (19\%), whereas SXOs from WS and BS had similar values (around $17 \%$ ), and from RH were the less acetylated SXOs (12\%). These values agree reasonably well with the average degree of acetylation determined by ${ }^{1} \mathrm{H}$ NMR spectroscopy for OS (41\%), AS (31\%), CC (21\%) and RH (11\%) and less in the case of BS (8\%) and WS (9\%). As shown in Table 3.8, the DXOs were acetylated mainly in position 3 (between 60 and $67 \mathrm{~mol} \%$ ), whereas the occurrence of acetyl groups in position 2 and in both positions 2 and 3 was similar (19 - $30 \mathrm{~mol} \%$ and $8-25 \mathrm{~mol} \%$, respectively).

\begin{tabular}{|c|c|c|c|c|c|c|}
\hline \multirow[t]{2}{*}{ Raw material } & \multirow{2}{*}{$\begin{array}{c}\text { MeGA/Xyl } \\
\text { Mole ratio } \\
\text { NMR a }^{\text {a }}\end{array}$} & \multicolumn{2}{|c|}{$\begin{array}{l}\text { Degree of Acetylation } \\
\text { (Acetyl/Xyl) }\end{array}$} & \multicolumn{3}{|c|}{$\begin{array}{c}\text { Acetylated positions in } \mathrm{Xyl} \\
(\% \text { of the total })\end{array}$} \\
\hline & & NMR b & HPLC c & 2 & 3 & 2,3 \\
\hline Corncobs & $2.5: 100$ & 0.21 & 0.19 & 19.3 & 67.1 & 13.6 \\
\hline Almond shells & $4.4: 100$ & 0.31 & 0.30 & 21.6 & 59.4 & 16.0 \\
\hline Olive stones & $9.1: 100$ & 0.41 & 0.35 & 23.3 & 62.7 & 21.0 \\
\hline Rice husks & $4.3: 100$ & 0.11 & 0.12 & 29.8 & 62.7 & 7.5 \\
\hline Wheat straw & $7.4: 100$ & 0.08 & 0.16 & 22.1 & 51.9 & 26.0 \\
\hline Barley straw & $6.0: 100$ & 0.09 & 0.17 & 19.1 & 66.9 & 14.0 \\
\hline
\end{tabular}

Table 3.8. Relative amounts of monosaccharides and acetyl groups, and distribution of acetyl groups among xylose residues in the DXOs from different raw materials. a Approximate values determined by integration of signals in the fingerprint region of the ${ }^{1} \mathrm{H}$ NMR spectra. ${ }^{b}$ Approximate values determined by integration of the $\mathrm{H}-1$ signals of acetyl groups and of all carbohydrate signals [44]. c See experimental.

Estimation of the MeGA content from the ${ }^{1} \mathrm{H}$ NMR spectra, expressed in mol MeGA per $100 \mathrm{~mol}$ Xyl, revealed a very low value for XOs from CC (2.5:100), higher values for those from AS, RH, BS and WS ranging from 4.3:100 to 7.4:100. The highest content was found for XOs from OS, having 9 of $100 \mathrm{Xyl} p$ residues on the average substituted by MeGA residues, what is close to the average MeGA / Xyl ratio (1:10) found in 4-O-methylglucuronoxylans from hardwoods [37]. 
All lignocellulosic substrates, independently on their structurally different heteroxylan components, generated xylo-oligomers typical of partially acetylated 4-Omethylglucuronoxylan, however, with different degrees of substitution for the acetyl and the 4-O-methylglucuronic acid groups. A comparative assessment of the results shows that the characteristics of the raw material determined the yield and composition of the XOs. Their yield depended not only on the content of xylan in the raw material, but was proportional to the content of acetyl groups, since their cleavage liberated acetic acid, which catalyzed the depolymerization of xylan into xylooligosaccharides and xylan polymers of low mass. However, the density of the substrate played a major role in the process. AS and OS had very lignified and dense cell wall structures that prevented the liberation of degraded lignin and the formation of gluco-oligosaccharides during autohydrolysis, and they yielded the purer XOs. From these results, AS are the best substrate for XOs preparation, because it allows processing at a high concentration of xylan in the reactor, offers an elevated yield (more than 55\% of the original xylan), and the XOs have a relatively low lignin content. For these reasons, the xylo-oligosaccharides mixture obtained from almond shells was characterized more deeply, and the results are presented in the next section.

\subsubsection{Characterization of xylo-oligosaccharides from almond shells}

Among the several xylan-rich biomass resources, almond shells, are produced in huge amounts (in Spain alone about $2 \times 10^{5}$ ton per year), and have a great potential for the production not only of xylose [47], but also of XOs. It was shown that by controlling the temperature and time of the hydrothermal treatment without addition of acid it is possible to influence the characteristics of the XOs obtained from almond shells, such as the acetyl content, molecular mass and purity. The acetic acid resulting from hydrolysis of acetyl groups present in the hemicelluloses acts as catalyst of the hydrolytic cleavage of the xylan chains. The water-soluble product recovered by spraydrying (SXOs) contained mainly xylo-oligosaccharides with a broad molecular mass distribution, and was contaminated with other carbohydrates, proteins, ash, various phenolics, and degradation products. Dialysis of the crude XO removed the monosaccharides and most of the shorter oligomers and other low molecular weight substances, leaving longer chain XOs with a main molecular peak (84\%) 5,000 Da. Solvent extraction was used to separate phenolics from the almond shell XOs. Further, the dialyzed XOs (DXOs) were characterized by FT-IR and NMR spectroscopy as well 
as MALDI-TOF mass spectrometry. This characterization was made in the Institute of Chemistry, Bratislava, Slovak Republic.

Carbohydrate composition of both SXOs and DXOs (Table 3.9) revealed the xylose to be the dominant sugar component. Its relative proportion increased by dialysis because of the loss of molar mass fragments originated mainly from contaminating cell wall components (hexosans and pectic polysaccharides). The presence of 4-O-methylglucuronic acid (MeGA) in the hydrolysates was identified by paper chromatography [48].

\begin{tabular}{|c|c|c|c|c|c|c|c|c|c|c|}
\hline \multirow[t]{2}{*}{ Sample } & \multirow{2}{*}{$\begin{array}{l}\text { Ash } \\
(\%)^{a}\end{array}$} & \multicolumn{7}{|c|}{ Neutral sugar composition $(\mathrm{mol} \%)^{b}$} & \multirow{2}{*}{$\begin{array}{l}\text { UA } \\
(\%)^{c}\end{array}$} & \multirow{2}{*}{$\begin{array}{c}\text { Ac } \\
(D S)^{d}\end{array}$} \\
\hline & & Rha & Fuc & Ara & Xyl & Man & Glc & Gal & & \\
\hline SXO & 4.8 & 1.8 & 1.5 & 10.2 & 69.4 & 3.7 & 7.1 & 6.4 & 2.0 & $0.31^{\mathrm{e}}$ \\
\hline DXO & 0 & 1.9 & 1.6 & 4.7 & 86.3 & 4.1 & 1.4 & 0 & 4.3 & 0.32 \\
\hline
\end{tabular}

Table 3.9. Chemical characteristics of the crude (SXO) and dialyzed XO (DXO) obtained from almond shells. a Residue after combustion at $850-900^{\circ} \mathrm{C}$. ${ }^{\mathrm{b}}$ Sugars identified by GC of alditol trifluoroacetates after TFA hydrolysis. ${ }^{c}$ Content of 4-O-methylglucuronic acid (as anhydro unit) determined by potentiometry, related to dry XOs. ${ }^{d}$ Approximate average degree of substitution of the Xylp residues with acetyl groups, calculated by integration of acetyl group signals (at $\delta$

2.1 - 2.3) and of all carbohydrate proton signals [45], was 0.32. e Content of acetyl groups determined by HPLC.

The FT-IR spectrum of the crude (SXOs) and dialyzed (DXOs) samples (Figure 3.25) show similar patterns in the region $1200-1000 \mathrm{~cm}^{-1}$, typical of 4-Omethylglucuronoxylan xylan-type polysaccharides [49]. The absorption bands at $\sim 1740$ $\mathrm{cm}^{-1}$ and $\sim 1250 \mathrm{~cm}^{-1}$ confirmed the presence of acetyl groups. The band at $\sim 1515 \mathrm{~cm}^{-1}$ corresponds to aromatic type compounds, in accord with the lignin content of $5.3 \%$. 


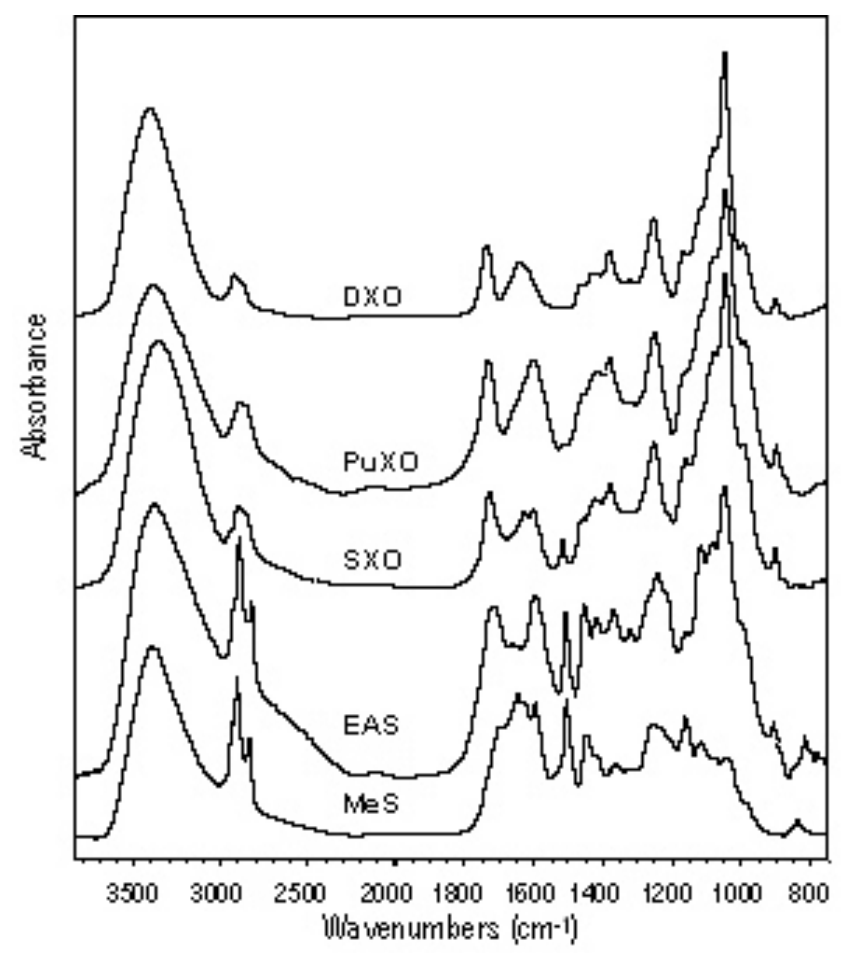

Figure 3.25. FT-IR spectra of the crude almond shell SXOs and its purification products: DXOs, dialyzed SXOs; MeS, methanol-soluble fraction; EAS, ethyl acetate soluble fraction; PuXOs, purified fraction after ethyl acetate extraction.

Two phenolic fractions were separated from the SXOs. The water-insoluble phenolic fraction (MeS) was obtained after re-dissolution of the SXOs in water as an insoluble residue, which was afterwards solubilized in methanol. The water-soluble phenolic fraction (EAS) was separated by extraction of the aqueous solution with ethyl acetate from the resulting organic phase. The aqueous phase yielded the purified XOs (PuXOs). As seen in Figure 3.25, the spectral pattern of MeS and EAS is similar and indicates the presence of various aromatic fragments [50], such as the bands at 1710$1730 \mathrm{~cm}^{-1}, 1600-1605 \mathrm{~cm}^{-1}$ and $1515 \mathrm{~cm}^{-1}$ (aromatic ring and carbonyl groups), at 2965 $\mathrm{cm}^{-1}$ and $2850 \mathrm{~cm}^{-1}\left(\mathrm{CH}_{3}\right.$ and $\mathrm{CH}_{2}$ groups connected with aromatic structures) and at $834 \mathrm{~cm}^{-1}$ (aromatic ring). However, weak xylo-oligosaccharides vibrations are seen in the water-soluble phenolics (EAS). Both the spectra of DXOs and PuXOs are essentially the same, showing a very weak absorption at $1515 \mathrm{~cm}^{-1}$. The residual contents of MeS and EAS in DXOs (determined gravimetrically) were 1.1 and $4.7 \%$, respectively. The results suggest that most of the contaminating phenolics were removed by dialysis of SXOs and they were mainly associated with the low molar mass substances. This residue might be used as a source of phenolics with antioxidant properties [51]. 


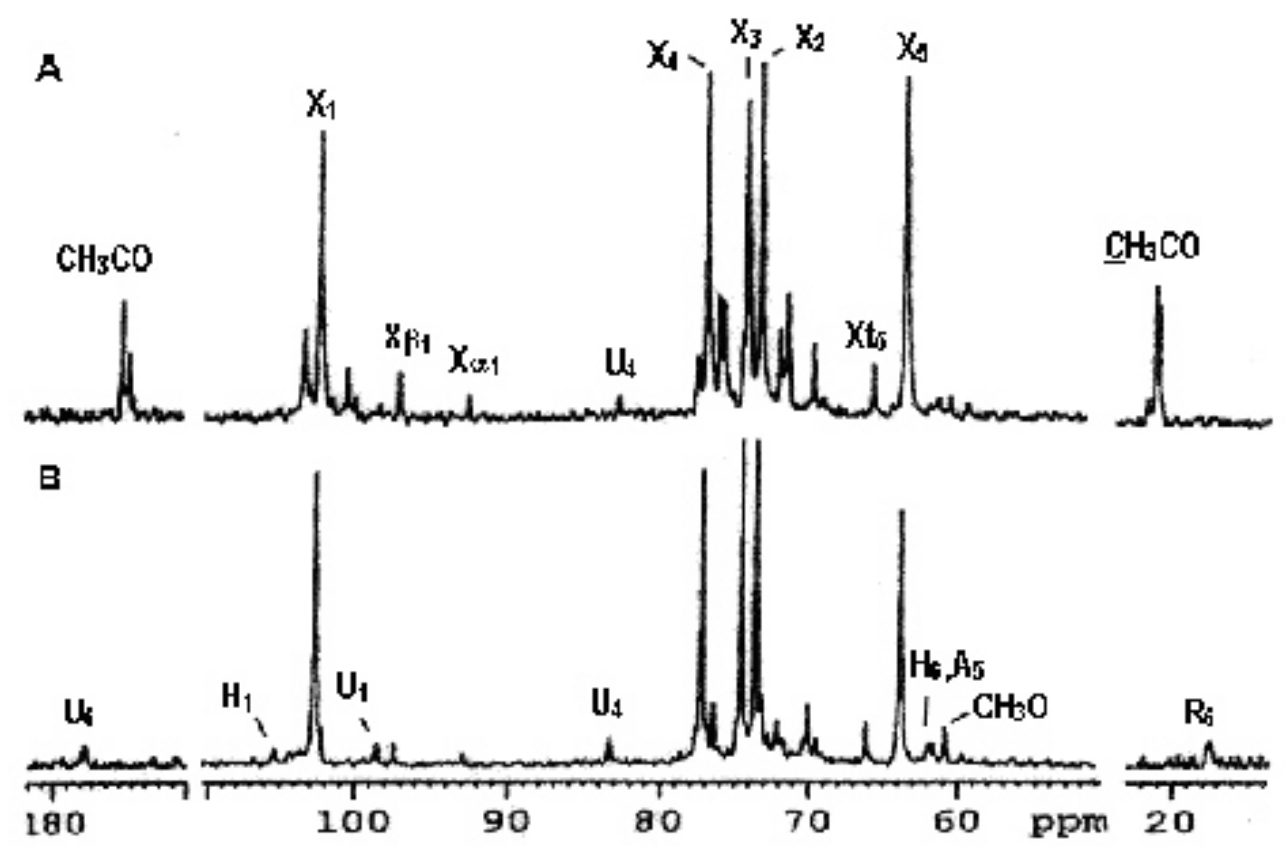

Figure 3.26. ${ }^{13} \mathrm{C}$ NMR spectra (in $\mathrm{D}_{2} \mathrm{O}$ ) of (A) dialyzed almond shell xylo-oligosaccharides (DXOs) and (B) the deacetylated sample (DeXOs). X1 - X5, internal Xylp, U, 4-Omethylglucuronic acid; $\mathrm{H}$, hexopyranose; R, Rhap; A, arabinofuranose.

The structural features of the almond shell oligosaccharides were examined by NMR spectroscopy of DXOs before and after de-acetylation. The chemical shifts of the signals observed in the ${ }^{13} \mathrm{C}$ NMR spectra (in $\mathrm{D}_{2} \mathrm{O}$ ) shown in Figure 3.26-A and 3.26- $\mathrm{B}$, respectively, are in excellent agreement with the values reported for various 4-Omethylglucuronoxylan oligomers and polymers, and their acetylated forms [43-45]. The relatively weak signals for the $\alpha$ - and $\beta$ - anomers of reducing Xylp end groups are in accord with the average of the molecular mass $(\sim 5,000 \mathrm{Da})$ of DXOs, indicating the presence of oligomeric/polymeric fragments. The xylan backbone of DXOs contains acetyl groups at various positions and a rather low amount of 2-linked 4-O-methyl- $\alpha$ D-glucuronic acid residues (MeGA). After deacetylation, signals of the contaminating carbohydrates, such C-6 of Rha at $\delta 17.9$ and C-5 of Ara and C-6 of Gal at 62.2 and 61.6, respectively, were observed. The presence and location of acetyl groups was assigned from the anomeric region of the ${ }^{1} \mathrm{H}$ NMR (not shown) and the 2D-HSQC spectra of DXOs (Figure 3.27) showing characteristic ${ }^{1} \mathrm{H} /{ }^{13} \mathrm{C}$ cross-peaks of various structural elements (Table 3.10). The present acetyl groups gave HSQC ${ }^{13} \mathrm{C} /{ }^{1} \mathrm{H}$ cross peaks at $\delta$ 22.0-20.7/2.22-2.10. In spite of the low MeGA content, the cross-peaks of both MeGA and element XG3, corresponding to Xylp unit substituted at position 2 by MeGA and 
acetylated at position 3, were detected. Similar results were reported for various $O$ acetylated hardwood glucuronoxylans $[44,45]$ isolated by different extraction methods.

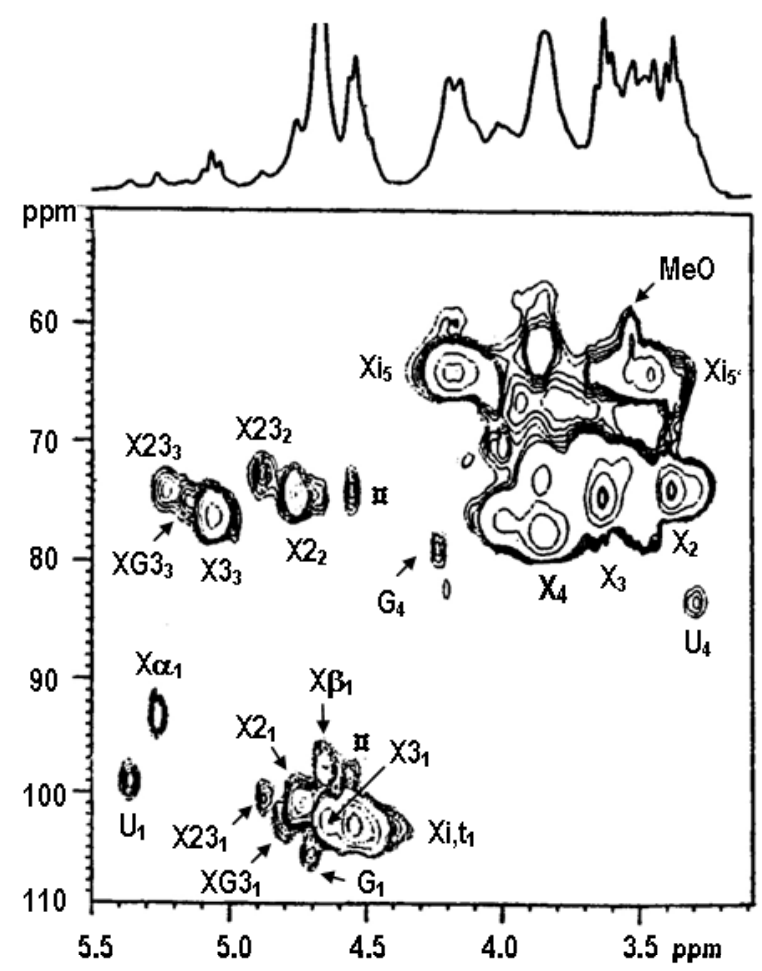

Figure 3.27. Partial ${ }^{1} \mathrm{H} /{ }^{13} \mathrm{C}$ HSQC NMR spectrum (in $\mathrm{D}_{2} \mathrm{O}$ ) of almond shell DXOs. For designations of the cross-peaks see annotation in Table 3.7; G, 4-linked $\beta$-Galp. The subscript number corresponds to the respective $\mathrm{H} / \mathrm{C}$ atom.

The ${ }^{13} \mathrm{C}$ NMR spectrum of DXOs (Figure 3.26-A) shows a strong, splitted anomeric signal at $\delta 103.5$, which diminished substantially after the deacetylation. However, the corresponding cross-peaks were not distinguishable from those of the prevailing internal non-acetylated $\mathrm{Xyl} p$ residues, indicating the signals to originate from non-reducing terminal $\mathrm{Xyl} p$ residues. It is to be mentioned that the shorter xylooligosaccharides were probably lost during the recovery of the deacetylated SXOs sample by dialysis. The cross-peaks depicted as arrows in Figure 3.27 were not assigned because of lack of further information. They might indicate the occurrence of various possible combinations of the presented structural elements. 


\begin{tabular}{|c|c|c|}
\hline Element & $\begin{array}{l}\text { Chemical shift } \\
{ }^{1} \mathrm{H} /{ }^{13} \mathrm{C}(\mathrm{ppm})\end{array}$ & Assignment \\
\hline MeGA & $5.34 / 98.4$ & $\mathrm{H}-1 / \mathrm{C}-1$ \\
\hline$X_{\alpha}$ & $5.26 / 93.5$ & H-1 / C-1 \\
\hline$X \beta$ & $4.66 / 97.9$ & H-1 / C-1 \\
\hline$X \mathrm{i}, \mathrm{Xt}_{\mathrm{t}}$ & $4.40-4.48$ / 102.3-103.6 & H-1 / C-1 \\
\hline \multirow[t]{2}{*}{$\mathrm{X} 2$} & $4.75 / 100.9$ & H-1 / C-1 \\
\hline & $4.76 / 74.5$ & $\mathrm{H}-2$ / C-2 \\
\hline \multirow[t]{2}{*}{ X3 } & $4.54 / 102.6$ & H-1 / C-1 \\
\hline & $5.06 / 76.4$ & H-3 / C-3 \\
\hline \multirow[t]{2}{*}{$X 23$} & $4.87 / 100.3$ & H-1 / C-1 \\
\hline & $4.87 / 73.0$ & H-3 / C-3 \\
\hline \multirow[t]{2}{*}{ XG3 } & $4.68 / 102.1$ & H-1 / C-1 \\
\hline & $5.16 / 75.0$ & $\mathrm{H}-3$ / C-3 \\
\hline
\end{tabular}

Table 3.10. HSQC NMR cross-peaks of various structural elements of almond shell DXO. Designation used were: MeGA, 4-O-methylglucuronic acid; $\mathrm{X} \alpha$ and $\mathrm{X} \beta$, $\mathrm{Xyl} p$ reducing ends; $\mathrm{Xi}$ and $\mathrm{Xt}, \mathrm{Xyl} p$ internal and non-reducing terminal end; $\mathrm{X} 2$, 2-O-acetylated $\mathrm{Xyl} p ; \mathrm{X} 3,3-\mathrm{O}-$ acetylated Xylp; X23, 2,3-di-O-acetylated Xylp; XG3, MGA 2-O-linked and 3-O-acetylated Xylp.

The molar proportion of $\mathrm{Xyl} p$ and MeGA residues of DXOs, calculated by integration of the corresponding H-1 signals areas, was 100:4.1. A similar ratio (100:4.8) was obtained by integration of the corresponding C-1 signals of the deacetylated sample.

The average degree of substitution of the Xylp residues with acetyl groups, calculated by integration of acetyl group signals (at $\delta$ 2.1-2.3) and of all the carbohydrate proton signals [44], was 0.32. The distribution of acetyl groups in Xylp residues was determined [45] by integrating the areas of $\mathrm{H}-1$ signals of internal, nonreducing and reducing terminal $\mathrm{Xyl} p(\mathrm{Xint}, \mathrm{Xt}, \mathrm{X} \alpha, \mathrm{X} \beta$ ), of the H-2 signal from 2-O- 
acetylated $\mathrm{Xyl} p(\mathrm{X} 2)$, the H-3 signals from 3-O-acetylated Xylp (X3), 2,3-O-diacetylated Xylp (X23), and Xylp bearing the 2-linked MeGA (XG3). The results indicated that approximately $29 \%$ of the acetyl groups are located in position 2, 61\% in position 3 including about $3 \%$ from $X G 3$, and the rest $(10 \%)$ in both positions.

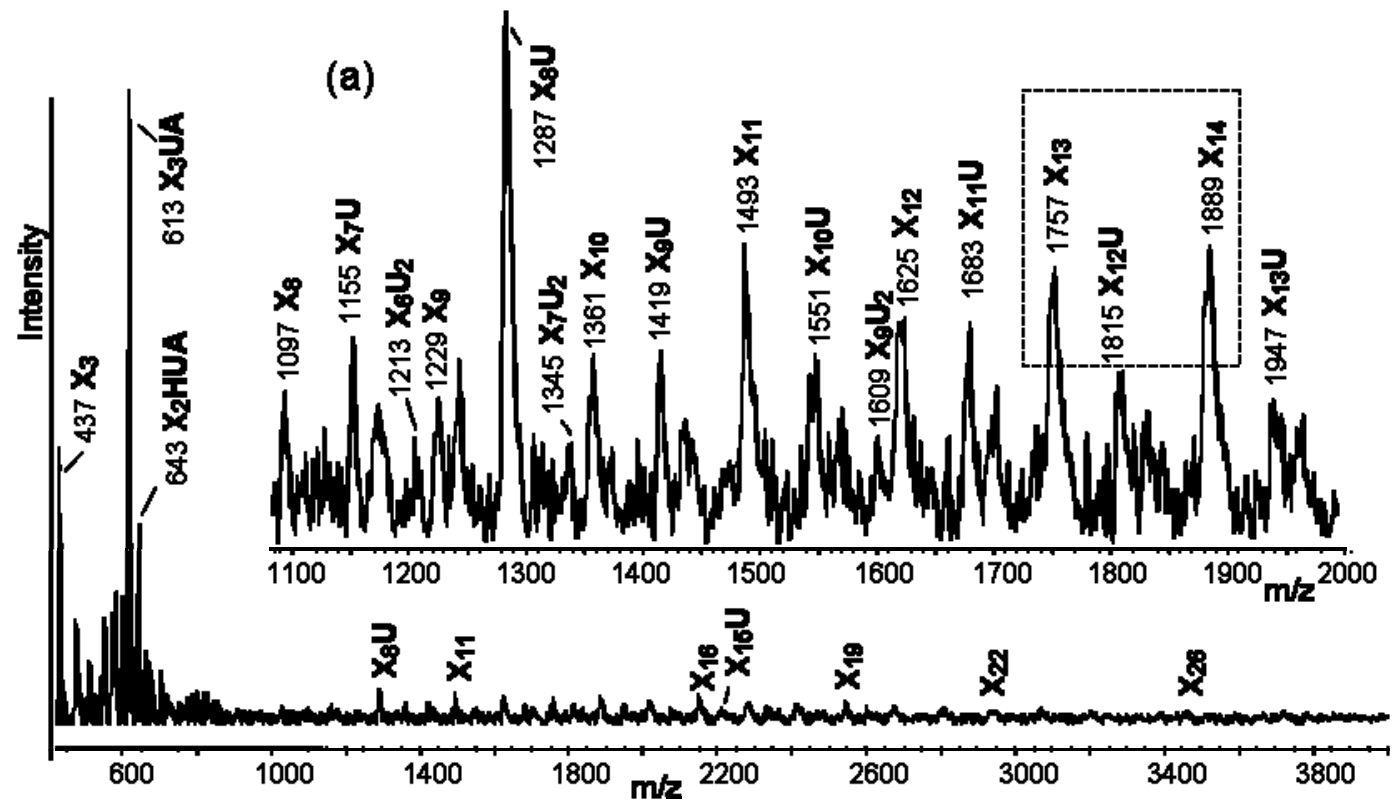

Figure 3.28. MALDI -TOF mass spectrum in $\mathrm{D}_{2} \mathrm{O}$ (sodium-adducts) of the deacetylated sample (DeXO) and the inserted (a) extended region with $\mathrm{m} / \mathrm{z}$ from 1000 to 2000 mass units. $\mathrm{X}=$ xylose; $\mathrm{U}=4$-O-methylglucuronic acid; $\mathrm{UA}$, glucuronic or galacturonic acid; $\mathrm{H}$, hexose; $(\bullet)$ = acetyl group.

Further analysis of the almond shell xylo-oligosaccharides was performed by MALDI-TOF MS of DXO and the deacetylated sample (DeXO), which both contained more than 90\% xylo-oligosaccharides. In accord, the spectrum of De-XO (Figure 3.28) contained a series of neutral xylo-oligosaccharides $\left[X_{n}\right]$ starting from $X_{5}$ and distinguishable up to $X_{20}$, the higher oligomers disappeared in the noise. A series of the expected acidic xylo-oligosaccharides branched with one uronic acid [ $\mathrm{X}_{\mathrm{n}} \mathrm{MeGA}$ ] were detectable from $\mathrm{X}_{5} \mathrm{MeGA}$ up to $\mathrm{X}_{16} \mathrm{MeGA}$. They show weaker intensities, and were separated from the two neighboring $\left[X_{n}\right]$ by 58 and 74 mass units, respectively. Also, some oligomers containing more than one MeGA were detected such as $\mathrm{X}_{3} \mathrm{MeGA}_{2}(\mathrm{~m} / \mathrm{z}$ 818), $\mathrm{X}_{7} \mathrm{MeGA}_{2}\left(\mathrm{~m} / \mathrm{z}\right.$ 1343) up to $\mathrm{X}_{10 \mathrm{MeGA}_{2}}(\mathrm{~m} / \mathrm{z} 1742)$ and $\mathrm{X}_{4} \mathrm{MeGA}_{3}(\mathrm{~m} / \mathrm{z} 1141)$, 
$\mathrm{X}_{7 \mathrm{MeGA}}\left(\mathrm{m} / \mathrm{z}\right.$ 1536), and $\mathrm{X}_{9} \mathrm{MeGA}_{3}(\mathrm{~m} / \mathrm{z}$ 1797). Taking into account the MeGA/X ratio of the DXOs about 1:25, estimated by NMR spectroscopy, the distribution of the uronic acid side chains along the xylan chains seems to be rather block wise than random.

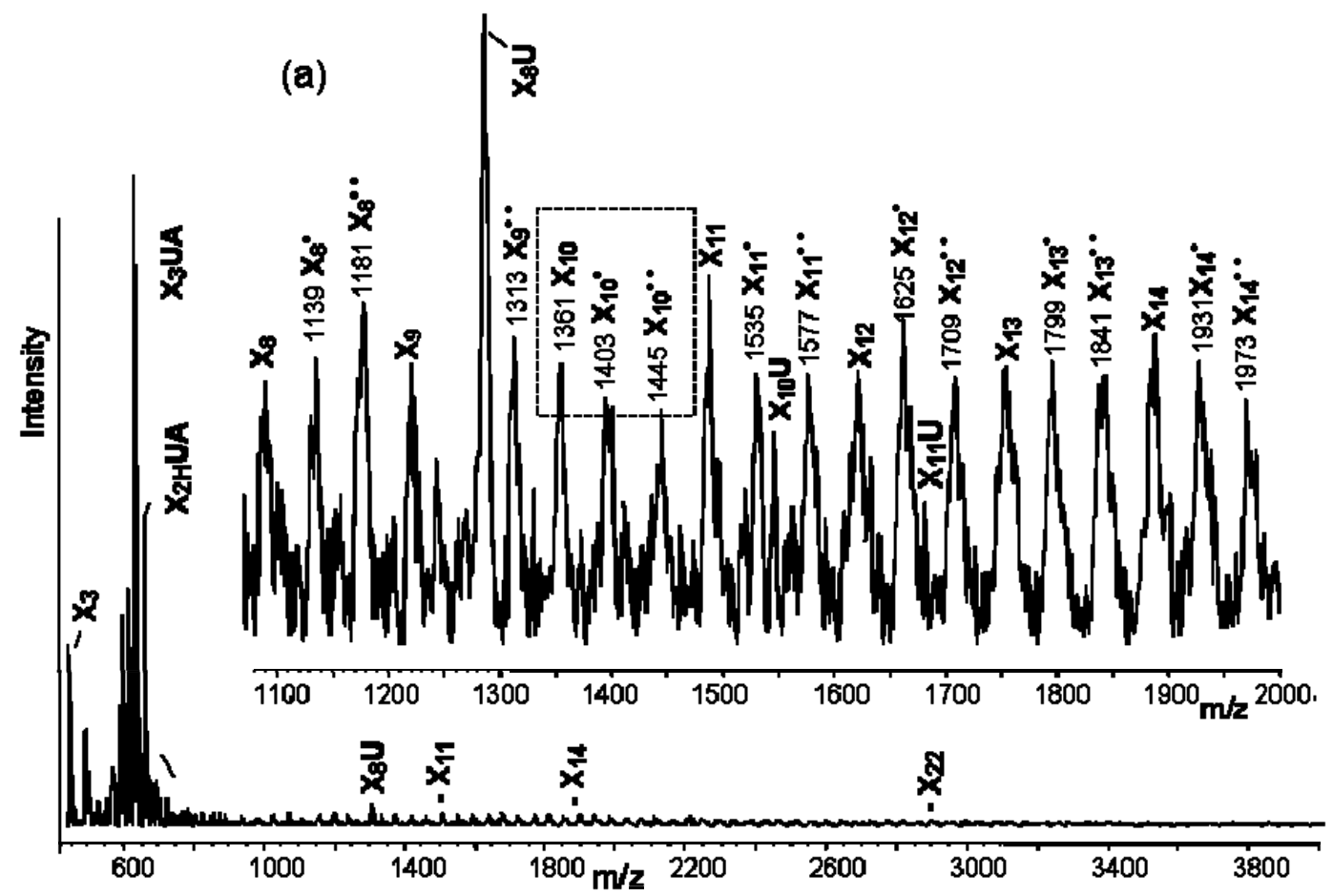

Figure 3.29. MALDI -TOF mass spectrum (sodium-adducts) of almond shell xylooligosaccharides DXOs. Inserted (a) is the extended region with m/z from 1000 to 2000 mass units. For abbreviations see Figure 3.28.

The spectrum of DXO (Figure 3.29) was more complicated due to the presence of neutral xylo-oligosaccharides with one to two acetyl groups $\left[\mathrm{X}_{\mathrm{n}} \mathrm{Acm}\right]$, clearly separated by 42 mass units, up to a DP 16. Also some acidic oligomers containing one acetyl group [ $\mathrm{X}_{n} \mathrm{MeGAAc}$ ] were observed. The acidic xylo-oligosaccharides $\mathrm{X}_{2} \mathrm{M}_{2}$ and $\mathrm{X}_{3} \mathrm{M}_{2}$ containing one acetyl group, i.e. $\mathrm{m} / \mathrm{z} 725$ and 857, respectively, confirms the presence of the XG3 structural element, detected by NMR spectroscopy. 


\subsection{PURIFICATION TREATMENTS}

\subsubsection{Precipitation with a non solvent}

Further treatment stages of the hydrolysis liquor can provide effective process strategies for producing xylo-oligosaccharides with narrower molar mass distributions and absence of monomers and low molar mass products (monosaccharides, acetic acid, furfural, etc.). Selective precipitation of the xylo-oligosaccharides and their fractionation by molar-mass can be performed by adding controlled amounts of a nonsolvent to the hydrolysis liquor.
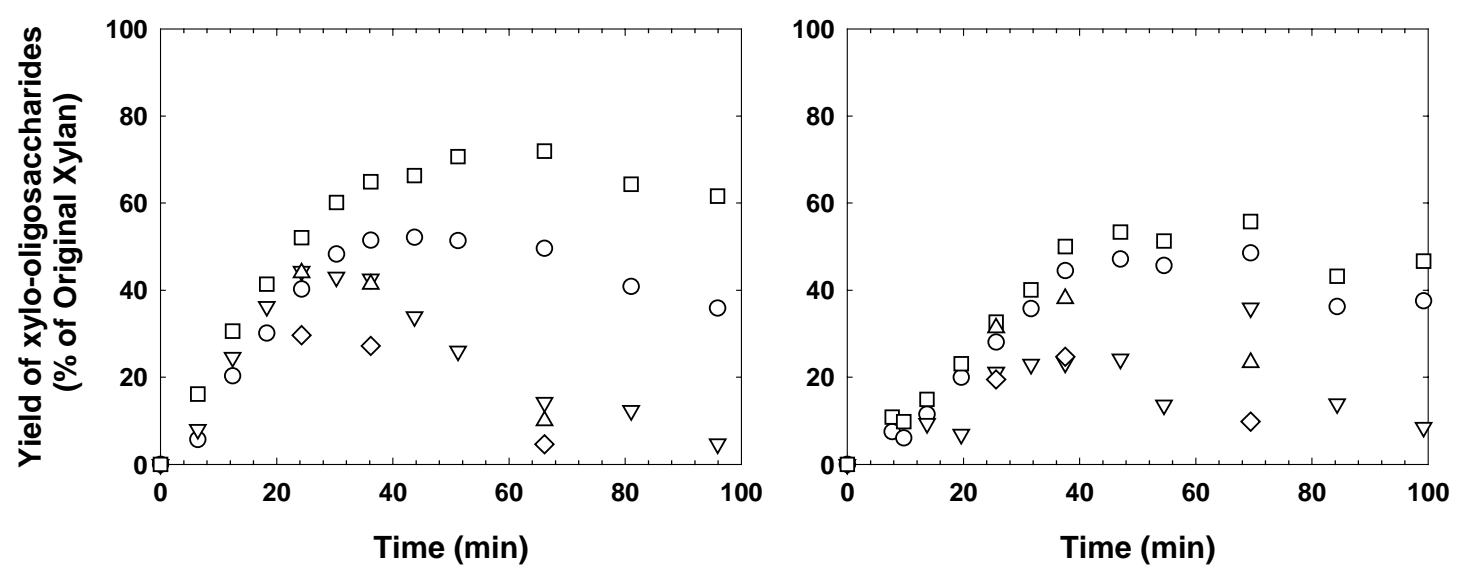

Figure 3.30. Alcoholic precipitation: $\bigcirc$ Estimation of the amount of $X O s$ present in the hydrolysis liquor, $\nabla$ total powder recovered by ethanol precipitation, $\square$ estimation of the amount of XOs, GOs and monomers present in the hydrolysis liquor, $\diamond$ XOs and GOs recovered by ethanol precipitation, $\triangle$ total powder recovered by ethanol precipitation (repetition). All of them are expressed as function of the time for the isothermal series at $169^{\circ} \mathrm{C}$ for corncobs (left) and almond shells (right).

Figure 3.30 shows the yield of solid xylo-oligosaccharides recovered by selective precipitation with the addition of ethanol to the hydrolysis liquor $(7 / 1, \mathrm{vol} / \mathrm{vol})$ for the experiments performed in small reactors at $169^{\circ} \mathrm{C}$ for corncobs (left) and almond shells (right). In this figure were compared the theoretical production of xylooligosaccharides (XOs), the theoretical production of XOs plus monomers and glucooligosaccharides (GOs), with the total amount of powder, and also with the total 
amount of XOs plus GOs recovered by precipitation. All of them are expressed as \% of the original xylan.

If the theoretical production of XOs is compared with the theoretical sum when GOs and monomers are included, is possible to observe that for almond shells (AS), the differences are not so remarked, but for corncobs (CC) the levels of monomers and GOs becomes important when the reaction time is above $30 \mathrm{~min}$. That indicates a strong depolymerization in the case of CC when they are compared to AS. That is coincident with the differences when the oligomers were precipitated with ethanol. As can be observed, around 95\% of the theoretical xylo-oligosaccharides were recovered by precipitation when the reaction time was around $25 \mathrm{~min}$ of reaction (for AS), and around $85 \%$ at the same time of reaction for CC. The yield of product precipitated tended to be much lower above that time, since the low molar mass oligomers and monomers were soluble in the ethanol-water mixture. That depends strongly on the raw material used, because around $76 \%$ of the product from AS and $64 \%$ from CC was recovered at $37 \mathrm{~min}$ of reaction, but when this time is increased until $69 \mathrm{~min}$ (for AS) the percentage remains near $42 \%$, while the recovery for CC falls until $14 \%$. This result indicates that for AS, exist a higher proportion of big oligosaccharides that remained at high reaction times, while that from CC were depolymerized. A sample of the precipitated xylo-oligosaccharides was dissolved in pure water and the absorbance at $205 \mathrm{~nm}$ was measured to estimate the amount of residual lignin present in the xylooligosaccharides mixture. The lignin content was around $2.8 \%$ regardless of the time of reaction (results not shown) for XOs from CC, and around 1.4\% for XOs from AS. Since the precipitated oligomers were thoroughly washed with an ethanol/water mixture $(7 / 1 \mathrm{vol} / \mathrm{vol})$ to remove traces of soluble impurities, the absorbance was probably caused by lignin fragments that remained chemically bonded to some of the xylooligosaccharides.

Figure 3.31 compares the molar mass distribution of the xylo-oligosaccharides in the hydrolysis liquor with that of the oligomers recovered by precipitation, for CC (left) and AS (right). As can be observed, the molar mass distribution was strongly dependant of the time of reaction, for a certain temperature. Also there are important differences between the molar mass distribution from CC and from AS. In the case of $\mathrm{CC}$, at low reaction time $(18 \mathrm{~min})$ there are two zones: one with a degree of polymerization (DP) between $3-1000$, and one with a DP between $3-0.1$ (that 
corresponds to monomers, dimmers, and low molecular weight material). With the increase in time, the big oligomers (with DP > 200) tends to disappear, yielding low molecular weight material, which is evidenced by the increase of the peaks with low DP. At the maximal reaction time the oligomers with DP $>30$ almost disappears and there is an important increase in the zone with DP between $2-10$, indicating an important depolymerization during the reaction.
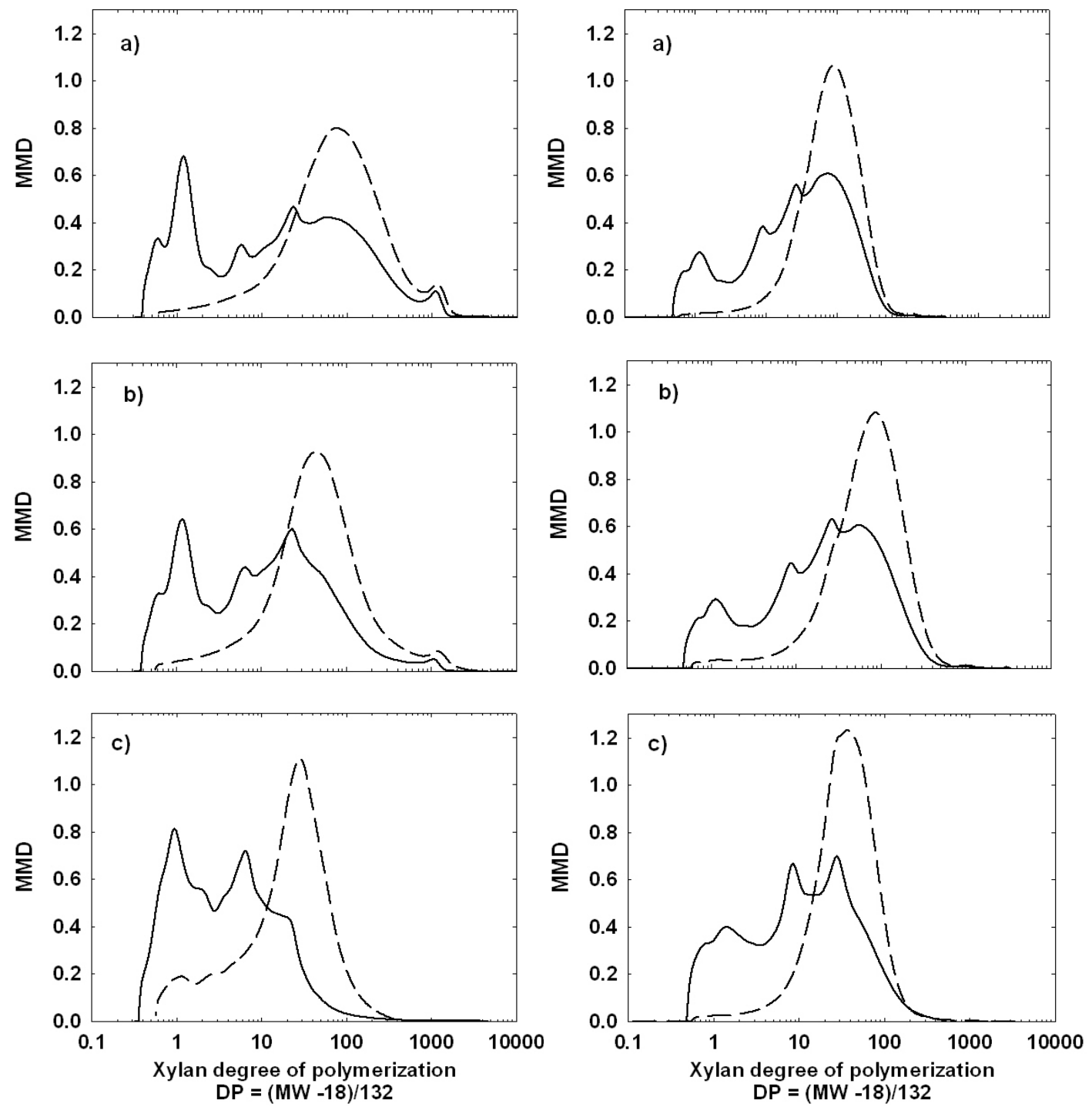

Figure 3.31. Comparison of the molar mass distribution of the soluble products presents in the hydrolysis liquor (-) and that of the xylo-oligosaccharides recovered by ethanol precipitation (--) for the experiments at $169^{\circ} \mathrm{C}$ and different reaction times: a) $25 \mathrm{~min}$, b) $36 \mathrm{~min}$, c) $66 \mathrm{~min}$; for corncobs (left) and almond shells (right). 
For AS, the behavior is more or less the same. At low reaction times, the molar mass distribution shows two main zones: one with DP between $0.1-3$ and one with DP between 3 - 100. As can be observed, the distribution indicates that the oligomers are considerably smaller than the oligomers produced in the same reaction conditions from CC. At the highest reaction time, the bigger oligomers tends to disappear, and the remaining oligomers have a DP between $3-100$. However, there is a difference with that from CC, because the zone corresponding to the oligomers is higher than the low molecular weight zone, indicating less depolymerization as was mentioned before. After the fraction with ethanol (dashed line), in all the cases the high molar mass oligomers were completely precipitated, but most of the oligomers with DP below 10 did not precipitate. That indicates that the material with DP lower than 10 is soluble in ethanol, allowing to separate them from the high molecular weight oligomers. Therefore, fractionation of the xylo-oligosaccharides according to their molar mass appears feasible through selective extraction with solvent mixtures of different compositions and polarities.

\subsubsection{Removal of lignin impurities by adsorption onto activated carbons}

As possible purification method, the performance of three commercial activated carbons was study for the purification of xylo-oligosaccharides by the selective adsorption of lignin-derived compounds and other impurities. Equilibrium experiments were conducted to obtain the adsorption isotherms, and the results were correlated with the physicochemical properties of the carbons. Continuous adsorption experiments were conducted in a packed-bed column to obtain the breakthrough curves for xylo-oligosaccharides and lignin-derived impurities.

\subsubsection{Adsorption equilibrium tests}

Adsorption equilibrium tests were developed using a sample of crude xylooligosaccharides obtained by spray drying of the hydrolysis liquor (batch 1). This sample comprised 58.3\% xylo-oligosaccharide, 5.0\% monomer products ( $2.4 \%$ xylose, $1.5 \%$ arabinose, $0.78 \%$ glucose, $0.27 \% \mathrm{HMF}$, and trace amounts of acetic acid and furfural), $4.8 \%$ ash, and $16 \%$ Klason-type lignin. The remaining $14.9 \%$ of the solid was made up of compounds from the almond shells that were solubilized during the 
autohydrolysis reaction, e.g., extractives, low molar mass phenolics from lignin, and byproducts from the degradation and condensation of monosaccharides and furfural, which were not identified with the analytical procedures used.

The adsorption of the carbohydrate and lignin-derived fractions of the xylooligosaccharides on activated carbons was tested at $30^{\circ} \mathrm{C}$ using a constant concentration of crude xylo-oligosaccharides of $20 \mathrm{~g} / \mathrm{L}$ in deionized water, and concentrations of activated carbon of 1.5, 3.3, 10.0, 16.7, 30.0 and 50.0 gAC/L. Figure 3.32 shows the GPC chromatograms of the feed solution. The UV signal at $254 \mathrm{~nm}$ was attributed to the presence of compounds derived from lignin and extractives and from their condensation with furfural, HMF and other carbohydrate-degradation products, which accounted for around $30 \%$ of the mass of the sample. It was assumed that the signal of the refractive index detector was caused mainly by carbohydrates and inorganic salts (soluble ashes), since they constituted nearly $70 \%$ of the mass in the crude xylo-oligosaccharides, though all the species in the mixture contributed to the signal of this non-selective detector. The retention times for narrow standards of dextran, malto-oligosaccharides and xylose are included in Figure 3.32 for comparison. The RI signal shows that the xylo-oligosaccharides had a molar mass of below $50 \mathrm{kDa}$. The most abundant species had a molar mass of between 1 and $5 \mathrm{kDa}$. There was also a small fraction of the mixture with a molar mass of below $0.15 \mathrm{kDa}$ (xylose). Some of these were inorganic salts (ashes) that eluted after monosaccharides in this chromatographic system. Data from the UV signal revealed two important facts. Firstly, a significant amount of lignin-derived products eluted at the same interval of retention time as did the xylo-oligosaccharides. This was in agreement with the existence of phenolic side groups such as ferulic acids and lignin fragments, which are directly attached to the xylan backbone chains [30]. Secondly, almost half of the ligninderived products were eluted at a retention time that was well above that of xylose $(0.15 \mathrm{kDa})$. These products were low-molar mass phenolics that eluted from the chromatographic column with a different pattern from that of oligosaccharides, partly because they may have hydrodynamic volumes in $0.05 \mathrm{~mol} / \mathrm{L} \mathrm{KNO}_{3}$ that are lower than those of carbohydrates of equivalent molar mass, but mainly because of adsorption on the gel of the GPC column, which increases the elution time. Palm and Zacchi [52] observed the adsorption of lignin-derived compounds from wood autohydrolysis on the gel of filtration columns. 


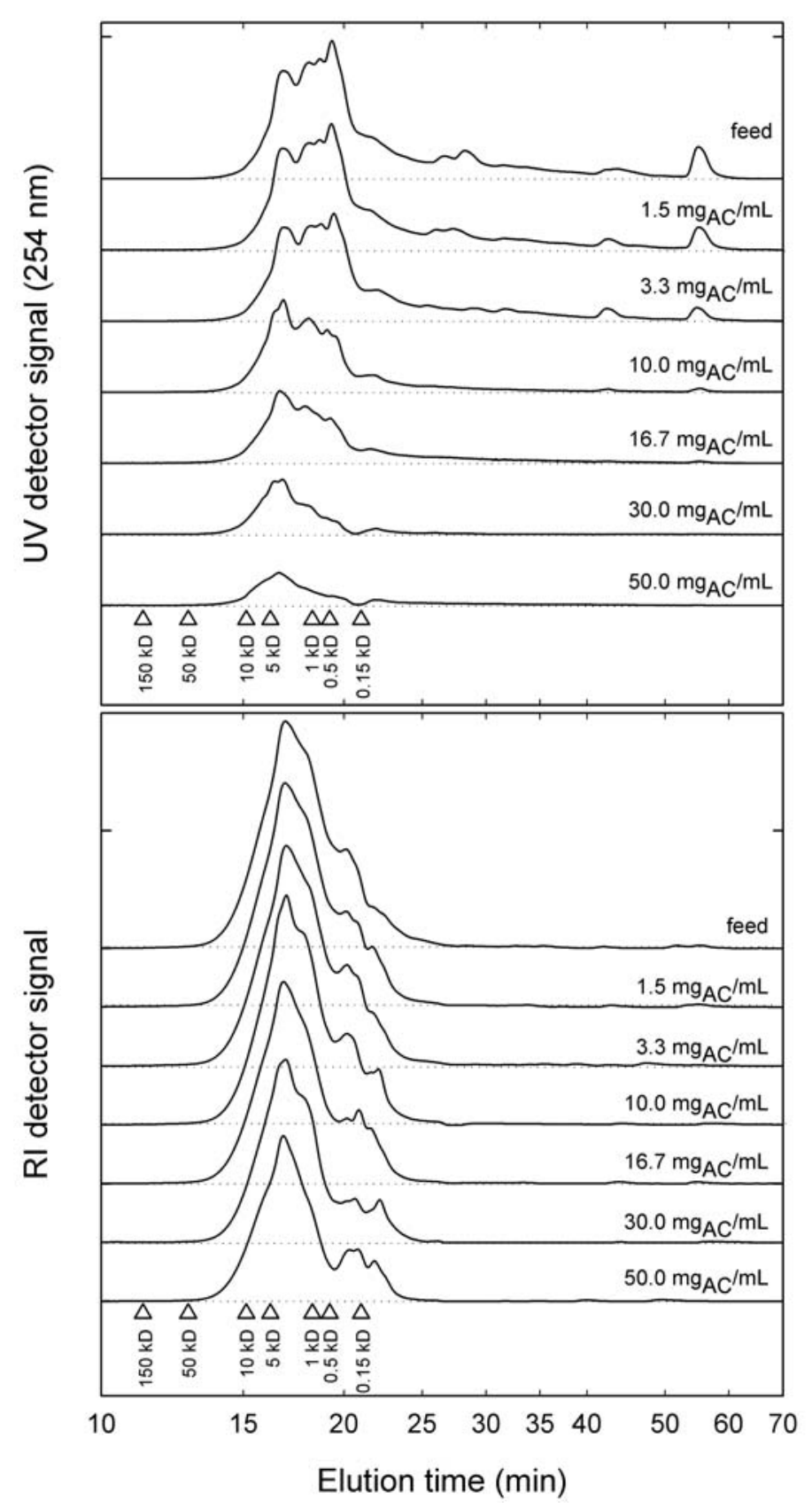

Figure 3.32. GPC chromatograms (time in log-scale) for the xylo-oligosaccharides remaining in solution in the equilibrium adsorption experiments at $30^{\circ} \mathrm{C}$ and different loads of the AC-1 activated carbon. The UV signal at $254 \mathrm{~nm}$ (top) is caused by lignin-derived phenolics, while the refractive index signal (bottom) is mainly attributed to carbohydrates (oligomers and monomers). 
Figure 3.32 also shows the GPC chromatograms for selected samples of the xylooligosaccharide solution treated with AC-1. The low molar mass lignin-derived products, which have the longest elution times in the GPC system, are preferentially adsorbed when small amounts of activated carbon are added to the solution. Figure 3.32 shows that they were completely adsorbed when $16.7 \mathrm{~g}_{\mathrm{AC}} / \mathrm{L}$ was used. The ligninproducts in the range of the elution time of oligosaccharides were also adsorbed, but they were still detected even at $50 \mathrm{gAC} / \mathrm{L}$ since they are linked to xylose in xylooligosaccharides. The adsorption of the carbohydrate fraction was less significant. Below a carbon load of $16.7 \mathrm{~g}$ AC/L, only species with a molar mass of below $0.5 \mathrm{kDa}$ were adsorbed. At a higher carbon load, there was a reduction in the signal of the sample at all molar masses, but even at $50 \mathrm{~g}_{\mathrm{AC}} / \mathrm{L}$ the total amount of carbohydrates adsorbed was still below $40 \%$. The same qualitative trends were observed for the other activated carbons tested.

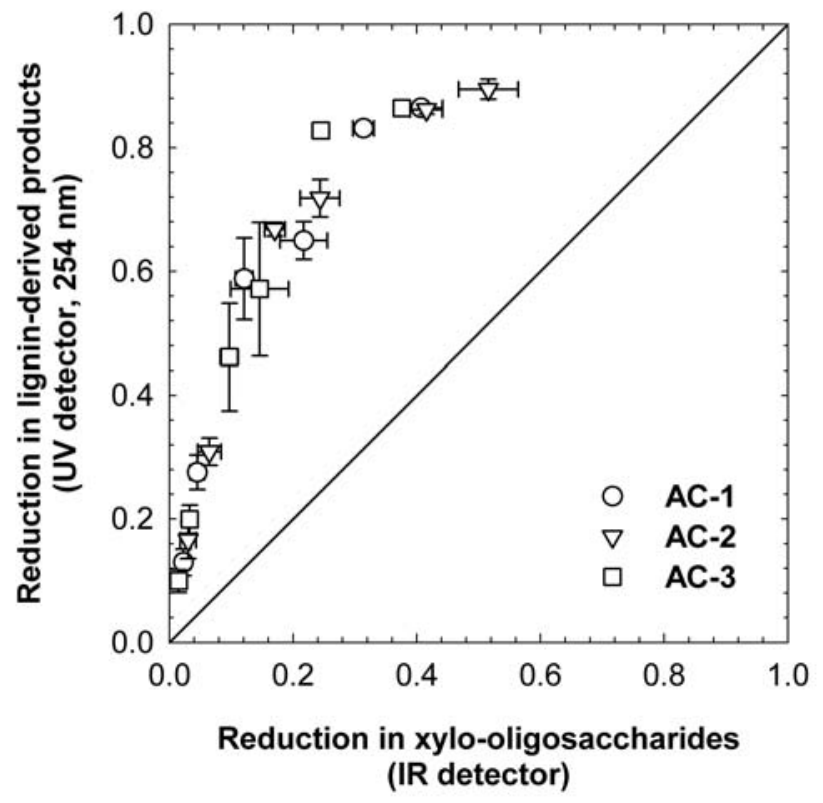

Figure 3.33. Relation between the reduction in the concentrations of lignin-derived phenolics and carbohydrates at equilibrium for various loads of activated carbon at $30^{\circ} \mathrm{C}$. Error bars are confidence intervals at the $95 \%$ probability level. 
The reductions in the concentrations of lignin-derived products and carbohydrates $\left(r d_{j}\right)$ were calculated from the areas of the GPC chromatograms by assuming constant response factors (Equation 3.34), and the amounts of each solute adsorbed were calculated from a mass balance for the batch system using Equation 3.35 , in which $j$ indicates lignin-derived products or carbohydrates, $C_{0, j}(\mathrm{~g} / \mathrm{L})$ is the concentration of solute in the feed, $C_{e, j}(\mathrm{~g} / \mathrm{L})$ is the equilibrium concentration of species $j$ in the solution, $C_{s e, j}\left(\mathrm{~g} / \mathrm{g}_{\mathrm{AC}}\right)$ is the concentration of solute $j$ adsorbed on the activated carbon at equilibrium, $m$ is the mass of activated carbon $\left(\mathrm{g}_{\mathrm{AC}}\right)$ and $V$ is the volume of the solution (L). Figure 3.33 shows the reduction in the concentrations of lignin-derived products and xylo-oligosaccharides in solution for the three activated carbons tested. Lignin-derived products were preferentially adsorbed over the carbohydrate fraction, especially at low concentrations of AC when the low molar mass aromatics were adsorbed. For instance, when $70 \%$ of the lignin-derived compounds were adsorbed, around $80 \%$ of the carbohydrates were still in solution. When over $80 \%$ of these compounds were adsorbed, the adsorption of carbohydrates dramatically increased.

The adsorption of mixtures of organic solutes onto activated carbons is a complex process that is determined by the chemistry of the carbon surface, the interactions between the solutes and the surface, the interactions of the solutes with the solvent and those of the solvent with the carbon surface. The molar mass of the solute and the distribution of pore diameters of the carbon also play a significant role in determining the fraction of carbon surface that is actually accessible to a specific solute. The preferential adsorption of lignin-derived species over xylo-oligosaccharides may be attributed to several factors. Lignin-derived species are substituted phenolic monomers and oligomers that are more hydrophobic than carbohydrates. Xylo-oligosaccharides will be therefore more stable in water solution than lignin-derived products especially if, like in activated carbons, the surface of the adsorbent is predominantly hydrophobic.

The characterization of the different carbons used was made by courtesy of V. Torné and Dr. V. Fierro, in the Universitat Rovira I Virgili, Tarragona, Spain. Average pore diameters were 2.4, 2.1 and $4.1 \mathrm{~nm}$ for AC-1, AC-2, and AC-3, respectively. Table 3.11 shows that the activated carbons had a significant fraction of micropores, while Figure 3.34 shows that the pore volume distribution, which was calculated with the Density Functional Theory (DFT) model [53], was different for the three carbons. Most 
of the mesopore volume in the AC-1 carbon corresponded to pores with diameters from 2 to $10 \mathrm{~nm}$ and the rest corresponded to large mesopores (30 - 50 nm). The AC-2 carbon had the largest mesopore pore volume, but it had more pore volume than the AC-1 in the zone of small mesopores and a similar amount of large mesopores.

\begin{tabular}{|c|c|c|c|}
\hline & \multicolumn{3}{|c|}{ Activated carbons } \\
\hline & $\begin{array}{c}\text { AC-1 } \\
(\mathrm{ROX} 0.8)\end{array}$ & $\begin{array}{c}\text { AC-2 } \\
(\text { PAC 200) }\end{array}$ & $\begin{array}{c}\text { AC-3 } \\
(\text { Darco } 12 \times 40)\end{array}$ \\
\hline S & $1024(1100)^{a}$ & 1346 & $616(650)^{a}$ \\
\hline $\mathrm{V}_{0.99}(\mathrm{~mL} / \mathrm{g})$ & 0.625 & 0.713 & 0.637 \\
\hline $\mathrm{V}_{\alpha, \text { umic }}(<0.8 \mathrm{~nm})(\mathrm{mL} / \mathrm{g})$ & 0.152 & 0.139 & 0.085 \\
\hline Mean pore diameter $(\mathrm{nm})$ & 2.4 & 2.1 & 4.1 \\
\hline Iodine number & $960(1000)^{a}$ & $1060(900)^{a}$ & $635(600)^{a}$ \\
\hline Methylene blue (g/100g) & $22.3(22)^{a}$ & 47.0 & 17.4 \\
\hline \multirow[t]{2}{*}{ pHpzc } & 8.0 & 8.7 & - \\
\hline & \multicolumn{3}{|c|}{ Surface groups (meq/g): } \\
\hline Carboxyl & 0.2 & 0.3 & 0.4 \\
\hline Phenolic & 4.2 & 3.0 & 0.8 \\
\hline Lactone & 0.1 & 0.0 & 0.5 \\
\hline Carbonyl & 0.5 & 4.6 & 0.9 \\
\hline Basic groups & 2.1 & 1.2 & 0.5 \\
\hline
\end{tabular}

Table 3.11. Surface characteristics of the commercial activated carbons (NORIT) used in this

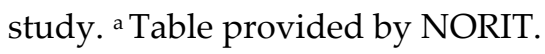


Finally, the AC-3 carbon had very low volume in the small mesopore region, and most of its mesopore volume corresponded to large pores, from 10 to $50 \mathrm{~nm}$. Around half of the lignin-derived compounds and associated impurities that are present in the crude xylo-oligosaccharides had a low molar mass (i.e., around $0.1 \mathrm{kDa}$ ) and were easily adsorbed in the three activated carbons, since their entire surface was accessible to these small solute molecules. On the other hand, xylo-oligosaccharides and some of the lignin-derived impurities had molar masses from 1 to $50 \mathrm{kDa}$, which is roughly equivalent to an interval of molecular diameters from 2 to $10 \mathrm{~nm}$. The area available for the adsorption of the oligomers was therefore dependent on their molar mass: the larger the molar mass, the lower the area they could access. This effect should be more important for carbons AC-1 and AC-2, which have a significant fraction of pores below $10 \mathrm{~nm}$.

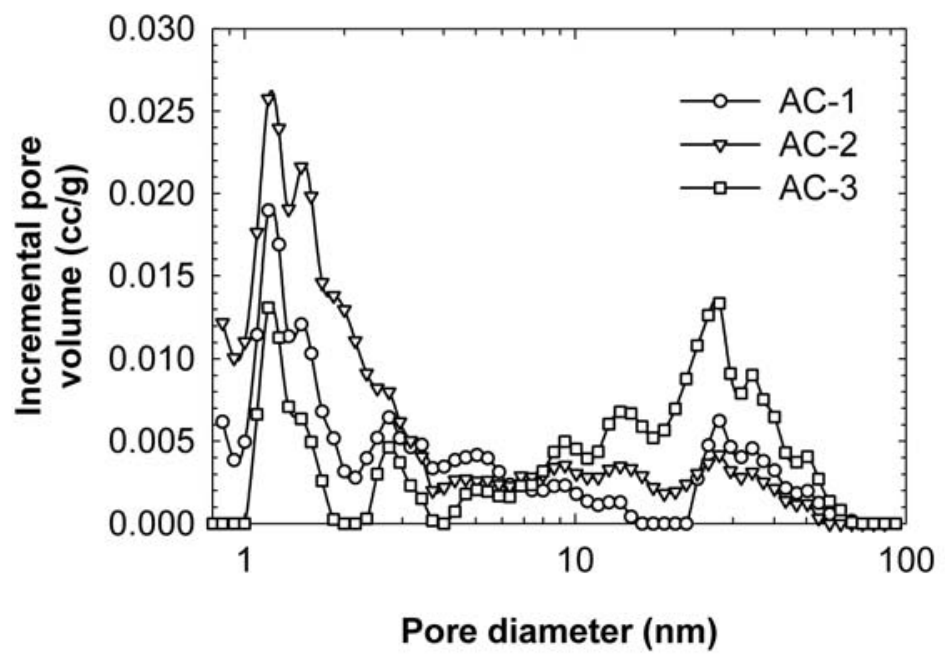

Figure 3.34. Pore volume distributions for the three activated carbons used in this study.

However, the solute size and the pore diameters are not the only variables governing adsorption. If the GPC chromatograms in Figure 3.32 are compared for xylooligosaccharides and lignin products at a high concentration of carbon AC-1, can be seen that the reduction in the concentration of high-molar mass solutes was much greater for the lignin products than for xylo-oligosaccharides. The presence of carboxylic and other acidic groups on the surface of the carbon has a definite effect on 
the adsorption of phenol, since it favors the chemisorption of phenol but hinders physisorption [54]. It may be expected the same to be true for the lignin-derived phenolics present in the crude xylo-oligosaccharides. Finally, electrostatic interactions between charged solutes and the surface of the carbon must also be considered. The $\mathrm{pH}$ of the xylo-oligosaccharide solution was 5.7 due to the dissociation of the acetyl groups in the backbone chain of the xylo-oligosaccharides and the carboxyl groups in ferulic acids and in some lignin-derived products. Since this $\mathrm{pH}$ is below the $\mathrm{pH}$ of zero charge of the activated carbons $(8<\mathrm{pHpzc}<8.7)$, it can be expected the surface of the carbons to have a positive charge distributed among the basic superficial groups [54]. This should create favorable electrostatic interactions between the positive surface and the negatively charged solutes such as the xylo-oligosaccharide chains that contain dissociated acetyl groups.

$$
\begin{aligned}
& r d_{j}=1-\frac{C_{e, j}}{C_{0, j}} \\
& C_{S e, j}=\frac{V}{m}\left(C_{0, j}-C_{e, j}\right) \\
& \ln C_{S e, j}=\ln K_{j}+n_{j} \ln C_{e, j}
\end{aligned}
$$

Regardless of the complexity of the phenomena involved in the competitive adsorption of mixtures of polydisperse oligomers with dissimilar chemical structures, simple models can provide some insight into the factors that have a determining influence on the selective adsorption of lignin-related species over xylooligosaccharides. Adsorption equilibrium was modeled through the Freundlich isotherm, which relates the concentration of a $j$ solute at equilibrium $\left(C_{e, j}\right)$ to the concentration of $j$ adsorbed on the surface $\left(C_{s e, j}\right)$. The unit-capacity parameter, $K_{j}$, is a measure of the degree of strength of adsorption and $n_{j}$, the site-energy parameter, is an indication of the heterogeneity of the surface adsorption sites. The closer the value of $n_{j}$ is to unity, the more homogeneous is the energy of the surface sites. The Freundlich isotherm was linearized to calculate the constants $n_{j}$ and $K_{j}$ (Equation 3.36). Figure 3.35 shows the linearized isotherms and Table 3.12 shows the best-fit values of $n_{j}$ and $K_{j}$ for the three activated carbons and their confidence intervals at $95 \%$ probability. Calculations were done using the robust linear regression algorithm implemented in the robustfit function of the statistics toolbox of MATLAB (MathWorks Inc., USA). The 
isotherm provided an acceptable description of the adsorption of both the ligninderived products and carbohydrates for the three activated carbons, since the model predictions fell within the scattering of the experimental data.

Possible correlations between the main properties of the activated carbons and the parameters of the Freundlich equation for xylo-oligosaccharides and lignin-derived products were analyzed. Figure 3.36 shows that the unit-capacity parameter for xylooligosaccharide adsorption $(K x)$ increased with the mesopore volume of the activated carbon, while the site-energy parameter increased linearly with the concentration of basic surface groups.

\begin{tabular}{|c|c|c|c|c|}
\hline & & AC-1 (ROX 0.8) & AC-2 (PAC200) & AC-3 (Darco 12x40) \\
\hline \multirow{5}{*}{$K_{x O}$} & \multirow[b]{2}{*}{$\mathrm{n}$} & \multicolumn{3}{|c|}{ Xylo-oligosaccharides } \\
\hline & & $1.00 \pm 0.13$ & $0.81 \pm 0.11$ & $0.66 \pm 0.09$ \\
\hline & $L^{\frac{1}{n}}$ & $0.0148 \pm 0.0046$ & $0.0324 \pm 0.0084$ & $0.0249 \pm 0.0054$ \\
\hline & \multirow[b]{2}{*}{$\mathrm{n}$} & \multicolumn{3}{|c|}{ Lignin-derived products } \\
\hline & & $0.82 \pm 0.06$ & $0.82 \pm 0.05$ & $0.62 \pm 0.05$ \\
\hline$K_{L P}$ & $\left(\frac{L^{\frac{1}{n}}}{g_{A C} \cdot g^{\left(\frac{1}{n}-1\right)}}\right)$ & $0.145 \pm 0.008$ & $0.184 \pm 0.009$ & $0.134 \pm 0.007$ \\
\hline
\end{tabular}

Table 3.12. Freundlich isotherms: results for the adsorption of the carbohydrate fraction and the lignin-derived products on commercial activated carbons. Confidence intervals were calculated at $\alpha=0.05$.

The carbons with more developed mesoporous structures had more surface area available for the adsorption of xylo-oligosaccharides with larger molar mass, thus giving higher values for the unit-capacity parameter of the Freundlich isotherm. Also, the higher the number of basic surface groups on the surface, the stronger the electrostatic interactions between the dissociated acetyl groups of the xylo- 
oligosaccharide chains and the positively charged surface, thus increasing the siteenergy parameter nxo for xylo-oligosaccharides adsorption.

The $K_{L P}$ parameter for the lignin-derived phenolics grew with the total concentration of acidic superficial groups. In studies on phenol adsorption from acidic water solutions, the increase in the unit-capacity parameter with the concentration of acidic surface groups has been explained by the existence of two parallel routes: physical adsorption and acid-catalyzed chemisorption [55].

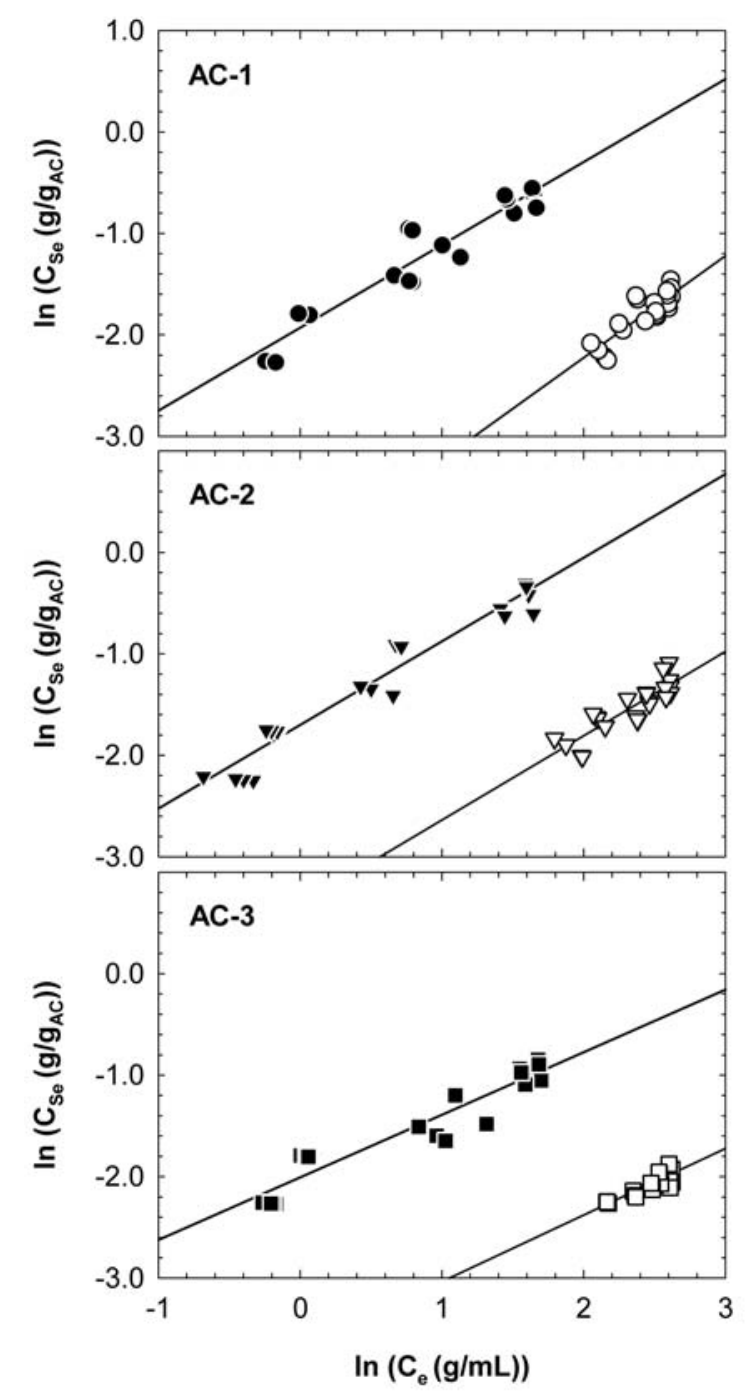

Figure 3.35. Freundlich isotherms for the adsorption of lignin-derived phenolics (open symbols) and xylo-oligosaccharides (solid symbols) on the three activated carbons at $30^{\circ} \mathrm{C}$. 

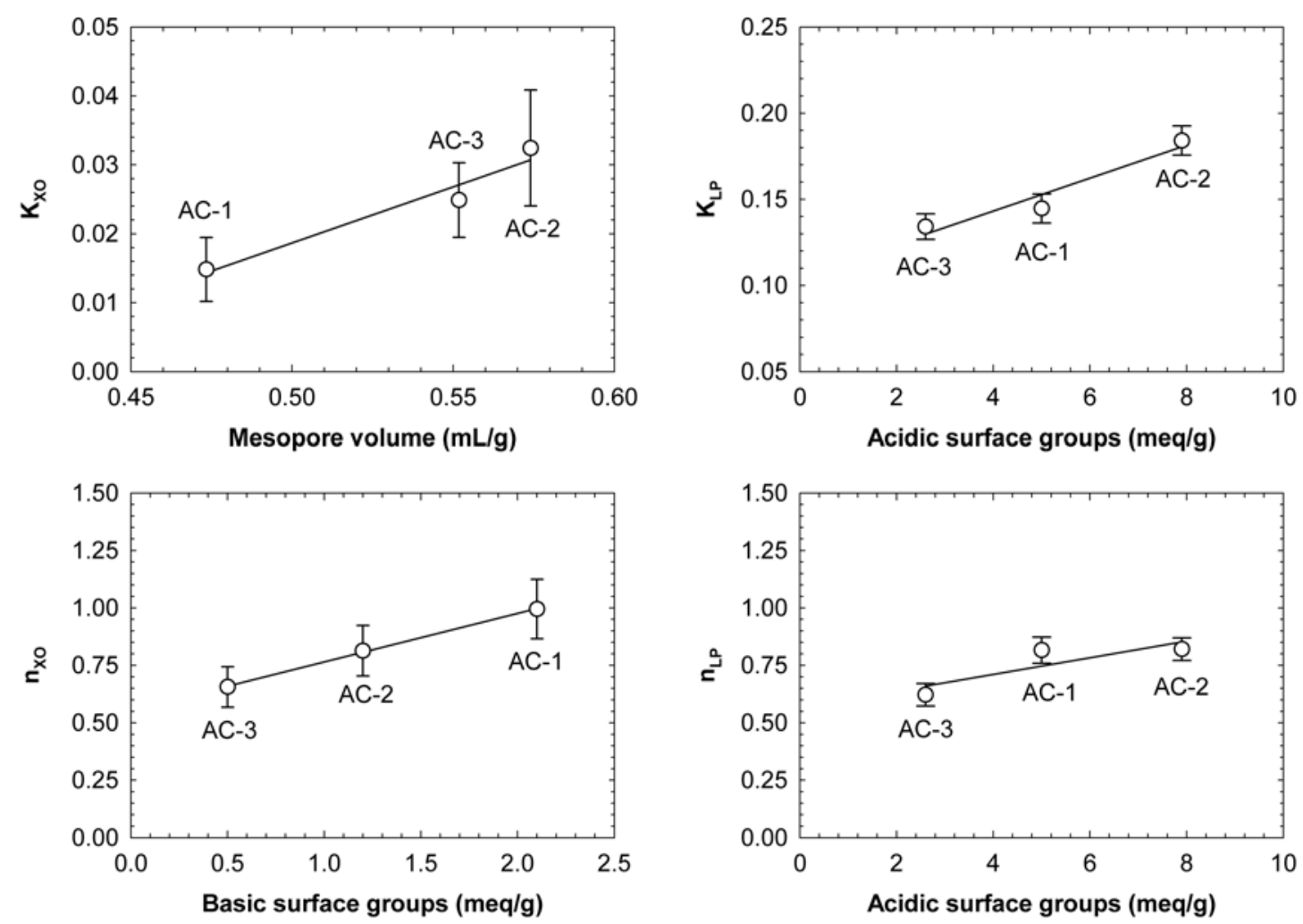

Figure 3.36. Variation in the constants of the Freundlich isotherms of lignin-derived compounds $\left(\mathrm{K}_{\mathrm{LP}}\right)$ and xylo-oligosaccharides $(\mathrm{K} \times \mathrm{O})$ with the surface properties of the activated carbons. The lines only indicate trends.

It may be expected that the contribution of chemisorption to the overall adsorption of the low molar mass phenolics present in the complex mixture of ligninrelated products to become more important as the number of acidic surface groups increases, thus increasing $K_{L P}$. In contrast, the site-energy parameter, $n_{L P}$, did not have a clear correlation with the concentration of acidic surface groups. Promoting the surface acidic groups by oxidation of an activated carbon reduces the adsorption of phenol from aqueous solution [54]. More acidic groups should favor chemisorption, but they lower physical adsorption because the acidic groups act as electron acceptors and lower the $\pi$-electron density in the carbon planes, thus decreasing the interaction between the aromatic rings and the carbon basal planes. Since physical adsorption is the dominant mechanism, the overall consequence is lower phenol adsorption and a decrease in the site-energy parameter, $n$, of the Freundlich isotherm [55]. In this case, it seems that $n_{L P}$ increased for activated carbons with more acidic surface groups, though 
the values of $n_{L P}$ for AC-1 $(0.82 \pm 0.06)$ and AC-2 $(0.82 \pm 0.05)$ were statistically the same even if they had different concentrations of acidic surface groups $(6.0 \mathrm{meq} / \mathrm{g}$ for AC-1 and $7.9 \mathrm{meq} / \mathrm{g}$ for $\mathrm{AC}-2$ ). This behavior may be caused by the different nature of the predominant acidic groups in each carbon, which were manufactured from a variety of raw materials using different methods of activation. Phenols are the main acidic group in AC-1 (4.2 meq/g), while in AC-2 the main group is carbonyls (4.6 meq/g). The relative importance of the chemisorption and physical adsorption paths will therefore be different in each carbon because of the different acidity of these groups. Finally, no direct correlations of the Freundlich parameters with other properties of the activated carbons such as the surface area or the total pore volume were observed.

On the basis of the analysis of the Freundlich isotherms, the purification of xylooligosaccharides will require activated carbons with unit-capacity and site-energy parameters that are low for xylo-oligosaccharides and high for lignin-derived products. The AC- 1 carbon, with a $K_{L P} / K_{x o}$ of $9.8 \pm 3.6$, had a slightly better ratio of unit-capacities than AC-2 $(5.7 \pm 1.8)$, and AC-3 $(5.4 \pm 1.4)$, while the ratio $n_{L P} / n \times O$ did not present significant differences because of the large scattering of the results $(0.82 \pm 0.17$ for AC- 1 , $1.01 \pm 0.20$ for AC-2, and $0.94 \pm 0.20$ for AC-3). In general, a suitable activated carbon should have small mesopore diameters, a low volume of mesopores, and a low concentration of basic surface groups to limit xylo-oligosaccharide adsorption. It should also be highly microporous and have acidic surface groups to favor the adsorption of the lignin-related products (high $\mathrm{K}_{\mathrm{LP}}$ ).

\subsubsection{Column tests}

Column tests were performed with the ROX 0.8 granular activated carbon (AC1). This carbon was selected because of its slightly better selectivity towards lignin adsorption and because it was readily available in granular form and more suitable for column packing than AC-2 and AC-3. The latter contained fines and caused problems during operation due to the entrainment of carbon particles and because it led to larger pressure drops across the bed.

Figure 3.37 shows the breakthrough curves for an experiment performed using the second batch of xylo-oligosaccharides solution directly. The solution was fed at 6.0 $\mathrm{mL} / \mathrm{min}$, and a column loaded with $22.0 \mathrm{~g}$ of activated carbon was used. The activated carbon was rapidly saturated with carbohydrates. Retention for carbohydrates was 
only $10 \%$ after $60 \mathrm{~min}$ (6.55 bed volumes circulated), while retention for lignin-derived products was over $60 \%$. After $180 \mathrm{~min}$ (19.6 bed volumes), the column was completely saturated with carbohydrates and retention was $0.2 \%$ but it was still $30 \%$ for lignin products.

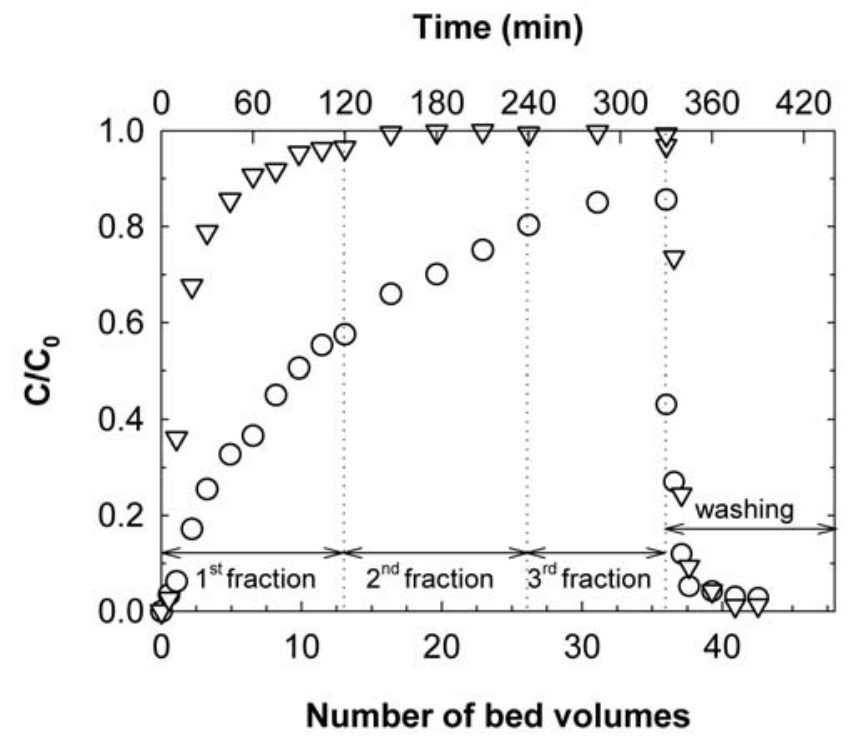

Figure 3.37. Adsorption of the crude xylo-oligosaccharides from reaction batch 2 on an AC-1 activated carbon column: breakthrough curves for carbohydrates $(\nabla)$ and lignin-derived products $(\bigcirc)$.

Figure 3.38 shows the GPC chromatograms for samples of the effluent taken at selected times during the experiment. The lignin-derived products of low molar mass were completely adsorbed on the column during the first $45 \mathrm{~min}$ of the experiment, which corresponds to 4.91 bed volumes of feed circulated through the column, but the high-molar mass fraction of lignin-products associated to carbohydrates was not adsorbed completely even when the volume circulated was small ( 2.18 bed volumes). The carbohydrate fraction had low adsorption, and there were few differences in the degree of adsorption with molar mass. 


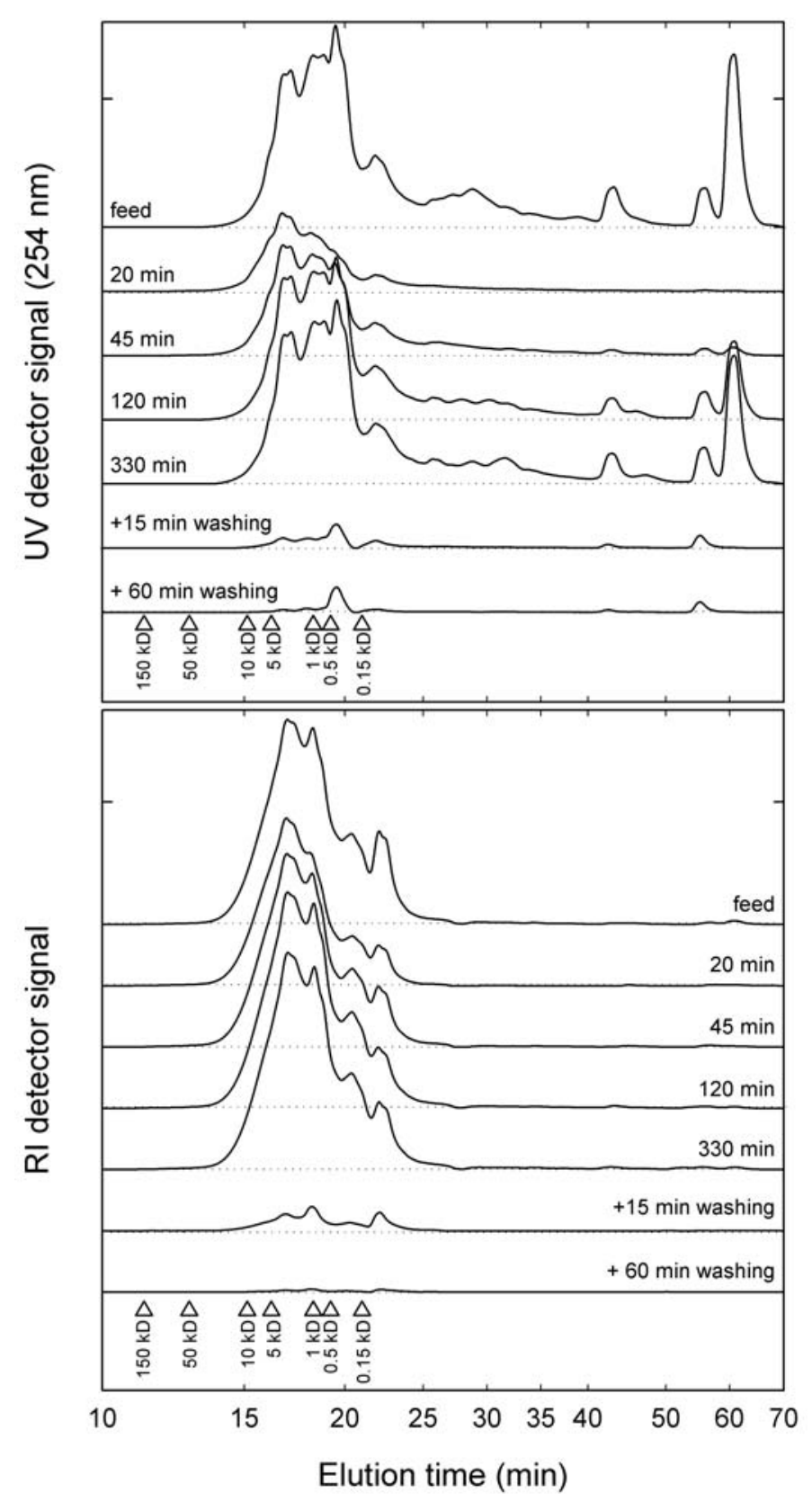

Figure 3.38. Adsorption of the crude xylo-oligosaccharides from reaction batch 2 on an AC-1 activated carbon column: GPC chromatograms (time in log-scale) for the xylo-oligosaccharides remaining in solution: The UV signal at $254 \mathrm{~nm}$ (top) is caused by lignin-derived phenolics, while the RI signal (bottom) is mainly attributed to carbohydrates (xylo-oligosaccharides and monomers). 
The fraction collected during the cleaning of the carbon bed with deionized water contained both carbohydrates and lignin-derived species. The latter were detected in the washing stream even after 60 min of cleaning (6.55 bed volumes of water), which suggests that they were strongly adsorbed on the surface of the carbon.

The fractions collected during the experiment were lyophilized to recover the xylo-oligosaccharides (F1, 0-2 h; F2, 2-4 h; F3, 4-5.5 h; F4, washing, 5.5-6.5 h). The dry product was weighed to calculate the yield and analyzed for ash, klason lignin, monomers, xylo-oligosaccharides and the molar mass distribution. Table 3.13 shows that the average concentration of non volatile soluble products decreased from $35.2 \mathrm{~g} / \mathrm{L}$ in the feed to $25.2 \mathrm{~g} / \mathrm{L}$ in the product collected from the column outlet during the first 2 $h$ of the experiment. Analysis of the recovered product shows that monosaccharides and xylo-oligosaccharides were partially adsorbed on the carbon, but the highest adsorption was for lignin-related products and for furfural and HMF, which were almost completely removed from the solution. The product fractions collected afterward (F2 and F3) showed a dramatic decrease in the capacity of adsorption of the column for carbohydrates, although some retention capacity was still observed for furfural, HMF, and lignin-derived species.

The retention for carbohydrates, mainly xylo-oligosaccharides but also monosaccharides, was calculated by integrating the RI signal of the GPC chromatograms of the feed and the samples taken during the experiment, whereas the retention for lignin and carbohydrate-degradation products (furfural and HMF) was calculated from the signal of the UV detector at $254 \mathrm{~nm}$. Retentions for fractions F1 - F3 were 20.2, 0.7 and $0.5 \%$ for carbohydrates, and $64.3,30.2$ and $16.0 \%$ for lignin, in accordance with the preferential adsorption of lignin products over carbohydrates observed earlier. The retentions were also calculated from the mass and composition of the non volatile products recovered by lyophilization of the fractions F1, F2 and F3. The results were close to those calculated from the GPC chromatograms, especially for carbohydrates. 


\section{Collected fractions}

Feed

F1 (0-2h) F2 (2-4 h)

F3 (4-5.5 h)

Average concentration of dissolved products for the fraction $(\mathrm{g} / \mathrm{L})$

$35.2 \quad 25.2 \quad 33.6$

Composition (\% of the dissolved products in the feed)

$\begin{array}{lllll}\text { Glucose } & 1.84 & 1.28 & 1.76 & 1.75 \\ \text { Xylose } & 3.95 & 2.81 & 3.96 & 3.97 \\ \text { Arabinose } & 3.61 & 2.58 & 3.58 & 3.57 \\ \text { Acetic acid } & 3.89 & 1.74 & 3.78 & 3.85 \\ \text { Furfural } & 0.85 & 0.01 & 0.40 & 0.87 \\ \text { Hydroxymethyl furfural } & 0.43 & 0.03 & 0.26 & 0.39 \\ \text { Xylo-oligosaccharides } & 57.8 & 46.0 & 59.3 & 58.6 \\ \text { Lignin-related products } & 6.85 & 2.90 & 5.55 & 5.95 \\ \text { Ash } & 9.02 & 7.66 & 7.36 & 7.60 \\ \text { Other (by difference) } & 11.8 & 6.78 & 9.49 & 9.84\end{array}$

\section{Retention (\% of feed)}

Calculated by integration of the GPC chromatograms (data in Figure 3.38)

Xylo-oligosaccharides (RI signal)

20.2

0.7

0.5

Lignin-related products (UV signal)

64.3

30.2

16.0

Calculated from the yield and chemical analysis of lyophilized samples

Xylo-oligosaccharides ${ }^{a}$

Lignin-related products ${ }^{b}$
22.5

63.9
0.5

23.6
0.9

11.4

Table 3.13. Adsorption on an AC-1 activated carbon column: composition of the lyophilized samples of the product fractions collected during the experiment and retentions calculated for xylo-oligosaccharides and lignin-related products (Xylo-oligosaccharide solution from reaction batch 2). ${ }^{a}$ Including monosaccharides, acetic acid and ash. ${ }^{b}$ Including furfural and HMF. 
Vegas and co-workers have investigated several sequential treatments for the removal of extractive- and lignin-derived compounds from the aqueous solutions of crude xylo-oligosaccharides of barley residues [34] and rice husks [33]. After three sequential extraction stages with ethyl acetate, $6.2 \%$ of the carbohydrates and $38.2 \%$ of non-carbohydrates were removed from the solution in the case of rice husks, while for barley residues removal was $15.9 \%$ for carbohydrates and $32.9 \%$ for extractives- and lignin-related products. These values are close to those obtained for fraction F2. Further processing of the ethyl acetate-extracted solutions with a strong anion exchange resin increased the removal of non-carbohydrates to $78.2 \%$ and $54.0 \%$ for rice husks and barley residues, respectively, while carbohydrate removal was $22.2 \%$ and $20.4 \%$. The results from the F1 fraction indicate that treatment with activated carbon provides better results than extraction with ethyl acetate and that it may even produce a similar degree of removal of non-carbohydrate compounds to extraction combined with treatment with anion exchange resins.

The treatment with activated carbon of raw xylo-oligosaccharide solutions obtained by autohydrolysis of lignocellulosics is a feasible option for the removal of extractives- and lignin-derived compounds, and carbohydrate-degradation products. The selective adsorption of lignin products over carbohydrates has been observed for three commercial activated carbons at slightly acidic pHs. Selectivity towards lignin adsorption was higher when the carbon was highly microporous and had small mesopore diameters, a low volume of mesopores, a low concentration of basic surface groups to limit xylo-oligosaccharide adsorption, and acidic surface groups to favor the adsorption of the lignin-related products.

\subsubsection{Ultrafiltration of xylo-oligosaccharides from almond shells}

Xylans are polyoses that are formed by an homopolymer backbone of xylose units. Several functional groups (uronic acids, arabinose, galactose, acetyl and ferulic acids) can be attached to the xylan backbone in variable amounts, which results in the large diversity of xylan structures found in plants $[29,30]$. In this case, xylan was considered to be a polymer formed by three constitutive monomers: xylose, arabinose and acetic acid, but in this case the amounts of glucuronic and ferulic acids were measured as well. 


\subsubsection{Composition of the crude xylo-oligosaccharides from almond shells}

The autohydrolysis of almond shells does not differ substantially from the autohydrolysis of other lignocellulosic materials, like agriculture residues and hardwoods. Xylan is extensively depolymerized and becomes soluble in the aqueous media, while cellulose and lignin remain mostly in the solid, even though they are depolymerized partially $[14,19]$.

Table 3.14 shows the distribution of the products among the solid and soluble fractions. All results are reported on the basis of $100 \mathrm{~kg}$ of dry almond shells entering the process $\left(\mathrm{kg}_{\mathrm{DAs}}\right)$. Autohydrolysis of almond shells at the conditions tested solubilized $35.1 \mathrm{~kg} / 100 \mathrm{~kg}$ DAs, although the degree of solubilization was different for each component. Most cellulose and lignin remained in the hydrolyzed solid, $95.5 \%$ and $93.8 \%$ of the initial, respectively. Xylan was converted into soluble xylooligosaccharides and degradation products, and only $36.7 \%$ of the original remained in the hydrolyzed almond shells (11.2 kg/100 kgDas).

The yield of xylo-oligosaccharides measured in the hydrolysis liquor was 17.4 $\mathrm{kg} / 100 \mathrm{~kg}$ Das, which corresponds to $57.0 \%$ of the potential, and their composition was $88.1 \%$ of anhydroxylose, $3.6 \%$ of anhydroarabinose and $8.3 \%$ of acetyl groups. Spray drying of the hydrolysis liquor gave a yield of dry powder of $29.4 \mathrm{~kg} / 100 \mathrm{~kg}$ Das, in which xylo-oligosaccharides only accounted for 58.3\% of the mass recovered. Monomer products and ash accounted for $4.95 \%$ (2.4\% xylose, $1.5 \%$ arabinose, $0.78 \%$ glucose and $0.27 \% \mathrm{HMF}$ ) and $4.8 \%$ of the powder, respectively. Only trace amounts of acetic acid and furfural were detected. Recovery of the xylo-oligosaccharides by spray drying produced a decrease in their arabinose content, from $3.6 \%$ in the autohydrolysis liquid product to $2.5 \%$ after spray drying, although the acetyl-to-xylose ratio remained almost unchanged. Also, there was a significant increase in the yield of arabinose monomer, from $0.18 \mathrm{~kg} / 100 \mathrm{~kg}$ DAs in the autohydrolysis liquor, to $0.44 \mathrm{~kg} / 100 \mathrm{~kg}$ DAs in the solid recovered by spray drying. This indicates that the xylo-oligosaccharides are affected by temperature during drying and that some of the most labile bonds between arabinose and the xylan backbone are broken. The quantitative acid hydrolysis of the crude xylo-oligosaccharides to measure their total content of monosaccharides produced a $4.7 \mathrm{~kg} / 100 \mathrm{~kg}$ das of solid, which was associated to acid-insoluble lignin. The uronic acid content was around $0.62 \mathrm{~kg} / 100 \mathrm{kgDAs}$, and the ferulic acid content 
(quantified as free and bounded ferulic acid) accounted $0.07 \mathrm{~kg} / 100 \mathrm{~kg}$ DAs. Finally, $12.6 \%$ of the solid was not identified $(3.7 \mathrm{~kg} / 100 \mathrm{~kg}$ Das $)$.

\begin{tabular}{|c|c|c|c|}
\hline Basis: $100 \mathrm{~kg}$ of dry almond shells & $\begin{array}{c}\text { Hydrolyzed } \\
\text { shells }\end{array}$ & $\begin{array}{l}\text { Solution + } \\
\text { volatiles }\end{array}$ & $\begin{array}{l}\text { Recovered by } \\
\text { spray drying }\end{array}$ \\
\hline Cellulose (kg) & 25.6 & $0.38^{a}$ & $0.33^{\text {a }}$ \\
\hline Lignin $(\mathrm{kg})$ & 25.7 & n.a. & 4.7 \\
\hline Ash (kg) & n.a. & n.a. & 1.4 \\
\hline Xylan / xylo-oligosaccharides (kg) & 11.2 & 17.4 & 17.1 \\
\hline Xylose (\% of xylan / XO) & 89.1 & 88.1 & 88.8 \\
\hline Arabinose ( $\%$ of xylan / XO) & 3.7 & 3.6 & 2.5 \\
\hline Acetyl (\% of xylan / XO) & 7.2 & 8.3 & 8.7 \\
\hline \multicolumn{4}{|l|}{ Monomers } \\
\hline Glucose (kg) & - & 0.30 & 0.23 \\
\hline Xylose $(\mathrm{kg})$ & - & 0.76 & 0.71 \\
\hline Arabinose $(\mathrm{kg})$ & - & 0.18 & 0.44 \\
\hline Acetic acid $(\mathrm{kg})$ & - & 1.56 & n.d. \\
\hline Furfural (kg) & - & 0.30 & n.d. \\
\hline Hydroxymethyl furfural (kg) & - & 0.09 & 0.08 \\
\hline Uronic acid (kg) & n.a. & n.a. & 0.62 \\
\hline Ferulic acid (kg) & n.a. & n.a. & 0.07 \\
\hline Other (by difference, $(\mathrm{kg})$ ) & 2.4 & $14.1^{\mathrm{b}}$ & 3.7 \\
\hline Total (kg) & 64.9 & 35.1 & 29.4 \\
\hline
\end{tabular}

Table 3.14. Autohydrolysis of almond shells at $179^{\circ} \mathrm{C}$ and 29 min: yields and composition of the products (based on $100 \mathrm{~kg}$ of dry almond shells). a glucose oligomers; ${ }^{\mathrm{b}}$ includes lignin, ash, and non-quantified volatiles; n.a. = not analyzed; n.d. = not detected. 
The non-identified fraction was probably formed by compounds from almond shells that were solubilized during the autohydrolysis reaction, like extractives, low molar mass phenolics, and also by products from the degradation of monosaccharides and furfural. The high content of impurities and the relatively low percentage of xylooligosaccharides (XOs) in the non-volatile hydrolysis products for almond shells (58.3\%) agrees with that reported for rice husks [33] (54.8\% XOs) and barley residues [34] $(46.3 \%$ XOs).

Besides the presence of a significant fraction of impurities, the xylooligosaccharides produced by autohydrolysis of almond shells show a broad distribution of molar mass regardless of the reaction conditions. Although it tends to narrow at high reaction time and temperature, the molar mass distribution includes molar masses from around 0.1 to $70 \mathrm{kDa}$ at the conditions that guarantee a reasonable yield of xylo-oligosaccharides (see feed MMD in Figure 3.39). It is thus evident that purification and processing techniques have to be developed to obtain a product with sufficient purity and repetitive and well-defined molar mass distribution.

\subsubsection{Ultrafiltration of the xylo-oligosaccharides solution}

Ultrafiltration of the solution of xylo-oligosaccharides (XOs) was studied in the flat-membrane module at pressures between 2.6 and 9 bar. All membranes were assayed with water before and after the experiments with the xylo-oligosaccharide solution to assess the extent of fouling. Figure 3.39 shows the GPC elugrams of the feed and permeate from the GE membrane (MWCO of $1 \mathrm{kDa}$ ) operated at 2.6 to 8.6 bar. The UV signal at $254 \mathrm{~nm}$ was attributed to the presence of compounds derived from lignin and extractives, and from their condensation with furfural, HMF and other carbohydrate-degradation products. Those accounted for $30 \%$ of the mass of the sample (equivalent to $6.0 \mathrm{~g} / \mathrm{L}$ of "lignin-derived" products). It was assumed that the signal of the refractive index detector was caused mainly by carbohydrates and inorganic salts (soluble ashes) since they constituted nearly $70 \%$ of the mass in the crude xylo-oligosaccharides (equivalent to $14.0 \mathrm{~g} / \mathrm{L}$ of "carbohydrates"), although all species in the mixture contributed to the signal of this non-selective detector. The elution time for narrow standards of dextran, malto-oligosaccharides and xylose is included in Figure 3.39 for comparison. The overall concentration of carbohydrates in the permeate decreased slightly with pressure. Rejection was complete for the xylooligosaccharides with molar mass above $6 \mathrm{kDa}$ and decreased steadily as their molar 
mass was lower. It was close to zero for the species with molar mass of around $0.1 \mathrm{kDa}$, which are impurities like furfural, HMF and acetic acid, and it was low for monosaccharides $(0.15 \mathrm{kDa})$.

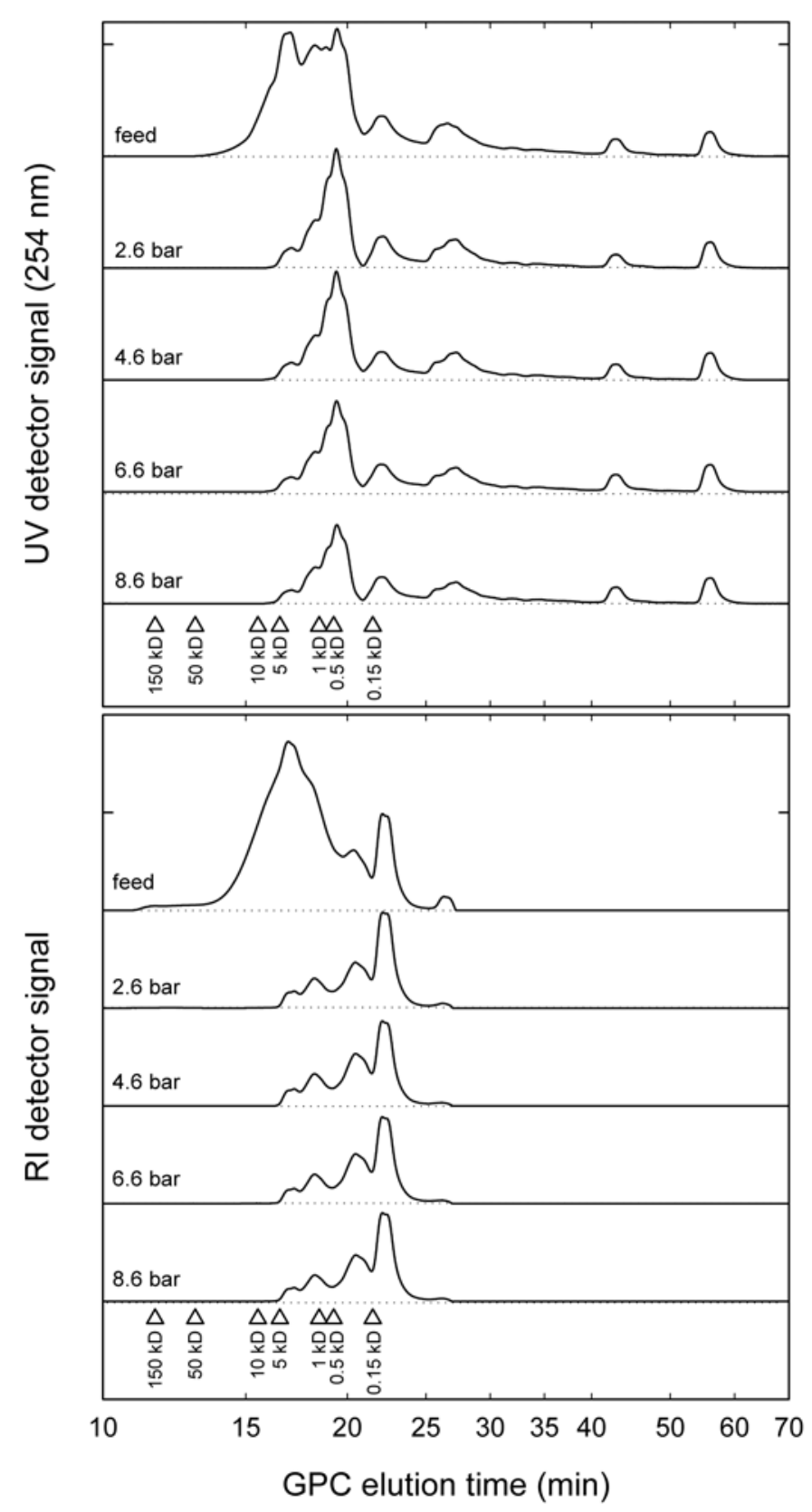

Figure 3.39. GPC elugrams of the lignin-related products and the xylo-oligosaccharides in the feed and permeate of the GE $-1 \mathrm{kDa}$ membrane at the different pressures tested. $\Delta$ : Elution times for the different standards used for the calibration curve. 
Data from the UV signal for the feed solution showed two important facts: first, there was a significant amount of lignin-derived products that eluted from the GPC column at the same interval of retention time than xylo-oligosaccharides, which was in agreement with the existence of phenolic side groups like ferulic acids and lignin fragments directly attached to the xylan backbone chains [30]; second, almost half the lignin-derived products were eluted at a retention time which was well above that of xylose $(0.15 \mathrm{kDa})$. These products were low-molar mass phenolics that eluted from the chromatographic column with a pattern that was different from that of oligosaccharides, in part because they may have hydrodynamic volumes in $0.05 \mathrm{~mol} / \mathrm{L}$ $\mathrm{KNO}_{3}$ that are lower than those of carbohydrates of equivalent molar mass, but mainly because of adsorption on the gel of the GPC column, which increases elution time. Palm and Zacchi [52] have observed a strong interaction and adsorption of ligninderived compounds from wood autohydrolysis on the gel of filtration columns. The low molar mass lignin products were not rejected by the membrane and had a concentration in the permeate that was the same than for the feed. The overall rejection for the lignin-related species eluted in the range of xylo-oligosaccharides molar mass from 0.15 to $5 \mathrm{kDa}$ was higher and it grew with pressure. The same qualitative trends were observed from the GPC chromatograms of the permeate for the other polymeric membranes.

Figure 3.40 shows the fluxes of water and xylo-oligosaccharide solution permeated as function of pressure. Water flux was linear with pressure for all membranes and their water permeability is listed in Table 3.15.

\begin{tabular}{cc}
\hline Membrane type and nominal MWCO & $\begin{array}{c}\text { Water permeability } \\
\left(\mathrm{L} / \mathrm{h} \mathrm{m}^{2} \mathrm{bar}\right)\end{array}$ \\
\hline $\mathrm{GE}-1 \mathrm{kDa}$ & $2.47 \pm 0.13$ \\
$\mathrm{GH}-2.5 \mathrm{kDa}$ & $5.53 \pm 0.08$ \\
$\mathrm{GK}-3.5 \mathrm{kDa}$ & $10.9 \pm 0.18$ \\
$\mathrm{GM}-8 \mathrm{kDa}$ & $20.0 \pm 0.78$ \\
\hline
\end{tabular}

Table 3.15. Water permeability for the clean membranes. 
The flux of XOs solution permeated on the membranes with the lower MWCO was almost linear with pressure, but for the higher MWCO membranes (3.5 and 8.0 $\mathrm{kDa})$, the permeate flux increased to a limiting value, presumably because of the resistance in the boundary layer on the membrane surface. The flux of solute was calculated from the flux of solution and the areas of the GPC chromatograms assuming constant response factors regardless of the molar mass.
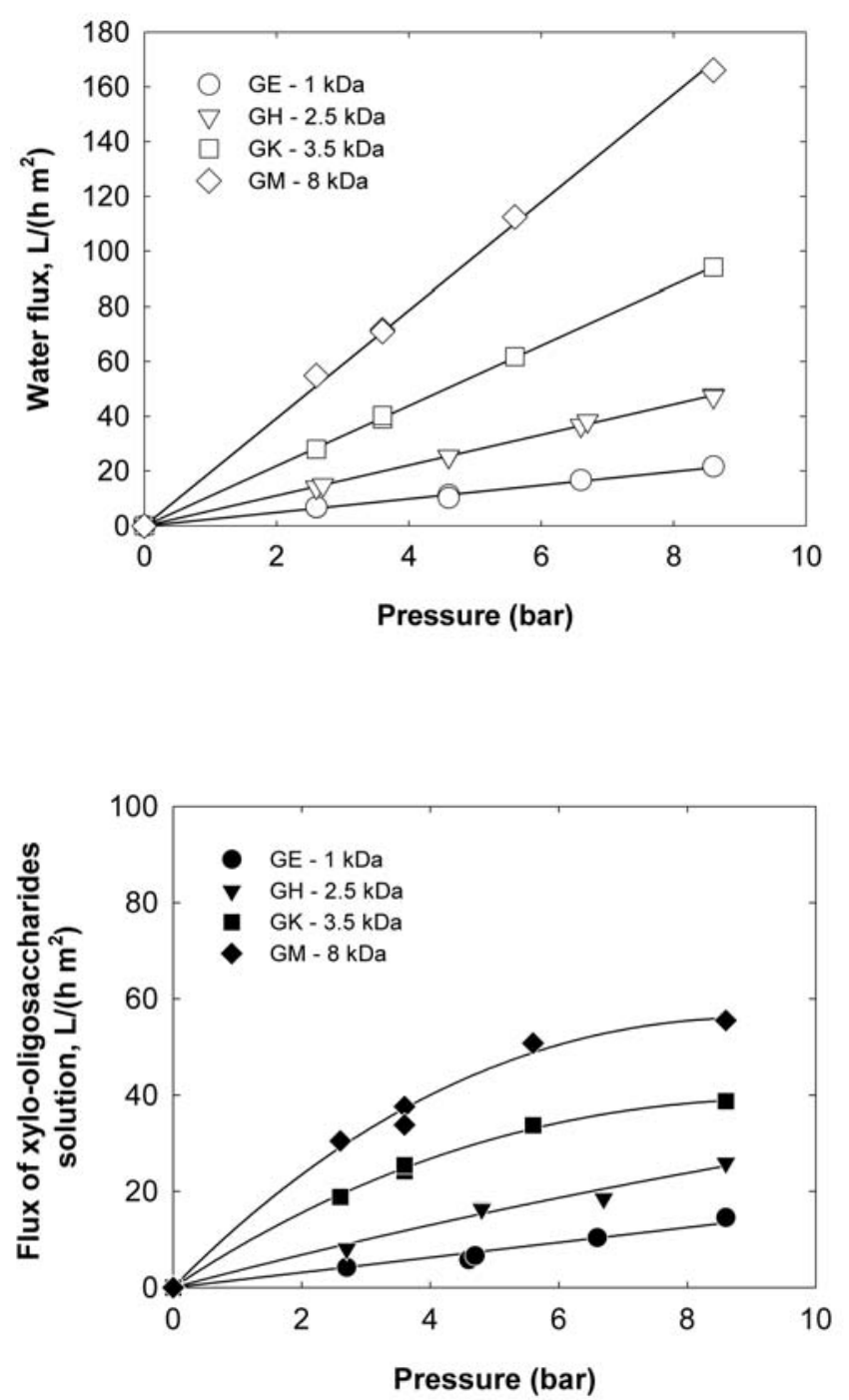

Figure 3.40. Influence of pressure on the fluxes of water (top) and xylo-oligosaccharides solution (bottom) for the thin-film ultrafiltration membranes. 
Figure 3.41 depicts the variation of the overall fluxes of carbohydrates and ligninrelated products as function of pressure for the polymeric membranes. As expected, the fluxes were higher in the range of pressure studied as larger was the nominal MWCO of the membranes. Fluxes in the $1 \mathrm{kDa}$ polymeric membrane (GE) were 19 and $10 \mathrm{~g} / \mathrm{h} \cdot \mathrm{m}^{2}$ at 2.7 bar for xylo-oligosaccharides and lignin products, respectively, and they increased almost linearly to 62 and $41 \mathrm{~g} / \mathrm{h} \cdot \mathrm{m}^{2}$ at $8.6 \mathrm{bar}$. The fluxes in the $8.0 \mathrm{kDa}$ membrane (GM) were an order of magnitude higher: 227 and $129 \mathrm{~g} / \mathrm{h} \cdot \mathrm{m}^{2}$ at $2.6 \mathrm{bar}$, and 579 and $264 \mathrm{~g} / \mathrm{h} \cdot \mathrm{m}^{2}$ at $8.6 \mathrm{bar}$ for xylo-oligosaccharides and lignin products, respectively. In this membrane, as well as in the $3.5 \mathrm{kDa}$ membrane (GK), the flux of lignin-related products tended to a limiting value above 6 bar, while the flux of xylooligosaccharides was still growing almost linearly. This is attributed to the accumulation of a polarization layer of high molar mass xylo-oligosaccharides (around $10 \mathrm{kDa}$ ) on the membrane surface because of the high flux of permeate, which impedes the flow and increases the retention of the low molar mass compounds (less than 1 $\mathrm{kDa})$, specially for lignin-related aromatic compounds.
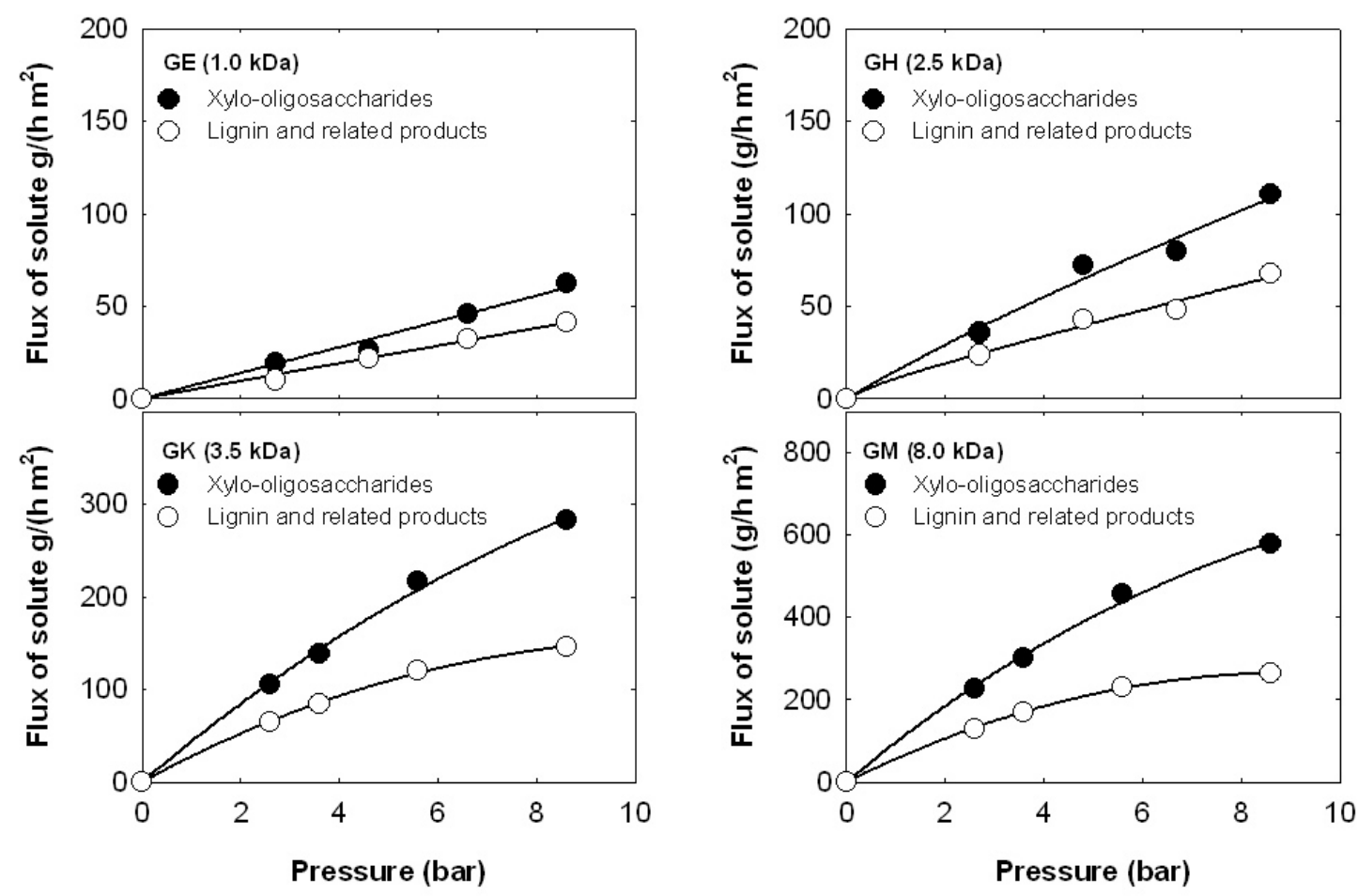

Figure 3.41. Influence of pressure on the fluxes of xylo-oligosaccharides and lignin-related products. 
The influence of the flux of permeate on the selectivity towards the separation of lignin-derived species from xylo-oligosaccharides is observed in Figure 3.42. Selectivity was defined as the relationship between the dimensionless concentrations of lignin products and xylo-oligosaccharides in the permeate according to Equation 3.37, where $\mathrm{C}_{\mathrm{LP}-\text {-feed }}$ and CXO-feed are the total concentrations of lignin-related products and XOs in the feed, and CLP and Cxo are their concentrations in the permeate.

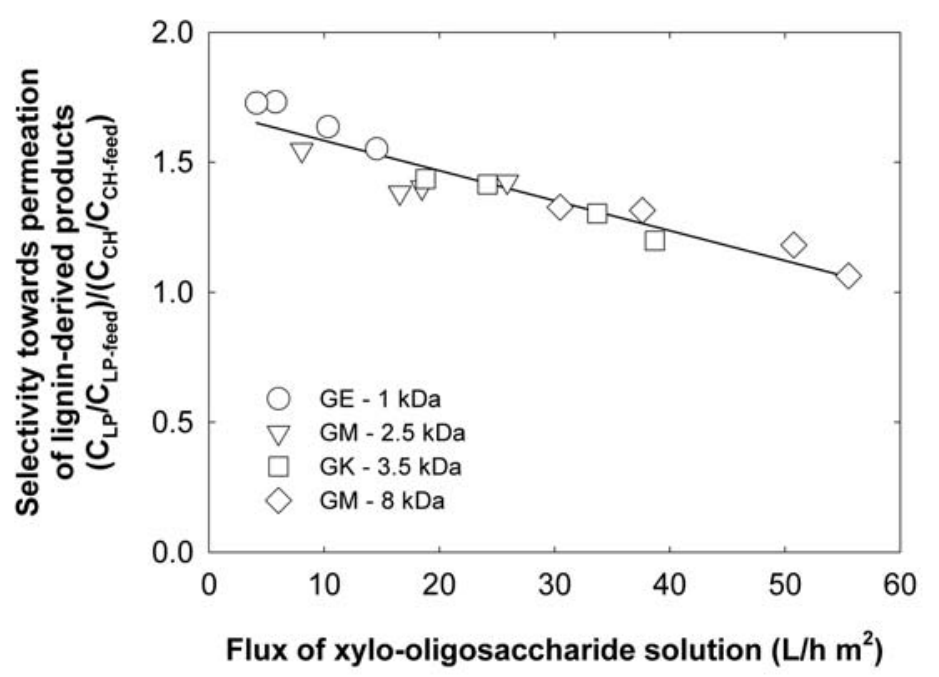

Figure 3.42. Relationship between the dimensionless selectivity towards permeation of the lignin-related products and the flux of permeate.

Selectivity decreased linearly with the flux of permeate regardless of the pressure and the MWCO of the membrane, from around 1.75 at $5 \mathrm{~L} / \mathrm{h} \cdot \mathrm{m}^{2}(1 \mathrm{kDa}$ GE membrane at 2.7 bar) to 1.1 at $55 \mathrm{~L} / \mathrm{h} \cdot \mathrm{m}^{2}$ ( $8 \mathrm{kDa}$ GM membrane at 8.6 bar). The main implications of this result are that membranes should be operated at low pressure to maximize selectivity, although this will imply a larger area for the same flow rate of permeate, and that selectivity will be lower as larger is the MWCO of the membrane. This is in complete agreement with the trends observed in a previous study for composite membranes with activated carbon applied to the ultrafiltration of dextran and xylooligosaccharide solutions [56].

$$
S_{L P / C H}=\frac{\left(C_{L P} / C_{L P-\text { feed }}\right)}{\left(C_{X O} / C_{X O-\text { feed }}\right)}
$$




$$
R_{o b s, M}=1-\frac{C_{X O, M}}{C_{X O-\text { feed }, M}}
$$

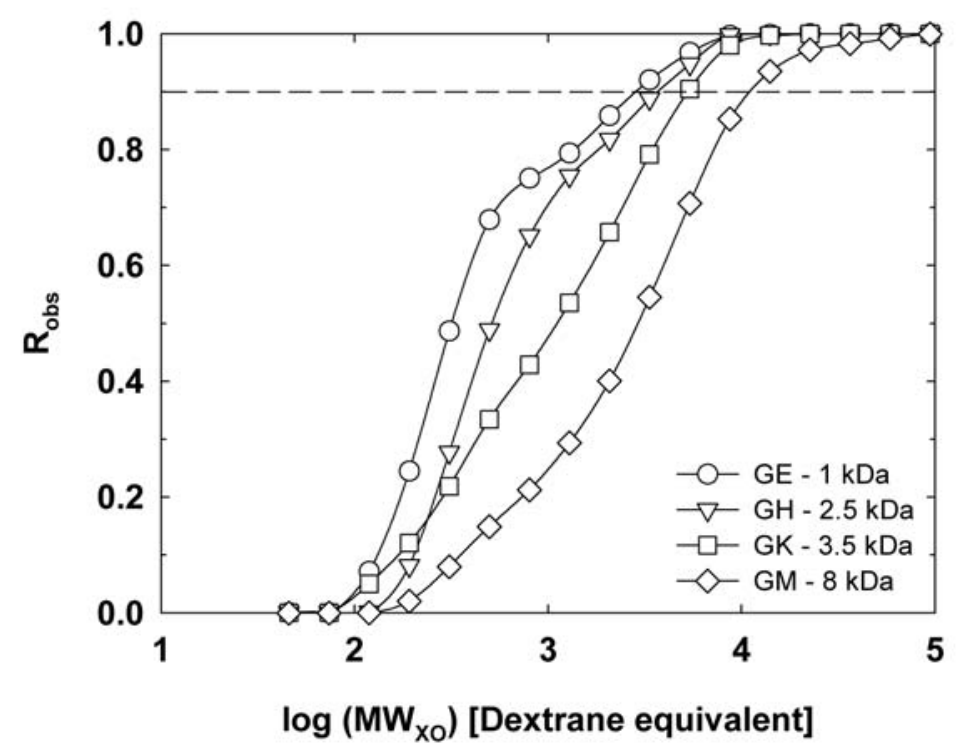

Figure 3.43. Ultrafiltration of xylo-oligosaccharides: observed rejection curves for the four polymeric membranes (dextran-equivalent molar masses).

Figure 3.43 shows the observed rejection curves for the four membranes. Rejection curves were calculated from the GPC elugrams of the xylo-oligosaccharides collected at the lowest flux of permeate by Equation 3.38, where Robs,M is the retention for a xylo-oligomer with a molar mass of $\mathrm{M}$, and Cxo-feed,M and $\mathrm{CxO}_{\mathrm{x}, \mathrm{M}}$ are its concentration in the feed and permeate, respectively. The apparent MWCOs of the membranes were estimated from the molar mass at $90 \%$ rejection.

Figure 3.44 shows that the apparent MWCOs of the membranes were higher than their nominal values. The measured MWCOs were $2.75 \pm 0.7 \mathrm{kDa}$ for the GE membrane, $3.82 \pm 0.7 \mathrm{kDa}$ for $\mathrm{GH}, 5.37 \pm 0.5 \mathrm{kDa}$ for the GK and $10.9 \pm 0.5 \mathrm{kDa}$ for the GM. This difference is attributed to the different molar mass calibration standards used in both measurements. The molar mass of the xylo-oligosaccharides was calculated by calibrating the GPC system with dextrans, whereas according to the manufacturer, the nominal MWCO of the polymeric membranes was determined using PEG standards. 


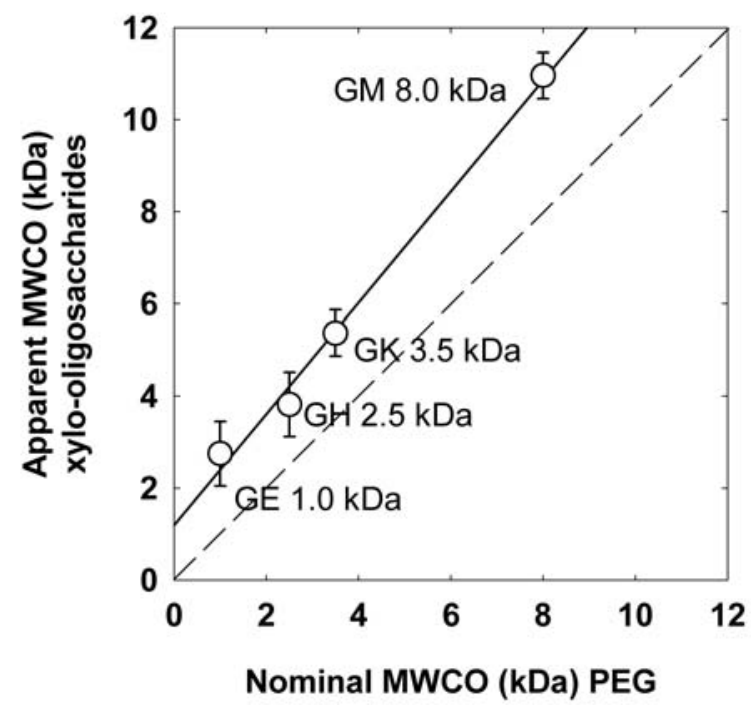

Figure 3.44. Relationship between the nominal MWCO of the membranes, and their apparent MWCO established from the molar mass distribution of the permeated xylo-oligosaccharides.

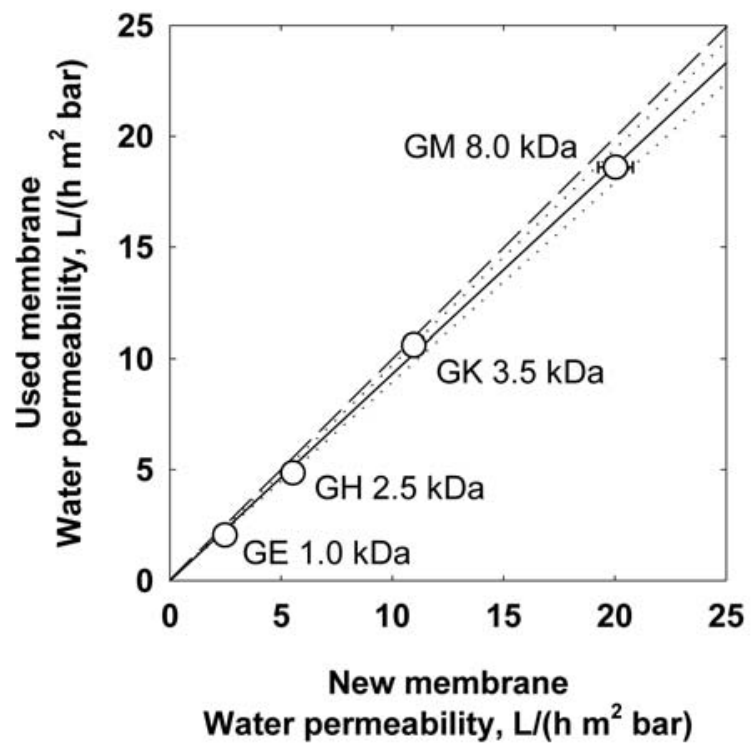

Figure 3.45. Membrane fouling: relationship between the water permeabilities of new and used membranes.

Finally, the fouling of the membranes was evaluated by measuring the water permeability of the clean membranes before use and after developing a series of 
experiments with the xylo-oligosaccharide solutions. Figure 3.45 shows that fouling was minor since the permeability of the used membrane was around $93 \%$ of that of a clean one.

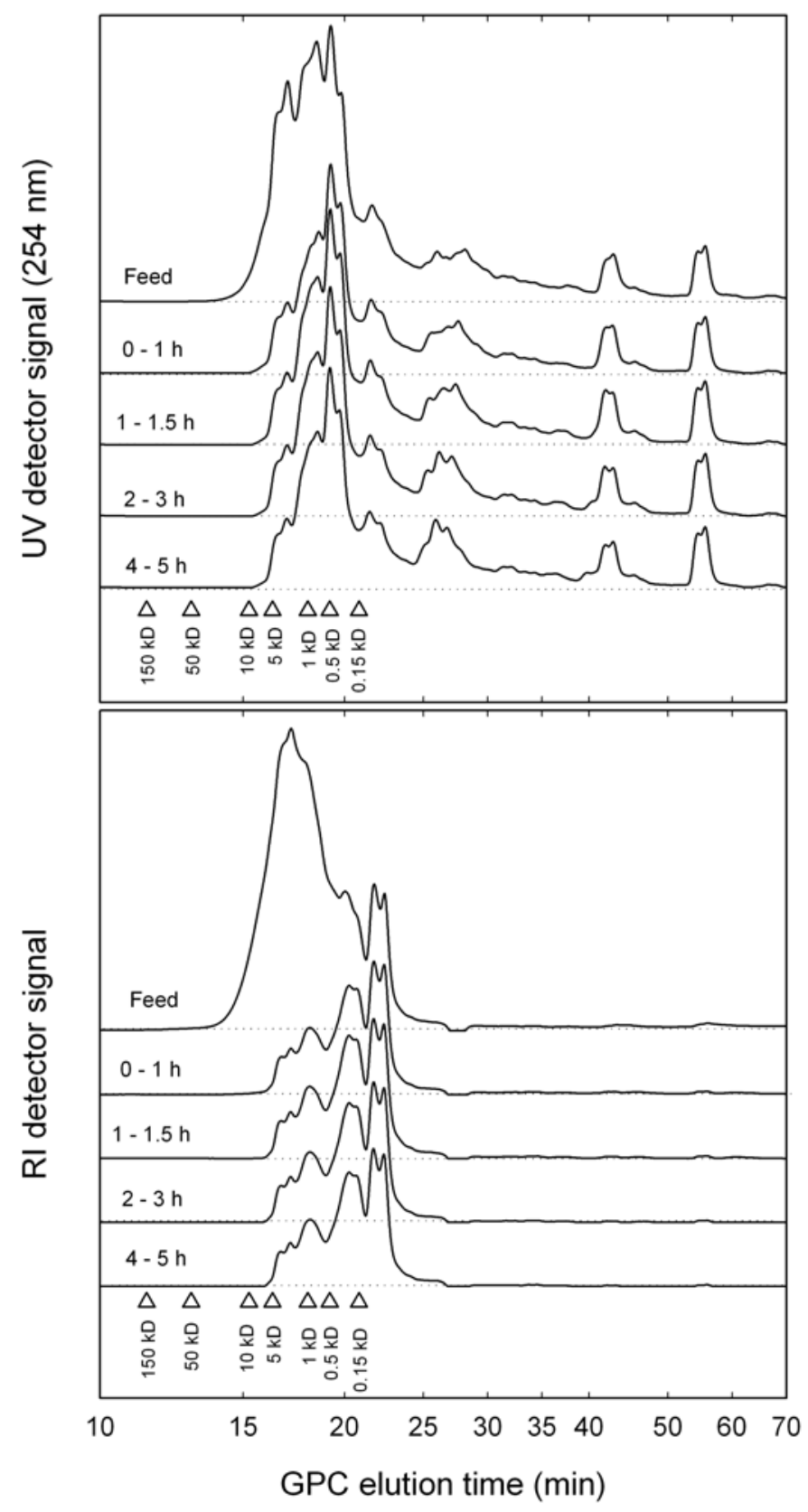

Figure 3.46. GPC elugrams of the lignin-related products and the xylo-oligosaccharides in the feed and permeate of the GE - $1 \mathrm{kDa}$ membrane as function of time for the fouling experiments. $\Delta$ : Elution times for the different standards used for the calibration curve. 
Figure 3.46 shows the GPC chromatograms for the feed and the different permeate fractions collected for the experiments on fouling in the GE (1 $\mathrm{kDa})$ membrane. The results demonstrated that the efficiency of the membrane was maintained throughout $5 \mathrm{~h}$ of experiment. Figure 3.47 showed the fluxes for the xylooligosaccharides products and the lignin-derived products related with the time used for the experiment. Is possible to observe that the membrane allowed to permeate the maximal flux for both products in the first hour of experimentation, and after that time the flux of solute reach a plateau. That indicates that the membrane experienced a initial fouling in the first hour, that is maintained for more than $5 \mathrm{~h}$ and doesn't affect the functioning of the membrane.

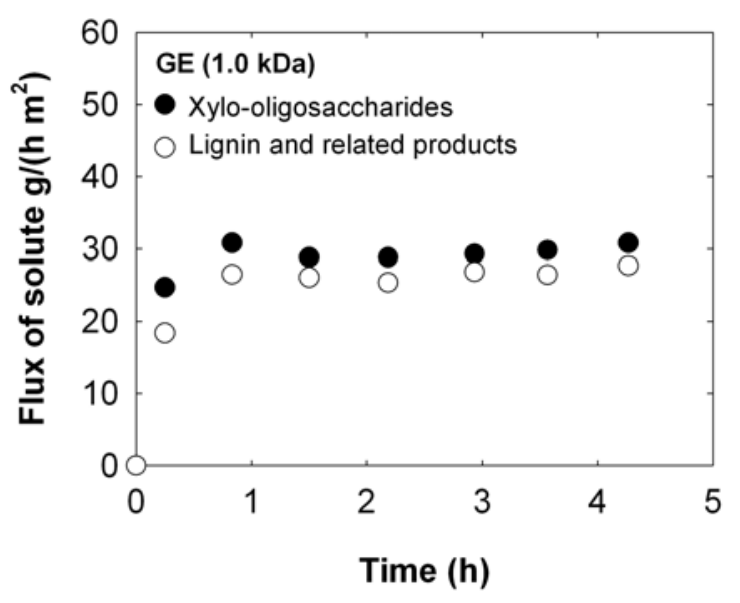

Figure 3.47. Influence of time in the fluxes of lignin-derived products and xylooligosaccharides, for the fouling experiments in the GE - $1 \mathrm{kDa}$ membrane.

Figure 3.48 shows the differences in composition between the feed and the permeate obtained as function of the experimental time tested. In Figure 3.48.a, is possible to observe that monomers like xylose and arabinose are present in higher concentration in the permeate than in the feed, while glucose and acetic acid are in the same concentration in the feed and in the permeate collected. That demonstrated that they preferentially permeated through the membrane, and the concentration remained constant throughout all the experimental time. Figure 3.48.b shows the composition of the oligosaccharides. In all the cases the concentration in the permeate is lower than in the feed. The reduction in the concentration of glucose and arabinose is considerably smaller than the reduction in the concentration of xylose (from around $8.8 \mathrm{~g} / \mathrm{L}$ to 0.8 
$\mathrm{g} / \mathrm{L}$ ) and acetic acid (from around $0.8 \mathrm{~g} / \mathrm{L}$ to $0.1 \mathrm{~g} / \mathrm{L}$ ). Also the reduction in the amount of uronic acid is significant. As can be seen in Figure 3.48. c, the concentration of uronic acid changed from around $0.8 \mathrm{~g} / \mathrm{L}$ to $0.08 \mathrm{~g} / \mathrm{L}$. That indicates that oligosaccharides with molecular weight higher than $2.5 \mathrm{kDa}$ (that was the $\mathrm{MWCO}$ calculated for this membrane) are formed by xylose, uronic and acetic acid, while arabinose and glucose constitutes mainly lower molecular weight oligosaccharides. The concentration of furfural and HMF remained constant and almost equal to that of the feed. In all the cases, the fouling seems to be negligible and does not affect the permeation of the products during all the experimental time tested.

The crude xylo-oligosaccharides produced by autohydrolysis of almond shells, or lignocellulosic biomass in general, contain large amounts of lignin-derived phenolics, carbohydrate dehydration and condensation products, ashes, and other impurities derived from the extractives present in the raw material. Additionally, they show a broad distribution of molar mass regardless of the reaction conditions and it is not feasible to tailor the molar mass distribution by adjusting reaction temperature and time during hydrolysis while maintaining a reasonable yield. Certainly, a high purity and a narrower, well-controlled, and repetitive molar mass distribution are needed to make use of the xylo-oligosaccharides, which means that additional processing is required to meet specifications for purity and molar mass distribution. Ultrafiltration using commercial thin-film polymeric membranes is a suitable process for the purification of xylo-oligosaccharide solutions obtained by autohydrolysis of lignocellulosic biomass. The polymeric membranes with a nominal MWCO as low as 1 $\mathrm{kDa}$ do not reject lignin-derived low molar mass compounds, which represent almost half of the impurities in the raw xylo-oligosaccharides, thus allowing purification by continuous diafiltration. Selectivity towards the permeation of lignin-related products over xylo-oligosaccharides is better at low fluxes of permeate and with membranes of low MWCO. Furthermore, irreversible fouling of the membranes was very limited. In conclusion, the rejection characteristics of the polymeric membranes tested and their limited fouling show that it is feasible to design a separation sequence using membranes with different MWCO to purify xylo-oligosaccharides, and to separate them into fractions with narrower and repetitive molar mass distribution, although a more comprehensive study is required to optimize the process conditions. 

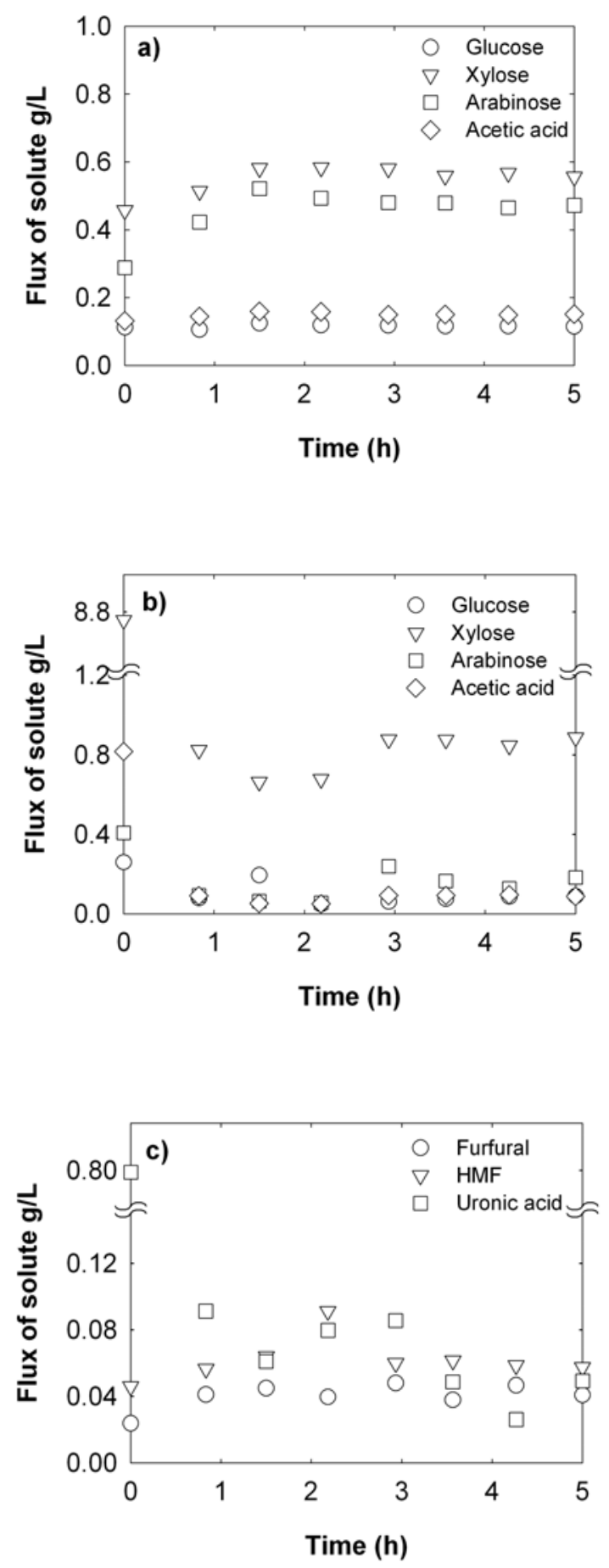

Figure 3.48. a) Comparison between the monomers content (glucose, xylose and arabinose) and acetic acid, between the feed and permeate collected during $5 \mathrm{~h}$ of experiment. b) Comparison between the oligosaccharides content (glucose, xylose and arabinose) and acetic acid, between the feed and permeate collected during $5 \mathrm{~h}$ of experiment. c) Comparison of the uronic acid, furfural and HMF between the feed and permeate collected during $5 \mathrm{~h}$ of experiment. 


\subsubsection{Enzymatic membrane reactors}

Process intensification is one of the most promising areas in chemical engineering. Related to membranes, it means that the reaction and separation/purification steps are combined in a new single unit. This can be carried out in enzymatic membrane reactors (EMRs), which include a membrane that holds an active enzyme, either by light or by strong bonding. In addition to the intrinsic advantages of these systems, the process is continuous, the catalyst component can be re-used and a permeate is obtained free of this compound [57, 58]. In these experiments, a carbon/polysulfone composite membrane was used, in which the carbon acts as the base support on which the enzyme bonds [59]. The EMRs were used in dextrans purification, in order to obtain compounds with low degree of polymerization. The experiments are still in process. Nevertheless, previous results with another enzyme and with high $M_{\mathrm{w}}$ dextrans in the feed stream, but with the same type of EMR (without the commercial layer and with an own MWCO of $25 \mathrm{kDa}$ ) and experimental devices were used as initial guess for this work $[1,56]$.

Different levels of experiments were carried out. First of all, the activity of the enzyme dextranase was tested using a solution of dextran $(40 \mathrm{kDa}, 1.5 \mathrm{~g} / \mathrm{L})$ as substrate. The concentration of the enzyme was varied between $0.1 \mathrm{~mL} / \mathrm{L}, 0.2 \mathrm{~mL} / \mathrm{L}, 0.5$ $\mathrm{mL} / \mathrm{L}, 2 \mathrm{~mL} / \mathrm{L}$ and $10 \mathrm{~mL} / \mathrm{L}$ of solution. The results for the experiments with a dextranase concentration of $0.5 \mathrm{~mL} / \mathrm{L}$ at $50^{\circ} \mathrm{C}$ are showed in Figure 3.49 a). This figure compares the GPC signals of the original dextran solution, the original enzyme solution, and the mixture at different reaction times. As can be observed, even at $5 \mathrm{~min}$ of reaction almost all the dextran was converted into small oligomers, having a molecular weight between 0.2 and $5 \mathrm{kDa}$. As the reaction time increased, the bigger oligomers were depolymerized, showing a decrease in the signal for the oligomers with a molecular weight between 1 and $5 \mathrm{kDa}$. Figure $3.49 \mathrm{~b}$ ) shows the results for the activity of the enzyme when it was adsorbed on activated carbon. In this case, for the preparation of the enzyme -carbon complex, the concentration of the enzyme used was $0.5 \mathrm{~mL}$ of enzyme/ $10 \mathrm{~mL}$ solution, being adsorbed over $50 \mathrm{mg}$ of activated carbon at three different $\mathrm{pH}(3,5$ and 7$)$. The concentration of the dextran solution used for the activity experiments was $1.5 \mathrm{~g} / \mathrm{L}$, using two loads of carbon (2 and $10 \mathrm{mg}$ of carbon on $100 \mathrm{~mL}$ of dextran solution), being stirred during $1 \mathrm{~h}$ at $50^{\circ} \mathrm{C}$. The results showed that the enzyme was active after the adsorption onto activated carbon, but showed 
differences in the activity depending on the $\mathrm{pH}$ of the solution and the amount of carbon used. At low $\mathrm{pH}(\mathrm{pH}=3)$, the enzyme was active but there were still oligomers with MW higher than $10 \mathrm{kDa}$, and the amount seemed to be not so high. For the experiments at $\mathrm{pH}=5$, is possible to observe that the increase in the amount of carbon, and consequently in the amount of active enzyme increased the depolymerization of the dextran oligomers, observing that the peak with MW between $0.3-2 \mathrm{kDa}$ appears bigger. For the experiments at $\mathrm{pH}=7$, there was no significant increase in the depolymerization when more activated carbon was used, and the oligomers obtained had the same molecular weight distribution as those obtained at $\mathrm{pH} 5$, using less amount of carbon.
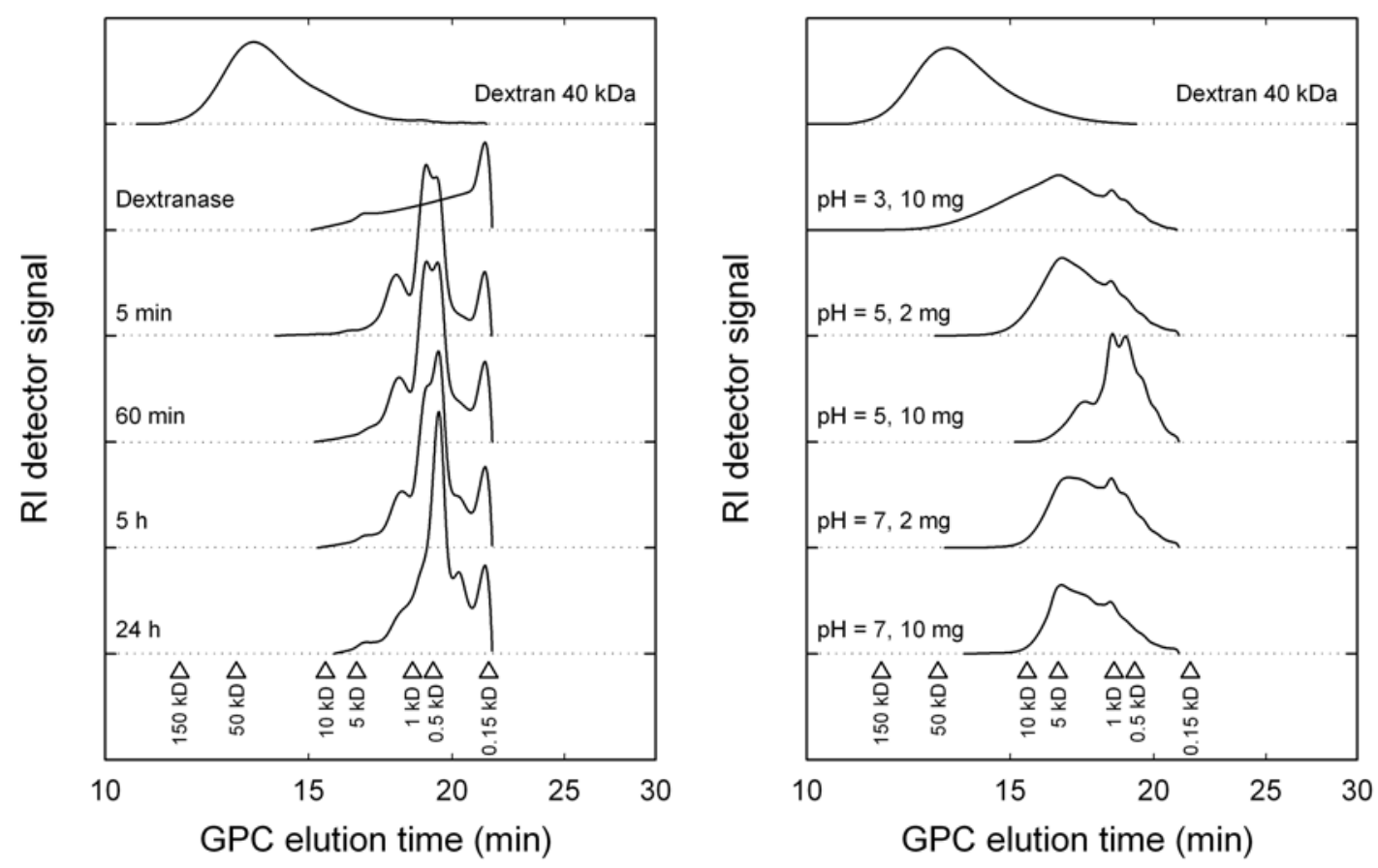

Figure 3.49. (a) GPC signal of the dextran $(40 \mathrm{kDa})$ solution, the enzyme dextranase, and the samples of the mixture taken at different reaction times. b) GPC signal showing the activity of the enzyme-carbon complex, at different $\mathrm{pH}$ and different ratios carbon/enzyme.

The preliminary results about the EMRs are showed in Figure 3.50. The EMR used for these experiments was composed by two layers. The first one was a polymeric membrane made of 1.5 (\%wt) polysulfone, with 4 (\%wt) of the complex enzyme carbon incorporated inside the membrane during its preparation. The complex enzyme 
carbon used was prepared in the same way as previously. The second layer was composed of a commercial polymeric membrane with MWCO $8 \mathrm{kDa}$. Both layers were physically joined, and tested in the ultrafiltration unit at $50^{\circ} \mathrm{C}$ using a dextran solution $(40 \mathrm{kDa}, 1.5 \mathrm{~g} / \mathrm{L})$ as substrate. The results showed that the enzyme was active after its incorporation inside the membrane. As can be observed, with the increase of the reaction time increased the signal for the oligomers, showing that its amount in the permeate increased. That indicates that more oligomers were depolymerized to a MW that can pass through the $8 \mathrm{kDa}$ membrane. Several possibilities have to be explored in this stage, because there are so many factors that affect the functioning of the membrane. Some of them are the residence time of the permeate inside the membrane, the influence of the reaction time when the experiments are carried out during long periods, the influence of the MWCO of the commercial membrane used, etc. The preliminary results showed here seems promising for the preparation of a EMR capable to convert also high MW xylo-oligosaccharides into low MW xylooligosaccharides, useful for their use as dietary fibre.

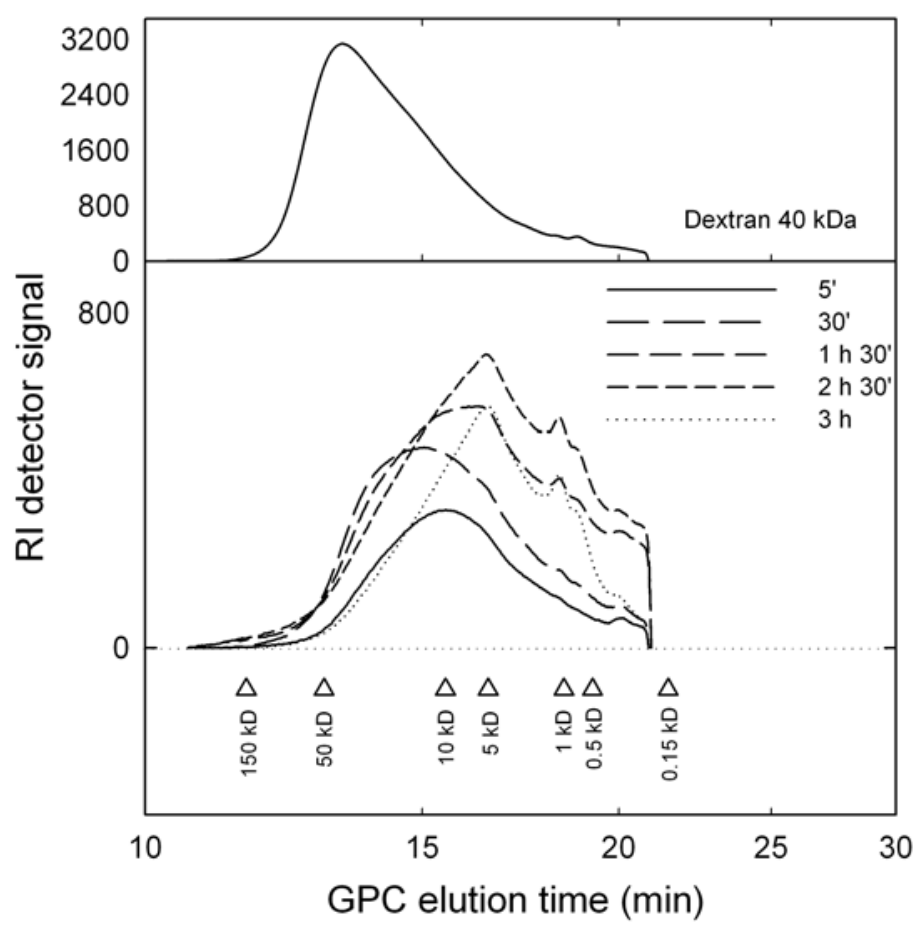

Figure 3.50. GPC signal of the experiments for the EMR. Up: Feed (solution of dextran, MW: 40 kDa). Down: Permeate collected at different reaction times. 


\subsection{PRELIMINARY RESULTS ABOUT POSSIBLE APPLICATIONS OF XYLO-OLIGOSACCHARIDES}

\subsubsection{Antioxidant activity of the xylo-oligosaccharides}

Spray-dried xylo-oligosaccharides (SXOs) were tested to determine the antioxidant activity (AA) based on TEAC analysis. The experiments were made by courtesy of Mrs. Aleksandra Rozek and Dr. Monserrat Ferrando, GITA, Universitat Rovira i Virgili, Spain.

\begin{tabular}{lc}
\hline \multicolumn{1}{c}{ Source of the XOs } & $\begin{array}{c}\text { Antioxidant Activity } \\
\text { (mmol Trolox / kg XOs) }\end{array}$ \\
\hline Almond shells & 365.3 \\
Olive stones & 589.7 \\
Corncobs & 519.2 \\
Rice husks & 486.0 \\
Wheat straw & 403.4 \\
Barley straw & 486.4 \\
Permeate from olive stones & 608.8 \\
Permeate from rice husks & 537.3 \\
\hline
\end{tabular}

Table 3.16. Antioxidant activity for XOs from the different raw materials.

The Table 3.16 show the main results for the XOs from the different raw materials, and also for the permeate obtained after the dialysis treatment. It was found that the highest activity was for SXOs from olive stones (which have an AA of 589.7 mmol Trolox / kg XOs), and from corncobs (519.2 mmol Trolox / kg XOs). The others raw materials have less antioxidant activity, being the lowest for almond shells, which have an AA of $365.3 \mathrm{mmol}$ Trolox / kg XOs. From the literature [60] it was found that 
the normal levels of AA for natural products like olives is an AA of 10.4 mmol Trolox / $\mathrm{kg}$ of fresh weight of fruit for the green olives, or $14.7 \mathrm{mmol}$ Trolox / $\mathrm{kg}$ of fresh weight of fruit for the black ones. As shown in Table 3.16, the permeate from the dialysis treatment has higher antioxidant activity than the original SXOs, indicating that this process allows to recover the compounds in the mixture that provide the antioxidant activity. These preliminary results indicate that all of these xylo-oligosaccharides have strong antioxidant activity making them potential candidates for their use as food additive.

\subsubsection{Immunomodulatory activity of almond shells xylo- oligosaccharides}

Some preliminary studies have been carried out to evaluate the possible applications of the xylo-oligosaccharides in the future. The immunomodulatory activity of the xylo-oligosaccharides obtained from autohydrolysis of almond shells was evaluated. These experiments were made by courtesy of the Institute of Chemistry of the Slovak Academy of Sciences, in Bratislava, Slovak Republic.

The immunomodulatory activity was assessed using the comitogenic thymocyte test, which was proved to be applicable for polysaccharides of known immunomodulatory activities $[42,48,61]$. The test is based on the capacity of adjuvant immunomodulators to augment the proliferate response of rat thymocytes to $\mathrm{T}$ mitogens in 'vitro'. As illustrated in Table 3.17, the dialyzed xylo-oligosaccharides from almond shells (AS-DXO) showed dose-dependent direct mitogenic as well as comitogenic activities, similarly as the immunogenic water-soluble arabinoglucuronoxylan from corncobs (CCX) [42], used as positive control. The activities in the whole doses range were about 30\% lower in comparison to the control. The SIcomit/SImit ratio of more than 2 indicates adjuvant properties [62]. For comparison, the CC-DXO isolated by the same hydrothermal treatment conditions from corncobs (not published), which has the same 4-O-methylglucuronoxylan-type structure as the almond shell DXO, showed also dose-dependent responses in the mitogenic and comitogenic tests increasing up to $300 \mathrm{mg} / \mathrm{mL}$, and decreasing at the highest applied dose. However, the immunomodulatory activity of the CC-DXO was significantly lower than that of the control and AS-DXO. 
Except of the known physiological effects of oligosaccharides [63, 64], only nigero- and agaro-oligosaccharides were found to exhibit immunopotentiating and apoptosis induction activities [63]. The results represent a first report on the immunomodulatory activity of acetylated xylo-oligosaccharides, which in the case of the almond shell XO comprise a mixture of neutral and acidic (MeGA-containing) xylooligosaccharides, contaminated with very low amounts of phenolics. The immune system potentiating activity as well as the presence of phenolics might support and contribute to further applications of the partially O-acetylated almond shell $\mathrm{XO}$, isolated under autohydrolytic conditions.

Stimulatory index, SI dose $(\mu \mathrm{g} / \mathrm{mL})$

\begin{tabular}{lccccc} 
& 10 & 30 & 100 & 300 & 1000 \\
\cline { 2 - 6 } Sample & \multicolumn{5}{c}{ Mitogenic activity } \\
\hline AS-DXO & $0.9 \pm 0.1$ & $1.2 \pm 0.1$ & $1.5 \pm 0.3$ & $4.6 \pm 0.8$ & $18.5 \pm 4.2$ \\
CC-DXO & $1.5 \pm 0.4$ & $2.1 \pm 0.5$ & $4.2 \pm 1.3$ & $9.4 \pm 2.8$ & $7.0 \pm 0.5$ \\
CCX & $1.1 \pm 0.1$ & $1.4 \pm 0.1$ & $2.9 \pm 0.4$ & $15.6 \pm 3.8$ & $31.4 \pm 5.5$ \\
& & & Comitogenic activity & \\
AS-DXO & $1.4 \pm 0.1$ & $1.2 \pm 0.1$ & $2.0 \pm 0.2$ & $10.4 \pm 4.2$ & $39.7 \pm 17.3$ \\
CC-DXO & $1.6 \pm 0.3$ & $3.0 \pm 0.6$ & $9.7 \pm 2.8$ & $24.9 \pm 4.9$ & $14.1 \pm 1.8$ \\
CCX & $1.1 \pm 0.1$ & $1.4 \pm 0.1$ & $2.9 \pm 0.4$ & $15.6 \pm 3.8$ & $31.4 \pm 5.5$ \\
\hline
\end{tabular}

Table 3.17. Mitogenic and comitogenic activities of partially O-acetylated xylo-oligosaccharides from almond shells (AS-DXO) and corncobs (CC-DXO) in comparison to the corncob xylan (CCX) used as positive control. The mean cpm for control cultures without any addition was $\varnothing$ 948 (704 - 1143). For cultures incubated with PHA, the mean cpm was $\varnothing 1331$ (1081 - 1601). The $\mathrm{P}$ (ANOVA) at doses $300-1000 \mu \mathrm{g} / \mathrm{mL}$ was $>0.05$ for the DXO samples vs CCX; P was not determined at $1000(\mu \mathrm{g} / \mathrm{mL})$ for CC-DXO. 


\subsection{REFERENCES}

1. Torras, C., Torné-Fernández, V., Fierro, V., Montané, D., \& García-Valls, R. Polymeric composite membranes based on carbon/PSf. Journal of Membrane Science, 2006, 273 (1-2): p. 38 $-46$.

2. Nabarlatz, D., Farriol, X., \& Montané, D. Kinetic Modeling of the Autohydrolysis of Lignocellulosic Biomass for the Production of Hemicellulose-Derived Oligosaccharides. Industrial and Engineering Chemistry Research, 2004, 43: p. 4124 - 4131.

3. Nabarlatz, D., Farriol, X., \& Montané, D. Autohydrolysis of Almond Shells for the Production of Xylo-oligosaccharides: Product Characteristics and Reaction Kinetics. Industrial and Engineering Chemistry Research, 2005, 44: p. 7746 - 7755.

4. Montané, D., Nabarlatz, D., Martorell, A., Torné-Fernández, V., \& Fierro, V. Removal of lignin and associated impurities from xylo-oligosaccharides by activated carbon adsorption. Industrial and Engineering Chemistry Research, 2006, 45: p. 2294 - 2302.

5. Torras, C., Nabarlatz, D., Montané, D., \& García-Valls, R. Enzymatic membrane reactors based on polysulfone/activated carbon. Desalination, 2006, 199: p. 438 - 440.

6. Nabarlatz, D., Torras, C., García-Valls, R., \& Montané, D. Purification of xylo-oligosaccharides from almond shells by ultrafiltration. Separation and Purification Technology, 2006, in press.

7. Nabarlatz, D., Ebringerová, A., \& Montané, D. Autohydrolysis of agricultural by-products for the production of xylo-oligosaccharides. Carbohydrate Polymers, 2006, in press.

8. Garrote, G., Domínguez, H., \& Parajó, J. Autohydrolysis of corncob: study of non-isothermal operation for xylooligosaccharide production. Journal of Food Engineering, 2002, 52: p. 211-218.

9. Allen, S., Kam, L., Zemann, A., \& Antal, M. Fractionation of sugar cane with hot, compressed, liquid water. Industrial and Engineering Chemistry Research, 1996, 35: p. 2709 - 2715.

10. Garrote, G. \& Parajó, J. Non-isothermal autohydrolysis of Eucalyptus wood. Wood Science and Technology, 2002, 36: p. 111-123.

11. Montané, D., Salvadó, J., Farriol, X., \& Chornet, E. The fractionation of almond shells by thermo-mechanical aqueous phase (TM-AV) pretreatment. Biomass and Bioenergy, 1993, 4 (6): p. 427-437.

12. Heitz, M., Capek-Ménard, E., Koeberle, P., Gagné, J., Chornet, E., Overend, R., Taylor, J., \& Yu, E. Fractionation of Populus Tremuloides at the Pilot Plant scale: optimization of steam pretreatment conditions using the Stake II Technology. Bioresource Technology, 1991, 35: p. 2332.

13. Jollez, P., Chornet, E., \& Overend, R. Steam aqueous fractionation of sugar cane bagasse: an optimization study of process conditions at the pilot plant level., in Advances in Thermochemical Biomass Conversion, B.A.a.P.C.a.H. A.V. Bridgewater, Editor. 1994: London. p. 1659-1669. 
14. Montané, D., Farriol, X., Salvadó, J., Jollez, P., \& Chornet, E. Fractionation of wheat straw by steam-explosion pretreatment and alkali delignification. Cellulose pulp and byproducts from hemicellulose and lignin. Journal of Wood Chemistry and Technology, 1998, 18 (2): p. 171191.

15. Mehlberg, R. \& Tsao, G.T. Low liquid hemicellulose hydrolysis of hydrochloric acid. in 178th ACS National Meeting. 1979. Washington DC, USA.

16. Maloney, M., Chapman, T., \& Baker, A. Dilute acid hydrolysis of paper birch: kinetic studies of xylan and acetyl-group hydrolysis. Biotechnology and Bioengineering, 1985, 27: p. 355 - 361.

17. Grohmann, K., Torget, R., \& Himmel, M. Optimization of dilute acid pretreatment of biomass. Biotechnology Bioengineering Symposia, 1985, 15: p. 59 - 80.

18. Conner, A.H. \& Lorenz, L. Kinetic modeling of hardwood prehydrolysis. Part III. Water and dilute acetic acid prehydrolysis of southern Red Oak. Wood Fiber Science, 1986, 18: p. 248 - 263.

19. Overend, R. \& Chornet, E. Fractionation of lignocellulosics by steam-aqueous pretreatment. Phil. Trans. R. Soc. Lond., 1987, 321: p. 523-536.

20. Brasch, D.J. \& W., F.K. Prehydrolysis - kraft pulping of Pinus radiata grown in New Zealand. Tappi Journal, 1965, 48: p. 245 - 248.

21. Chum, H.L., Johnson, D.K., Black, S.K., \& Overend, R.P. Pretreatment-catalyst effects and the combined severity parameter. Applied Biochemistry and Biotechnology, 1990, 24/25: p. 1 - 14.

22. Belkacemi, K., Abatzoglou, N., Overend, R., \& Chornet, E. Phenomenological kinetics of complex systems: Mechanistic considerations in the solubilization of hemicelluloses following aqueous-steam treatments. Industrial and Engineering Chemistry Research, 1991, 30: p. 24162425.

23. Abatzoglou, N., Chornet, E., Belkacemi, K., \& Overend, R.P. Phenomenological kinetics of complex systems: the development of a generalized severity parameter and its application to lignocellulosics fractionation. Chemical Engineering Science, 1992, 47: p. 1109 - 1112.

24. Montané, D., Overend, R., \& Chornet, E. Kinetic Models for Non-Homogeneous Complex Systems with a Time - Dependant Rate Constant. The Canadian Journal of Chemical Engineering, 1998, 76: p. 58 - 68.

25. Conner, A.H. Kinetic modeling of hardwood prehydrolysis. Part I. Xylan removal by water prehydrolysis. Wood Fiber Science, 1984, 16: p. 268 - 277.

26. Garrote, G., Domínguez, H., \& Parajó, J. Kinetic modelling of corncob autohydrolysis. Process Biochemistry, 2001, 36: p. 571-578.

27. Converse, A.O., Kwarteng, I.K., Grethlein, H.E., \& Ooshima, H. Kinetics of thermochemical pretreatment of lignocellulosic materials. Applied Biochemistry and Biotechnology, 1989, 20/21: p. 63 - 78. 
28. Garrote, G., Domínguez, H., \& Parajó, J. Manufacture of xylose-based fermentation media from corncobs by posthydrolysis of autohydrolysis liquors. Applied Biochemistry and Biotechnology, 2001, 95: p. 195-207.

29. Fengel, D. \& Wegener, G. Wood: Chemistry, Ultrastructure, Reactions. 1989, Berlin - New York: Walter de Gruyter.

30. De Vries, R.P. \& Visser, J. Aspergillus enzymes involved in degradation of plant cell wall polysaccharides. Microbiological Molecular Biology Revision, 2001, 65: p. 497 - 522.

31. Saura-Calixto, F., Cañellas, J., \& García-Raso, J. Contents of detergent-extracted dietary fibers and composition of hulls, shells and teguments of almonds (Prunus amygdalus). Journal of Agricultural and Food Chemistry, 1983, 31: p. 1255 - 1259.

32. Ebringerová, A., Hromádková, Z., \& Heinze, T. Hemicellulose. Advances in Polymer Science, 2005, 186: p. 1 - 67.

33. Vegas, R., Alonso, J., Domínguez, H., \& Parajo, J.C. Processing of rice husk autohydrolysis liquors for obtaining food ingredients. Journal of Agricultural and Food Chemistry, 2004, 52: p. 7311 - 7317.

34. Vegas, R., Alonso, J.L., Domínguez, H., \& Parajó, J.C. Manufacture and refining of oligosaccharides from industrial solid wastes. Industrial and Engineering Chemistry Research, 2005, 44: p. $614-620$.

35. Theander, O. \& Åman, P. Anatomical and chemical characteristics, in Straw and other byproducts as feed. 1984, Elsevier Publishers: Amsterdam. p. 45 - 78.

36. Anglés, M., Reguant, J., Martínez, J., Farriol, X., Montané, D., \& Salvadó, J. Influence of the ash fraction on the mass balance during the summative analysis of high-ash content lignocellulosics. Bioresource Technology, 1997, 59: p. 185 - 193.

37. Ebringerová, A. \& Heinze, T. Xylan and xylan derivatives - biopolymers with valuable properties, 1. Naturally occuring xylans structures, isolation procedures and properties. Macromolecular Rapid Communications, 2000, 21 (9): p. 542-556.

38. Vazquez, M., Alonso, J., Domínguez, H., \& Parajó, J. Enhancing the potential of oligosaccharides from corncob autohydrolysis as prebiotic food ingredients. Industrial Crops and Products, 2006, 24: p. 152 - 159.

39. Parajó, J., Domínguez, H., \& Domínguez, J. Study of charcoal adsorption for improving the production of Xylitol from wood hydrolysates. Bioprocess Engineering, 1995, 16: p. 39-43.

40. Yuan, Q.P., Zhang, H., Qian, Z.M., \& Yang, X.J. Pilot-plant production of xylo-oligosaccharides from corncob by steaming, enzymatic hydrolysis and nanofiltration. Chemical Technology and Biotechnology, 2004, 79: p. 1073-1079.

41. Carvalheiro, F., Esteves, M., Parajo, J.C., Pereira, H., \& Gírio, F. Production of oligosaccharides by autohydrolysis of brewery's spent grain. Bioresource Technology, 2004, 91: p. 93 - 100. 
42. Ebringerová, A., Hromádková, Z., \& Hríbalová, V. Structure and mitogenic activities of corncob heteroxylans. International Journal of Biological Macromolecules, 1995, 17 (6): p. 327-331.

43. Kardosová, A., Matulová, M., \& Malovíková, A. (4-O-Methyl-a-D-glucurono)-D-xylan from Rudbeckia fulgida, var. sullivantii (Boynton et Beadle). Carbohydrate Research, 1998, 308: p. 99 - 105.

44. Teleman, A., Tenkanen, M., Jacobs, A., \& Dahlman, O. Characterization of O-acetyl-(4-Omethylglucurono)xylan isolated from birch and beech. Carbohydrate Research, 2002, 337: p. 373 - 377.

45. Teleman, A., Lundqvist, J., Tjerneld, F., Stalbrand, H., \& Dahlman, O. Characterization of acetylated 4-O-methylglucuronoxylan isolated from aspen employing ${ }^{1} \mathrm{H}$ and ${ }^{13} \mathrm{C} N \mathrm{NR}$ spectroscopy. Carbohydrate Research, 2000, 329: p. 807 - 815.

46. Gröndahl, M., Teleman, A., \& Gatenholm, P. Effect of acetylation on the material properties of glucuronoxylan from aspen wood. Carbohydrate Polymers, 2003, 52: p. 359 - 366.

47. Pou-Ilinas, J., Canellas, J., Driguez, H., Excoffier, G., \& Vignon, M. Steam pretreatment of almond shells for xylose production. Carbohydrate Research, 1990, 207: p. 126-130.

48. Ebringerová, A., Kardosová, A., Hromadková, Z., Malovíkova, A., \& Hribalová, V. Immunomodulatory activity of acidic xylans in relation to their structural and molecular properties. International Journal of Biological Macromolecules, 2002, 30 (1): p. 1-6.

49. Kacuráková, M., Capek, P., Sasinková, V., Wellner, N., \& Ebringerová, A. FT-IR study of plant cell wall model compounds: pectic polysaccharides and hemicelluloses. Carbohydrate Polymers, 2000, 43 (2): p. 195-203.

50. Faix, O. Classification of lignins from different botanical origins by FT-IR spectroscopy. Holzforschung, 1991, 45: p. 21 - 27.

51. Garrote, G., Cruz, J., Domínguez, H., \& Parajó, J. Valorisation of waste fractions from autohydrolysis of selected lignocellulosic materials. Journal of Chemical Technology and Biotechnology, 2003, 78: p. 392-398.

52. Palm, M. \& Zacchi, G. Separation of hemicellulosic oligomers from steam - treated spruce wood using gel filtration. Separation and Purification Technology, 2004, 36: p. 191 - 201.

53. Olivier, J.P. Improving the models used for calculating the size distribution of micropore volume of activated carbons from adsorption data. Carbon, 1998, 36: p. 1469 - 1472.

54. Moreno-Castilla, C. Adsorption of organic molecules from aqueous solutions on carbon materials. Carbon, 2004, 42: p. 83 - 94.

55. Salame, I.I. \& Bandosz, T.J. Role of surface chemistry in adsorption of phenol on activated carbons. Journal of Colloid and Interface Science, 2003, 264: p. 307 - 312.

56. Torras, C. Preparation of selective polymeric membranes. September 2005, Rovira i Virgili University: Tarragona, SPAIN. p. 237. 
57. Bouhallab, S. Les separations par membranes dans les procédés de l'industrie alimentaire, in Tech. Doc. Lavoisier. 1998: Paris.

58. Moon, C. \& Lee, J. Use of curdlan and activated carbon composed adsorbents for heavy metal removal. Process Biochemistry, 2005, 40: p. 1279 - 1283.

59. Üçer, A. Immobilisation of tannic acid onto activated carbon to improve Fe(III) adsorption. Separation and Purification Technology, 2005, 44: p. 11 - 17.

60. Pellegrini, N., Serafini, M., Colombi, B., Del Rio, D., Salvatore, S., Bianchi, M., \& Brighenti, F. Total antioxidant capacity of plant foods, beverages and oils consumed in Italy assessed by three different in vitro assays. Journal of Nutrition, 2003, 133: p. 2812 - 2819.

61. Rovenský, J., Pekárek, J., Mlynarcík, D., Kasafírek, E., Lackovic, V., Hríbalová, V., \& Buc, M. in Immunology: Clinical, Fundamental and Therapeutic Aspects, B.P. Ram, M.C. Harris, and P. Tyle, Editors. 1990, VCH Publishers Inc.: New York. p. 344 - 354.

62. Iribe, H. \& Koga, T. Augmentation of the proliferation response of thymocytes to phytohemagglutinin by the muramyl dipeptide. Cell Immunology, 1984, 88: p. 9 - 15.

63. Nakakuki, T. Development of functional oligosaccharides in Japan. Trends in Glycoscience and Glycotechnology, 2003, 15 (82): p. 57 - 64.

64. Crittenden, R. \& Playne, M. Production, properties, and applications of food-grade oligosaccharides. Trends in Food Science and Technology, 1996, 7: p. 353-361. 
Debora Alcida Nabarlatz

ISBN: 978-84-690-7617-0 / DL: T.1385-2007 
AUTOHYDROLYSIS OF AGRICULTURAL BY-PRODUCTS FOR THE PRODUCTION OF XYLO-OLIGOSACCHARIDES.

Debora Alcida Nabarlatz

ISBN: 978-84-690-7617-0/DL: T.1385-2007 


\subsection{CONCLUSIONS}

The main objective of this thesis was to evaluate several lignocellulosic materials coming from agriculture residues, typical from the Mediterranean region of Spain, to obtain xylo-oligosaccharides with potential applications in the food and pharmaceutical field. Autohydrolysis was tested for the production of xylooligosaccharides from corncobs, almond shells, olive stones, rice husks, and the straws of wheat and barley. The main results from these experiments demonstrated that higher temperature and longer reaction times increased the depolymerization of xylan and the formation of low molar mass products.

$\square$ Between $70-90 \mathrm{wt} \%$ of the cellulose remained unaltered in the solid residue, depending on the raw material. The influence of the reaction temperature and time was less significant.

$\square$ The lignin that remained in the solid accounted up $60-95 \mathrm{wt} \%$. Again it was dependent on the raw material, and less influenced by the reaction conditions. The olive stones and almond shells showed the lower solubilization of lignin, regardless of their higher lignin content.

$\checkmark$ Up to $80 \mathrm{wt} \%$ of the original xylan was solubilized. The extent of the solubilization varied among the raw material, and was strongly influenced by the reaction conditions.

This result suggests that the solid residue obtained after the autohydrolysis reaction could be processed to recover the cellulose (i.e. for the production of glucose or ethanol), and lignin for the production of phenolic resins or other chemical derivatives.

Autohydrolysis showed that the maximal yield in the production of xylooligosaccharides was close to $50 \mathrm{wt} \%$ at $150^{\circ} \mathrm{C}$ after $200 \mathrm{~min}$ of reaction for corncobs. Higher temperatures slightly increased the yield until a maximum of $58 \mathrm{wt} \%$ at $190^{\circ} \mathrm{C}$ and $15 \mathrm{~min}$ of reaction. Autohydrolysis of almond shells gave a maximum yield of xylo-oligosaccharides that increased from $42 \mathrm{wt} \%$ at $150^{\circ} \mathrm{C}$ and $300 \mathrm{~min}$ up to $63 \mathrm{wt} \%$ at $190^{\circ} \mathrm{C}$ and 19 min of reaction. 
$\checkmark$ The yield of the xylo-oligosaccharides in the hydrolysis product depended on the content and accessibility of the xylan component and was proportional to the acetyl content of the raw materials. It was higher for corncobs (60 wt\%) and almond shells (55 wt\%), while the rice husks had the lowest yield (30 wt\%) in accord with its lowest acetyl content.

$\checkmark$ The increase in the hydrolysis time at constant temperature yielded xylooligosaccharides with higher contents of xylose and smaller contents of arabinose and acetic acid than the original xylan, indicating a preferential release of these two compounds compared to xylose.

$\square$ The molar mass distribution of the xylo-oligosaccharides mixture was very broad demonstrating that large oligosaccharides were solubilized significantly even at short reaction times. It comprised a wide range of molar masses (from 100 to $10^{6} \mathrm{~g} / \mathrm{mol}$ ) at the beginning of the hydrolysis process, that narrowed as the hydrolysis advanced, indicating a strong depolymerization of the xylo-oligosaccharides with the increase of the time at constant temperature.

$\square$ The mixture of xylo-oligosaccharides was constituted in $1 / 3$ by low molecular weight material (monosaccharides and degradation products), and 2/3 of mainly acetylated oligomeric $\left(\mathrm{M}_{\mathrm{p}} \sim 1000\right.$ and $\left.3000 \mathrm{~g} / \mathrm{mol}\right)$ and polymeric xylan fragments $(6000$ to $60000 \mathrm{~g} / \mathrm{mol})$. Wheat straw, barley straw and rice husks showed the higher proportions of polymeric fragments, while olive stones and almond shells had higher proportion of low molecular weight material, in agreement with the higher concentration of acetic acid in the reaction media.

$\checkmark$ All the xylo-oligosaccharides obtained by autohydrolysis reaction showed structural features of a partially $\mathrm{O}$-acetylated 4-O-methylglucuronoxylan with different degrees of substitution depending on the raw material where they came from. The acetyl groups were located in the xylose residues mainly in position 3 (between 60 and $67 \mathrm{~mol} \%$ ), whereas the occurrence of acetyl groups in position 2 and in both positions 2 and 3 
was similar (19-30 mol\% and 8 - $25 \mathrm{~mol} \%$, respectively). The $4-\mathrm{O}$ methylglucuronic acid (MeGA) residues were present in a MeGA/Xyl mole ratios ranging from 2.5:100 for corncobs up to 9.1:100 for olive stones.

Concerning the different methods tested for the purification and recovery of the xylo-oligosaccharides, the main conclusions are:

$\checkmark$ The results from the precipitation with ethanol indicate that the fractionation of the xylo-oligosaccharides according to their molar mass appears feasible, allowing to remove the impurities of low molecular weight but losing also the low molar mass oligomers. It was possible to recover between $85 \%$ and around $95 \%$ of the theoretical xylooligosaccharides for corncobs and almond shells, respectively, at $169^{\circ} \mathrm{C}$ and $25 \mathrm{~min}$ of reaction. The yield of product precipitated tended to be much lower at higher reactions times, since the low molar mass oligomers and monomers were soluble in the ethanol-water mixture. The high molar mass oligomers were completely precipitated, while most of the oligomers with lower degree of polymerization remained soluble in the solvent.

$\checkmark$ The purification by using commercial thin-film polymeric membranes seems the most promising method for the removal of lignin-derived compounds, and the fractionation of XOs according to their molar mass. The selectivity towards preferential permeation of the lignin-related impurities was larger for the $1 \mathrm{kDa}$ membrane, and it decreased linearly with the flux of permeate (or trans-membrane pressure) for all membranes. The membranes should be operated at low pressure to maximize selectivity, although this will imply a larger area for the same flow rate of permeate.

$\checkmark$ The adsorption in activated carbon was higher for lignin-related products than for xylo-oligosaccharides. The selectivity toward lignin adsorption was better when the carbon was highly microporous and had small mesopore diameters and low volume of mesopores. Probably the low concentration of basic surface groups limited the xylo-oligosaccharides 
adsorption, and the presence of acidic surface groups favoured the adsorption of the lignin-related products. The experiments in a column demonstrated that the average retention was around $64 \%$ for lignin products and $21 \%$ for carbohydrates for the fraction of treated solution collected during the first $2 \mathrm{~h}$ of operation, being the retention for ligninderived products limited because part of them seemed to be linked to the xylo-oligosaccharides.

$\checkmark$ Preliminary results obtained with the experiments using enzymatic membrane reactors showed that is possible to depolymerize dextrans and separate dextran oligomers in only one step, which suggest that the same treatment could be applied for the production of low molar mass xylooligosaccharides useful for food applications.

$\checkmark$ The antioxidant activity found for the different xylo-oligosaccharides was very high, compared with that of natural products, making them potential candidates for their use as food additives.

$\checkmark$ The preliminary results about the immunomodulatory activity of the xylo-oligosaccharides, showed that the xylo-oligosaccharides from almond shells showed dose-dependent direct mitogenic as well as comitogenic activities, similarly as the immunogenic water-soluble arabinoglucuronoxylan from corncobs used as positive control. The activities in the whole doses range were about 30\% lower in comparison to the control. These results suggests that the immune system potentiating activity as well as the presence of phenolics might support and contribute to further applications of the partially O-acetylated almond shells xylooligosaccharides.

\subsection{RECOMMENDATIONS}

The results obtained in this thesis can be used to propose several process layouts for the production of xylo-oligosaccharides depending on the final applications of the product obtained. As was demonstrated, autohydrolysis allow to produce higher molar mass XOs at the lower temperatures and/or shorten reaction time, together with 
lower amounts of lignin-derived impurities, monomers, and furfural. These high molar mass XOs can be used, after elimination of the low molecular weight material, for the production of hydrogel useful for drug delivery. Also they can be subsequently hydrolyzed by using an enzymatic treatment (for example by using endoxylanases) to obtain low molecular weight oligosaccharides that can be used as a source of dietary fibre.

The highest temperatures and/or longer reaction times allow to recover the lower molar mass XOs, but with higher amounts of lignin-derived compounds, higher formation of monomers and higher degradation into furfural. Depending on the application, might be interesting to produce low molar mass xylo-oligosaccharides with a high proportion of phenolics that have antioxidant properties, which could be used as food additive, or that can be separated in a subsequent purification step.

For the removal of low molecular weight material, the ultrafiltration is a promising method. Depending on the molecular weight cut off of the membrane, is possible to remove low molecular weight material (i.e. in the case of $1 \mathrm{kDa}$ or $2.5 \mathrm{kDa}$ ), or also separate the low molar mass products (included oligomers, and monomers) from the high molar mass oligosaccharides using a membrane with an intermediate molecular weight cut off (i.e. $8 \mathrm{kDa}$ ). The precipitation using a non solvent is also a suitable method for the removal of low molecular weight material, but the problem is that the low molar mass oligomers are also lost during the process, and that some of the phenolic compounds are covalently bounded to the xylo-oligosaccharides and they remained in the aqueous phase. The main disadvantage of this process is the recovery of the solvent. Adsorption on activated carbons is a clean and effective process for the removal of organic compounds. It may be used to remove phenolic compounds from $\mathrm{XOs}$, but more research on the regeneration and reusing of the carbon beds is required to asses its cost effectively.

To produce low molecular weight oligosaccharides and separate them in the same step, the enzymatic membrane reactors seems to be a suitable method mainly because the enzyme is immobilized in the membrane, being the reaction and separation produced at the same time. The use of enzymes is effective because the fraction of the product obtained is very precisely defined, in molecular weight and composition. It is not clear that some compounds (for example phenolics) can affect their activity. The advantages of the immobilization is that they cannot be washed out 
with the fluid of process, and that the reaction and the separation are produced in the same step.

\subsection{FUTURE WORK}

The results obtained until here leave a lot of questions to solve, between them, the next:

$\square$ Evaluate the possible combination of the autohydrolysis reaction with a previous or simultaneous delignification step by using organic solvents, for the elimination of the lignin derived compounds that are in the xylooligosaccharides mixture.

$\checkmark$ Evaluate the possible recovery and reuse of the activated carbon after the adsorption process, the amount of washing stages and cycles that it can be used. Also it will be interesting to study the differences in the adsorption process for the different compounds in the mixture.

$\checkmark$ About the use of polymeric membranes, fouling has to be studied in more detail. Also it will be interesting to propose a model for the prediction of the retention of oligosaccharides mixture, by knowing the molecular weight cut off provided by the manufacturer and the molar mass distribution of the xylo-oligosaccharides mixture.

$\checkmark$ The enzymatic membrane reactors have to be applied for the production of xylo-oligosaccharides by using endo-xylanases. The process for the synthesis of the membrane, and also the parameters for the operation of the reactor, have to be optimized to adapt the product according to the application required.

$\square$ About the characteristics of the xylo-oligosaccharides, they have to be evaluated as possible source of dietary fibre, studying their behaviour in a mimic gastric fluid media, their influence on bacterial cultures typical from the human bowel, etc. 
$\square$ Evaluate the application of the xylo-oligosaccharides as a mixture of compounds having antioxidant properties for their use as food additives. Also is necessary to study the possible separation of the antioxidant compounds.

$\checkmark$ Determine the immunomodulatory activity of the different xylooligosaccharides obtained.

$\checkmark$ Evaluate the possible production of high molecular weight oligosaccharides that can be useful for the production of hydrogels, or for the production of nanoparticles, useful for drug delivery. 
Debora Alcida Nabarlatz

ISBN: 978-84-690-7617-0 / DL: T.1385-2007 


\section{BIOGRAFÍA}

Debora Alcida Nabarlatz nació en el seno de una familia rural, allá por el año 1977. Debora por la elección de su madre y Alcida por el nombre de su abuela. El lugar, en medio de la pampa húmeda bonaerense, es pasto de ganado y admite la presencia de algunos arbolitos, los más populares

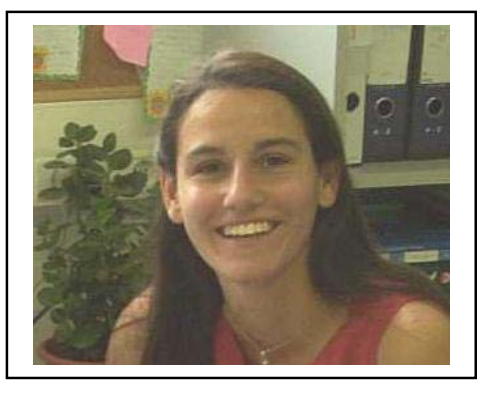
los eucaliptos, olorosos y que dan la posibilidad de criarlos a partir de unas graciosas semillitas...

Con dos años, se muda con su familia a la metrópoli de Mar del Plata, ciudad cercana, paraíso de turistas y veraneantes de bajo costo. Era la época del proceso, donde todo se sabía y se callaba al mismo tiempo. Con la llegada de Alfonsín al gobierno, las cosas en su casa se pusieron feas y tocó mudarse al campo con los abuelos. Una infancia tranquila, plagada de libros que la transportaban a otros mundos (en realidad, lo que fuera que cayera en la biblioteca pobre de su escuela, pasaba por sus manos)... juegos al aire libre, trabajo en el campo, donde sólo el cielo y el horizonte eran sus límites. Durante esos años su imaginación se disparaba, y se imaginaba de policía, de astronauta, de científica (qué sería eso?), de secretaria entre un montón de papeles, de madre...

Dadas las pocas posibilidades de progreso, sus padres y abuelos decidieron mandarla a un colegio interno de monjas, para que pudiera hacer el colegio secundario y ser alguien en la vida... En ese colegio se transformó, pasando poco a poco de niña a adolescente un tanto rebelde... Allí, de lunes a viernes compartía una vida de estudio (y limpieza, y religión), y el fin de semana se iba a su casa con sus padres... A los 15 años, su familia se mudó a Balcarce (pueblo chico infierno grande, patria de Fangio y cuna del automovilismo), donde continuó sus estudios ya en un colegio "normal" hasta los 18 años... El aroma de los tilos en la tardecita, paseando por sus calles en bicicleta la siguen por doquier... Allí, el nuevo mundo, y los primeros tropezones con la química y la física la marcaron para siempre... Cuando hubo que decidir, eligió la Ingeniería Química porque quería estar en la industria, 
entre caños, vestida con un enterito naranja y un casquito... Allí se mudó nuevamente a Mar del Plata, a vivir solita, a experimentar el mundo, a luchar en medio de ecuaciones y probetas, y fórmulas, y etc...

Cuando se graduó, en plena crisis del 2001, las esperanzas de encontrar un trabajo apropiado menguaron un poco, y se hizo necesario buscar nuevos horizontes... Así, gracias a la bondad de unos cuantos llegó a Tarragona, con los ojos abiertos y el estómago temblando de la emoción... Luego de cuatro años, las cosas parecen normales, pero aún se aprecian sus rasgos provincianos, su incredulidad ante el mundo, su sorpresa ante las vueltas de la vida... Ahora, casi 29 años después del comienzo, nuevas puertas se abren, hay caminos que se bifurcan quizás para volver a encontrarse, el miedo se instala nuevamente, y los nervios están a flor de piel... Pero su ángel, quien la ha acompañado durante todo este tiempo, le susurra al oído que hay que cruzar la puerta, perder el miedo, apechugar con todo y saltar hacia el otro lado... que hay nuevos mundos... que la vida sigue... y uno va embarcado en ella...

Continuará...

"No todo lo que he dicho aquí es falso, palabra de estafador..."

Miguel Ángel Solá, “La Fuga” (2001) 